Portland State University

PDXScholar

$11-29-2016$

\title{
Experimental Investigation of CFRP Wrapped Square Non-ductile Reinforced Concrete Columns
}

Hayder Lateef Al-Khafaji

Portland State University

Follow this and additional works at: https://pdxscholar.library.pdx.edu/open_access_etds

Part of the Civil Engineering Commons

Let us know how access to this document benefits you.

\section{Recommended Citation}

Al-Khafaji, Hayder Lateef, "Experimental Investigation of CFRP Wrapped Square Non-ductile Reinforced Concrete Columns" (2016). Dissertations and Theses. Paper 3374.

https://doi.org/10.15760/etd.5265

This Thesis is brought to you for free and open access. It has been accepted for inclusion in Dissertations and Theses by an authorized administrator of PDXScholar. Please contact us if we can make this document more accessible: pdxscholar@pdx.edu. 


\title{
Experimental Investigation of CFRP Wrapped Square \\ Non-ductile Reinforced Concrete Columns
}

$$
\text { by }
$$

\author{
Hayder Lateef Al-Khafaji
}

A thesis submitted in partial fulfillment of the requirements for the degree of

\author{
Master of Science \\ in \\ Civil and Environmental Engineering
}

Thesis Committee:

Franz Rad, Chair

Evan Kristof

Patrick McLaughlin

Portland State University

2016 


\begin{abstract}
The use of fiber-reinforced polymers (FRP) for retrofitting or strengthening deficient concrete columns noticeably increased in the past few decades. Plenty of research has been conducted on the behavior of FRP-strengthened circular concrete columns, but far less research has dealt with non-circular columns. In the current study, the focus was to investigate the behavior of square columns with low to medium grade concrete and low steel reinforcement that were strengthened using carbon fiber reinforced polymer (CFRP) wrap. In the experimental portion of this investigation, twelve short square reinforced concrete columns ( $5 "$ x 5" in cross section and 12" high) were cast and tested under concentric axial loading. The specimens were divided evenly into two series, named C2 and C4. In the first series, C2, six column specimens were cast with 2000-psi concrete, representing low grade concrete. One column was a "control specimen" designed based on older non-seismic codes. A second column, another "control specimen", was designed based on the current seismic design code, ACI 318-14. The four remaining columns were wrapped with CFRP sheets, but with different number of CFRP wraps. The same scheme was followed for the specimens of the second series (C4), but they were cast with 4000psi concrete, representing medium grade concrete. Thus, the main parameters considered in the current study were the concrete compressive strength and the thickness of the CFRP jacket (number of wraps). Those two parameters were utilized to investigate the effectiveness of the CFRP confinement in enhancing the axial load carrying capacity and ductility of the strengthened columns. Test results confirmed that the confinement produced by the CFRP jacket enhanced the axial load-carrying capacity, axial strain
\end{abstract}


capacity and energy absorption if compared to unwrapped columns. In addition, the results showed that there should be an effective thickness for the CFRP jacket in order to achieve a significant enhancement in the performance of the strengthened columns.

Moreover, the test results demonstrated that the effectiveness of the CFRP confinement was more pronounced in the case of the low-grade concrete columns (Series C2). 


\section{Acknowledgment}

There are no proper words to convey my deep and sincere gratitude and respect for the people who contributed to the completion of this research. I would like to extend my deepest appreciation to Professor Franz Rad, my academic advisor, for his support, guidance, and encouragement throughout the course of my MS education and thesis work. I would also like to thank Professors Evan Kristof and Patrick McLaughlin for their participation as members on my thesis committee. I would like to acknowledge the funding and support I received to complete this research from The Higher Committee for Education Development in Iraq. I must acknowledge the technical assistance of Mr. Tom Bennett. His technical expertise and experiences made the experimental aspect of this research more efficient and effective.

I am very grateful to graduate students: Yasir Saeed, Ali Zerkane, Ranj Rafeeq, Anas Yosefani, Salam Al-Obadi, Karrar Al-Lami and Salih Mahmmod for their advice, help and support through the various stages of this research.

Finally, I would like to thank my parents and sisters for their constant understanding, support, and encouragement. 


\section{Table of Contents}

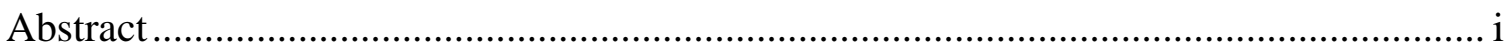

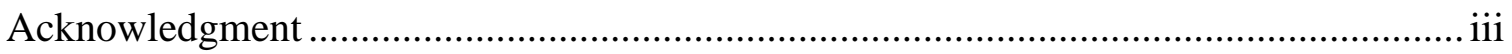

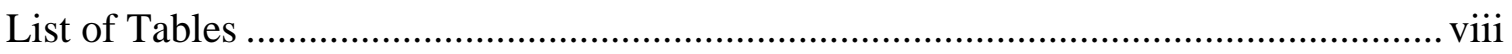

List of Figures ................................................................................................ ix

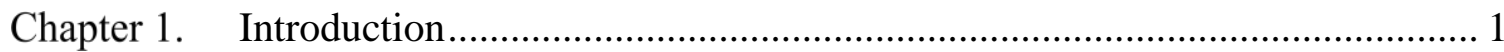

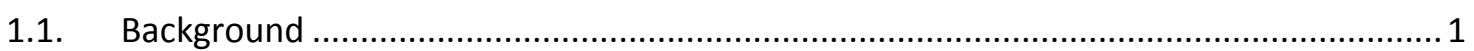

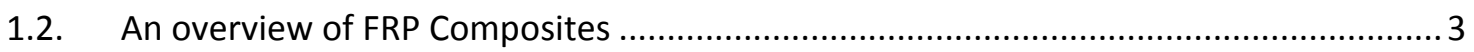

1.3. Research Significance......................................................................................... 4

1.4. Research Scope and Approach............................................................................

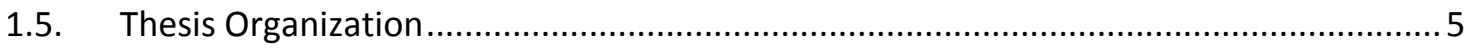

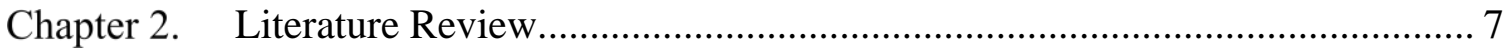

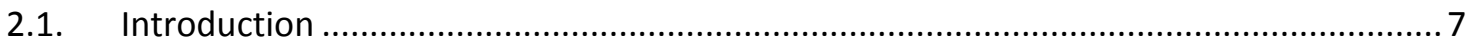

2.2. Confined Concrete Under Uniaxial Compressive Loading …………........................... 7

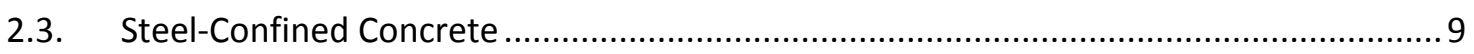

2.3.1. Mander et al. Model (1988) .......................................................................... 10

2.4. FRP-Confined Concrete in Circular Columns under Concentric Compression .................14

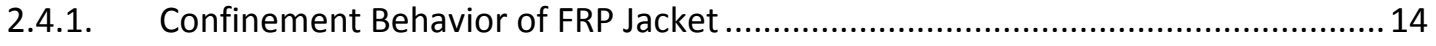

2.4.2. Rupture Strain of the FRP Jacket.................................................................16

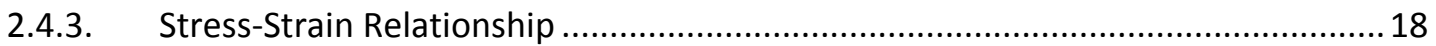

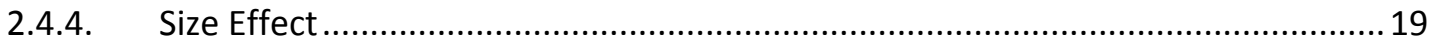

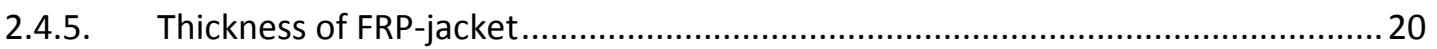

2.5. FRP-Confined Concrete in Non-Circular Columns Under Concentric Compression....21

2.5.1. Confinement Behavior of FRP Jacket .............................................................. 21

2.5.2. Effect of the Corner Radius ......................................................................... 23

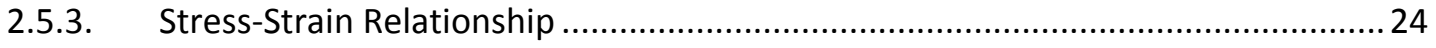

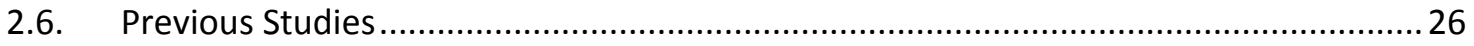

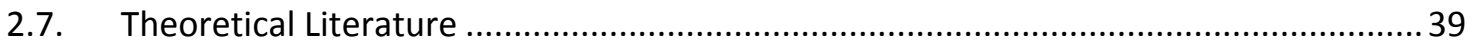

2.7.1. Lam and Teng model (2003b) .......................................................................

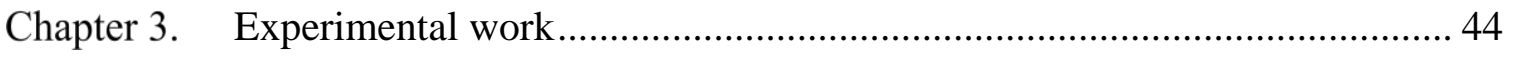

3.1. The Experimental Program ………………………………………………… 44 


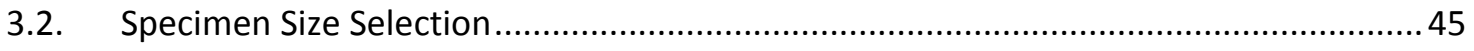

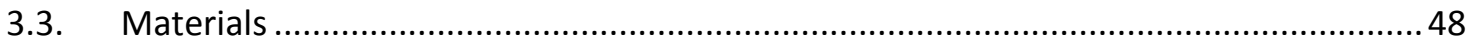

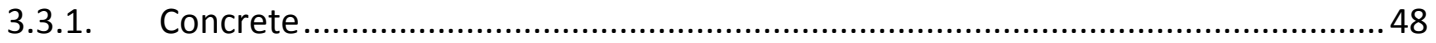

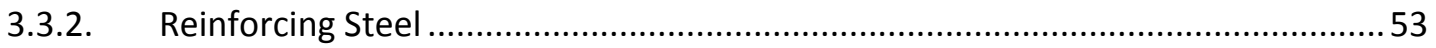

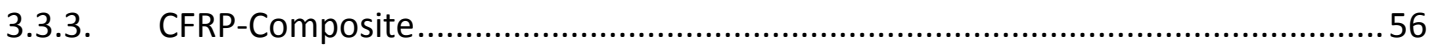

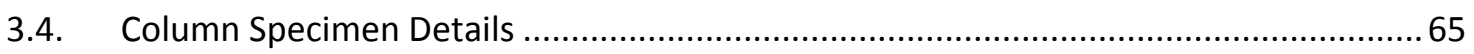

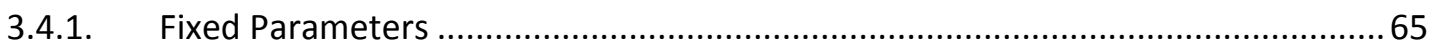

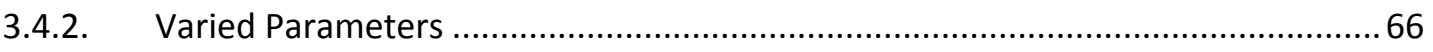

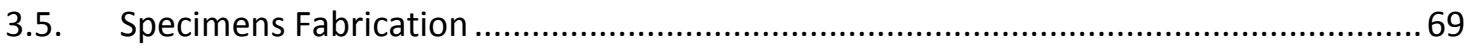

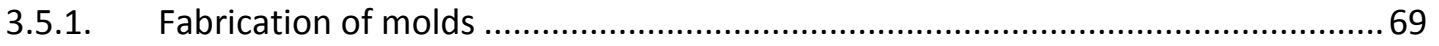

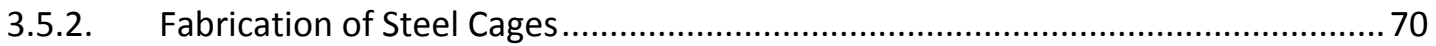

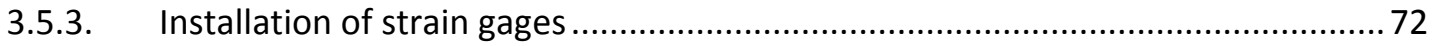

3.5.4. Mixing, Casting, and Curing the Concrete.......................................................... 74

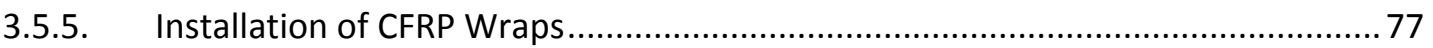

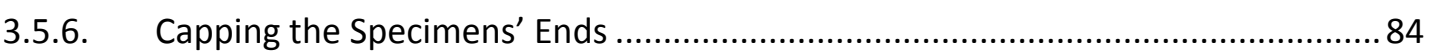

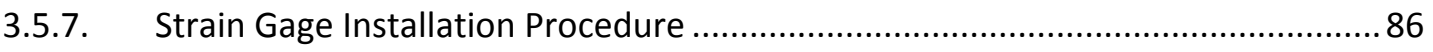

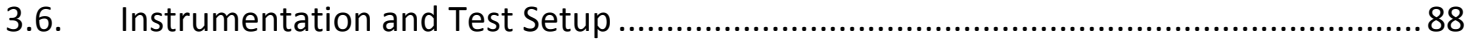

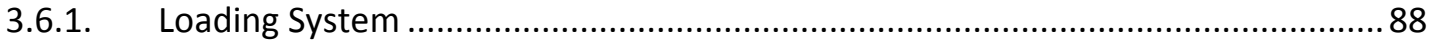

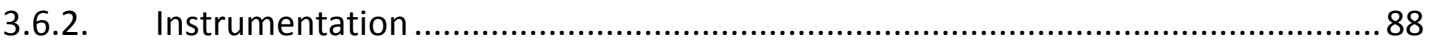

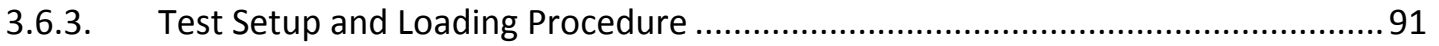

Chapter 4. Experimental Results and Discussion ...................................................... 94

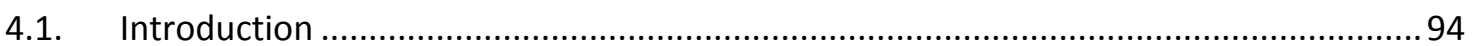

4.2. Specimen C2NDC (Unwrapped Non-ductile RC Column) .............................................95

4.2.1. General Behavior and Failure Mechanism ......................................................... 95

4.2.2. Axial Load-Strain Relationship ......................................................................... 96

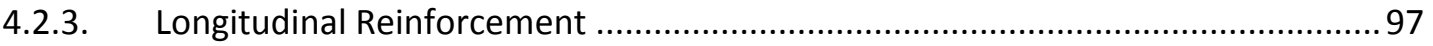

4.2.4. Concrete and Longitudinal Reinforcement Contribution ....................................98

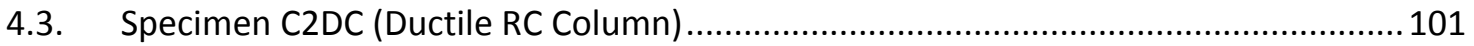

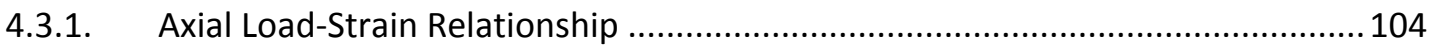

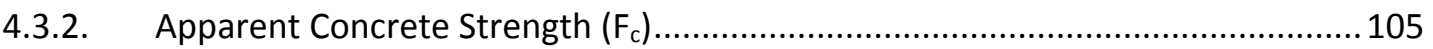

4.4. Specimen C2NDC-F1 (Non-Ductile RC Column Wrapped with One CFRP Layer).........107

4.4.1. General Behavior and Failure Mechanism ..........................................................107

4.4.2. Axial Load-Strain Relationship ........................................................................ 110 


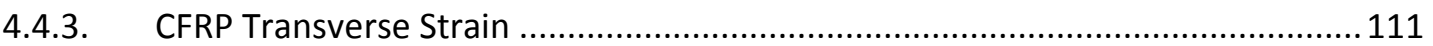

4.5. Specimen C2NDC-F2 (Non-Ductile RC Column Wrapped with Two CFRP Layers) ........113

4.5.1. General Behavior and Failure Mechanism ..................................................... 113

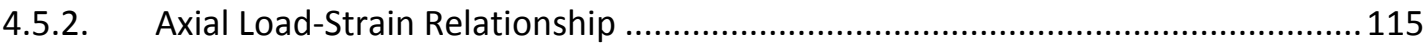

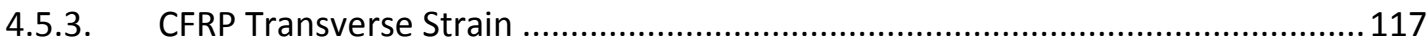

4.6. Specimen C2NDC-F3 (Non-Ductile RC Column Wrapped with Three CFRP Layers) ....118

4.6.1. General Behavior and Failure Mechanism ........................................................ 118

4.6.2. Axial Load-Strain Relationship .................................................................... 120

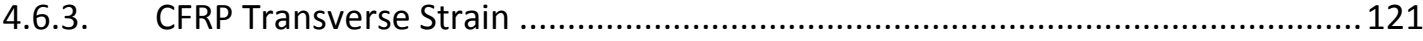

4.7. Specimen C4NDC (Unwrapped Non-ductile RC Column) .........................................122

4.7.1. General Behavior and Failure Mechanism ....................................................... 122

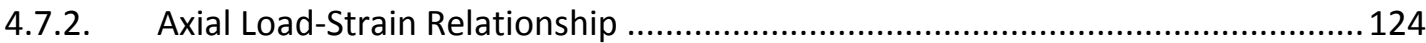

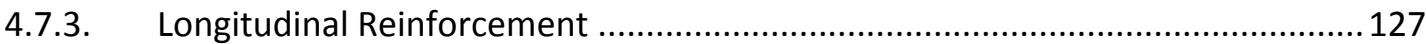

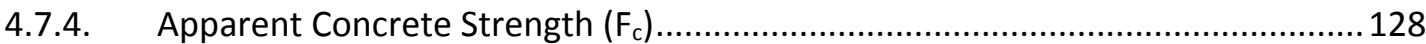

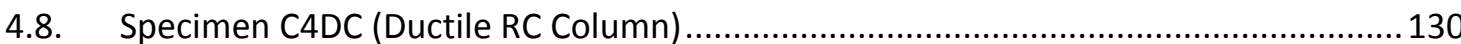

4.8.1. General Behavior and Failure Mechanism ...................................................... 130

4.8.2. Axial Load-Strain Relationship ......................................................................... 132

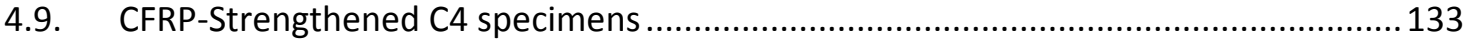

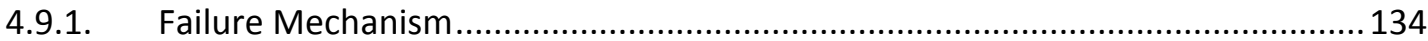

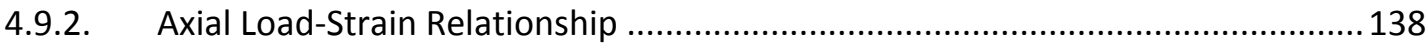

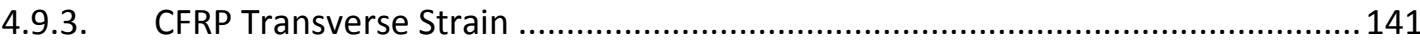

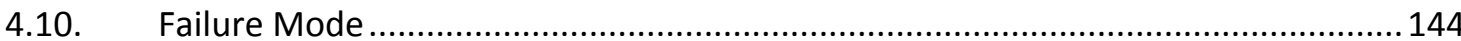

4.11. Axial Load-Axial Strain Relationship for Series C2 ...........................................147

4.12. Axial Load-Axial Strain Relationship for Series C4 ….........................................150

4.13. Idealized Axial Load-Deformation Relationship ..................................................152

4.14. Apparent Concrete Strength of CFRP-Wrapped Columns .....................................157

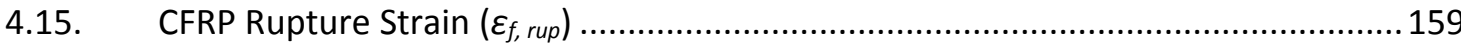

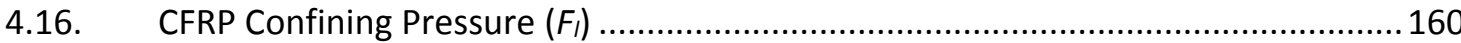

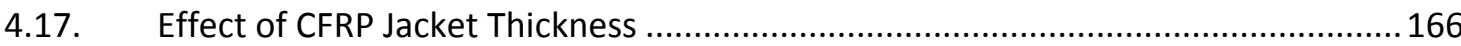

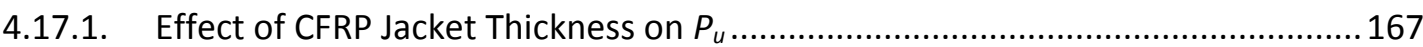

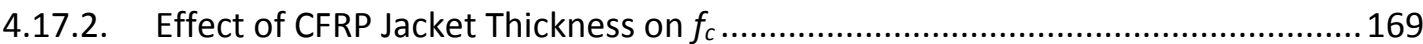

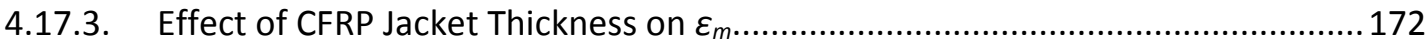

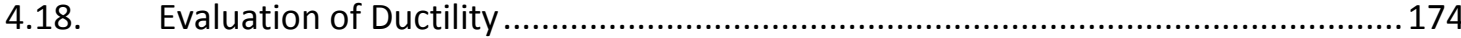




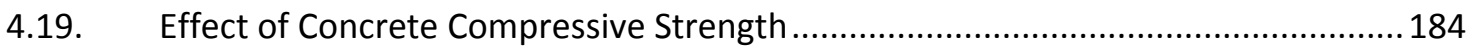

Chapter 5. Conclusions and Recommendations ................................................ 186

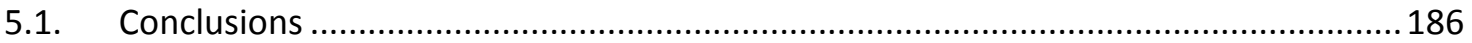

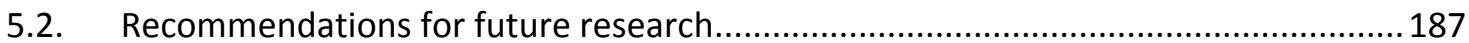

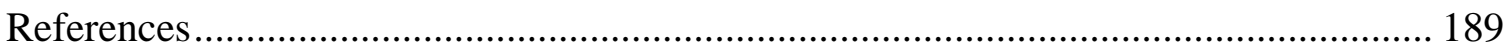

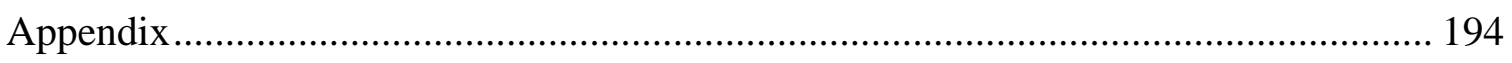




\section{List of Tables}

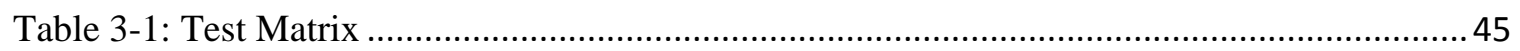

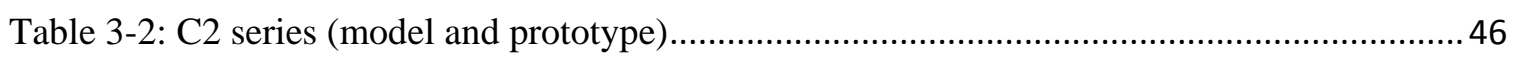

Table 3-3: C4 series (model and prototype).............................................................................. 47

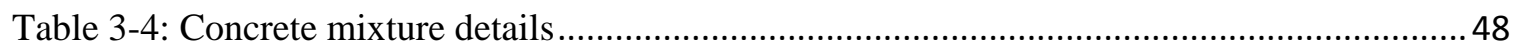

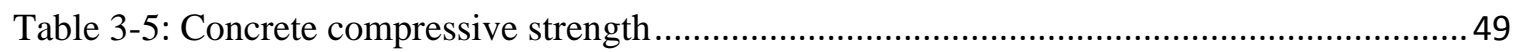

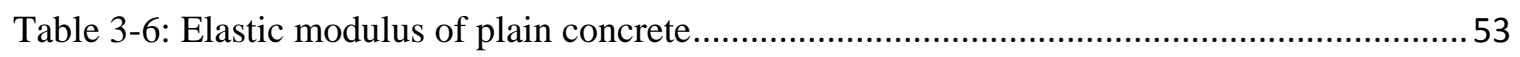

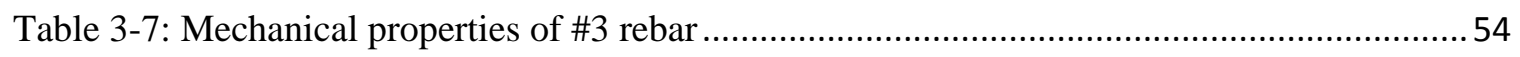

Table 3-8: Lateral reinforcing No.9 wire properties ................................................................ 54

Table 3-9: Mechanical properties of No.2 steel wire ............................................................... 56

Table 3-10: Mechanical properties of the CFRP system …...................................................... 57

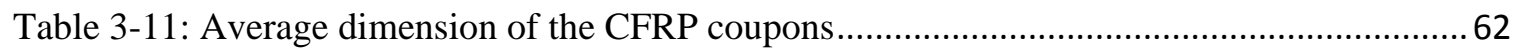

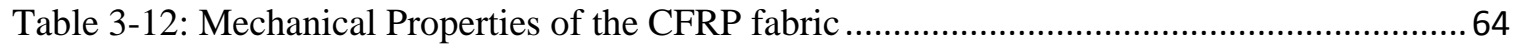

Table 4-1: Maximum CFRP transverse strain of C2NDC-F1 ................................................. 113

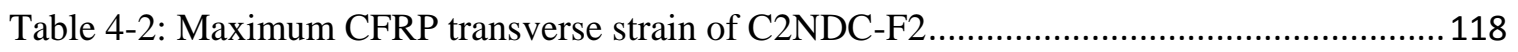

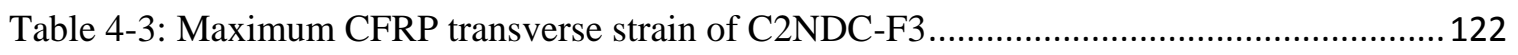

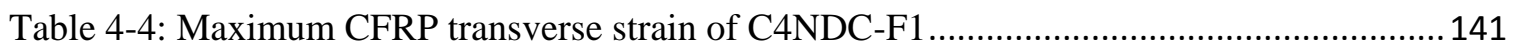

Table 4-5: Maximum CFRP transverse strain of C4NDC-F2 ................................................. 142

Table 4-6: Maximum CFRP transverse strain of C4NDC-F3 …............................................... 143

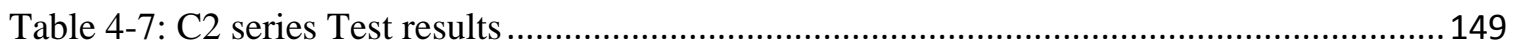

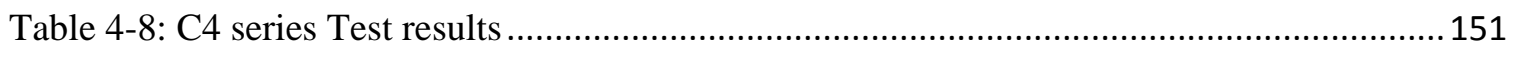

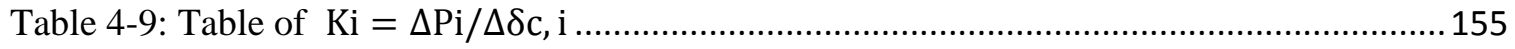

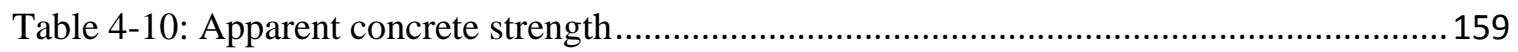

Table 4-11: Confinement effective coefficient, k .................................................................... 164

Table 4-12: The ductility values of test specimens (first definition) ........................................ 180

Table 4-13: The ductility values of test specimens (second definition) ..................................... 181 


\section{List of Figures}

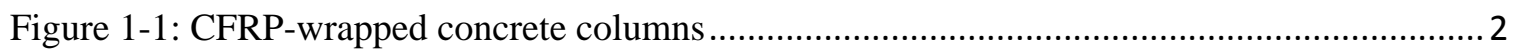

Figure 1-2: Typical stress-strain curves for common fibers (Abegaz, 2013) .................................. 3

Figure 2-1: Stress-strain response of a plain concrete cylinder (Tuğrul, 1992) ............................. 8

Figure 2-2: Stress-strain model of confined concrete proposed by Mander et al. (1988) .............. 11

Figure 2-3: Effectively confined concrete core area for both circular and rectangular hoop cases13

Figure 2-4: Axial load-deformation curve. (El Maaddawy et al., 2009)...................................... 15

Figure 2-5: Confining action of the FRP jacket. (Jiang, 2008) .................................................. 15

Figure 2-6: Axial load-deformation curve for high-strength FRP confined column. (Hadi, 2011)19

Figure 2-7: Stress-Strain Curve for a CFRP Confined Concrete Circular Column (Youssef, 2003)

Figure 2-8: Effectively Confined Concrete in a rectangular column (Lam and Teng, 2003) ........21

Figure 2-9: Equivalent circular cross section (Lam and Teng, 2003) ......................................... 23

Figure 2-10: Effect of corner radius on confinement (Wang and $\mathrm{Wu}, 2008)$................................. 24

Figure 2-11: Stress-strain curves for square column specimen (Benzaid and Mesbah, 2013) ......25

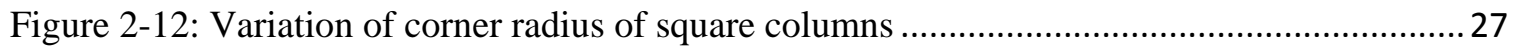

Figure 2-13: Axial stress-strain curves showing the effect of the transverse reinforcement (Turgay

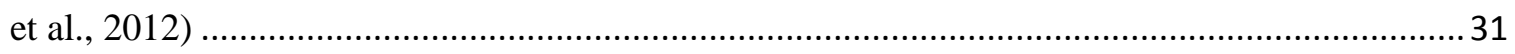

Figure 2-14: Selected axial stress-strain responses (Wang et al., 2012) ....................................... 33

Figure 2-15: Selected axial stress-strain curves considering the influence of the internal

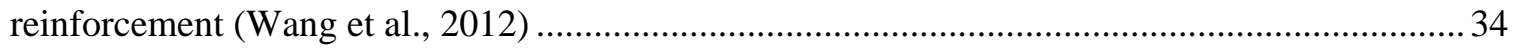

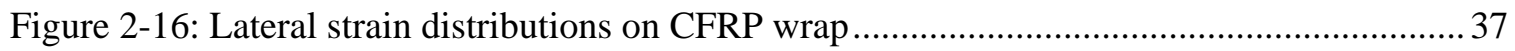

Figure 2-17: Stress-strain curves (Belouar et al. 2013 ............................................................... 38

Figure 2-18: Lam and Teng (2003) stress-strain relationship ................................................. 42

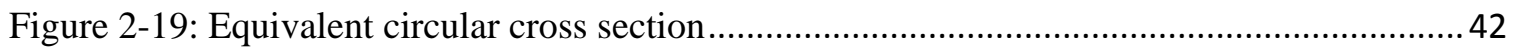

Figure 3-1: Concrete compression machine ............................................................................... 49

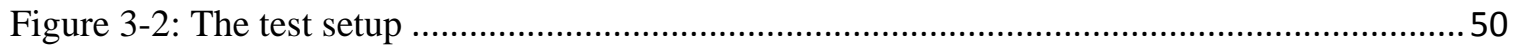

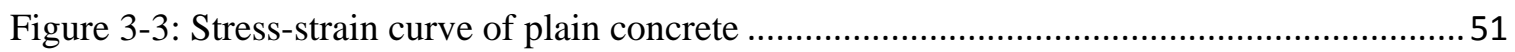

Figure 3-4: Stress-Strain curve of \#3 rebar (Al-Obaidi, 2015) ................................................... 53

Figure 3-5: Stress-Strain curve of No.9 steel wire (Al-Lami, 2015) ........................................... 54

Figure 3-6: Direct tensile testing machine and instrumentation ................................................55

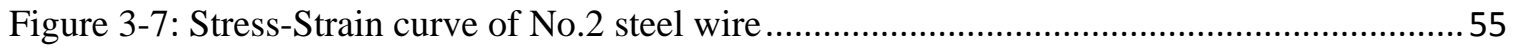


Figure 3-8: CFRP laminate panel fabrication

Figure 3-9: CFRP flat coupon fabrication: (a) CFRP laminate strips. (b) End aluminum tab. (c)

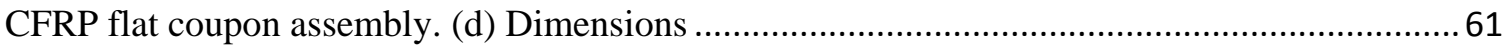

Figure 3-10: CFRP test coupons: Strain measuring instrumentation ...........................................62

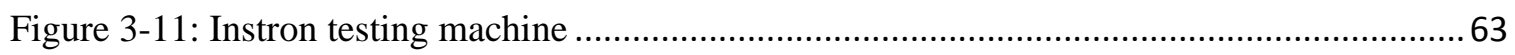

Figure 3-12: Stress-Strain curves of the test CFRP coupon ...................................................... 64

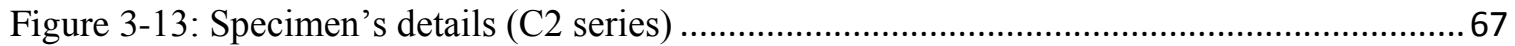

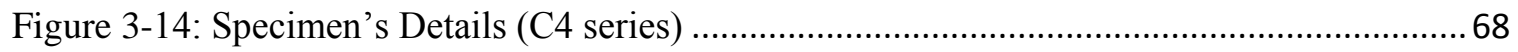

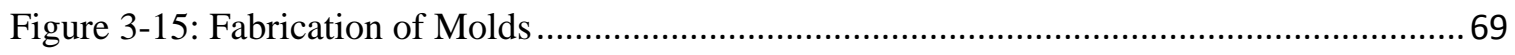

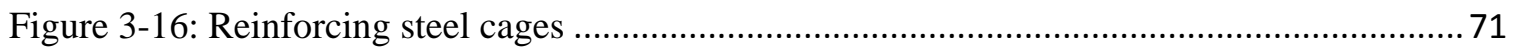

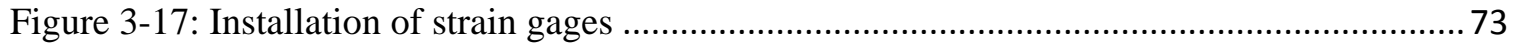

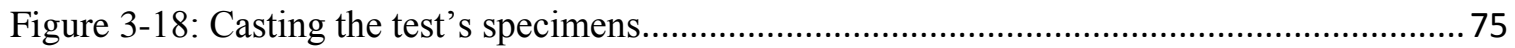

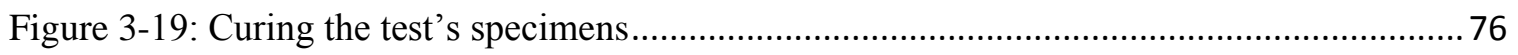

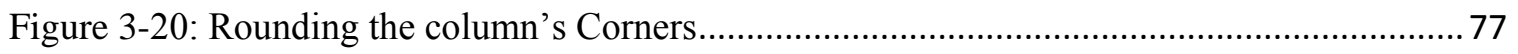

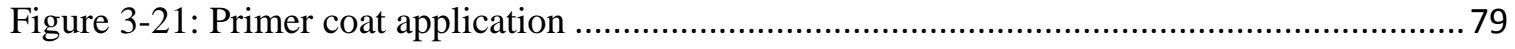

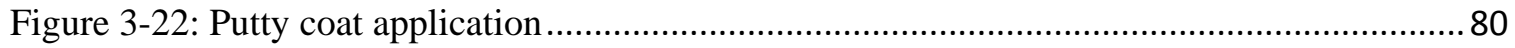

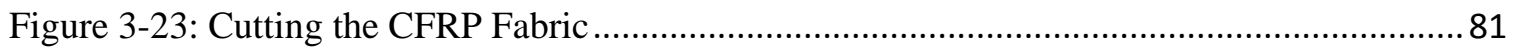

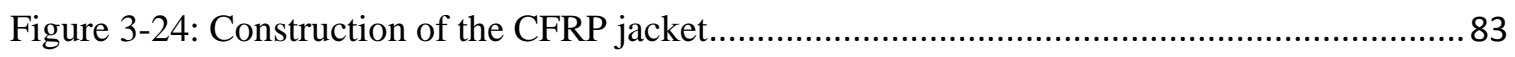

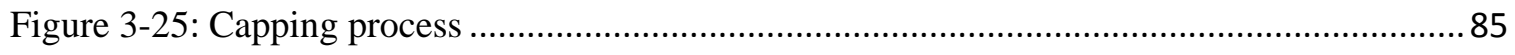

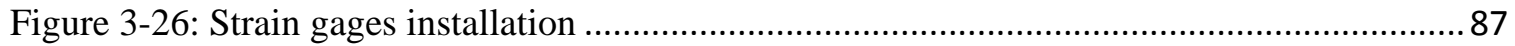

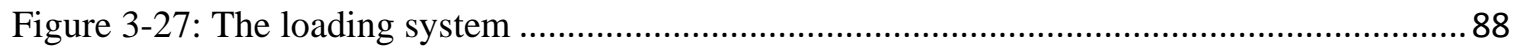

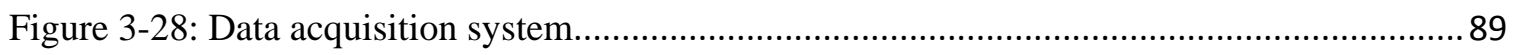

Figure 3-29: The displacement measurement system ............................................................ 90

Figure 3-30: Location of the strain gages ................................................................................. 91

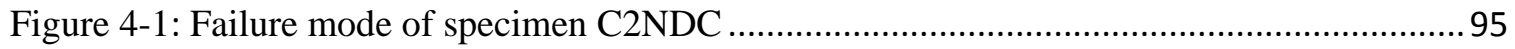

Figure 4-2: Axial load- Strain response of specimen C2NDC ..................................................... 96

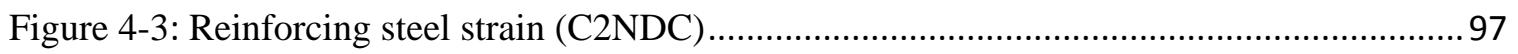

Figure 4-4: Concrete and Steel Reinforcement Contributions (C2NDC) ................................... 99

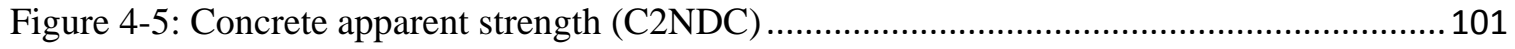

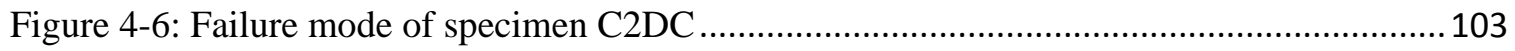

Figure 4-7: Axial load-Strain response of specimen C2DC................................................... 104

Figure 4-8: Close-up view for C2DC cyclic response .......................................................... 105 


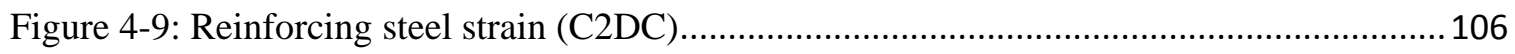

Figure 4-10: Concrete and Steel Reinforcement Contributions (C2DC) .................................... 106

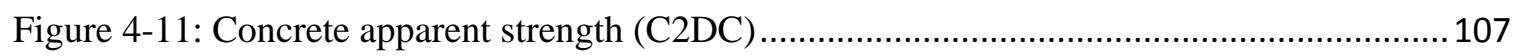

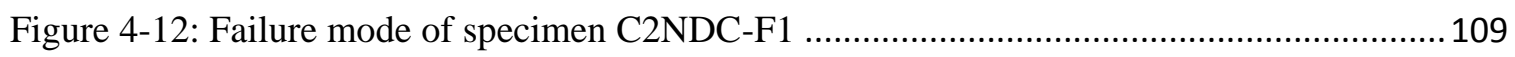

Figure 4-13: Axial load- Strain response of specimen C2NDC-F1 ........................................ 111

Figure 4-14: CFRP transverse strain response for C2NDC-F1 ................................................ 112

Figure 4-15: Failure Mode of Specimen C4NDC-F2 …......................................................... 114

Figure 4-16: Failure mode of specimen C2NDC-F2 …...................................................... 114

Figure 4-17: Axial load- Strain response of specimen C4NDC-F2 ........................................ 116

Figure 4-18: Close-up view for C4NDC-F2 cyclic response ....................................................116

Figure 4-19:CFRP transverse strain response for specimen C2NDC-F2 ................................. 117

Figure 4-20: Failure Mode of Specimen C2NDC-F3 …........................................................ 119

Figure 4-21: Axial load- Strain response of specimen C2NDC-F3 ........................................ 120

Figure 4-22: CFRP transverse strain response for specimen C2NDC-F3 ................................... 121

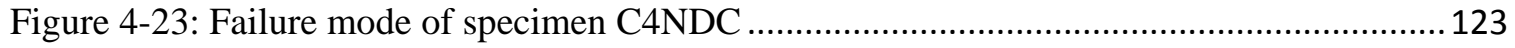

Figure 4-24: Axial load- Strain response of specimen C4NDC ...............................................125

Figure 4-25: Close-up view for C4NDC cyclic response ….................................................. 126

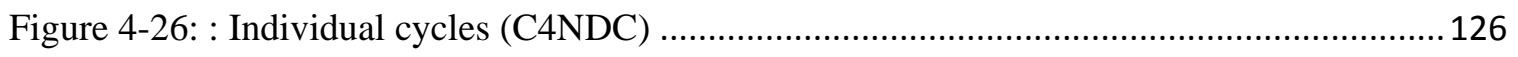

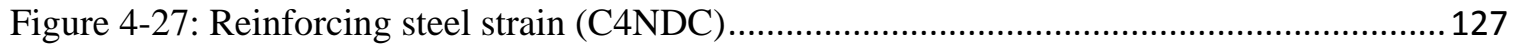

Figure 4-28: Concrete and Steel Reinforcement Contributions (C4NDC) ................................129

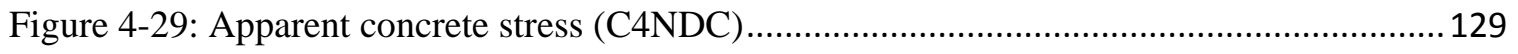

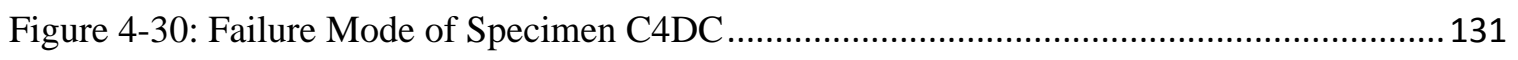

Figure 4-31: Axial load- Strain response of specimen C4NDC .............................................. 132

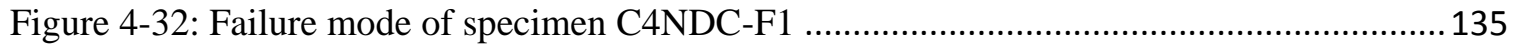

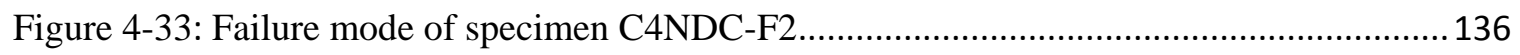

Figure 4-34: Failure Mode of Specimen C4NDC-F3 …......................................................... 137

Figure 4-35: Axial load- Strain response of specimen C4NDC-F1 ......................................... 138

Figure 4-36: Axial load- Strain response of specimen C4NDC-F2 ......................................... 139

Figure 4-37: Axial load- Strain response of specimen C4NDC-F3 …..................................... 140

Figure 4-38: CFRP transverse strain response for C4NDC-F1 ................................................ 141

Figure 4-39: CFRP transverse strain response for specimen C4NDC-F2 ................................. 142

Figure 4-40: CFRP transverse strain response for specimen C4NDC-F3 ................................. 143 


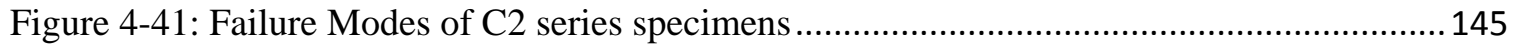

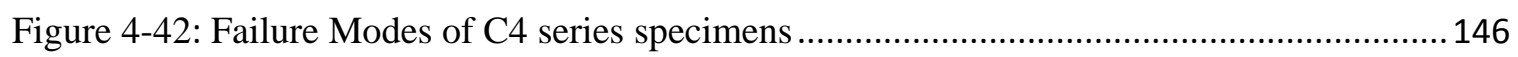

Figure 4-43: The height differences of some specimens after the test..................................... 147

Figure 4-44: Axial load vs. strain response of series C2 specimens ........................................149

Figure 4-45: Axial load vs. strain response of series C4 specimens .......................................150

Figure 4-46: Experimental axial load-deformation curves (Series C2) ..................................... 153

Figure 4-47: Experimental axial load-deformation curves (Series C4) ..................................... 154

Figure 4-48: Idealized axial load-deformation relationships (series C2) .................................. 155

Figure 4-49: Idealized axial load-deformation relationships (series C4) ................................... 156

Figure 4-50: Typical stress-strain curve of FRP-confined concrete ........................................ 157

Figure 4-51: Apparent concrete stress (Series C2) ……….................................................... 158

Figure 4-52: Apparent concrete stress (Series C4) ……................................................... 158

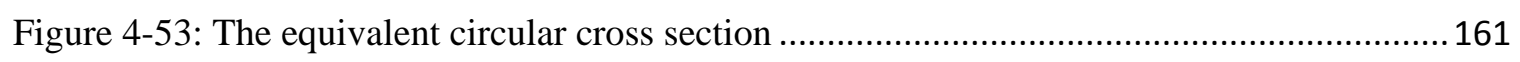

Figure 4-54: The effectively confined concrete area ............................................................ 161

Figure 4-55: Confining action of the CFRP jacket ............................................................... 162

Figure 4-56: CFRP Lateral Confining Pressure responses (Series C2) ……............................. 163

Figure 4-57: CFRP Lateral Confining Pressure responses (Series C4) .................................... 163

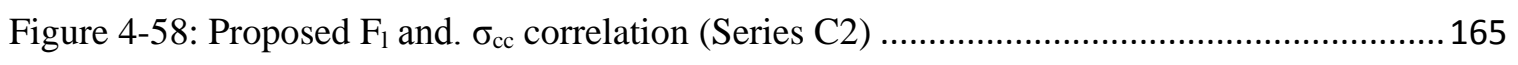

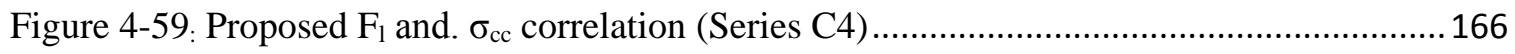

Figure 4-60: Comparison of the axial loading capacity (variable CFRP jacket thickness) .........168

Figure 4-61: Comparison of the axial loading capacity (variable CFRP jacket) ........................ 169

Figure 4-62: Comparison of the apparent concrete compressive strength (variable CFRP jacket)

Figure 4-63: Comparison of the apparent concrete compressive strength (variable CFRP jacket)

Figure 4-64: Maximum axial strain values of test specimens................................................ 172

Figure 4-65: Comparison of the maximum axial strain (variable CFRP jacket) ........................173

Figure 4-66: Effective axial load-deformation curves for ductility evaluation............................175

Figure 4-66: Effective axial load-deformation curves for ductility evaluation (Cont.) ...............176

Figure 4-66: Effective axial load-deformation curves for ductility evaluation (Cont.) ...............177

Figure 4-66: Effective axial load-deformation curves for ductility evaluation (Cont.) ...............178

Figure 4-66: Effective axial load-deformation curves for ductility evaluation (Cont.) ...............179 
Figure 4-67: Ductility evaluation (C2 series)

Figure 4-68: Ductility evaluation (C4 series)

Figure 4-69: Relative enhancement in axial ductility based on First Definition (variable CFRP jacket)...

Figure 4-70: Relative enhancement in axial ductility based on Second Definition (variable CFRP

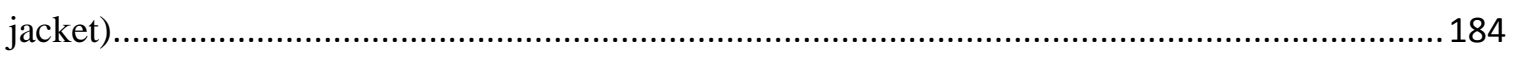

Figure 4-71: Effect of concrete compressive strength .......................................................... 185 


\section{Chapter 1. Introduction}

\subsection{Background}

One of the major activities in structural engineering nowadays is rehabilitating or repairing existing deficient concrete structural components. There are two options to deal with these deficient structures. Either demolishing and then rebuilding those structures, or strengthening them. The first option is not practical because in most cases it requires a lot of expense and time. On the other hand, the second option, which is strengthening the deficient structures, is a more economical and practical approach. Columns are the main load carrying elements in any structure, hence they are the most critical components that require strengthening once they are considered deficient. A column is considered deficient when it has a low concrete compressive strength and insufficient longitudinal and lateral reinforcement. This deficiency could be attributed to several factors: exposure to severe environmental conditions that cause concrete deterioration, excessive external applied loads due to the change in the structure occupancy, and changes in design codes' requirements. Strengthening a column means enhancing its axial strength and ductility (i.e. withstanding more axial load and deformation). In order to ensure higher strength and ductility, the current design codes require additional details to be considered in the design of lateral reinforcement for structural concrete members in areas prone to seismic activities. Because it is difficult or even impossible to replace the lateral reinforcing system of old, deficient columns, external lateral confinement is a practical technique to achieve an enhancement in the performance of concrete columns. There are many confining techniques used in the rehabilitation industry such as concrete jacketing, steel jacketing, external steel wiring, and fiber reinforced polymer (FRP) composite jacketing. 
However, these techniques yield different results in their performance efficiency and durability. Concrete jacketing, for example, is done by casting additional plain or reinforced concrete around the column. As this jacket increases the cross-sectional area and the weight of that column, it might not be preferable architecturally. Although steel is the main material used for confinement, corrosion is the main drawback in such material, therefore it needs to be protected which, in turn requires more cost. On the other hand, FRP composites are considered more promising materials for strengthening purposes. This is due to FRP's high strength-to-weight ratio, high corrosion resistance, and easy installation. Besides these advantages, FRP composites have a brittle behavior (i.e. sudden failure) and are relatively expensive. In the past few decades, with developing manufacturing technology and large amount of research that has been done on FRP materials, the interest of using theses composites as viable alternatives to conventional reinforcing materials has widely increased. Figure 1-1 shows how the FRP composites are used for strengthening existing concrete columns.
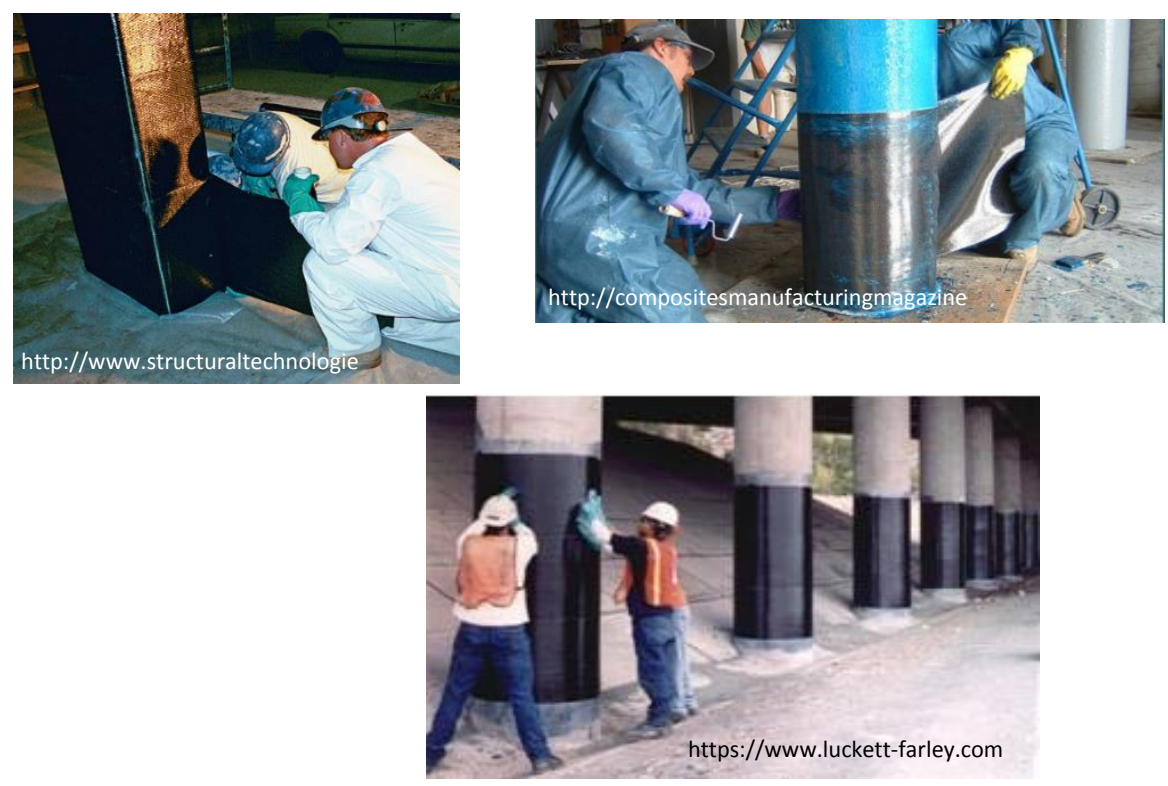

Figure 1-1: CFRP-wrapped concrete columns 


\subsection{An overview of FRP Composites}

Any FRP composite is made of two main components; reinforcing fibers and a resin matrix material. The engineering properties of an FRP composite are mainly attributed to its reinforcing fibers. Therefore, the strength, orientation, and length of the fibers considerably affect the overall composite properties.

On the other hand, the resin matrix is an adhesive that keeps the fibers together and gives the FRP element its composite structure. It supports the fibers against buckling under compression. In addition, the resin matrix greatly contributes to the shear strength of FRP composites which result in resisting delamination and impact damage ( $\mathrm{Au}, 2002)$ FRP composites are mainly categorized in accordance with the type of fibers used in the composite system. The main types of FRP composite that are used in structural engineering are carbon, glass, and aramid-based composites. Those composites are different in their mechanical properties, cost, and applications. Figure 1-2 shows the stress-strain relationship for different composites as compared with the conventional steel rebars. In this figure, it can be seen that all those types of FRP have a linear stress-strain relationship until they rupture. This indicates the brittle behavior of those composites as compared to the elastoplastic behavior of the steel.

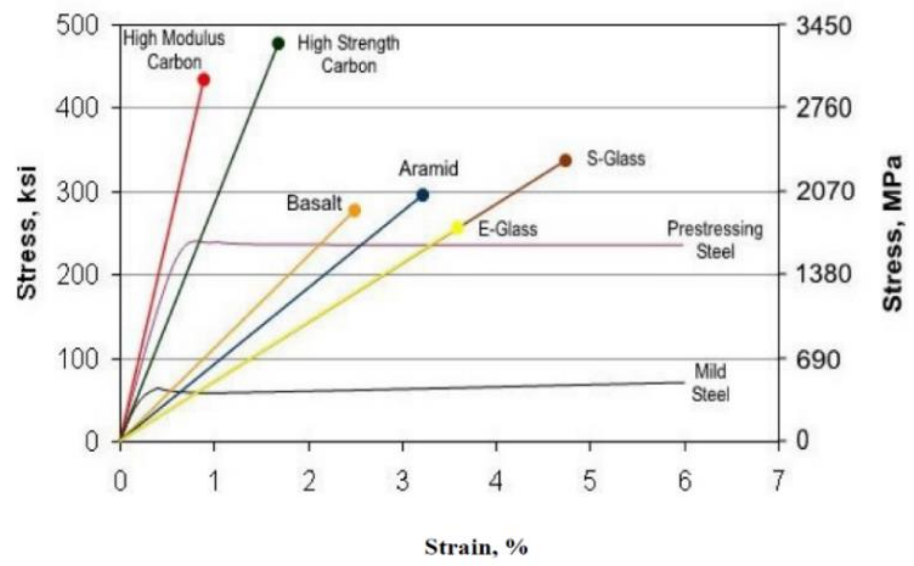

Figure 1-2: Typical stress-strain curves for common fibers (Abegaz, 2013) 


\subsection{Research Significance}

The primary objective of this study was to investigate the behavior of short square concrete columns when strengthened by wrapping them with carbon fiber reinforced polymer (CFRP) sheets. The focus was to study the effectiveness of using CFRP confinement technique in order to enhance the compressive load carrying capacity and the ductility (the deformation capacity) of deficient concrete columns. Although there is a great deal of research on the behavior of CFRP-confined circular concrete columns, less research has been conducted on non-circular columns. Therefore, a square cross section was chosen for the column specimens of the current study. The other objective of this study was to investigate the effect of varying the concrete compressive strength and the CFRP jacket thickness. In addition, because the main purpose of strengthening a nonductile concrete column is to enhance its strength and ductility so that it can be more resistant to seismic loading, it was necessary to compare the performance of a strengthened column with a well-designed column that included seismic reinforcement details (ductile column) and examine the required confinement ratio in the wrapped columns to attain a performance equivalent to the ductile column.

\subsection{Research Scope and Approach}

In order to accomplish the objectives mentioned above, twelve short square concrete column specimens were set into two series. To study the effect of varying the concrete strength on the column behavior, the first specimen's series (C2) includes six specimens with a concrete strength of 2000 psi. The second series (C4) includes six specimens with a concrete strength of $4000 \mathrm{psi}$. In each series, to achieve the objective regarding the effect of CFRP jacket, four of these six specimens were wrapped with identical CFRP 
sheets, but with different jacket thickness. The remaining two specimens were set as reference specimens; however, one of them was designed according to the older codes (non-ductile) and one designed based on new design code (ACI 318-14) taking into consideration the seismic design provisions. The specimen groups and configurations are illustrated in more details in Chapter 3-Experemental Work.

All the column specimens are tested under uniaxial cyclic compressive loading.

\subsection{Thesis Organization}

The current study work is organized into five chapters. The first chapter includes the introduction, the research significance, and the research scope and approach. The second chapter gives an overview of the basic concepts that explain the behavior of the steelconfined concrete column and the CFRP-confined concrete columns. It also contains an overall literature review on the previous research (experimental and theoretical) conducted on the confined concrete columns, and the factors affecting the behavior of this type of columns. The third chapter is devoted to presenting the experimental program and the procedure followed to develop the research specimens. It includes a full explanation of the mechanical testing conducted on the material used in this research (concrete, reinforcing steel, and CFRP composite). In addition, it demonstrates with explicit details the procedure of casting and curing the column specimens, and the process of the CFRP jacketing. It also reports the loading procedure, and the instrumentation used to record the experimental data. The forth chapter demonstrates the behavior of the test specimens and describes their failure modes. It also explains the effect of the CFRP confining action on the axial loading capacity and ductility of the 
confined columns. The last chapter was devoted to summarizing the test results and highlighting the conclusions. 


\section{Chapter 2. Literature Review}

\subsection{Introduction}

The basic philosophy of all seismic design provisions is to make structural elements behave in a ductile manner so that they are able to absorb and dissipate an appreciable amount of the energy imposed by an earthquake. This ductile behavior delays and minimizes the collapse of that structural element when hit by a severe earthquake. For concrete structural elements such as columns, it was found that confining the concrete core is an effective approach to achieve the ductile behavior. Different methods have been used to provide that confinement for the concrete core, such as internal transverse reinforcement (spirals or hoops) and external jacketing (Steel or FRP jackets). This chapter provides a brief review of the general behavior of the reinforced concrete columns, the behavior of the CFRP-confined columns, the concept of lateral confinement, and the parameters that influence the effectiveness of that confinement. This technical review is based on previous research performed on FRP-confined columns.

\subsection{Confined Concrete Under Uniaxial Compressive Loading}

When plain concrete is subjected to uniaxial compression, it undergoes a certain amount of axial strain that is proportional to the applied load. As a consequence of that generated axial strain, based on Poisson's effect, the tensile lateral strain is developed in concrete. Because concrete is very weak in tension, once it reaches its limiting tensile strain, vertical cracks develop and propagate dramatically until the concrete loses its integrity completely. In other words, the maximum stress cannot be maintained with the increasing deformation as illustrated in Figure 2-1. Therefore, with plain concrete, the ductile 
behavior cannot be achieved. In this case, the concrete is under a uniaxial state of stress (Saatcioglu \& Razvi, 1992).

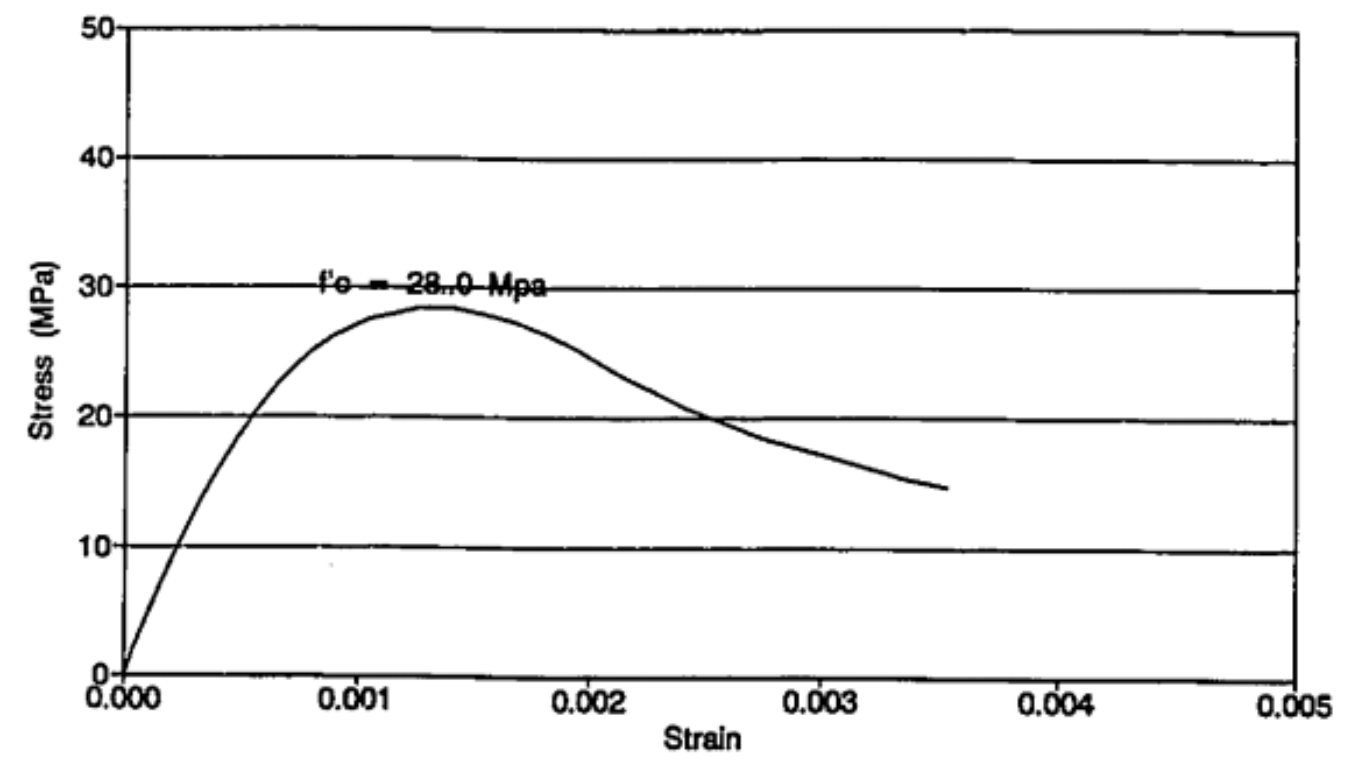

Figure 2-1: Stress-strain response of a plain concrete cylinder (Tuğrul, 1992)

In contrast, concrete is under a triaxial state of stress when subjected to an axial compressive loading with the existence of any kind of transverse reinforcement. To illustrate, the tendency of concrete to expand laterally when subjected to axial compression is counteracted by the lateral pressure generated by the tensile strain in the transverse confining reinforcement. This type of confinement action is called passive confinement since it is activated by the lateral expansion of the concrete core enclosed by the transverse reinforcement. As a result, the concrete compressive strength is increased. The amount of the gained strength is proportional to the level of lateral pressure generated. Richart and his research group, analyzed the data of their experimental tests on spirally confined concrete columns, and concluded that the relationship between the lateral confinement pressure and the confined concrete compressive strength can be 
presented by the following equation with some modification with notations (Richart, Brandtzaeg \& Brown, 1929):

$f^{\prime}{ }_{C C}=f^{\prime}{ }_{C O}+4.1 f_{l}$

Eq. 2-1

Where:

$f^{\prime}{ }_{c c}$ : Confined concrete compressive strength.

$f^{\prime}{ }_{c o}$ : Unconfined concrete compressive strength (concrete cylinder strength).

$f_{l}:$ Lateral confinement pressure.

In addition, the lateral confinement action improves the post-peak behavior of the reinforced concrete column by enhancing its axial deformation capacity without significant strength degradation. In other words, it enhances the concrete ductility. Ductility is an essential parameter for seismic design approaches.

\subsection{Steel-Confined Concrete}

Regardless of the shape of the cross section of a reinforced concrete column whether it is circular, square, or rectangular and regardless the configuration of the transverse reinforcement used for confinement action, the concept of confining the concrete is to meet the following two main conditions. The first condition is that the gained axial strength due to confinement is to compensate for the loss in strength due to the spalling of the concrete cover. The second condition is that confinement should result in a larger axial strain capacity without considerable strength loss. The most usable means of transverse reinforcement are steel spirals and square/rectangular hoops. In addition to the confinement action, the other reason for of providing transverse reinforcement in concrete columns are to prevent the buckling of the longitudinal reinforcing bars and to 
increase the shear strength of columns (Subramanian, 2011). Since understanding the confinement action of this type of lateral reinforcement is essential in any seismic design provisions, many theoretical models were developed to explain the behavior of the steelconfined concrete columns and predict the lateral confinement pressure induced by spirals and non-circular hoops.

\subsubsection{Mander et al. Model (1988)}

This theoretical model is the most known model for predicting the stress-strain curve for steel-confined concrete. It has been the basis of the most following models. Mander et al. developed a unified stress-strain model for confined concrete as shown in Figure 2-2 that can be applied to both circular and rectangular shaped transverse reinforcement. This

model is based on the stress-strain model of concrete developed by Popovics (1973) under monotonic loading. The suggested expression of the concrete compressive stress $f_{c}$ is given by

$f_{c}=\frac{f^{\prime}{ }_{c c} X \gamma}{\gamma-1+X^{\gamma}} \quad$ Eq. $2-2$

Where:

$f^{\prime}{ }_{c c}$ : Confined concrete copressive strength.

$X=\frac{\varepsilon_{c}}{\varepsilon_{c c}}$

Where:

$\varepsilon_{c}$ : Concrete axial compressive strain.

$\varepsilon_{c c}$ : Concrete axial srtrain coressponding to $\mathrm{f}^{\prime}{ }_{\mathrm{cc}}$ 


$$
\begin{aligned}
& \varepsilon_{c c}=\varepsilon_{c o}\left[1+5\left(\frac{f^{\prime} c c}{f^{\prime} c o}-1\right)\right] \\
& \gamma=\frac{E_{c}}{E_{c}-E_{s e c}}
\end{aligned}
$$

Where: Ec is the modulus of elasticity of concrete

$$
\begin{aligned}
& E_{c}=57000 \sqrt{f^{\prime} c o} \\
& E_{s e c}=\frac{f^{\prime}{ }_{c c}}{\varepsilon_{c c}}
\end{aligned}
$$

$f^{\prime}{ }^{\prime} o$ and $\varepsilon_{c o}$ are defined as the unconfined concrete compressive strength and the corresponding strain, respectively. $\varepsilon_{c o}$ is assumed to be 0.002 .

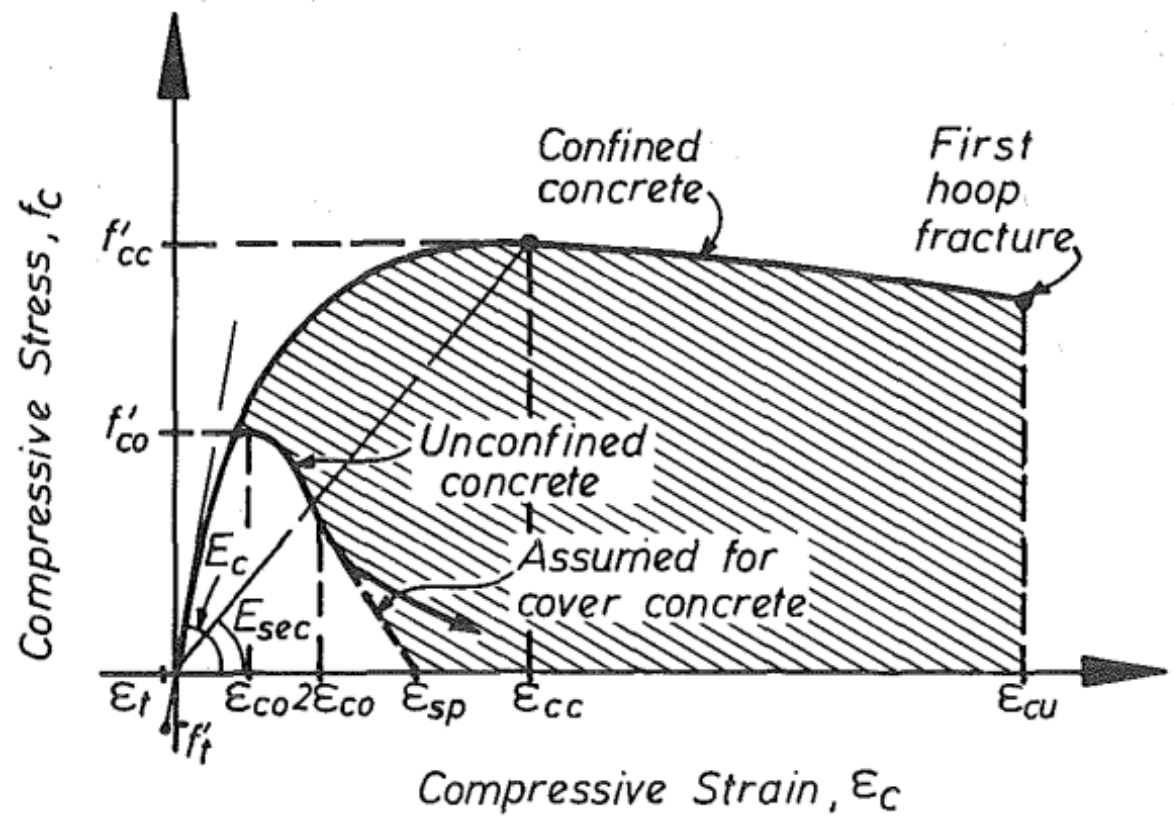

Figure 2-2: Stress-strain model of confined concrete proposed by Mander et al. (1988) 
To determine the effective lateral confining pressure and the confining efficiency factor, Mander et.al. (1988) adopted an approach proposed by Sheikh and Uzumeri (1980). According to this approach, due to the arching action as shown in Figure 2-3, the largest effectively confined concrete core area $\left(\mathrm{A}_{\mathrm{e}}\right)$ is the core cross-sectional area at the level of the transverse confining steel hoops or spiral. However, the smallest effectively confined area is the one midway between two consecutive hoops. This concept applies to both cases of circular and rectangular steel hoops. The confined concrete core area $\left(A_{c c}\right)$ is defined as the area enclosed by the center line of the transverse reinforcing hoop. To consider the fact that $A_{e}<A_{c c}$, the effective lateral confining pressure is given by: $f^{\prime}{ }_{l}=f_{l} k_{e}$

Where $f_{l}$ is the lateral confining pressure from the transverse reinforcement that is assumed to be uniformly distributed over the concrete core area, $k_{e}$ is the confinement effectiveness confinement:

$k_{e}=\frac{A_{e}}{A_{c c}}$

For non-circular (rectangular/square) columns, the effectively confined concrete area $\left(A_{e}\right)$ can be given by

$A_{e}=\left(b_{c} d_{c}-\sum_{i=1}^{n} \frac{\left(w^{\prime}{ }_{i}\right)^{2}}{6}\right)\left(1-\frac{s^{\prime}}{2 b_{c}}\right)\left(1-\frac{s^{\prime}}{2 d_{c}}\right)$

Where $b_{c}, d_{c}, w^{\prime}$ and $s$ ' are defined in Figure 2-2.

The lateral confining pressure on the concrete for $\mathrm{X}$ direction is:

$f_{l X}=\frac{A_{S X}}{s d_{c}} f_{y h}$

And in the $\mathrm{Y}$ direction as 
$f_{l Y}=\frac{A_{S Y}}{s b_{c}} f_{y h}$

Therefore, the effective lateral confining pressure is:

$f^{\prime}{ }_{l X}=f_{l X} k_{e}$

$f^{\prime}{ }_{l Y}=f_{l Y} k_{e}$

Where $A_{s x}$ and $A_{s y}$ are the total transverse reinforcement area, respectively, and fyh is the tensile yield strength of the steel hoops.

Mander et al. adopted an equation proposed by William and Wranke (1975) to determine the confined concrete compressive strength $\left(f^{\prime} c c\right)$. Because it showed an excellent agreement with triaxial test data. This equation is suitable for the situation where the confined concrete core is placed in triaxial compression with equal effective confining pressure $\left(f^{\prime} l\right)$ from the transverse reinforcing steel. The adopted equation herein is:

$$
f^{\prime}{ }_{c c}=f^{\prime}{ }_{c o}\left(-1.254+2.254 \sqrt{1+\frac{7.94 f^{\prime} l}{{f^{\prime}}_{c o}}}-2 \frac{f^{\prime}{ }_{l}}{{f^{\prime}}_{c o}}\right) \quad \text { Eq. } 2-4
$$
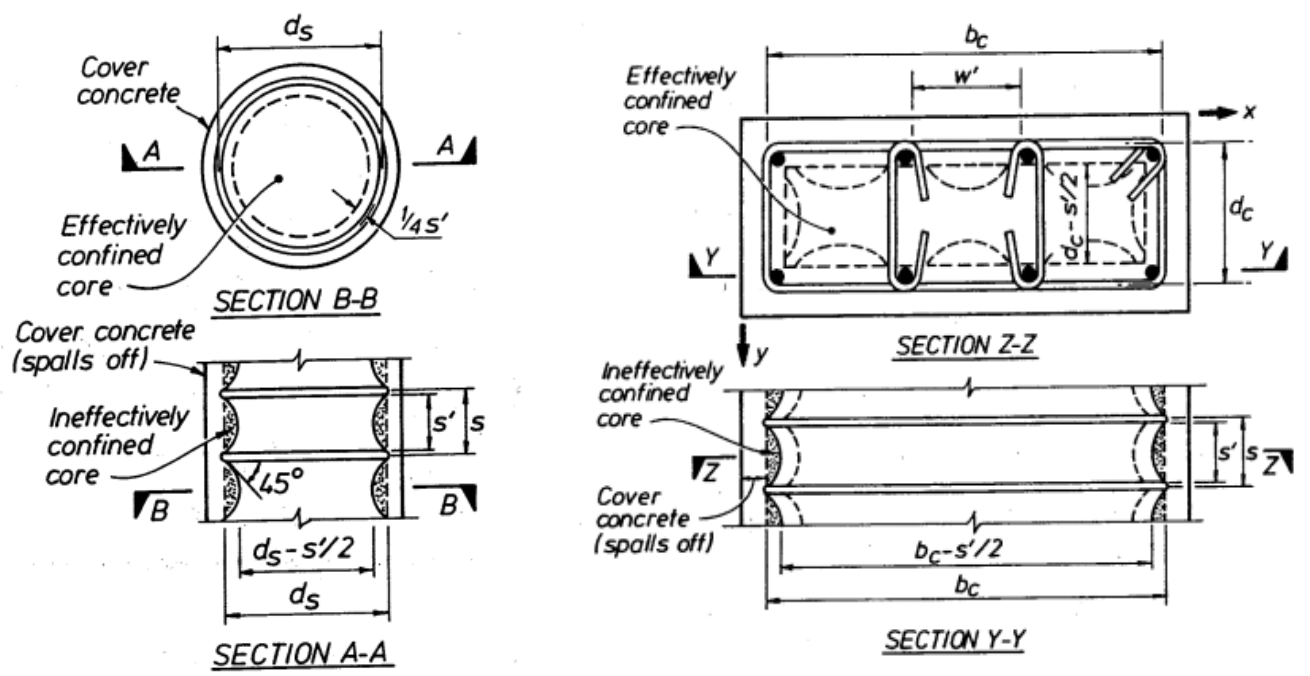

Figure 2-3: Effectively confined concrete core area for both circular and rectangular hoop cases 


\subsection{FRP-Confined Concrete in Circular Columns under Concentric Compression}

\subsubsection{Confinement Behavior of FRP Jacket}

The nature of the lateral confinement action that any FRP jacket provides is passive. It means that when a concrete element is subjected to an axial compressive loading, the result of this compression, in addition to the axial deformation, and following the Poisson's effect, the concrete tends to expand laterally. It continues to expand as long as the load increases until it reaches the ultimate lateral strain of the concrete when the concrete is no longer able to handle any lateral stress. So, when a column is wrapped with an FRP jacket and then subjected to axial compression, the FRP jacket confines the concrete while the concrete expands. In contrast to the steel jacket behavior, where the confinement pressure maintains constant after reaching the yield point of the steel material, the FRP confinement pressure increases with increasing the dilation of concrete until the rupture of the FRP jacket. In other words, the confinement action of the jacket is activated once the concrete reaches its maximum hoop strain that corresponds to its peak axial stress $\left(f^{\wedge} c\right)$ (Micelli \&Modarelli, 2013). After this point, the axial compressive strength of the FRP-confined concrete column continues to linearly increase until the FRP material reaches its hoop rupture strength Figure 2-4 shows an axial loaddeformation relationship of an FRP-confined concrete column. Figure 2-5 illustrates the confining action of the FRP jacket on a circular cross section column. 


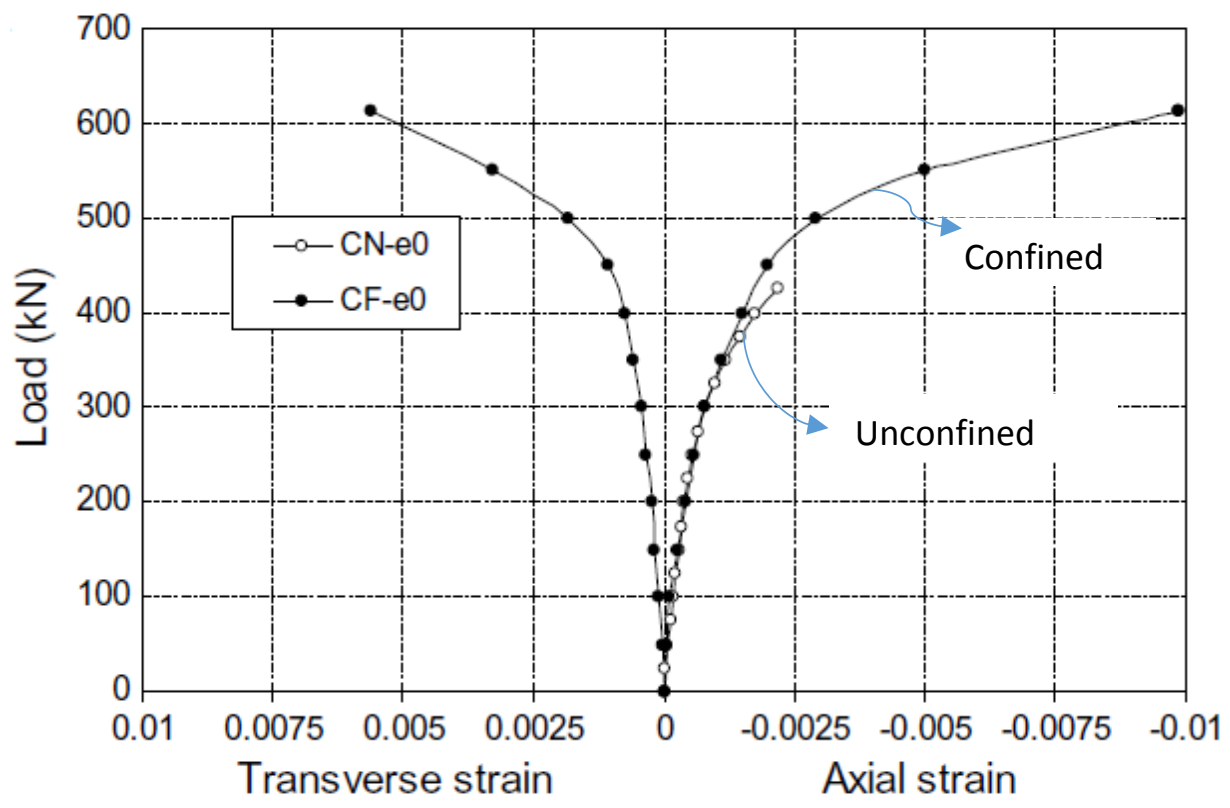

Figure 2-4: Axial load-deformation curve. (El Maaddawy et al., 2009)

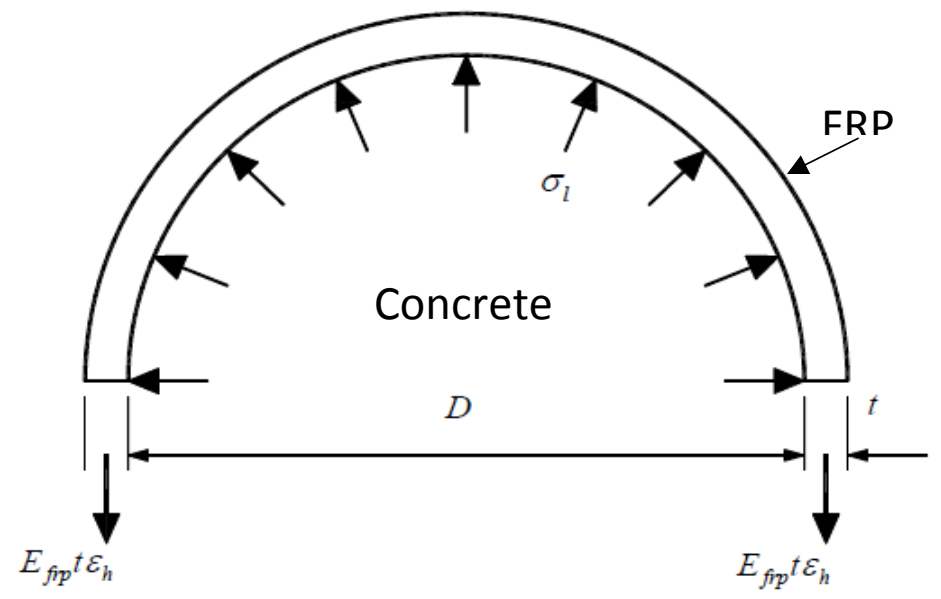

Figure 2-5: Confining action of the FRP jacket. (Jiang, 2008) 
The lateral confining pressure can be derived using the stress equilibrium and radial displacement compatibility considerations between the concrete core and the jacket. Due to the linear behavior of the FRP material, the hoop tensile stress of the FRP-jacket, $\sigma_{h}$ is a function of the hoop strain, $\varepsilon_{h}$.

$$
\sigma_{h}=E_{f r p} \varepsilon_{h}
$$

Where, $E_{f r p}$ is the elastic modulus of the FRP material.

The ultimate lateral confining pressure, $f_{l}$ can be given by:

$$
f_{l}=2 \frac{E_{\text {frp }} \varepsilon_{h r u p .} t_{f}}{D}
$$

Where $\varepsilon_{\text {h rup. }}$ is the ultimate tensile hoop strain of the FRP jacket (at rupture), $t_{f}$ is the thickness of the jacket, and $D$ is the diameter of the concrete core.

The distribution of this lateral confinement pressure is considered uniform around the perimeter of the circular cross section which means that this pressure is applied evenly on the concrete core.

\subsubsection{Rupture Strain of the FRP Jacket}

There has been a lot of research measuring the ultimate tensile hoop strain of FRP jackets, which is the strain at which the FRP jacket ruptured. A Sudden, explosive rupture of the FRP jacket is the dominant failure mode in almost all of the tested confined concrete columns (Xiao \& Wu, 2000; Liang et al., 2012; Micelli \& Modarelli, 2013; Wu \& Jiang, 2013). Consequently, it is crucial to know the strain capacity of the FRP material. There are several methods to measure the ultimate tensile strain of the FRP composite. The most common method is the ASTM D3039 (2008) flat coupon test. In this test a flat piece of FRP composite is gripped at its both ends and subjected to a tensile 
load until rupture. The rupture strain is measured by the means of strain gauges mounted at the mid- height of the coupon. However, investigations found that the strain at which the FRP jacket is ruptured is less than the strain measured by the coupon test. Xiao and Wu (2000) conducted an experimental work on small-scale cylindrical specimens confined by a CFRP jacket, and tested under concentric axial loading. It was noted that the measured rupture strain of the jacket was less than the one obtained from the tensile coupon test by $20 \%$ to $50 \%$. Similarly, Pessiki et al. (2001) observed a reduction in the ultimate strain of the FRP material of about $40 \%$ to $60 \%$ as compared to the jacket rupture strain. This observation was valid for both small and large-scale circular column specimens that were involved in this study. Researchers have proposed several possible causes to explain this reduction in strain: the fact that the FRP jacket is not only subjected to pure tensile stress, it might also be affected by axial stress and the lateral confinement pressure acting on its internal surface; the effect of the non-uniform deformation of the concrete; the effect of jacket curvature; and the effect of the misalignment of fibers in the jacket (Xiao \& Wu, 2000; Jiang, 2008; Wu \& Jiang, 2013). Therefore, most analysis and design confinement models suggest using an efficiency factor when calculating the effective confinement pressure to account for that reduction in the FRP ultimate strain. For example, the ACI 440-2R-08 recommends using a strain efficiency factor of 0.55 in its design-oriented model. However, it was found that the number and distribution of strain gauges used to measures the FRP rupture strain play a significant role in minimizing the difference between the listed and measured ultimate strain. The more the strain gauges that are used, the more the captured jacket strain converges to the strain measured by the flat coupon test. This means that by using a smaller number of strain 
gauges, the chance of capturing the actual rupture strain is less (Wu \& Jiang, 2013). As a results, the authors suggested using a strain efficiency factor of 0.9.

\subsubsection{Stress-Strain Relationship}

The axial stress-strain response is an important aspect for investigating the axial compressive behavior of FRP-confined circular columns. Generally, the typical stressstrain curve of this type of columns has an almost bilinear trend. It consists of two main regions; the first (initial) region is an ascending curve governed by the stiffness of the unconfined concrete. This region ends when the concrete reaches its compressive strength $\left(f^{\prime} c o\right)$. After that, the FRP confinement action is activated and results in another ascending curve but with a lower slope. The ascending trend of the second line indicates an increase in the compressive strength and strain of the confined column. The second region is mainly governed by the stiffness of the confining jacket and the formation of cracks in the concrete core. When the FRP material reaches the rupture point (failure), the curve shows a considerable sudden drop in axial stress (Xiao \& Wu, 2000; Lee e al., 2004; Benzaid et al., 2010; Liang et al., 2012). This ascending bilinear behavior is perfectly valid for circular columns with low-grade concrete (refer to Figure 2-4). However, for columns with high-strength concrete, the stress-strain curve shows a descending second branch with a small flat plateau followed by a sudden drop in ductility. Despite the descending trend, the curve exhibits a peak stress that is greater than the unconfined compressive strength, but smaller ultimate strength at failure. This phenomenon was observed by Xiao and Wu (2000), Benzaid et al. (2010), Hadi et al. (2012), and Micelli and Modarelli (2013). The drop in the deformation capacity in this type of column might be due to the higher stiffness of the high-strength concrete, which 
limits the dilation of the core that activates the confinement action of the FRP jacket. This behavior is illustrated in Figure 2-6, and shows load-deformation relationship for a highstrength FRP confined concrete column $\left(f^{\prime}{ }_{c o}=79.5 \mathrm{MPa}\right)$.

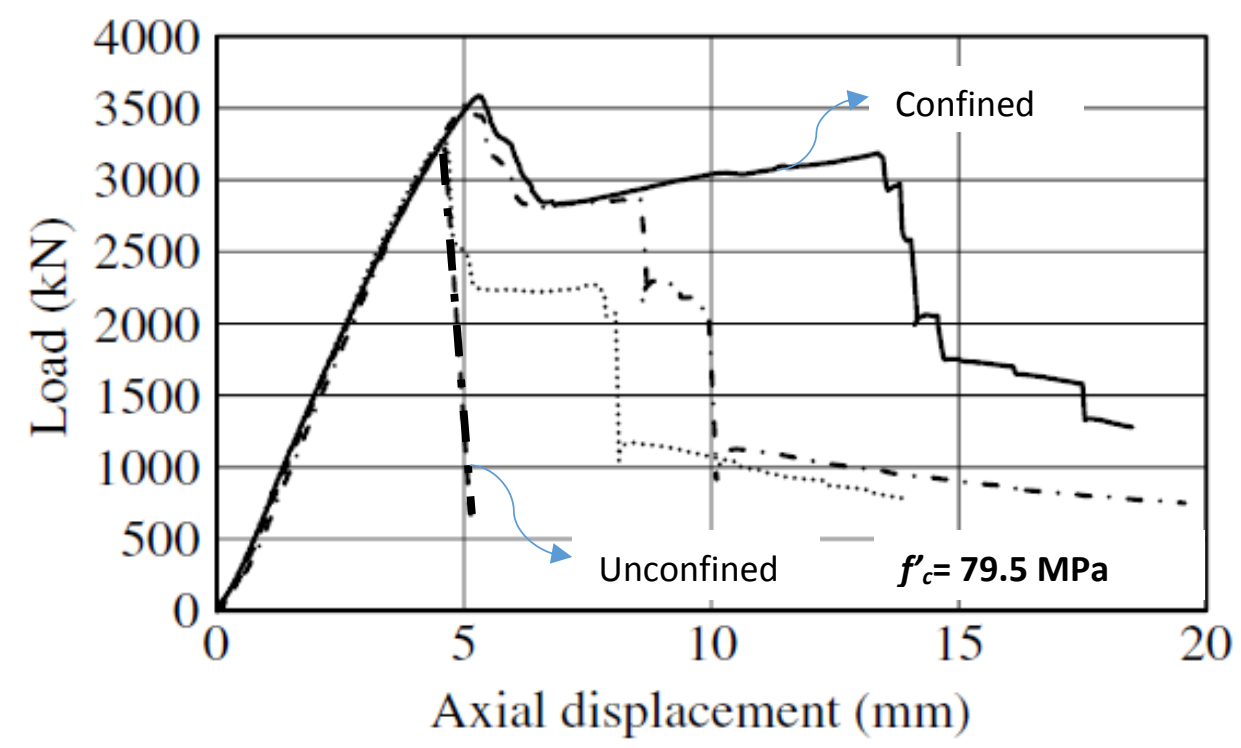

Figure 2-6: Axial load-deformation curve for high-strength FRP confined column. (Hadi, 2011)

\subsubsection{Size Effect}

It is worth noting that the majority of research investigating the behavior of FRPconfined concrete columns was conducted on small-scale specimens. Consequently, most the FRP confinement models were derived from results obtained from small-scale specimens. However, the suitability of applying these models on large-scale specimens is still not confirmed. Nevertheless, some recent research was conducted to study the effect of test specimen size in FRP-wrapped concrete columns (Wang \& Wu, 2010; Elsanadedy, 2012; Liang et al., 2012). The experimental results show that there is no significant size effect on the failure modes of the FRP-wrapped columns. The effect of the specimen's 
size on stress-strain curves is not obvious. In addition, the gain in compressive strength and ductility is almost the same in both small and large-size specimens. However, Elsanadedy (2012) found that the size effect is pronounced for unwrapped concrete. As a result, researchers suggest that there is no need to introduce the size factor when using existing FRP-confinement models with large-scale columns.

\subsubsection{Thickness of FRP-jacket}

One of the most effective factors that influence the performance of any FRP jacket is its thickness. The jacket thickness is usually defined by the number of the wraps applied around the confined column. The confinement stress that any FRP jacket provides is linearly proportional to its thickness:

$$
f_{l}=2 \frac{E_{\text {frp }} \varepsilon_{\text {hrup. }} t_{f}}{D}
$$

So, increasing the thickness of the jacket causes a higher lateral confinement pressure which, in turn, leads an enhanced effectiveness of the confining jacket. This enhancement appears as an increase in compressive strength and ductility as shown in Figure 2-7.

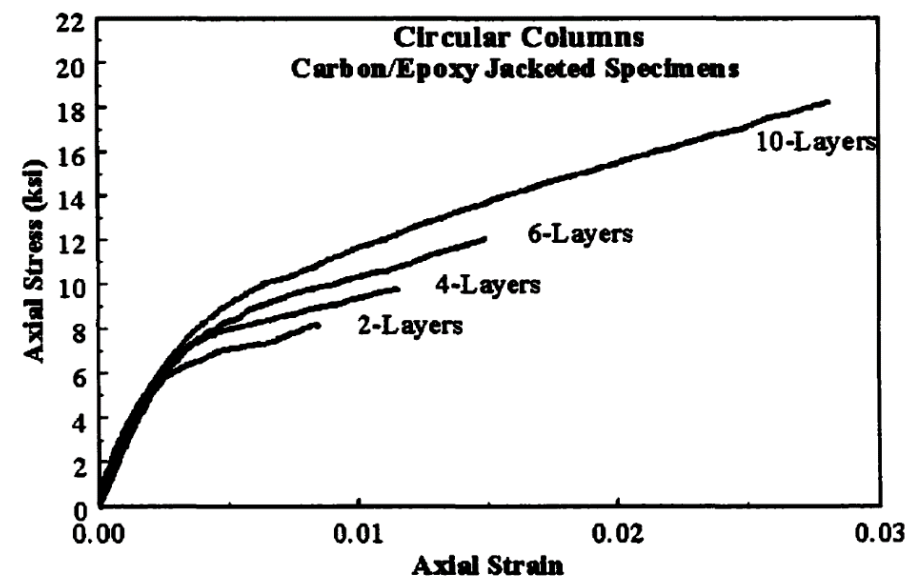

Figure 2-7: Stress-Strain Curve for a CFRP Confined Concrete Circular Column (Youssef, 2003) 


\subsection{FRP-Confined Concrete in Non-Circular Columns Under Concentric}

\section{Compression}

\subsubsection{Confinement Behavior of FRP Jacket}

Because rectangular and square columns are the most common type of columns used in the field, some research has been done to study the behavior of these types of columns when confined by a FRP jacket. In contrast to circular columns, the FRP jacket applies non-uniform lateral pressure on concrete due to the non-uniform concrete dilation. Corners are subjected to higher pressure than flat sides. In other words, the stress is concentrated at corners. Due to the cross section geometry and the non-uniform distribution of confinement pressure, only a percentage of the cross-sectional area is effectively confined. Therefore; the confinement action, in this case, is less effective than the case of circular columns. Another reason for the lower effectiveness is that in circular columns the confinement action relies mainly on the tensile stiffness of the FRP jacket, whereas in rectangular/square columns, it relies on the flexural stiffness of the jacket, which is much less than the tensile stiffness (Doan, 2013). Figure 2-8 shows the effective confinement area of a rectangular cross section.

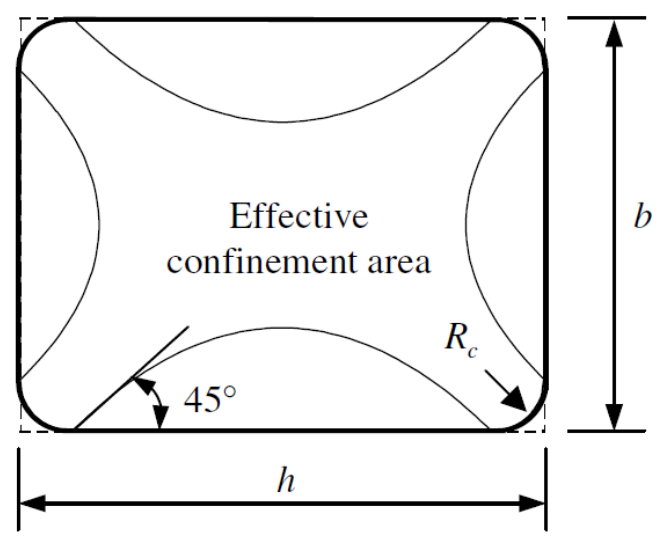

Figure 2-8: Effectively Confined Concrete in a rectangular column (Lam and Teng, 2003) 
Most of the models in the literature that are used to describe the behavior of an FRPconfined non-circular concrete column recommend applying a shape factor to account for the non-uniform distribution of confinement pressure. For instant, in the model by Lam and Teng (2003) that was later adopted by the ACI 440-2R-08, the proposed shape factor is a function of the ratio between the effectively confined concrete area $(\mathrm{Ae})$ and the gross area of an equivalent circular cross section (Ac), as illustrated in Figure 2-9. The same concept from the circular cross section case is followed to determine the effective confinement pressure except for applying the shape factor.

$$
f_{l}=2 \frac{E_{\text {frp }} \varepsilon_{h r u p .} t}{D}
$$

Where $\mathrm{D}$ is the diameter of the equivalent circular cross section:

$$
\begin{aligned}
& D=\sqrt{h^{2}+b^{2}} \\
& f_{l e}=K a\left(f_{l}\right)
\end{aligned}
$$

Where:

$f_{l e}$ : The effective confinement pressure

Ka: the shape factor

$$
\begin{gathered}
K a=\frac{A e}{A c}\left(\frac{b}{h}\right)^{2} \\
\frac{A e}{A c}=\frac{1-\frac{\left[\left(\frac{b}{h}\right)\left(h-2 r_{c}\right)^{2}+\left(\frac{h}{b}\right)\left(b-2 r_{c}\right)^{2}\right]}{3 A g}-\rho_{s}}{1-\rho_{s}}
\end{gathered}
$$

Where:

$\rho_{s}$ : The ratio of longitudinal reinforcement

$r_{c}:$ Corner radius 


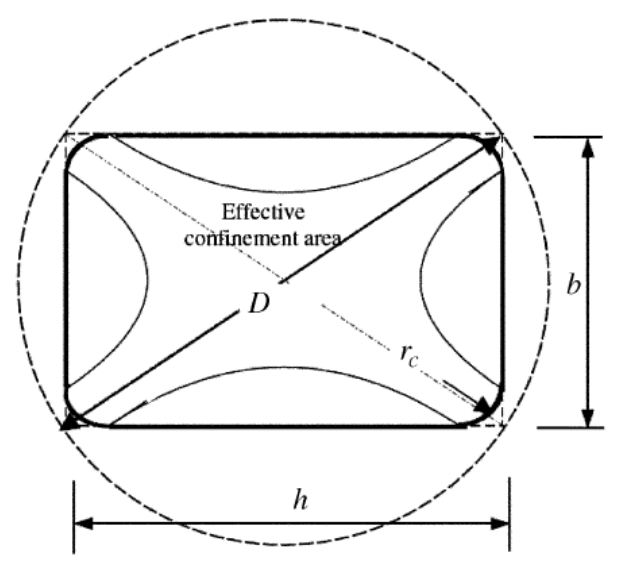

Figure 2-9: Equivalent circular cross section (Lam and Teng, 2003)

\subsubsection{Effect of the Corner Radius}

Sharp corners have a knife-effect on the FRP jacket causing a stress concentration at the corners, which leads to a premature rupture of the jacket when the compressive load on the column is increased. Consequently, it reduces the confinement effectiveness. To relieve this stress concentration, it is always recommended to round the corners to a certain radius before applying the FRP jacket. A significant amount of research has investigated the effect of corner radius on the effectiveness of the FRP confining action. Wang and $\mathrm{Wu}(2008)$ experimentally studied the effect of the corner radius on the FRP confining effect by testing a number of square specimens with different corner radii, and comparing them with a circular specimen. The test results showed that for specimens with sharp corners (i.e. zero corner radius), there was no significant gain in compressive strength due to confinement. However, as it is shown in Figure 2-10, for a given jacket thickness, it was found that increasing the corner radius increased the confining effectiveness, which caused an enhancement in compressive strength and ductility. This effect is also observed by Micelli and Modarelli (2013). 


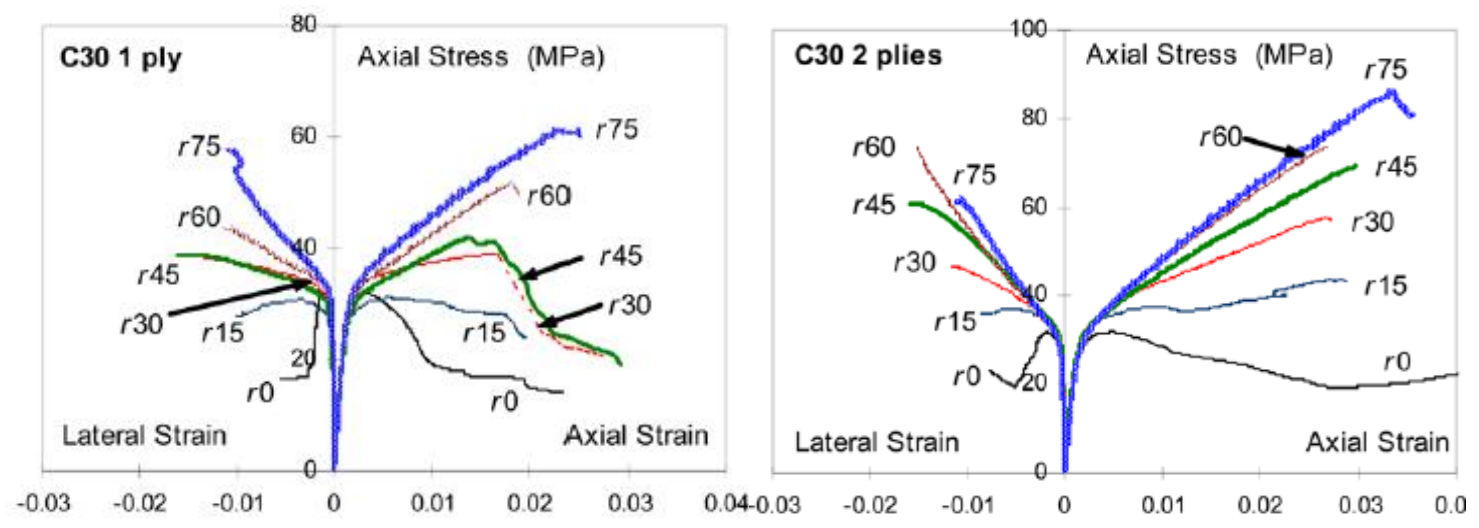

Figure 2-10: Effect of corner radius on confinement (Wang and Wu, 2008)

\subsubsection{Stress-Strain Relationship}

Similar to circular columns, the stress-strain curves of FRP-confined square columns are mostly bilinear. They are comprised of two zones; the initial zone is governed by the stiffness of the unconfined concrete. At this zone, the concrete experiences a small value of lateral strain, so the FRP confinement effect is not activated yet. The second zone starts when the concrete reaches its unconfined compressive strength. In this zone, increasing the compressive load causes higher lateral strain in concrete, which activates the lateral pressure of the FRP jacket. This confinement effect, in general, results in enhancing the compressive strength and ductility until failure. However, for square columns, the degree of this enhancement depends on the confinement level, which in turn, is influenced by two main factors; the corner radius and the thickness of the jacket. In the case of sharp corners and small jacket thickness (insufficient confinement), the second branch of the stress-strain curve tends to have a descending trend until failure. Consequently, the ultimate confined compressive strength is less than the unconfined compressive strength (Benzaid \& Mesbah, 2013). For well-rounded corner and well confined square column, the second branch has a positive slope until failure. This 
behavior results in an ultimate compressive strength higher than the unconfined one.

Figure 2-11 illustrates the stress-strain relationships of square columns with different level of confinement.

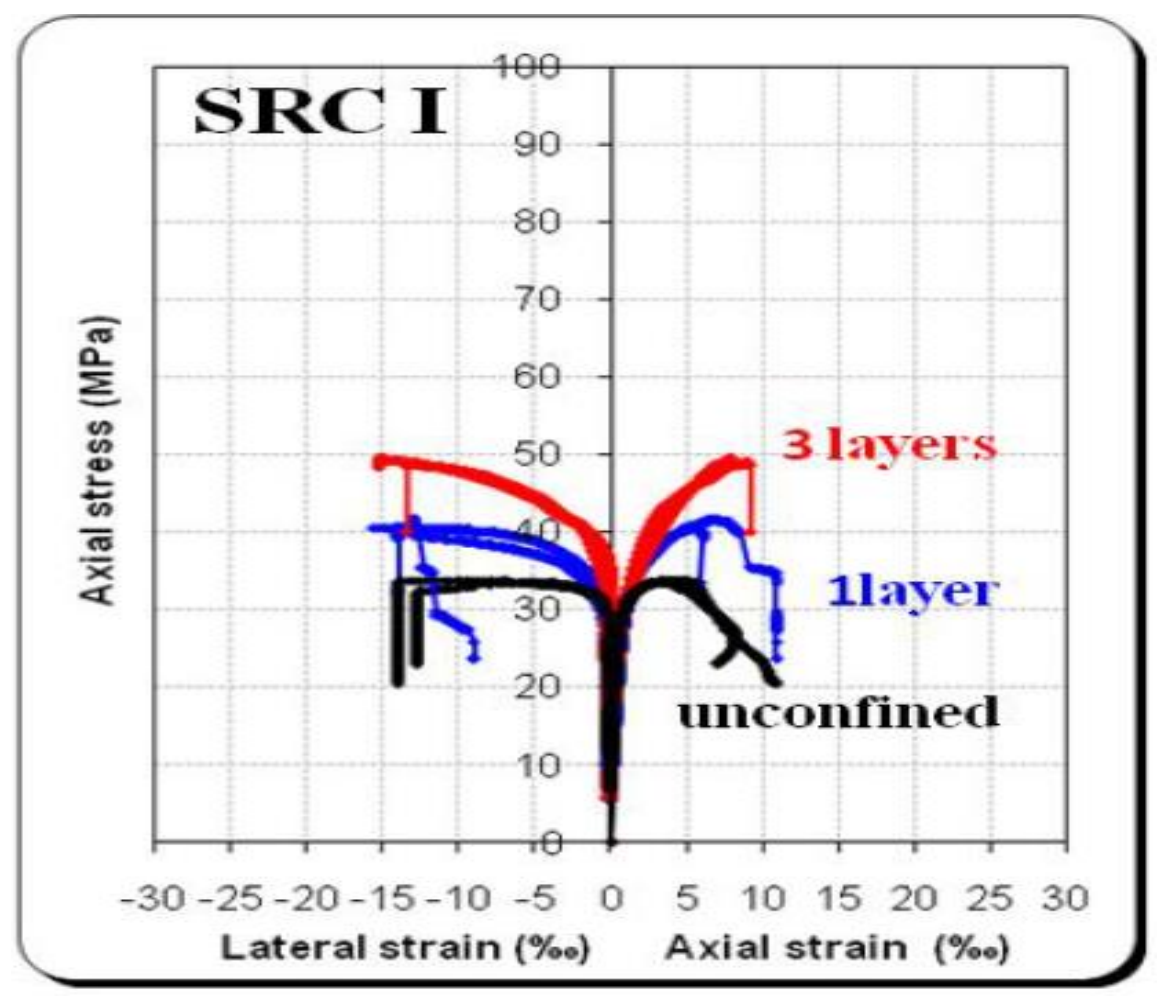

Figure 2-11: Stress-strain curves for square column specimen (Benzaid and Mesbah, 2013) 


\subsection{Previous Studies}

In the following section a brief summary of the reviewed research that was performed to study the effectiveness of strengthening concrete columns with FRP composites.

An experimental work by Rochette and Labossiere (2000) was done to investigate the effect of varying the FRP composite jacket's thickness on the behavior of a square and rectangular column in terms of its axial load carrying capacity and ductility. The effect of varying the cross-sectional shape on the behavior of the column was also examined. To conduct this study, a number of small-scale plain concrete specimens with various cross-section shape; circular, square and rectangular, were set in groups according to the number of the FRP-composite plies applied. For non-circular specimens, different corner radii were investigated as well. The grade of the concrete that used in this study was 40 MPa (5800 ksi). For the FRP composite jacket, CFRP Sheets with $0.3 \mathrm{~mm}$ thickness and $1265 \mathrm{MPa}(183.5 \mathrm{ksi})$ tensile strength. All specimens were tested under monotonic concentric axial loading until failure. The test results showed that increasing the thickness of the jacket enhanced the compressive strength and ductility of all specimens regardless the cross-section shape. Moreover, it was noted that for a given number of FRP layers, increasing the corner radii affected positively the axial strength and capacity of the noncircular specimens as shown in Figure 2-12 


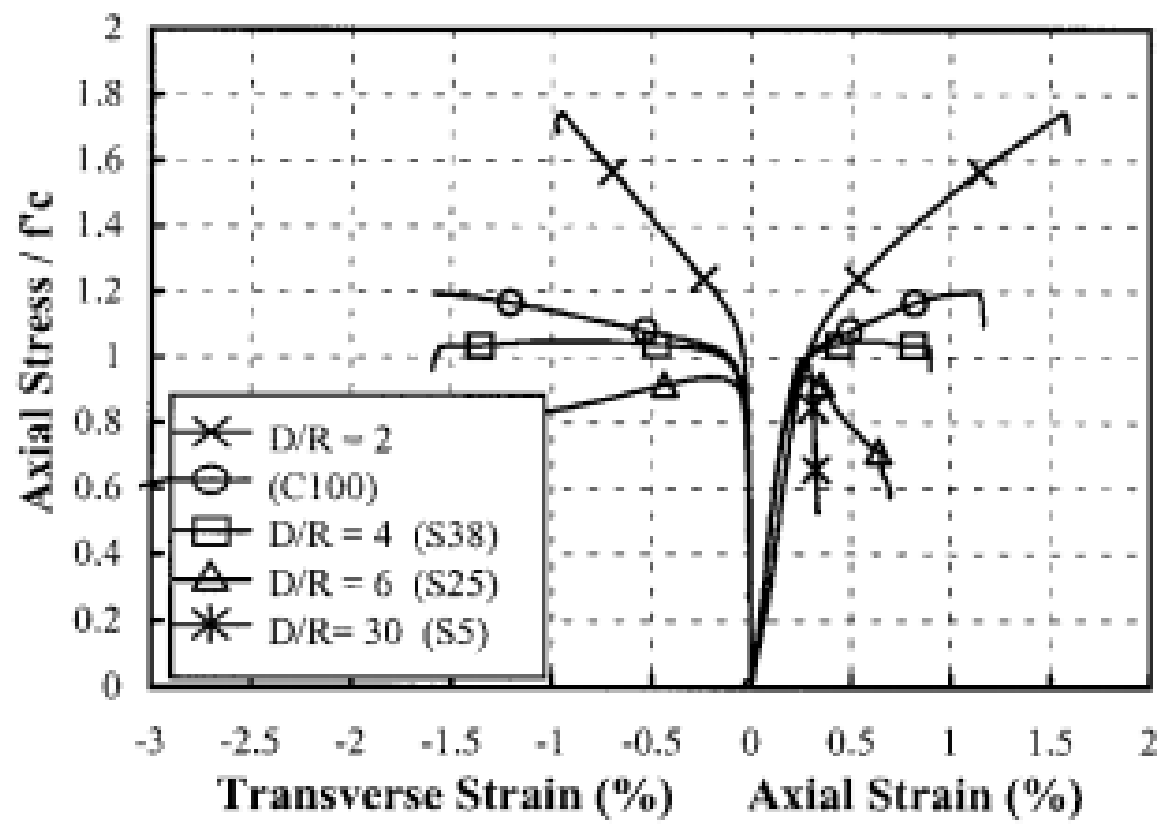

Figure 2-12: Variation of corner radius of square columns (Rochette \& Labossiere, 2000)

Another experimental work was done by Pessiki et al. (2002) to study the effect of the cross-sectional shape and the type and stiffness of the FRP jacket on the stress-strain relationship of the confined concrete columns. Specimens were divided into two main groups; plain concrete small-scale and reinforced concrete large-scale specimens. Each main group was set into two subgroups according to the cross-section shape; circular and square. In each small-scale subgroup, a different number of FRP plies were applied while it was kept constant in the case of large-scale specimens (3 plies). Also, two types of FRP composite material were used; CFRP and GFRP. For large-scale specimens, the ratio of the longitudinal and transverse reinforcement was $1.9 \%$ and $0.09 \%$, respectively. For small specimens, the increase in compressive strength was $128 \%$ for the multidirectional 
GFRP confined specimens and $244 \%$ for specimens wrapped with two layers of CFRP sheets, compared to the unconfined column. The axial strains recorded for wrapped specimens were seven times higher than the unwrapped specimens. It was found that the performance of the FRP confined circular columns was around $30 \%$ better than the confined square columns in terms of ultimate axial strength. However, both of them exhibited approximately the same amount of ductility. This similar behavior was explained by the fact that the square specimens were built with relatively large corner radii (1/4 the side dimension) that made their geometry close to circular section. In addition, it was observed that for a constant number of FRP plies, specimens confined with CFRP showed higher compressive strength and ductility than those confined with GFRP. For large-scale specimens, it was observed that the confinement provided by three-ply jacket was as much as that provided by the one-ply jacket in the case smallscale specimens. As a result, insufficient enhancement in strength and ductility was achieved. In addition, the ultimate hoop rupture strain reported at the mid-height of the specimen was about $60 \%$ and $42 \%$ of the FRP rupture strain from pure tension tests (coupon test) for the small-scale and large-scale circular specimens, respectively. Thus, a strain efficiency factor was suggested to account for the reduced in situ FRP sheet properties.

An experimental work was by Lee et al., (2004) was conducted to study the behavior of concrete columns confined by both internal steel spirals and external FRP sheets under uniaxial compression. In this experiment, twenty-four small-scale cylindrical specimens (150 $\mathrm{mm}$ in diameter and $300 \mathrm{~mm}$ in height) were tested under concentric compressive axial loading. The main study variables were the type of confinement material (FRP 
and/or steel spirals) and the lateral confinement pressure. Some of the specimens were confined only by spirals. Others were confined by FRP jackets, the rest were wrapped by FRP composite in addition to the internal steel spirals. To vary the confinement pressure, different spiral pitches $(20,40$, and $60 \mathrm{~mm})$ and different number of FRP wraps $(1,2,3$, 4 , and 5 wraps) were used. The results show that, generally, the compressive strength and strain depend on the thickness of the FRP jackets as well as the volume of steel spirals. The axial compressive strength increases with increasing the FRP thickness and decreasing the spirals pitch due to increasing the lateral confinement pressure. However, the maximum strain does not increase proportionally with increasing the lateral pressure, but it significantly depends on the ratio of the confining pressure created by steel hoop, and the pressure created by FRP. It is noted that increasing the total confining pressure (i.e. steel spirals plus FRP composite) leads to increasing the compressive strength but decreasing the ductility or the axial strain capacity. The other interesting finding is that the maximum axial strain of both-material confined concrete is greatly influenced by the higher value of strain between the FRP-confined concrete and the steel confined concrete. Wang and $\mathrm{Wu}(2008)$ conducted a study to investigate the effect of varying the corner radius on the strength and ductility of a square concrete column confined by FRP sheets. In this study, 108 small-scale square column specimens were tested under monotonic compression load. All specimens were 150 x $150 \mathrm{~mm}$ in cross-section and $300 \mathrm{~mm}$ in height. The study parameters were corner radius, FRP jacket thickness, and concrete grade. The specimens were set into two series according to the concrete grade used (C30 and C50). In each series, columns were varied in corner radius $(0,15,30,45,60$ and 75 $\mathrm{mm})$. Also, the jacket thickness varied from none to 2-ply CFRP. The test results showed 
that for C30 series with small corner radii, specimens mainly failed with CFRP rupture mode while specimens with larger corner radii failed due to a combination of delamination and tensile rupture of the CFRP jacket. On the other hand, for C50 series, all specimens failed due to CFRP rupture regardless the corner radius. In addition, from the stress-strain curves, it was observed that there was a combined effect of the corner radius and the level of confinement (i.e. jacket thickness). For C30 series, relatively small corner radius and high confinement level significantly increased the ductility compared with the case of small corner radius and low level of confinement. However, increasing the confinement enhanced the ductility regardless the corner radius. In terms of compressive strength, it was found that the gain in strength due to confinement is in direct proportion to corner radius. In other words, increasing the corner radius leads to a higher gain in compressive strength. However, the enhancement of ductility due to confinement is more pronounced than the gain in compressive strength.

Turgay et al. (2010) conducted an experimental study on large-scale square RC columns confined with CFRP wraps to investigate the effect of longitudinal and hoop reinforcement on the behavior of a concentrically loaded column. In this project, twenty column specimens with dimensions of $200 \mathrm{~mm}\left(8^{\prime \prime}\right)$ in width and $1000 \mathrm{~mm}\left(40^{\circ 6}\right)$ in height were divided into groups based on: 1) the CFRP wrapping scheme (unwrapped, partially wrapped, fully wrapped, partially with two layers, and fully wrapped with two layers); 2) The number of $\emptyset 10 \mathrm{~mm}$ longitudinal bars (4 bars (L4) or 8 bars (L8)) and 3) the size of the transverse reinforcing bars ( $\varnothing 8 \mathrm{~mm}(\mathrm{~S} 8)$ or $\emptyset 12 \mathrm{~mm}(\mathrm{~S} 12))$. The average concrete compressive strength was $19 \mathrm{MPa}$ (2755 psi). The CFRP material used in this experiment had a thickness of $0.165 \mathrm{~mm}$ and tensile strength of $3430 \mathrm{MPa}$ (497 ksi). All 
the test specimens failed when the CFRP jacket ruptured near the corners. However, the failure region varied based on the CFRP wrapping scheme; in the fully wrapped specimens, the fracture occurred at the top or bottom quarters, whereas, the fracture occurred the end of the CFRP-confined regions in the partially wrapped specimens. The test results showed that increasing the diameter of the transverse reinforcement significantly enhanced the ductility by increasing the maintained axial strain at failure; however, it did not affect the ultimate axial strength as depicted in Figure 2-13. In addition, it was noted that there was no clear effect of the number of the longitudinal reinforcing bars on the ductility enhancement.
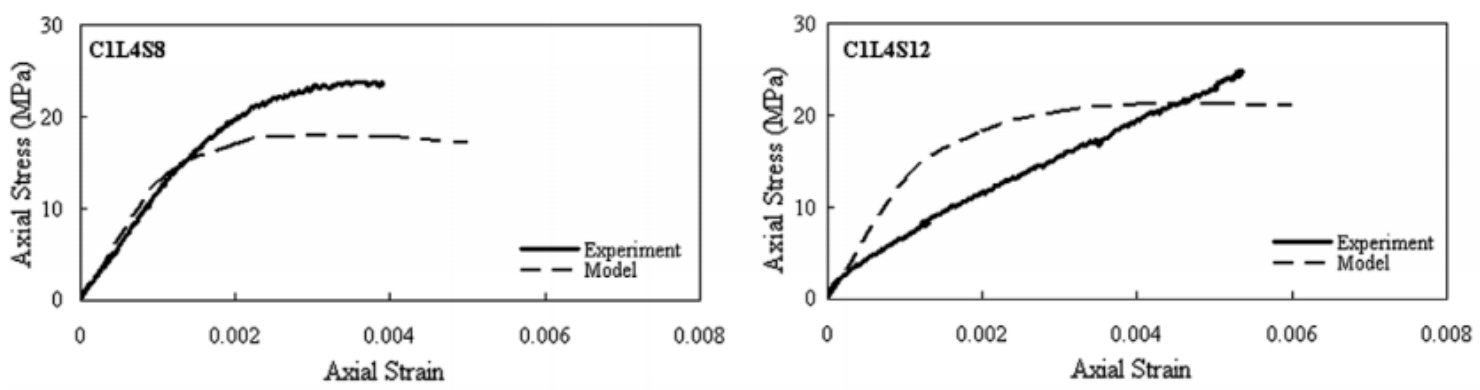

(a)

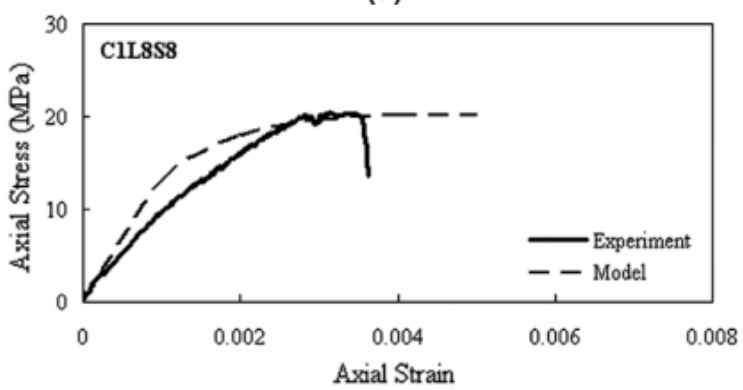

(c)

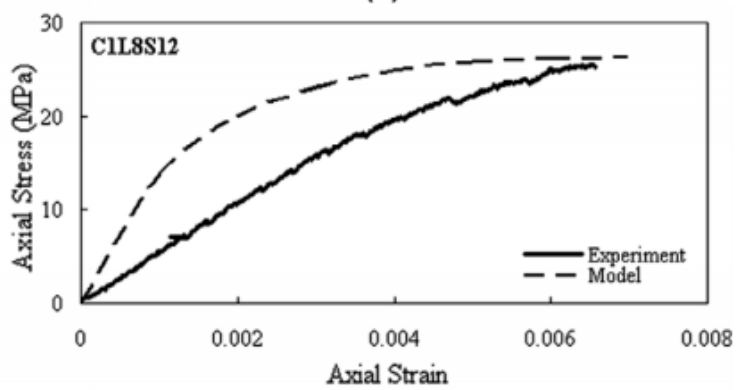

(d)

Figure 2-13: Axial stress-strain curves showing the effect of the transverse reinforcement (Turgay et al., 2012) 
In a study by Wang et al. (2012), the stress-strain relationship of large-scale CFRPconfined square concrete columns was investigated. This investigation was done according to some parameters that affect this relationship. Those parameters were the cross-sectional size, the volumetric ratio of the hoop reinforcement, the number of FRP layers and the loading condition (cyclic and monotonic). Thirty-four specimens were set in groups in accordance with the aforementioned parameters and then tested. The average compressive strength of concrete used in these specimens was $25.5 \mathrm{MPa}$ (3700 psi). The properties of the FRP sheets used in this study were $0.167 \mathrm{~mm}$. in thickness and 4340 $\mathrm{MPa}(630 \mathrm{ksi})$ in ultimate tensile strength. The results of this study showed that all the CFRP-wrapped specimens failed by a tensile rupture of the CFRP jacket within the midheight region. This rupture has initiated near the corners and then gradually extended. The rupture was accompanied by a sudden lose in the axial strength. It was noted that the Loading condition (cyclic and monotonic) had a little effect on the failure mechanism. The CFRP application significantly enhanced the axial strain capacity; however, it slightly enhanced the axial compressive stress capacity. In addition, generally, it was noted that smaller-sized specimens (S2 series) demonstrated softening post-peak axial response. On the other hand, the larger-sized specimens ( $\mathrm{S} 1$ series) showed descending bilinear curves as shown in Figure 2-14. Therefore, the confinement effectiveness decreased as the cross section size increased. 


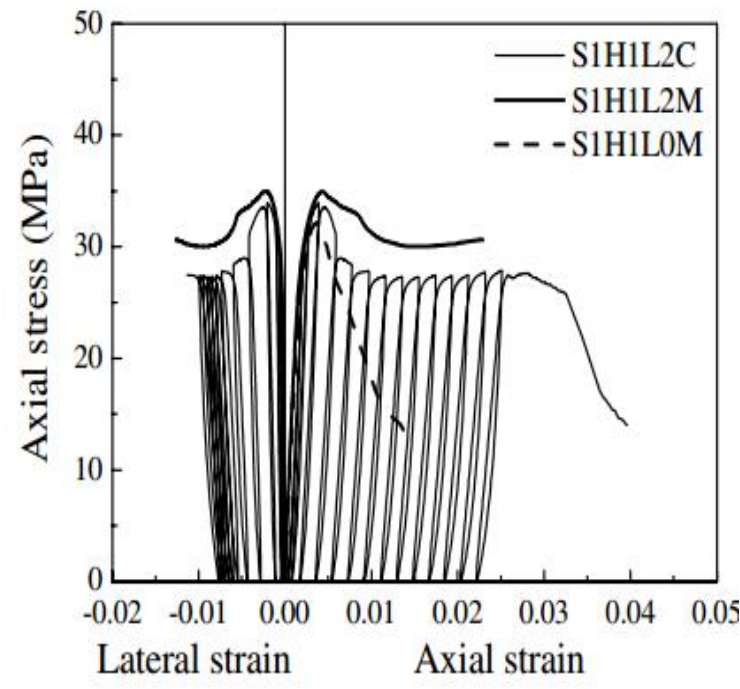

Figure 2-14: Selected axial stress-strain responses (Wang et al., 2012)

It was concluded that the existence of the longitudinal and hoop reinforcement had a significant influence on the axial strain capacity of square columns. To illustrate, for a given number of CFRP layers the ultimate axial strain of the reinforced specimens was (50-85) \% higher than those of the plain (unreinforced) specimens. Figure 2-15 demonstrates a comparison of selected stress-strain curves of reinforced and unreinforced column specimens (unreinforced: S2H0L2, reinforced: S2H1L2 and S2H2L2). 


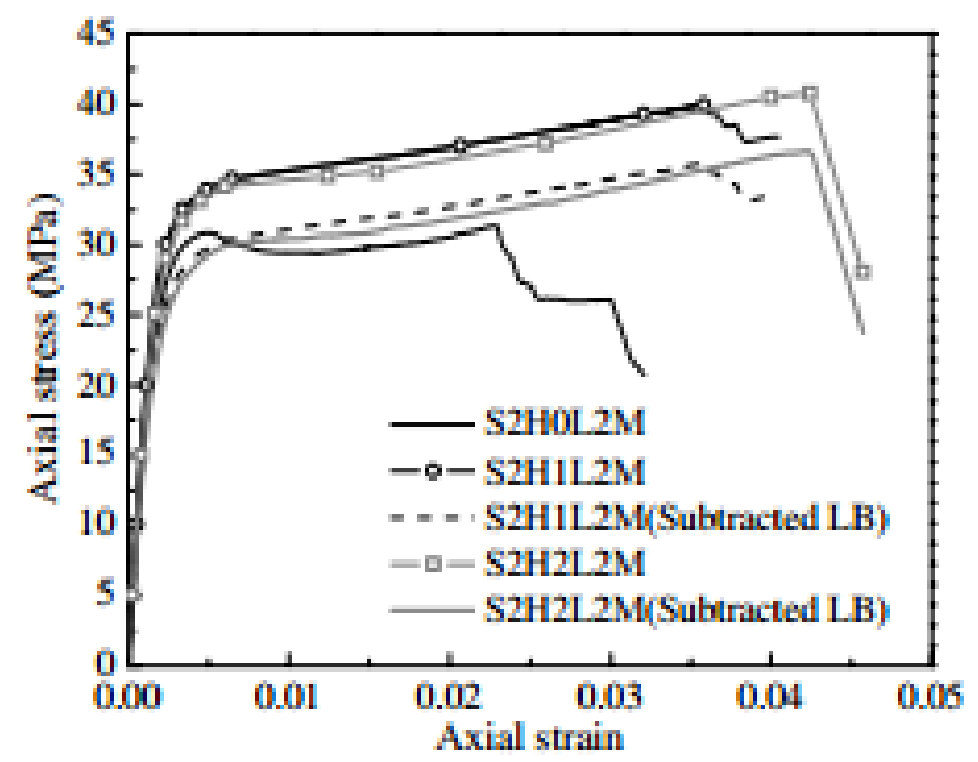

Figure 2-15: Selected axial stress-strain curves considering the influence of the internal reinforcement (Wang et al., 2012)

In a research done by Liang et al. (2012), twenty-four concrete cylinders were tested under concentric axial compressive load. Half of these specimens were confined by CFRP sheets with a different number of layers. Specimens were cast in three different sizes (diameter and height); (100 x 200), (200x400), and (300x600) mm. the main goal of this study was to investigate the effect of specimen size on the axial stress-strain relationship. All specimens were cast from one concrete patch with an average compressive strength of 34 MPa. It was observed that all confined specimens failed in the same manner; sudden explosive failure due to the rupture of the CFRP. Results showed that under the same amount of lateral pressure, the specimen's size had no significant effect on the axial stress and ultimate axial strain and almost all specimens had axial stress-stain curves that follow the same trend. 
Micelli and Modarelli (2012) conducted an experimental research to examine the influence of different properties on the behavior of confined concrete columns. Some of those properties were the cross-section shape (circular and rectangular), concrete grade (25 and $35 \mathrm{MPa}$ ), type of the confining material (CFRP and GFRP), jacket thickness, and corner radii (10 and $25 \mathrm{~mm}$ ). Results showed that the gain in compressive strength due to external confinement was higher in circular specimens than this in rectangular specimens. This difference is caused by the non-uniform confinement pressure around the circumference of the rectangular specimens; it is higher near the corners so most specimens failed by the rupture of FRP jacket in this area. In addition, corner radii play a significant role in the level of enhancement of strength and ductility. Moreover, it was noticed that the FRP confinement technique was more sufficient for low-grade concrete than this with the higher grade.

Most analysis and design- oriented FRP confinement models in literature recommend reducing the FRP ultimate tensile strain by an efficiency factor before using it in calculating the effective confinement pressure. This reduction is concluded experimentally by comparing the strain at which the FRP jacket ruptures to the ultimate strain that is measured by the tensile coupon test. It is claimed that this difference in strain is caused by the curvature in the jacket, multi-axis stress conditions and the nonuniform deformation concrete. In contrast, pure axial stress is applied in the coupon test In a study by $\mathrm{Wu}$ and Jiang (2013), the authors studied experimentally and analytically the necessity of using this efficiency factor. To conduct this work, 39 plain concrete cylinders with a diameter of $150 \mathrm{~mm}$ and height of $300 \mathrm{~mm}$ were tested. The specimens were designed with different compressive strength (20, 25, and $40 \mathrm{MPa})$. All specimens 
were jacketed with CFRP fabric which had a nominal thickness of $0.167 \mathrm{~mm}$, an ultimate strain of 0.0174 , and modulus of elasticity of $244 \mathrm{GPa}$. Specimens were grouped according to the number of FRP layers applied (i.e. 1, 2, 3, 4, and 5 layers). Two LVDTs were used to measure the axial deformation. The circumferential strain in the FRP jacket was measured by seven strain gauges mounted around the specimens at the mid-height region. Those strain gauges were distributed by placing two of them in the overlapping zone and the other five were at the non-overlapping zone. All specimens were tested under a concentric axial loading. By comparing this work results with some other results from the literature, it was found that the more the strain gauges used, the more the captured jacket strain converges to the strain measured by the flat coupon test. This means that, by using a smaller number of strain gauges, the chance of capturing the actual rupture strain is less. Also, it was concluded, by analyzing microscope images of the FRP material, that the misalignment of fibers is the main factor that affects the measured maximum strain rather than the curvature. Consequently, the authors suggest using an efficiency factor of 0.90 when calculating the effective confinement pressure. Wang and Wang (2012) studied the effect of the cross section size on the behavior of CFRP-confined square concrete columns. In this experimental work, nine plain concrete column specimens were set in five groups according to their cross-sectional sizes that range from 100 to $400 \mathrm{~mm}$. In each group, two specimens with two different sizes, but they are confined with same level of confinement. All specimens were cast in one batch of concrete with an average compressive strength of 24.4 MPa. All specimens were tested under monotonic axial compression load up until failure. The test results showed that there was no significant effect of the cross-sectional size on the failure mode since all 
specimens failed by tensile rupture of the CFRP wraps at the mid-height region near the corners. In general, the CFRP confinement enhanced the axial strength and strain capacity of all specimens. However, the enhancement in axial stress was more pronounced in small-size specimens than those with a larger cross section but the same level of confinement. Unlike the axial stress, the increase in axial strain capacity was significant in both small and large-size specimens. By mounting a large number of strain gauges around the perimeter of the column to measure the lateral strain of the FRP jacket, researchers were able to investigate the distribution of lateral strain around the perimeter. Although the FRP composite rupture occurred in the corners, it was observed that the lateral strains at corners were smaller than those at the middle of the sides as shown in Figure 2-16. Therefore, this study suggests using the corner lateral strains only to calculate the average effective ultimate strain in the FRP jacket instead of using the average of all strain values around the perimeter as it is usually done since the latter approach overestimates the FRP rupture strain.

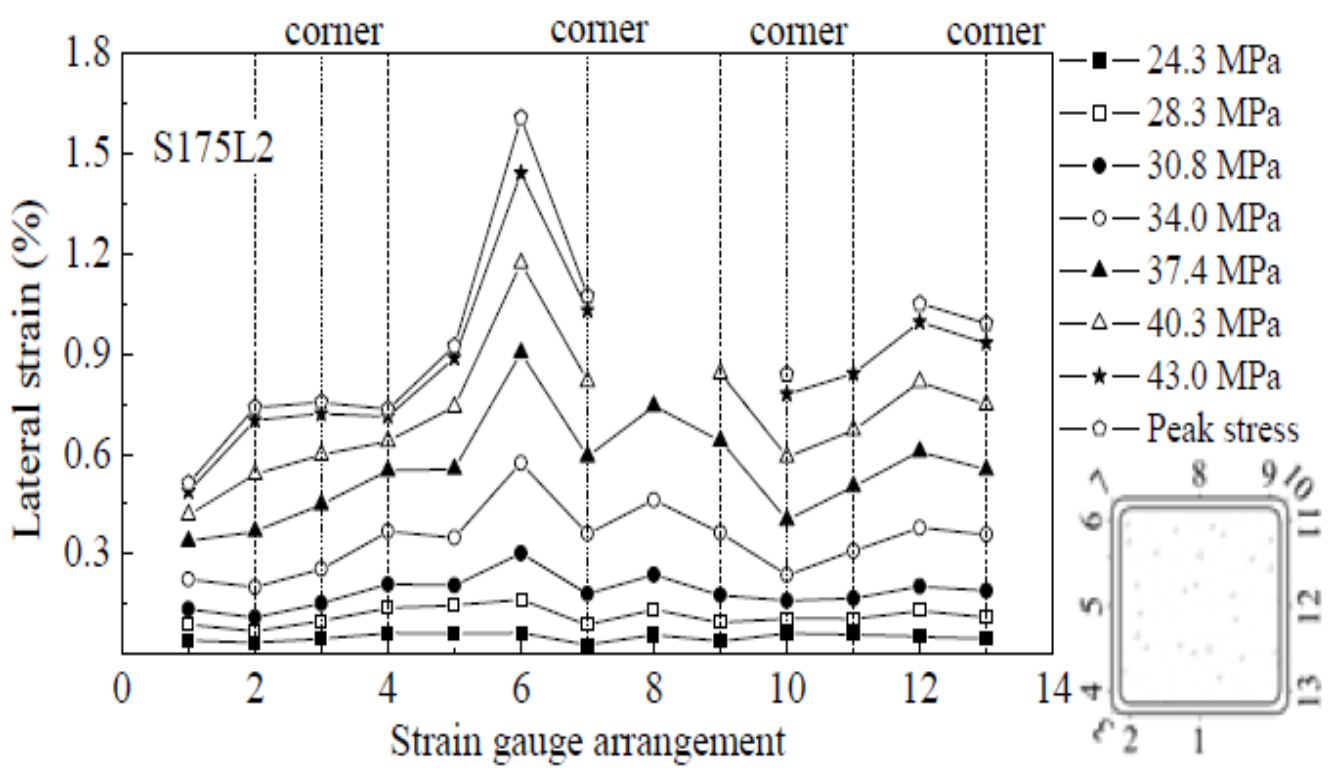

Figure 2-16: Lateral strain distributions on CFRP wrap 
A study by Belouar et al. (2013) was conducted to investigate the effect of a number of variables on the performance of square concrete columns wrapped with CFRP sheets. Those variables were slenderness of the columns, the number of wraps, and concrete grade. Forty-eight column specimens were cast with two different concrete grade; high strength concrete (NSC-24 MPa) and high strength concrete (HSC-60 MPa). Some of these specimens were plain and the rest were reinforced. Three slenderness ratios, L/a (2, 4, and 7.4) and two level of CFRP confinement (1 and 3 layers) were tested. All specimens were tested under a monotonic uniaxial compression load up to failure. By comparing the resulted stress-strain curves of NSC and HSC specimens, for the same level of confinement, it can be noted that in the case NSC columns, the curve is bilinear with a small non-linear transition zone while for HSC columns, the curve is linear up to the peak stress then it shows a small plateau form followed by sudden drop in stress.

Figure 2-17 shows the stress-strain curves NSC and HSC specimens.
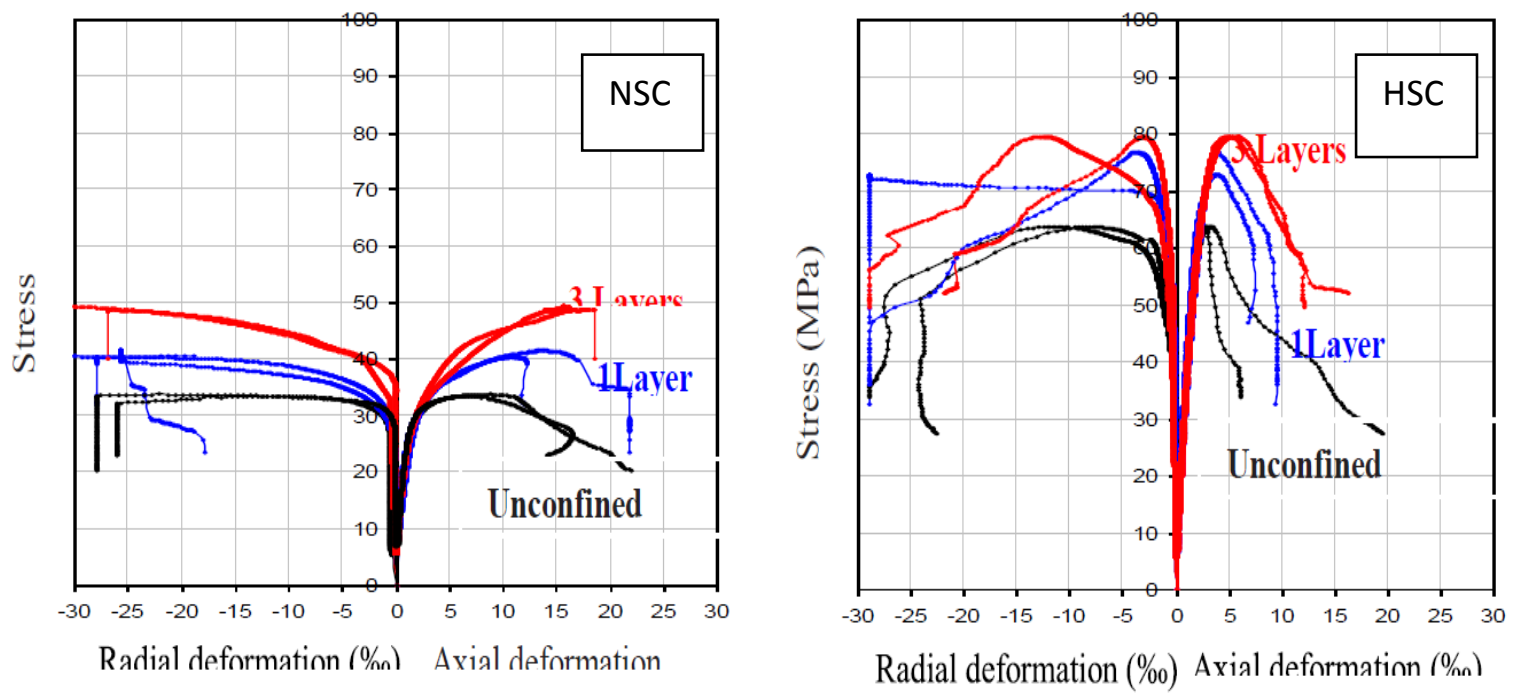

Figure 2-17: Stress-strain curves (Belouar et al. 2013 
The gain in compressive strength and ductility due to confinement was about $58 \%$ and $280 \%$, respectively in some NSC specimens whereas it was less than $30 \%$ and $73 \%$ for

some HSC specimens. In addition, it was found that increasing the confinement pressure resulted in increasing in compressive strength and ductility. However, the enhancement in ductility was more significant than that in strength.

\subsection{Theoretical Literature}

Different studies have proposed analysis and design-oriented stress-strain models to describe the behavior of the FRP confined concrete columns and to predict the compressive strength and the ultimate axial strain of the confined concrete. The most widely accepted model is the design-oriented model proposed by Lam and Teng in 2003. This model was later adopted by the ACI Committee 440 in their guidelines for the design of the FRP-strengthened concrete columns (ACI 440.2R-08). Thus, it is reported in details herein.

\subsubsection{Lam and Teng model (2003b)}

The Lam and Teng's design-oriented stress-strain model (Lam and Teng 2003b) was developed to predict the stress-strain curve for FRP-confined concrete in rectangular columns. This model was built based on the following assumptions: (i) that the stressstrain curve consists of two portions; the first one is a parabolic potion while the second portion is a straight line as shown in Figure 2-18; (ii) that the slope of the initial part of the parabola is the elastic modulus of the unconfined concrete (Ec); (iii) that the nonlinear part of the parabola is somewhat affected by the presence of the FRP jacket; (iv) that the parabolic first portion meets the linear second portion smoothly; (v) and that the linear 
second portion ends at the point where the compressive strength of the confined concrete ( $\left.\mathrm{f}^{\prime} \mathrm{cc}\right)$ and the ultimate axial strain ( $(\mathrm{cu})$ are achieved. The model was developed based on a large test database assembled from literature in addition to the experimental tests that were conducted by the authors. Based on the aforementioned assumptions, the stressstrain model was expressed by:

$$
\begin{array}{ll}
\sigma_{c}=\left(E_{c} \varepsilon_{c}-\frac{\left(E_{c}-E_{2}\right)^{2}}{4 f^{\prime}{ }^{\prime} c o} \varepsilon_{c}^{2}\right) & \left(0 \leq \varepsilon_{c} \leq \varepsilon_{t}\right) \\
\sigma_{c}=f^{\prime}{ }_{c o}+E_{2} \varepsilon_{c} & \left(\varepsilon_{t} \leq \varepsilon_{c} \leq \varepsilon_{c u}\right)
\end{array}
$$

Where $\sigma_{c}$ and $\varepsilon_{c}$ were the axial stress and the axial strain of confined concrete, respectively, $E_{c}$ was the elastic modulus of unconfined concrete, $\varepsilon_{t}$ was the axial strain at transition point, and $E_{2}$ is the slope of the straight second portion of the curve.

$$
\begin{gathered}
\varepsilon_{t}=\frac{2 f^{\prime}{ }_{c o}}{E_{c}-E_{2}} \\
E_{2}=\frac{f^{\prime}{ }_{c c}-f^{\prime}{ }_{c o}}{\varepsilon_{c u}}
\end{gathered}
$$

Lam and Teng gave two equations to predict the compressive strength the ultimate axial strain of the confined concrete $\left(f^{\prime}{ }_{c c}\right)$. Those were:

$$
\begin{gathered}
\frac{f^{\prime}{ }_{c c}}{f^{\prime}{ }_{c o}}=1+k_{1} k_{s 1} \frac{f_{l}}{f^{\prime}{ }_{c o}} \\
\frac{\varepsilon_{c u}}{\varepsilon_{c o}}=1.75+k_{2} k_{s 2}\left(\frac{k_{\varepsilon} \varepsilon_{f r p}}{\varepsilon_{c o}}\right)^{0.45}
\end{gathered}
$$

The confinement effectiveness coefficient proposed by the authors was $k_{1}=3.3, k_{2}$ was the strain enhancement coefficient and is equal to 12 , and $f_{l}$ was the lateral confining pressure generated by the FRP jacket, which was given by the following equation: 


$$
f_{l}=\frac{2 E_{f r p} k_{\varepsilon} \varepsilon_{f r p} t}{D}
$$

The elastic modulus and the thickness of the FRP material was $E_{f r p}$ and $t$, respectively. The ultimate tensile strain of the FRP material was $\varepsilon_{f r p}, k_{\varepsilon}$ was an FRP efficiency factor that was proposed by the authors to account for the fact the actual rupture strain of the FRP jacket is less than the strain measured by the pure tensile coupon test. A value of 0.586 was suggested in this model. Because of the fact that the confining pressure was not uniformly distributed around the circumference of the rectangular column, part of the cross section is effectively confined as shown in Figure 2-19. Therefore, an equivalent circular cross section with a diameter of $D$ was proposed in this model in order to simulate a uniformly distributed confining pressure. That is:

$$
D=\sqrt{h^{2}+b^{2}}
$$

The shape factors used to account for the rectangular cross section were $k_{s 1}$ and $k_{s 2}$ and were derived from the shape of the effectively confided area. They were defined as the follows:

$$
\begin{aligned}
& k_{s 1}=\frac{A_{e}}{A_{c}}\left(\frac{b}{h}\right)^{2} \\
& k_{s 2}=\frac{A_{e}}{A_{c}}\left(\frac{h}{b}\right)^{0.5}
\end{aligned}
$$

Where $A e$ was the effectively confined concrete area and was given by

$$
\frac{A_{e}}{A_{c}}=\frac{1-\left(\frac{\left(\frac{b}{h}\right)\left(h-2 R_{c}\right)^{2}+\left(\frac{h}{b}\right)\left(b-2 R_{c}\right)^{2}}{3 A_{g}}\right)-\rho_{s}}{1-\rho_{s}}
$$




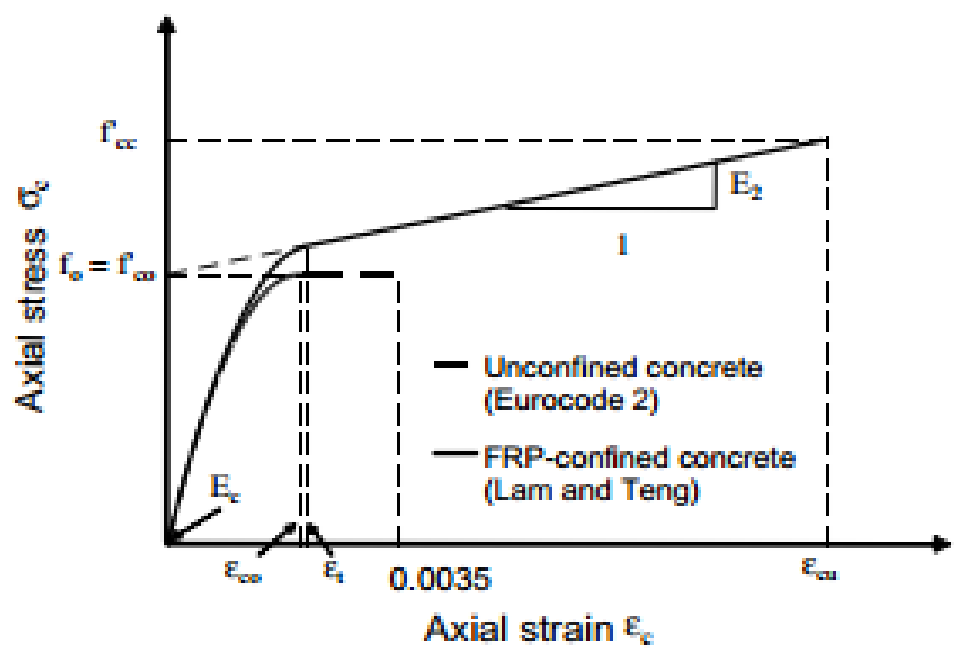

Figure 2-18: Lam and Teng (2003) stress-strain relationship

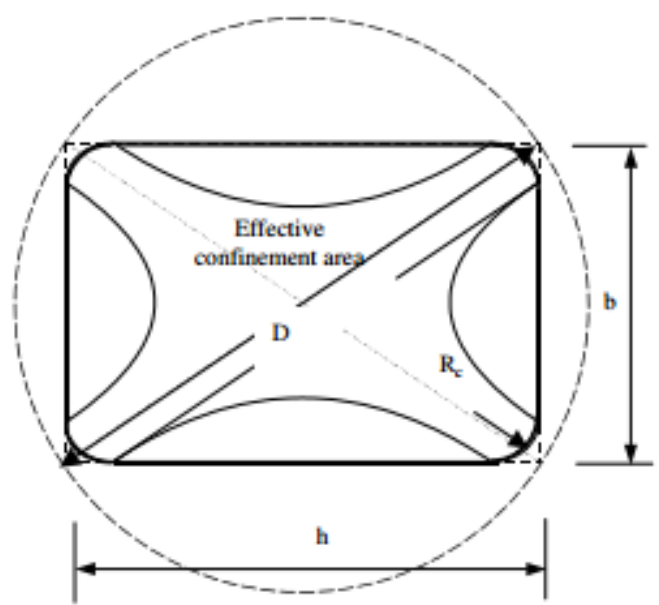

Figure 2-19: Equivalent circular cross section

In 2008, the ACI Committee 440 adopted, with some modifications, Lam and Teng's designoriented stress-strain model and is recommended for the design of the FRP strengthened concrete compression members. However, this model was refined by the same authors in 2009 based on recent experimental tests and an accurate analysis-oriented stress-strain model of the FRP 
confined concrete. The authors took into account the effect of the confinement stiffness and the jacket stain capacity $\left(\rho_{\varepsilon}\right)$. The confinement stiffness $\left(\rho_{k}\right)$ is defined as the ratio of the stiffness of the FRP jacket to the stiffness of the concrete core. The two ratios are expressed as:

$$
\begin{gathered}
\rho_{k}=\frac{2 E_{f r p} t}{\left(\frac{f \prime_{c o}}{\varepsilon_{c o}}\right) D} \\
\rho_{\varepsilon}=\frac{k_{\varepsilon} \varepsilon_{f r p}}{\varepsilon_{c o}}
\end{gathered}
$$

Consequently, the refined stress-strain model is given by the following expressions:

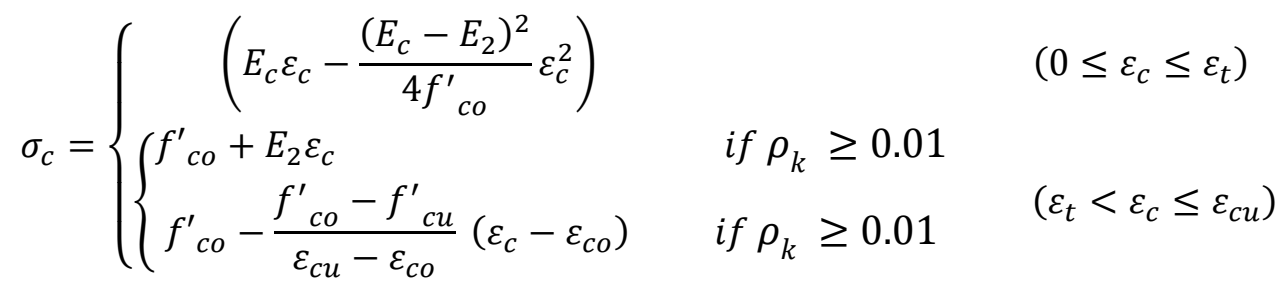

And the compressive strength of the confined concrete is given by:

$$
\begin{array}{ll}
\frac{f^{\prime}{ }_{c c}}{f^{\prime}{ }_{c o}}=1+3.5\left(\rho_{k}-0.01\right) \rho_{\varepsilon} & \text { if } \rho_{k} \geq 0.01 \\
\frac{f^{\prime}{ }_{c c}}{f^{\prime}{ }_{c o}}=1 & \text { if } \rho_{k} \geq 0.01
\end{array}
$$

The ultimate axial strain is given by:

$$
\frac{\varepsilon_{c u}}{\varepsilon_{c o}}=1.75+6.5 \rho_{k}^{0.8} \rho_{\varepsilon}^{1.45}
$$

More details about the derivation of the above equations are given in Lam and Teng (2009). 


\section{Chapter 3. Experimental work}

\subsection{The Experimental Program}

A total of twelve square reinforced concrete columns were prepared and tested in this study. The test specimens were set equally into two main series in accordance with the concrete grade used; 2000 psi (C2) and 4000 psi (C4). In each series, there were two control (unwrapped) specimens. The first control specimen represented a non-ductile column with low lateral reinforcement based on older codes, titled "Non Ductile Column" (NDC). The second one represented a ductile specimen titled "Ductile Column" (DC) with seismically designed lateral reinforcement. The remaining four specimens from each series were NDC specimens wrapped with a different number of CFRP layers. Therefore, the designation system used for labeling the test specimens was based on three characteristics. The first two characters refer to the specimen series; C2 (2000 psi concrete) and C4 (4000 psi concrete). The second part refers to the type of a column specimen in terms of lateral reinforcement; NDC and DC. The last part refers to the number of CFRP wraps; F1, F2, F3, etc., with F representing "Fiber". For example, C4NDC-F1 represents a column specimen with 4000 psi-concrete and low lateral reinforcement ratio (thus Non Ductile) that is wrapped with one layer of CFRP. Table 3-1 summarizes the testing matrix for the current study. 
Table 3-1: Test Matrix

\begin{tabular}{|c|c|c|c|c|}
\hline Series & $\begin{array}{c}f^{\prime} c \\
(p s i)\end{array}$ & Specimen Label & Ductility & $\begin{array}{c}\text { No. of } \\
\text { CFRP wraps }\end{array}$ \\
\hline \multirow{6}{*}{$\mathrm{C} 2$} & \multirow{6}{*}{2000} & C2NDC & Non-ductile & 0 \\
\hline & & C2DC & Ductile & 0 \\
\hline & & C2NDC-F1 & Non-ductile & 1 \\
\hline & & C2NDC-F2 & Non-ductile & 2 \\
\hline & & C2NDC-F3 & Non-ductile & 3 \\
\hline & & C2NDC-F4 & Non-ductile & 4 \\
\hline \multirow{6}{*}{ C4 } & \multirow{6}{*}{4000} & C4NDC & Non-ductile & 0 \\
\hline & & C4DC & Ductile & 0 \\
\hline & & C4NDC-F1 & Non-ductile & 1 \\
\hline & & C4NDC-F2 & Non-ductile & 2 \\
\hline & & C4NDC-F3 & Non-ductile & 3 \\
\hline & & C4NDC-F4 & Non-ductile & 4 \\
\hline
\end{tabular}

\subsection{Specimen Size Selection}

The size of the specimens of the present study was 5"x 5" in cross section and 12 " in height. The test specimens were designed to emulate prototype (actual) columns with a scale factor of approximately $1 / 3$ or $1 / 4$. Table 3-2 and Table 3-3 summarize the details of both of the prototypes, and the models that will be illustrated thoroughly later in this chapter. The reason for selecting the square cross section was because square columns are the most common type of columns in old buildings, and there is less research dedicated to this type of column cross section as compared to circular columns. In terms of the size of the specimens, the small-size specimens were selected mainly because of the limitation in the size and the capacity of the available testing machine at the time of this study. From the technical literature reviewed by the author, small-size models were considered to adequately represent an actual prototype, and to produce meaningful results and observations. 
Table 3-2: C2 series (model and prototype)

\begin{tabular}{|c|c|}
\hline 1- Scale factor $=1 / 3$ & 2- Scale factor $=1 / 4$ \\
\hline $\begin{array}{l}\text { Model: } \\
\text { - } \mathrm{f}^{\prime} \mathrm{c}=2000 \mathrm{psi} \\
\text { - Dimensions }(\mathrm{B} \times \mathrm{H} \times \mathrm{L}):(5 \times 5 \times 12) \text { in } \\
\text { - Longitudinal reinforcement: } 4-\# 3 \\
\rho_{g}=1.76 \% \\
\text { - Lateral (confinement) reinforcement: } \\
\text { 1- Non-ductile column } \\
\text { No.9 gage steel wire hoops } \\
\text { ( } \varnothing 0.15 \text { in, fy= } 31 \mathrm{ksi}) \text { spacing at } \\
5 \text { in o.c. } \\
\text { 2- } \text { Ductile column } \\
\text { No.9 gage steel wire hoops } \\
\text { ( } \varnothing 0.15 \text { in, fy= } 31 \mathrm{ksi}) \text { spacing at } \\
0.9 \text { in o.c. }\end{array}$ & $\begin{array}{l}\text { Prototype: } \\
\text { - } f^{\prime} c=2000 \text { psi } \\
\text { - Dimensions }(\mathrm{B} \times \mathrm{H} \times \mathrm{L}):(20 \times 20 \times 48) \\
\text { in } \\
\text { - Longitudinal reinforcement: As = } 7 \mathrm{in}^{2} \\
\text { Approx. } 4-\# 11 \\
\rho_{g}=1.76 \% \\
\text { - Lateral (confinement) reinforcement: } \\
\text { 1- Non-ductile column } \\
\quad \# 4 \text { hoops ( } \varnothing 0.5 \text { in, fy= } 60 \mathrm{ksi}) \\
\text { spacing at } 20 \text { in o.c. } \\
\text { 2- Ductile column } \\
\text { \#4 hoops with one crosstie } \\
\text { ( } \varnothing 0.5 \text { in, fy= } 60 \text { ksi) spacing at } 5 \\
\text { in o.c. }\end{array}$ \\
\hline
\end{tabular}


Table 3-3: C4 series (model and prototype)

\begin{tabular}{|c|c|}
\hline 1- Scale factor $=1 / 3$ & 2- Scale factor $=1 / 4$ \\
\hline $\begin{array}{l}\text { Model: } \\
\text { - } \mathrm{f}^{\prime} \mathrm{c}=4000 \mathrm{psi} \\
\text { - Dimensions }(\mathrm{B} \times \mathrm{H} \times \mathrm{L}):(5 \times 5 \times 12) \text { in } \\
\text { - Longitudinal reinforcement: } 4-\# 3 \\
\rho_{g}=1.76 \% \\
\text { - Lateral (confinement) reinforcement: } \\
\text { 3- Non-ductile column } \\
\text { No.9 gage steel wire hoops } \\
\text { ( } \varnothing 0.15 \text { in, fy= } 31 \text { ksi) spacing at } \\
5 \text { in o.c. } \\
\text { 4- Ductile column } \\
\text { No.2 gage steel wire hoops } \\
\text { ( } \varnothing 0.25 \text { in, fy= } 38 \text { ksi) spacing at } \\
1.25 \text { in o.c. }\end{array}$ & $\begin{array}{l}\text { Model: } \\
\text { - } \mathrm{f}^{\prime} \mathrm{c}=4000 \mathrm{psi} \\
\text { - Dimensions }(\mathrm{B} \times \mathrm{H} \times \mathrm{L}):(5 \times 5 \times 12) \text { in } \\
\text { - Longitudinal reinforcement: 4-\#3 } \\
\rho_{g}=1.76 \% \\
\text { - Lateral (confinement) reinforcement: } \\
\text { 3- Non-ductile column } \\
\text { No.9 gage steel wire hoops } \\
\text { ( } \varnothing 0.15 \text { in, fy= } 31 \text { ksi) spacing at } \\
5 \text { in o.c. } \\
\text { 4- Ductile column } \\
\text { No.2 gage steel wire hoops } \\
\text { ( } \varnothing 0.25 \text { in, fy= } 38 \text { ksi) spacing at } \\
1.25 \text { in o.c. }\end{array}$ \\
\hline 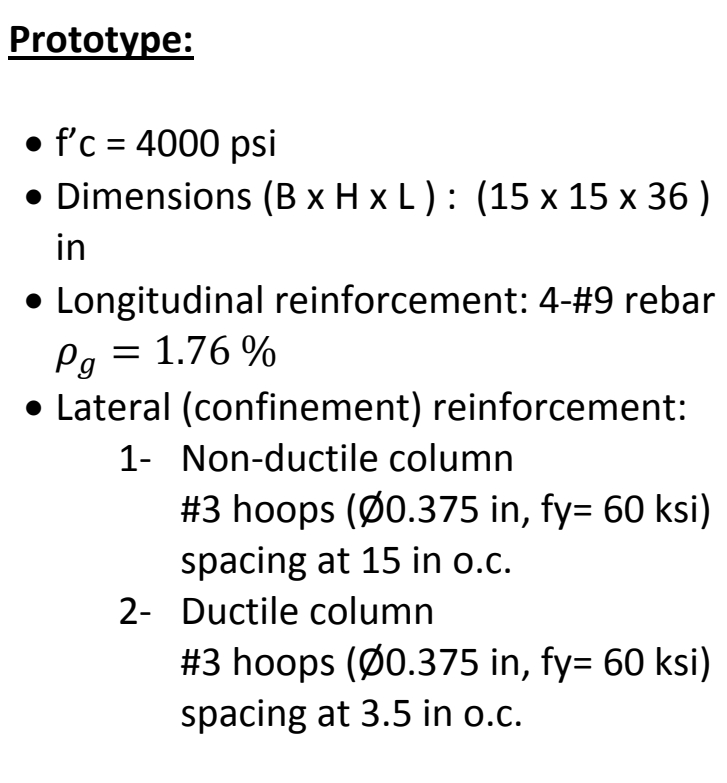 & $\begin{array}{l}\text { Prototype: } \\
\text { - } f^{\prime} \mathrm{c}=4000 \mathrm{psi} \\
\text { - Dimensions }(\mathrm{B} \times \mathrm{H} \times \mathrm{L}):(20 \times 20 \times 48) \\
\text { in } \\
\text { - Longitudinal reinforcement: } \mathrm{As}=7 \mathrm{in}^{2} \\
\text { Approx. } 4-\# 11 \\
\rho_{g}=1.76 \% \\
\text { - Lateral (confinement) reinforcement: } \\
\text { 1- Non-ductile column } \\
\quad \# 4 \text { hoops ( } \varnothing 0.5 \mathrm{in}, \mathrm{fy}=60 \mathrm{ksi}) \\
\text { spacing at } 20 \text { in o.c. } \\
\text { 2- Ductile column } \\
\quad \# 4 \text { hoops ( } \varnothing 0.5 \mathrm{in}, \mathrm{fy}=60 \mathrm{ksi}) \\
\text { spacing at } 5 \text { in o.c. }\end{array}$ \\
\hline
\end{tabular}




\subsection{Materials}

\subsubsection{Concrete}

Two types of concrete mix, C2 (2000 psi) and C4 (4000 psi) were designed and prepared to cast all of the reinforced concrete (RC) square columns. The mix design was established in accordance with the Portland Cement Association (PCA) design guidelines. For $\mathrm{C} 4$ and $\mathrm{C} 2$ concrete, dry coarse aggregate (CA) with a maximum size of $3 / 8$ in $(10 \mathrm{~mm})$, wet fine aggregate (FA), Portland cement type I (C), and tap water (W) were used. The water to cement ratio (W/C) was 0.80 for $\mathrm{C} 2$ and 0.67 for $\mathrm{C} 4$. The target slump was 6"-7". Before casting the test specimens, different trial batches of concrete were mixed and cast in ASTM standard cylinders with a 6" diameter and 12" high to examine the compressive strength. Three cylinders were provided for each trial batch. After curing for 28 days, the concrete cylinders were tested for compressive strength. According to the test results, the concrete mix proportions were adjusted. The concrete mixture proportions and the target compressive strength are illustrated in Table 3-4.

\section{Table 3-4: Concrete mixture details}

\begin{tabular}{|c|c|c|c|c|c|c|c|}
\hline \multirow{2}{*}{$\begin{array}{c}\text { Concrete } \\
\text { grade }\end{array}$} & $\begin{array}{c}\text { Compressive } \\
\text { Strength, fc } \\
\text { (psi) }\end{array}$ & \multirow{2}{*}{$\begin{array}{c}\text { Target } \\
\text { Slump } \\
\text { (in) }\end{array}$} & & W/C & \multicolumn{4}{|c|}{$\begin{array}{c}\text { Mixture proportions } \\
\text { (Ib/ ft3) }\end{array}$} \\
\cline { 5 - 9 } & & & $\mathrm{C}$ & $\mathrm{W}$ & $\mathrm{CA}$ & $\mathrm{FA}$ \\
\hline $\mathrm{C} 2$ & 2000 & $6-7$ & 0.80 & 17 & 13.5 & 47 & 63 \\
\hline $\mathrm{C} 4$ & 4000 & $6-7$ & 0.67 & 18 & 12 & 46 & 61 \\
\hline
\end{tabular}

A number of ASTM standard cylinders were prepared during the casting of the column specimens for both $\mathrm{C} 2$ and $\mathrm{C} 4$ series. There were six cylinders for each series. Two 
different quality tests were performed on those cylinders at two different times, after the concrete was cured for 28 days, and at the time when the column specimens were tested. The first test determined the concrete compressive strength $\left(f^{\prime} c\right)$ in accordance with ASTM C 39/C 39M test method. The second test determined the static modulus of elasticity $\left(E_{c}\right)$ by following the test method illustrated in ASTM C 469-02 standard.

\subsubsection{Concrete Compressive Strength $\left(f^{\prime}{ }^{\prime}\right)$}

The test was performed using an Accu-Tek Touch 250 Series compression machine shown in Figure 3-1.Table 3-5 illustrates the test results for both specimen series.

Table 3-5: Concrete compressive strength

\begin{tabular}{|c|c|c|}
\hline \multirow{2}{*}{ Series } & Age (day) & $\begin{array}{c}\text { Compressive strength, } f^{\prime}{ }^{\prime} \\
(\mathrm{psi})\end{array}$ \\
\hline \multirow{2}{*}{$\mathrm{C} 2$} & 28 & 2100 \\
\cline { 2 - 3 } & 40 & 2450 \\
\hline \multirow{2}{*}{$\mathrm{C} 4$} & 28 & 3085 \\
\cline { 2 - 3 } & 120 & 4115 \\
\hline
\end{tabular}

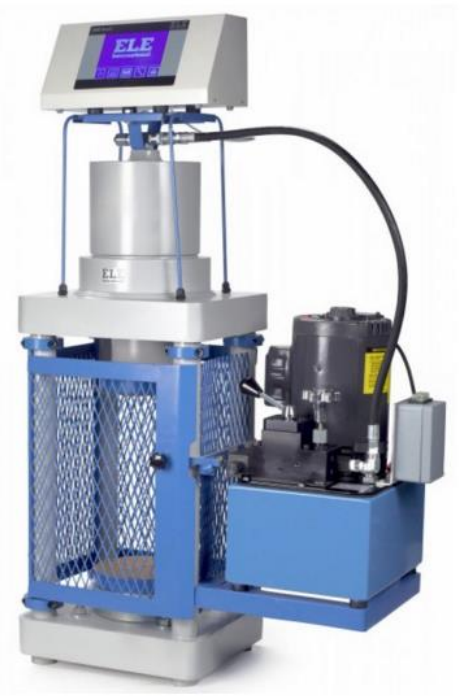

Figure 3-1: Concrete compression machine

(http://www.ele.com/Product/accu-tek-touch-250-series-220v-50hz) 


\subsubsection{Static Modulus of Elasticity of Concrete}

The test was performed in accordance with the ASTM C 469-02 standard. In this test, the strain was measured using a compressometer with two Leaner Variable Displacement Transducers (LVDT) as shown in Figure 3-2. The gage length of the compressometer was 6". The load was measured using a pressure sensor. The strain was calculated by dividing the LVDTs readings by the gage length. The compressive stress was calculated by dividing the applied load by the cross-sectional area of the cylinder. Figure 3-3 presents the test results for both concrete grades and at different concrete ages.

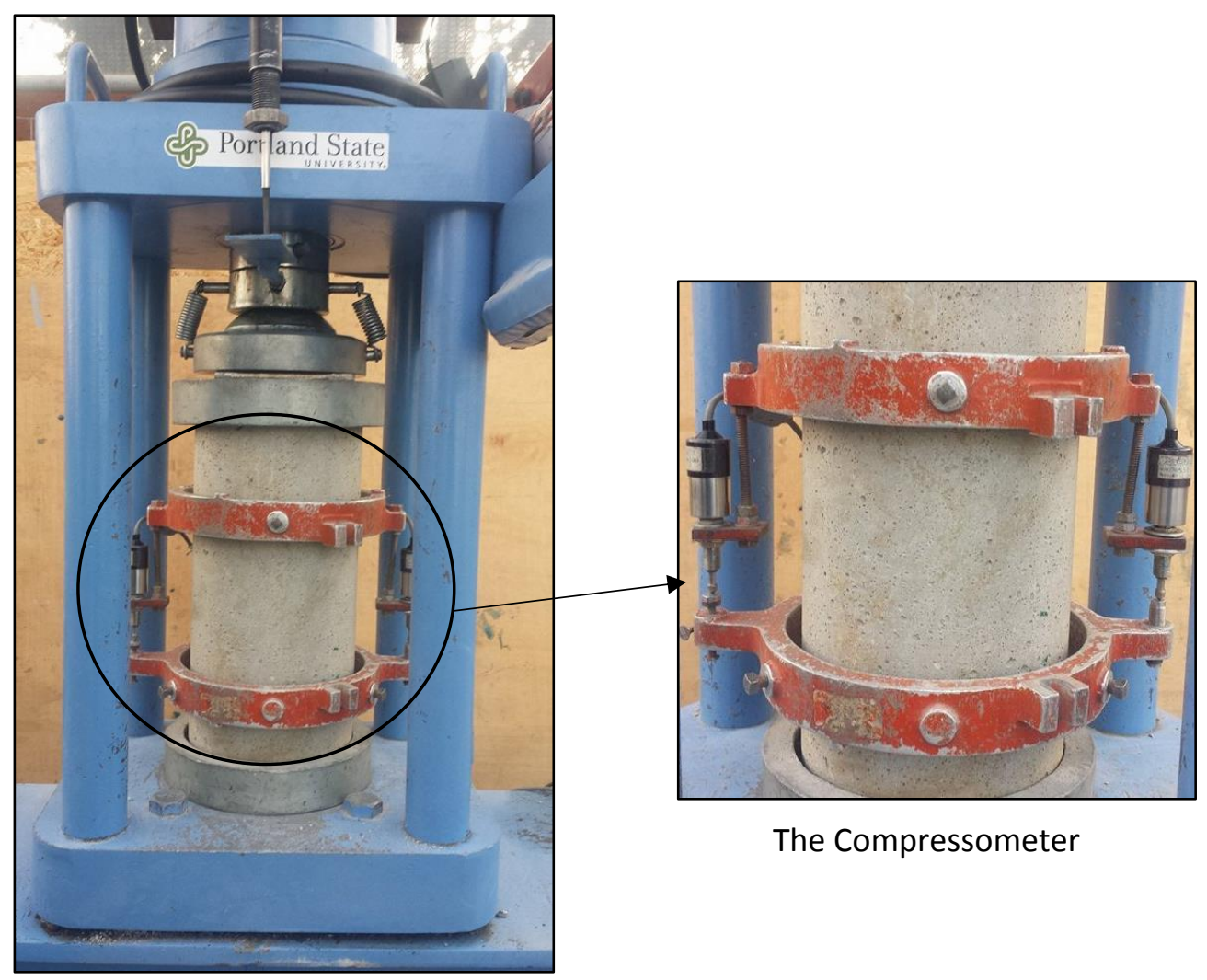

Figure 3-2: The test setup 


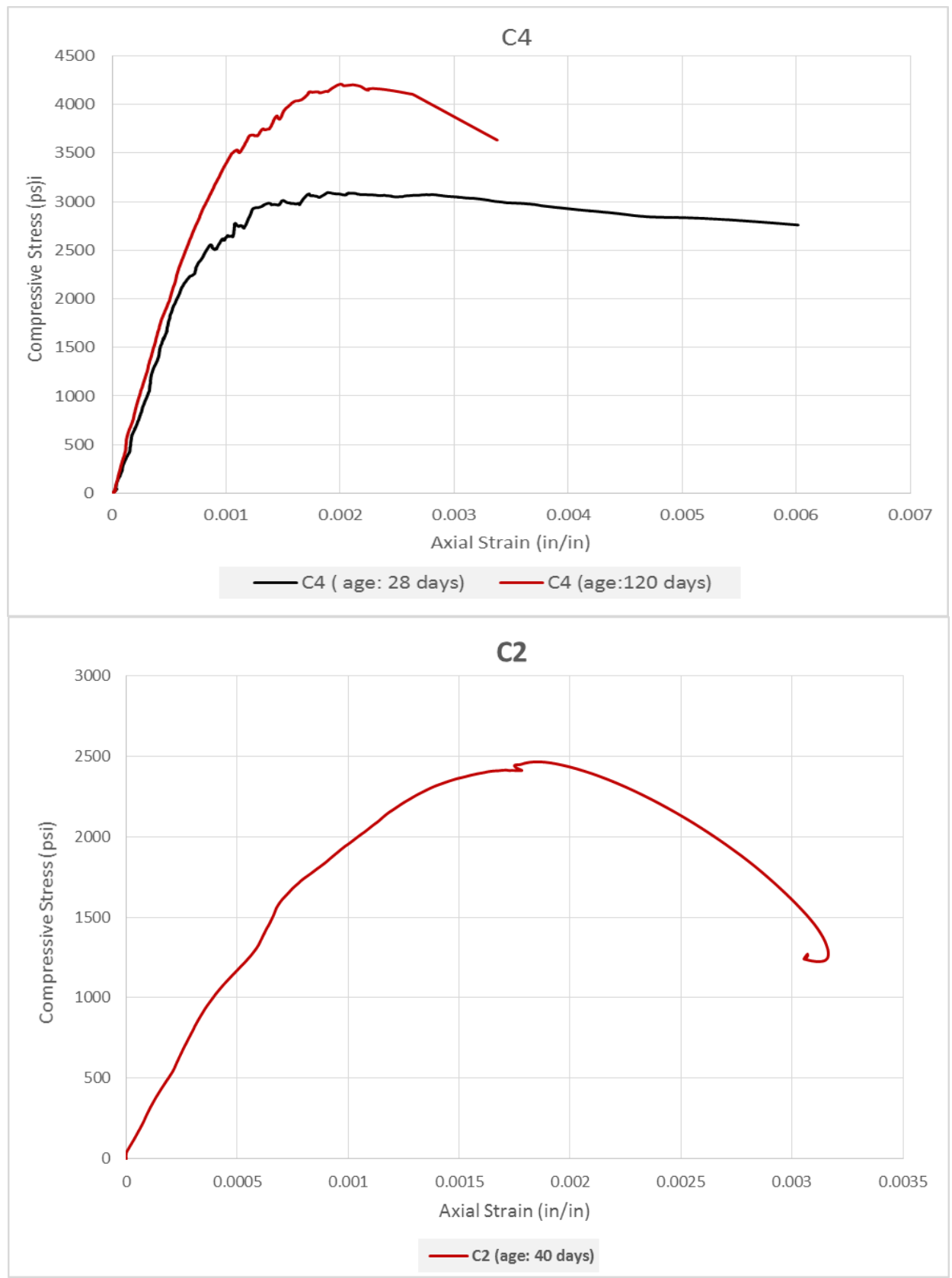

Figure 3-3: Stress-strain curve of plain concrete

Figure 3-3 shows that for $\mathrm{C} 4$ concrete, the stress-strain curve obtained after 28 days had a peak compressive stress $\left(f^{\prime}{ }_{c}\right)$ of $3085 \mathrm{psi}$, and the corresponding peak axial strain $\left(\varepsilon_{c}\right)$ was 0.0018. On the other hand, for the stress-strain curve obtained at the age of 120 days, the 
peak compressive stress was 3900 psi, and the corresponding peak axial strain was 0.0025.The slope of the initial, linear portion of the stress-strain curve was defined by ASTM C469- 02 as the elastic modulus of concrete $\left(E_{c}\right)$. It is calculated by:

$E_{c}=\frac{\left(S_{2}-S_{1}\right)}{\left(\varepsilon_{2}-0.000050\right)} \quad$ Eq. 3-1

Where:

$E_{c}$ : The elastic modulus of concrete, psi.

$S_{2}$ : Stress corresponding to $40 \%$ of peak stress, psi.

$S_{1}$ : Stress corresponding to a longitudinal strain, $\varepsilon_{2}$, of 50 millionths, psi, and $\varepsilon_{2}$ : Longitudinal strain produced by stress, $S_{2}$.

\section{Calculation Example:}

\section{For series C4}

At age 28 days: $S_{1}=137.5$ psi, $S_{2}=0.4 f^{\prime}{ }^{\prime}{ }^{\prime}=1234$ psi, and $\varepsilon 2=0.00035$

Therefore,

$E_{c}=3655 \times 10^{3}$ psi

At age 120 days: $S_{1}=184$ psi, $S_{2}=0.4 f^{\prime}{ }^{\prime}=1680$ psi, and $\varepsilon_{2}=0.0004$

Therefore,

$E_{c}=4300 \times 10^{3}$ psi

The ACI-318-14 gives the following simplified equation to estimate the modulus of elasticity of the concrete based on its compressive strength:

$$
E_{c}=57000 \sqrt{f^{\prime}{ }_{c}(p s i)} \quad \text { Eq. 3-2 }
$$

Table 3-6 summarizes the values of $E_{c}$ obtained experimentally using Eq. 3-1 and theoretically using Eq. 3-2 for both C4 and C2 series. 
Table 3-6: Elastic modulus of plain concrete

\begin{tabular}{|c|c|c|c|c|c|}
\hline \multirow{2}{*}{ Series } & \multirow{2}{*}{$\begin{array}{c}\text { Age } \\
(\text { day })\end{array}$} & \multirow{2}{*}{$\begin{array}{c}f_{c}^{\prime} \\
(\mathrm{psi})\end{array}$} & $\begin{array}{c}\varepsilon_{c o} \\
(\mathrm{in} / \mathrm{in})\end{array}$ & \multicolumn{2}{|c|}{$\begin{array}{r}\text { Elastic Modulus, } E_{c} \\
(\mathrm{ksi})\end{array}$} \\
\cline { 5 - 6 } & & & & Experimental & Theoretical \\
\hline $\mathrm{C} 2$ & 40 & 2465 & 0.0018 & 2378 & 2821 \\
\hline \multirow{2}{*}{$\mathrm{C} 4$} & 28 & 3000 & 0.0019 & 3655 & 3166 \\
\cline { 2 - 6 } & 120 & 4200 & 0.0020 & 4300 & 3694 \\
\hline
\end{tabular}

\subsubsection{Reinforcing Steel}

\subsubsection{Longitudinal Reinforcement}

For compression (axial) reinforcement, \#3 rebars were used. The type of the reinforcing rebar used in this study had been tested and used by another researcher for another study at PSU. The stress-strain behavior and mechanical properties of this type of rebar were obtained by testing a 3 -ft specimen following the testing method outlined in the ASTMA370. The test was performed by an MTS machine located at the iSTAR laboratory at PSU. The stress-strain diagram is shown in Figure 3-4. From this diagram, the mechanical properties listed in Table 3-7 were obtained (Al-Obaidi, 2015).

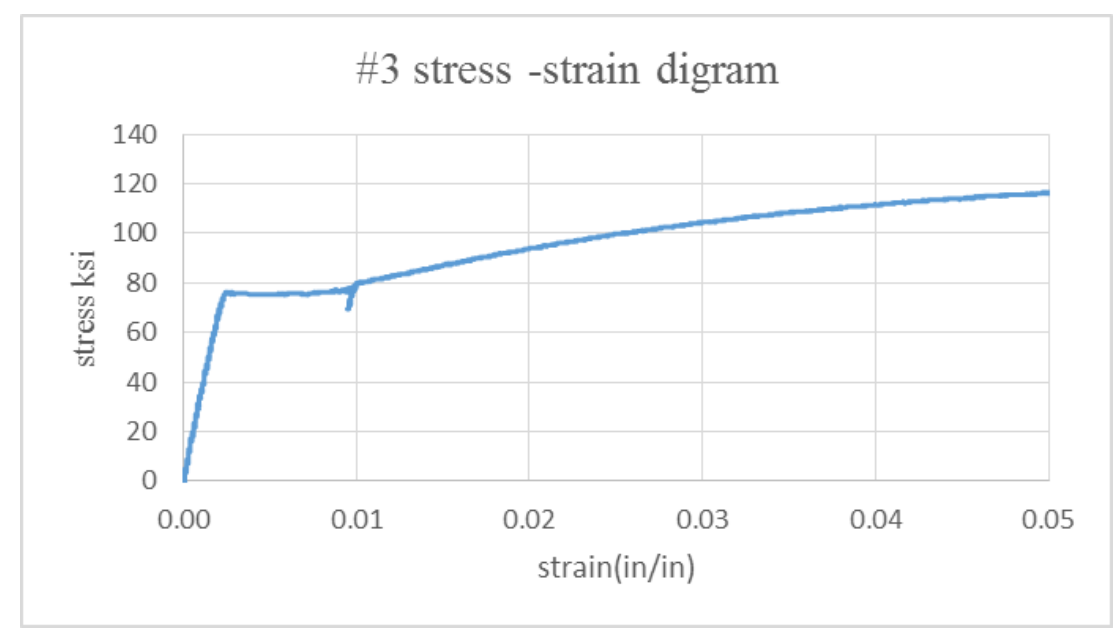

Figure 3-4: Stress-Strain curve of \#3 rebar (Al-Obaidi, 2015) 
Table 3-7: Mechanical properties of \#3 rebar

\begin{tabular}{|c|c|c|c|}
\hline Rebar & $\begin{array}{c}\text { Tensile Strength, } \mathrm{f}_{\mathrm{y}} \\
(\mathrm{ksi})\end{array}$ & $\begin{array}{c}\text { Modulus of Elasticity, E } \\
(\mathrm{ksi})\end{array}$ & $\begin{array}{c}\text { Yield Strain, } \varepsilon_{\mathrm{y}} \\
(\%)\end{array}$ \\
\hline$\# 3$ & 74 & 27407 & 0.0027 \\
\hline
\end{tabular}

\subsubsection{Lateral (Confinement) Reinforcement}

For the specimens in series C2, \#9 gage steel wires were used. This type of reinforcing wire that was used in this study had been tested and used by another researcher for another study at PSU. The direct tensile test was performed according to the ASTMA370 method. The obtained mechanical properties and stress-strain relationships of this type of steel wire are shown in Table 3-8 and Figure 3-5, respectively.

Table 3-8: Lateral reinforcing No.9 wire properties

\begin{tabular}{|c|c|c|c|}
\hline Wire type & $\begin{array}{c}\text { Diameter } \\
\text { (in) }\end{array}$ & $\begin{array}{c}\mathbf{F}_{\mathbf{y}} \\
\text { (ksi) }\end{array}$ & $\begin{array}{c}\mathbf{F}_{\mathbf{u}} \\
\text { (ksi) }\end{array}$ \\
\hline Black Iron Wire & 0.145 & 31 & 51 \\
\hline
\end{tabular}

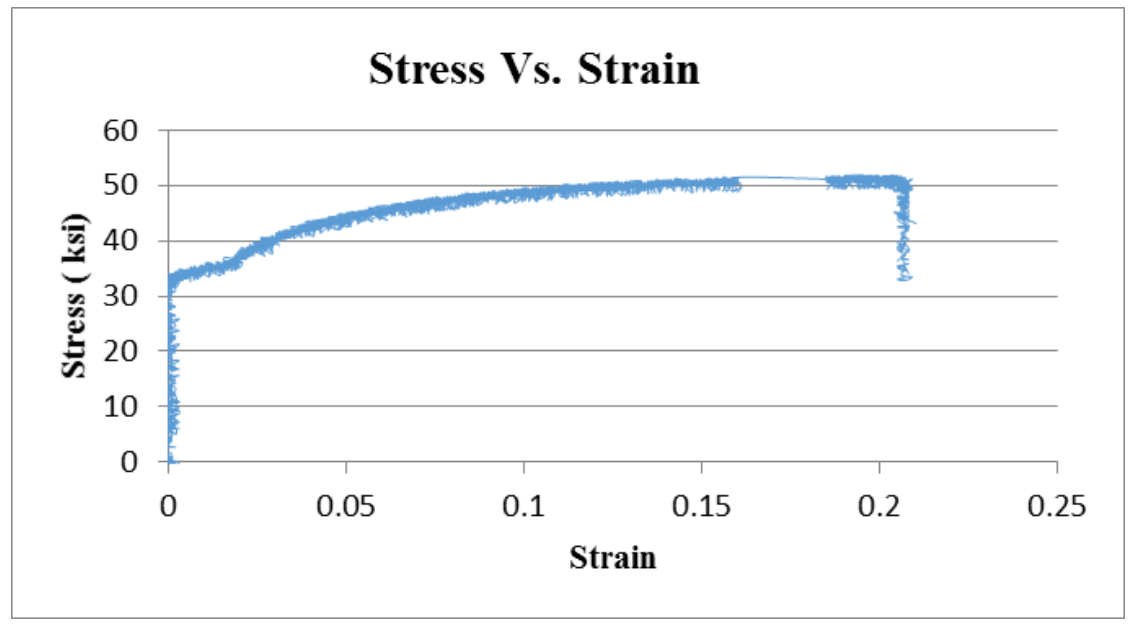

Figure 3-5: Stress-Strain curve of No.9 steel wire (Al-Lami, 2015) 
For the specimens in series $\mathrm{C} 4$, \#2 steel wires were used. A direct tensile test in accordance with ASTM-A370 guidelines was performed to obtain the mechanical properties and the stress-strain relationship of this type of wire. Two samples of the wire were tested using a 5-kip MTS as shown in Figure 3-6. The strain was measured using a laser extensometer and recorded by a data logger. Figure 3-7 and Table 3-9 illustrate the material properties of that type of wire.

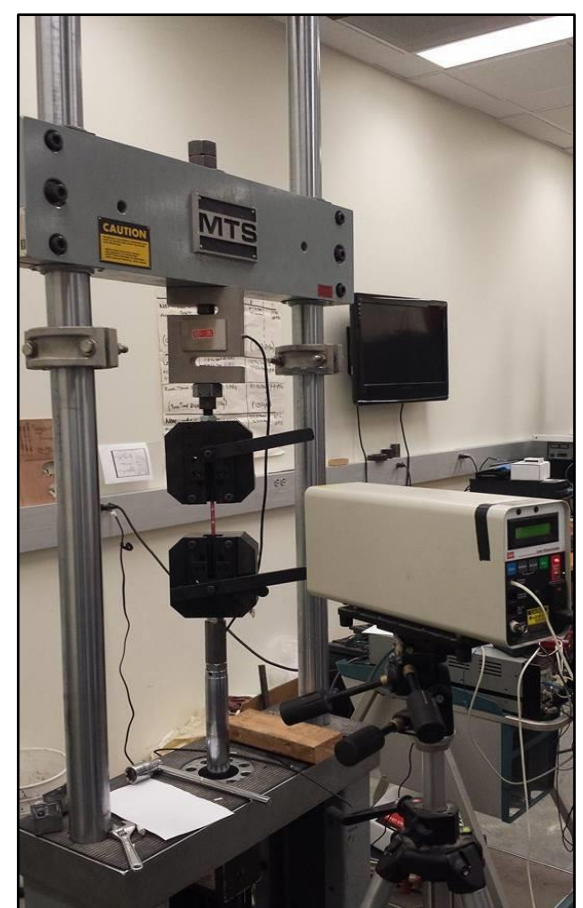

Figure 3-6: Direct tensile testing machine and instrumentation

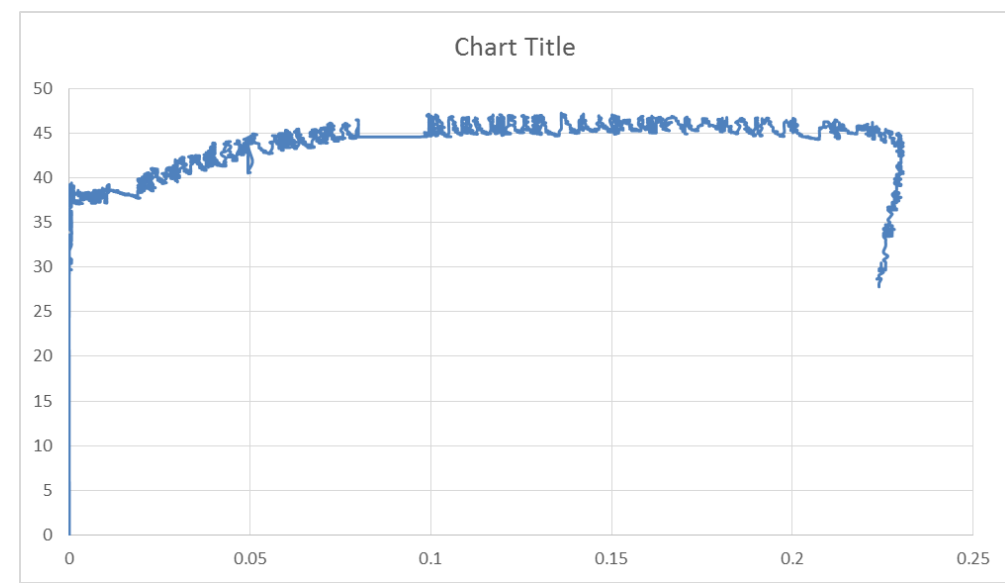

Figure 3-7: Stress-Strain curve of No.2 steel wire 
Table 3-9: Mechanical properties of No.2 steel wire

\begin{tabular}{|c|c|c|c|}
\hline Wire type & $\begin{array}{c}\text { Diameter } \\
\text { (in) }\end{array}$ & $\begin{array}{c}\mathbf{F}_{\mathbf{y}} \\
\text { (ksi) }\end{array}$ & $\begin{array}{c}\mathbf{F}_{\mathbf{u}} \\
\text { (ksi) }\end{array}$ \\
\hline Pencil Rod & 0.25 & 38 & 48 \\
\hline
\end{tabular}

\subsubsection{CFRP-Composite}

The FRP sheets used for jacketing in this study were $M B r a c{ }^{\circledR}$ FIB 300/50 CFS, a type of unidirectional high strength carbon fiber fabric. Per the manufacturer specifications for one ply of the fabric, the ultimate tensile strength $\left(f_{u}\right)$, modulus of elasticity (E), ultimate rupture strain $(\varepsilon f p)$, and nominal thickness $\left(t_{f}\right)$ were $550 \mathrm{ksi}, 34000 \mathrm{ksi}, 1.67 \%$, and 0.0065 in/ply, respectively. This type of fabric consists of high-strength dry carbon fibers impregnated with a polymer resin to form the composite material. To construct the CFRP jacket, a certain CFRP strengthening system was used. This system, in addition to the CFRP fabric, consists of three different layers of epoxy-based materials recommended by the manufacturer. They are illustrated below:

- Primer: The first layer of the epoxy system. It is a low viscosity epoxy used to penetrate the pore structure of the concrete surface and provide a proper bond for the remaining layers of the epoxy system. The two-part MasterBrace P 3500 was used as a primer.

- Putty: A thick non-sag epoxy paste used to level and smooth out the concrete surface on which the CFRP sheet was applied. The two-part MasterBrace F 2000 was used as a putty. 
- Saturant: A low viscosity epoxy material used to encapsulate the carbon fiber fabric. It provides a high-performance FRP laminate when it dries. The two-part MasterBrace SAT 4500 was used as a saturant.

The mechanical properties of both the CFRP fabric and the epoxy used in this study are shown in Table 3-10 as provided by their manufacturer.

Table 3-10: Mechanical properties of the CFRP system

\begin{tabular}{|c|c|c|c|c|c|}
\hline \multirow{2}{*}{ Material } & \multicolumn{5}{|c|}{ Properties ( by manufacturer) } \\
\cline { 2 - 6 } & $\begin{array}{c}f_{u} \\
\mathrm{ksi}\end{array}$ & $\begin{array}{c}f_{y} \\
\mathrm{ksi}\end{array}$ & $\begin{array}{c}\mathrm{E} \\
\mathrm{ksi}\end{array}$ & $\begin{array}{c}\varepsilon_{f p} \\
\%\end{array}$ & $\begin{array}{c}t_{f} \\
\text { in }(\mathrm{mm})\end{array}$ \\
\hline $\begin{array}{c}\text { MBrace } \\
\text { ( } \mathrm{FIB} \mathrm{300/50} \mathrm{CFS} \\
\text { (CFRP) }\end{array}$ & 550 & --- & 33000 & 1.67 & $0.0065(0.165)$ \\
\hline $\begin{array}{c}\text { MasterBrace SAT 4500 } \\
\text { (Epoxy) }\end{array}$ & 8.0 & 7.9 & 440 & 3.5 & --- \\
\hline
\end{tabular}

\subsubsection{CFRP Coupon Test}

A direct tensile coupon test was conducted according to the ASTM D3039/D3039M-08 standard to investigate the mechanical properties of the type of the CFRP composite used in this study, and to verify the material characteristics provided by the manufacturer. The test was conducted on coupons that were cut from a CFRP laminate panel that was made prior to the test. The following steps summarize the procedure for this test:

1. Preparing the CFRP laminate panel: The laminate panel was fabricated by hand lay-up technique. It began with preparing a smooth, ridged, and leveled surface using a plywood board covered with a thin plastic film. Then, the two-part saturant was thoroughly mixed and a thin layer of that saturant was applied on the board using a paint brush. After that, a 7" X 13" CFRP sheet was cut and placed 
on the saturant layer. By applying gentle pressure on the sheet using a plastic paddle or roller, the air entrapped between the sheet and the saturant was removed. Then, another layer of the saturant was applied on the CFRP sheet. The saturated sheet was covered by another plastic film. Then the plastic paddle was used again to get rid of the excessive saturant. Finally, the CFRP panel was left to cure at the room temperature for one day. Figure 3-8 illustrates this hand lay-up technique.

2. Preparing the CFRP coupons: After the CFRP panel had been cured, the two plastic films were peeled off. The nominal thickness of the laminate panel was $0.65 \mathrm{~mm}$. Then, it was cut into seven strips (coupons) using a proper shear scissor. Each strip was $17 \mathrm{~mm}$ wide and $254 \mathrm{~mm}$ long. Figure 3-9 demonstrates the dimensions of the CFRP coupons. To provide appropriate anchorage at the coupons' ends during the testing, rectangular aluminum tabs were prepared. They were cut and shaped as shown in Figure 3-9. Two tabs were used at each end of each specimen in order to diffuse the stress applied by the testing machine grips. MasterBrace SAT 4500 epoxy was used to adhere the tabs to the CFRP strips. The coupons were left for more than a week to cure.

3. Instrumentation and testing procedure: Each coupon was instrumented with one $10-\mathrm{mm}$ electrical strain gage to measure the axial strain during testing. Before installing the strain gage, the coupon surface where the gage was attached was rubbed with a sand paper to remove a thin layer of the epoxy coat to accurately measuring the strain of the CFRP composite. In addition to the strain gage, the 
axial elongation was measured by using a laser extensometer; therefore, two strips of a laser reflective tape were stuck on each coupon as shown in Figure 3-10. The test was performed in Materials Science lab at PSU, in the Department of Mechanical and Materials Engineering. Prior to the test, the dimensions of each coupon were measured. Table 3-11 shows the average dimensions of each coupon. Both the laser extensometer and the strain gage were connected to a data logging system that consists of a data logger and a computer to record the coupon strain data during the test. After that, the CFRP coupon was placed in the testing machines between its two grips. The coupon end tabs were firmly clamped by the grips. In this stage of the testing procedure, plenty of care was taken to ensure that the coupon was well aligned between the grips to eliminate the potential of bending or twisting of the specimens. All specimens were tested under displacement control with a constant rate of $0.02 \mathrm{in} / \mathrm{min}$. Figure 3-11 shows the test setup. 

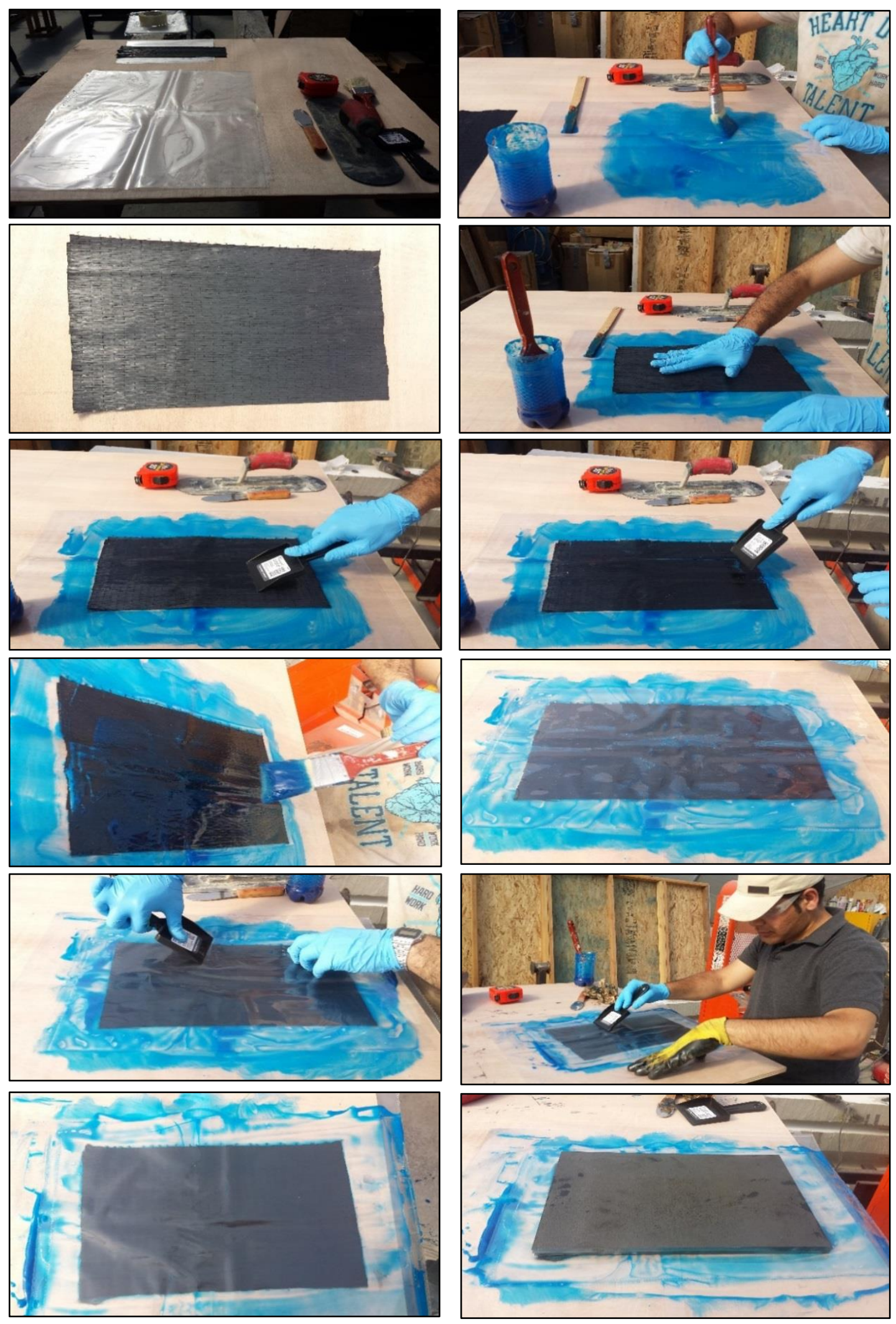

Figure 3-8: CFRP laminate panel fabrication 


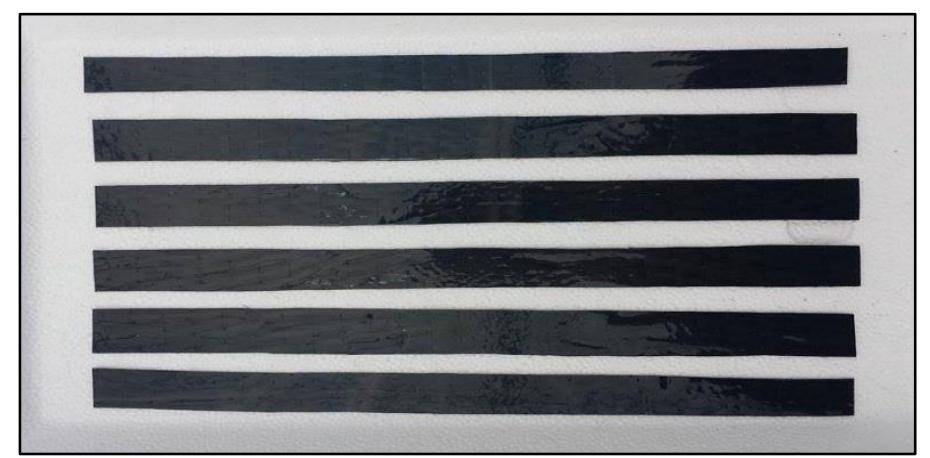

(a) CFRP laminate strips
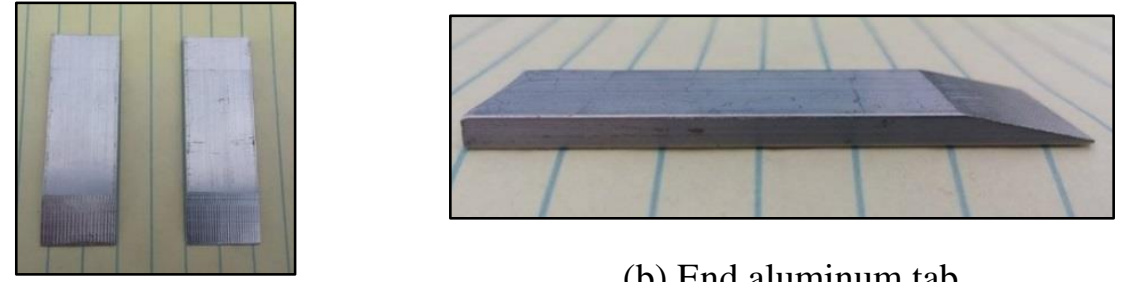

(b) End aluminum tab

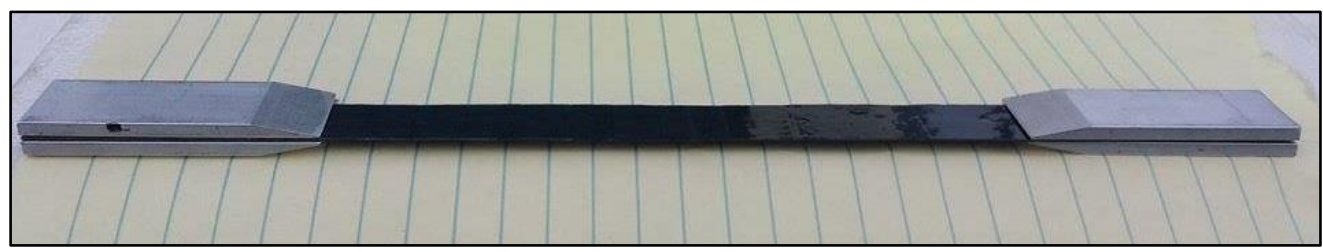

(c) CFRP flat coupon assembly
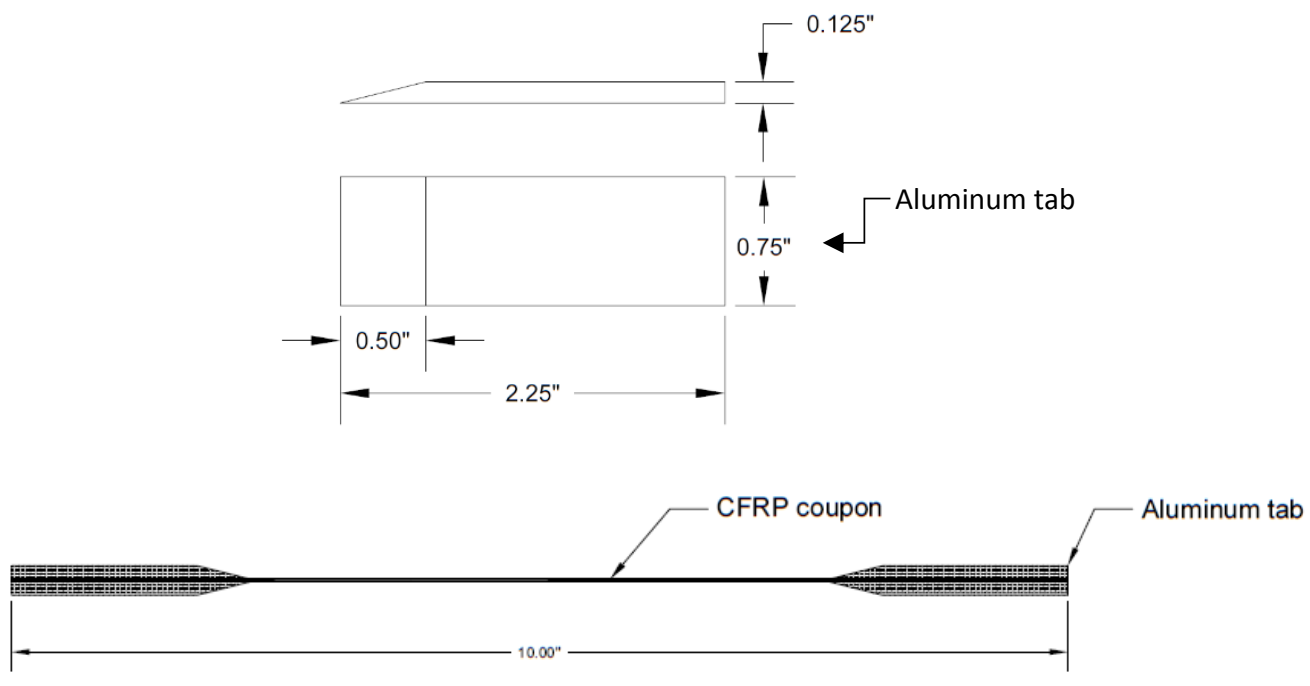

(d) Dimensions

Figure 3-9: CFRP flat coupon fabrication: (a) CFRP laminate strips. (b) End aluminum tab. (c) CFRP flat coupon assembly. (d) Dimensions 
Table 3-11: Average dimension of the CFRP coupons

\begin{tabular}{|c|c|c|c|c|}
\hline \multirow{2}{*}{ Coupon } & Gage & \multirow{2}{*}{ Width $(\mathrm{w})$} & \multicolumn{2}{|c|}{ Thickness } \\
\cline { 4 - 5 } & Length & & Laminate $(\mathrm{t})$ & Fabric $\left(\mathrm{t}_{\mathrm{f}}\right)$ \\
\hline$\# 1$ & 5.5 & 0.68 & 0.020 & 0.0065 \\
\hline$\# 2$ & 5.5 & 0.66 & 0.025 & 0.0065 \\
\hline$\# 3$ & 5.5 & 0.71 & 0.023 & 0.0065 \\
\hline$\# 4$ & 5.5 & 0.70 & 0.025 & 0.0065 \\
\hline$\# 5$ & 5.5 & 0.67 & 0.027 & 0.0065 \\
\hline$\# 6$ & 5.5 & 0.75 & 0.026 & 0.0065 \\
\hline$\# 7$ & 5.5 & 0.67 & 0.023 & 0.0065 \\
\hline
\end{tabular}

* All dimensions in inch

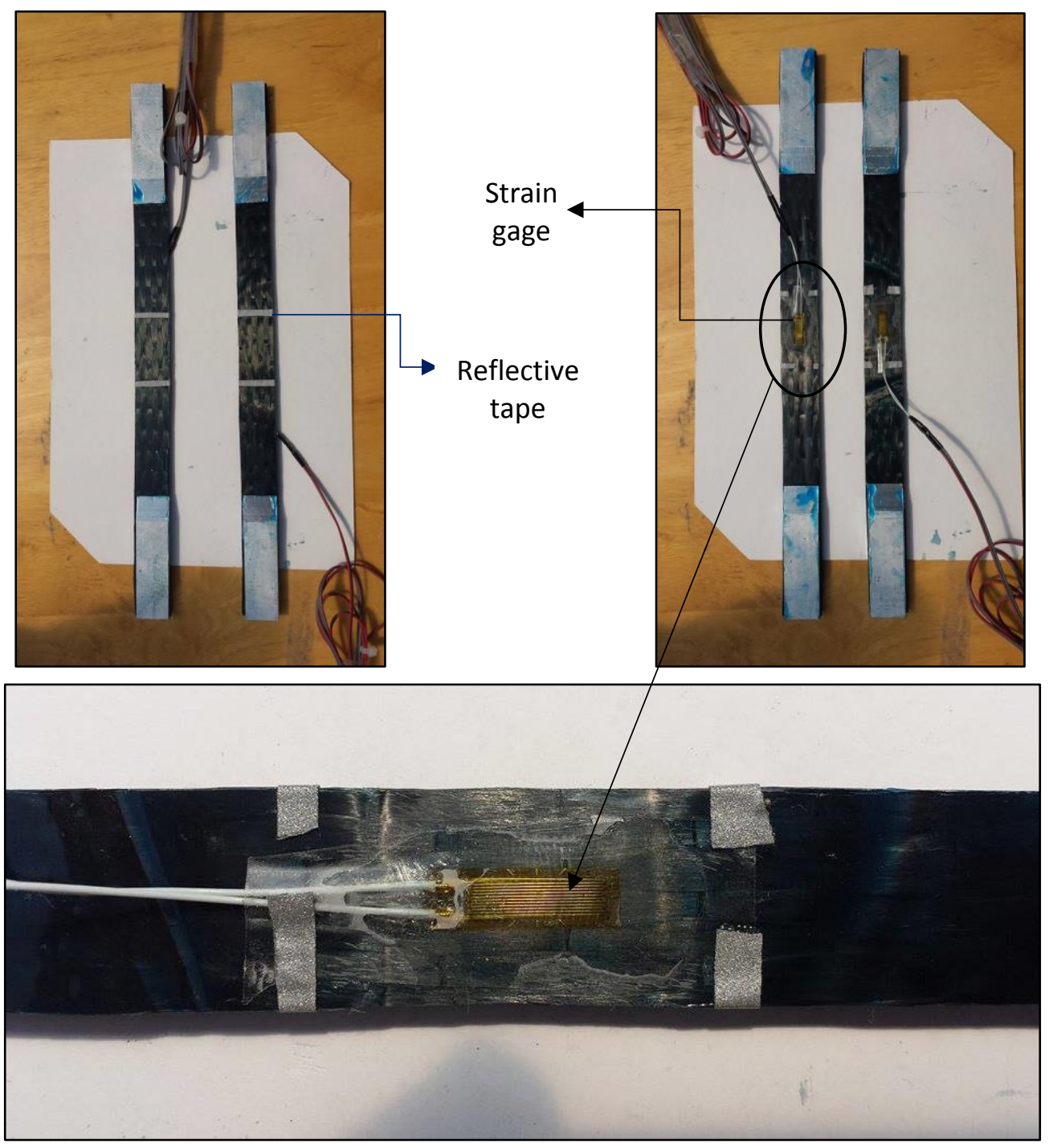

Figure 3-10: CFRP test coupons: Strain measuring instrumentation 


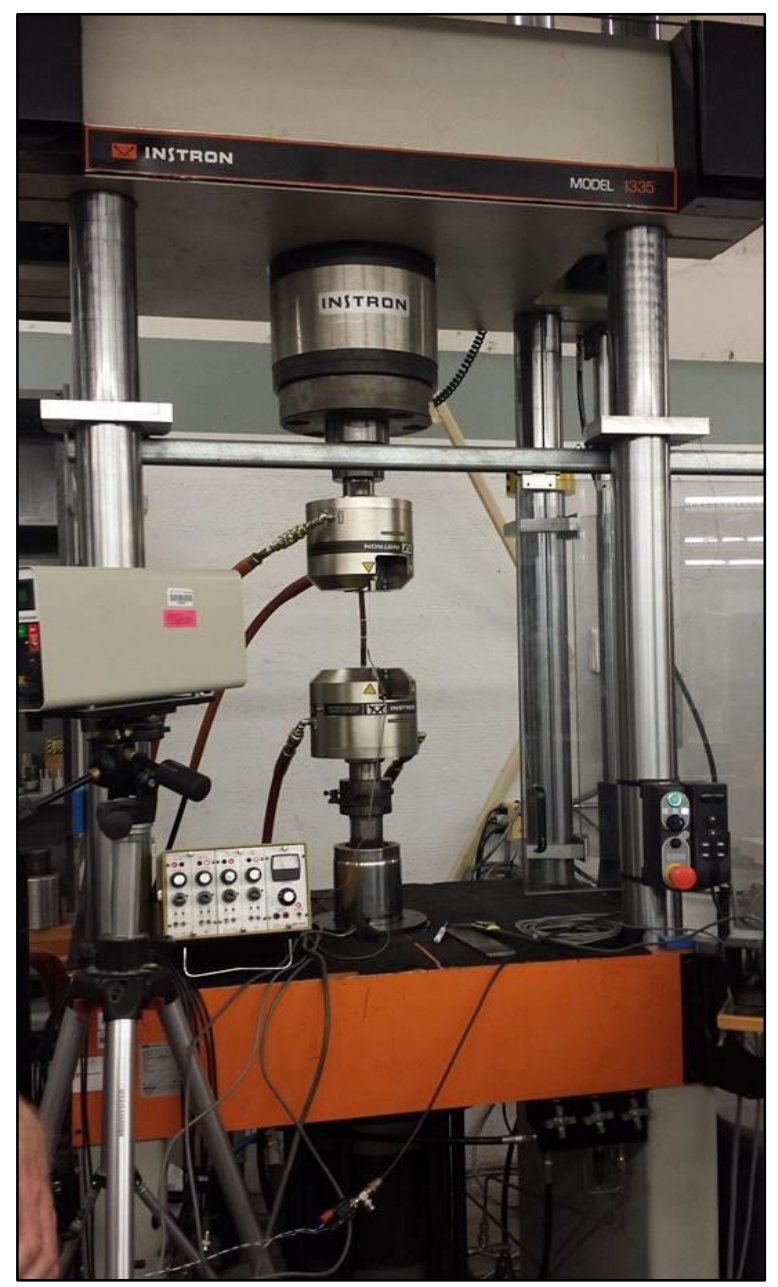

Figure 3-11: Instron testing machine

\subsubsection{Coupon Test Results}

Figure 3-12 shows the obtained stress-strain curves of the seven CFRP coupons. The tensile stress of each coupon was plotted as a nominal stress. This means that the stress was determined based on the assumption that the load was solely carried by the carbon fibers. Therefore, the tensile stress was calculated by dividing the tensile load by the gross area of the fibers $\left(w \times t_{f}\right) \mathrm{t}$ for each coupon. It can be noted from the figure that the tensile responses of all coupons were perfectly linear. However, they experienced some sudden drops at some strain points. It is believed that those drops are due to the formation 
of cracking as a result of some degree of misalignment when placing the coupon in the testing machine. This could be a good reason for the considerable difference in the values of the ultimate tensile strength and rupture strain provided by the manufacturer and those obtained from the test as it is illustrated in Table 3-12. The test values of the ultimate tensile strength $\left(f_{u}\right)$ and the ultimate tensile rupture strain $(\varepsilon f p)$ listed in the table are the average values of all the CFRP coupons. For each coupon, the elastic modulus was calculated as the slope of the linear portion of the response prior to the sudden drop.

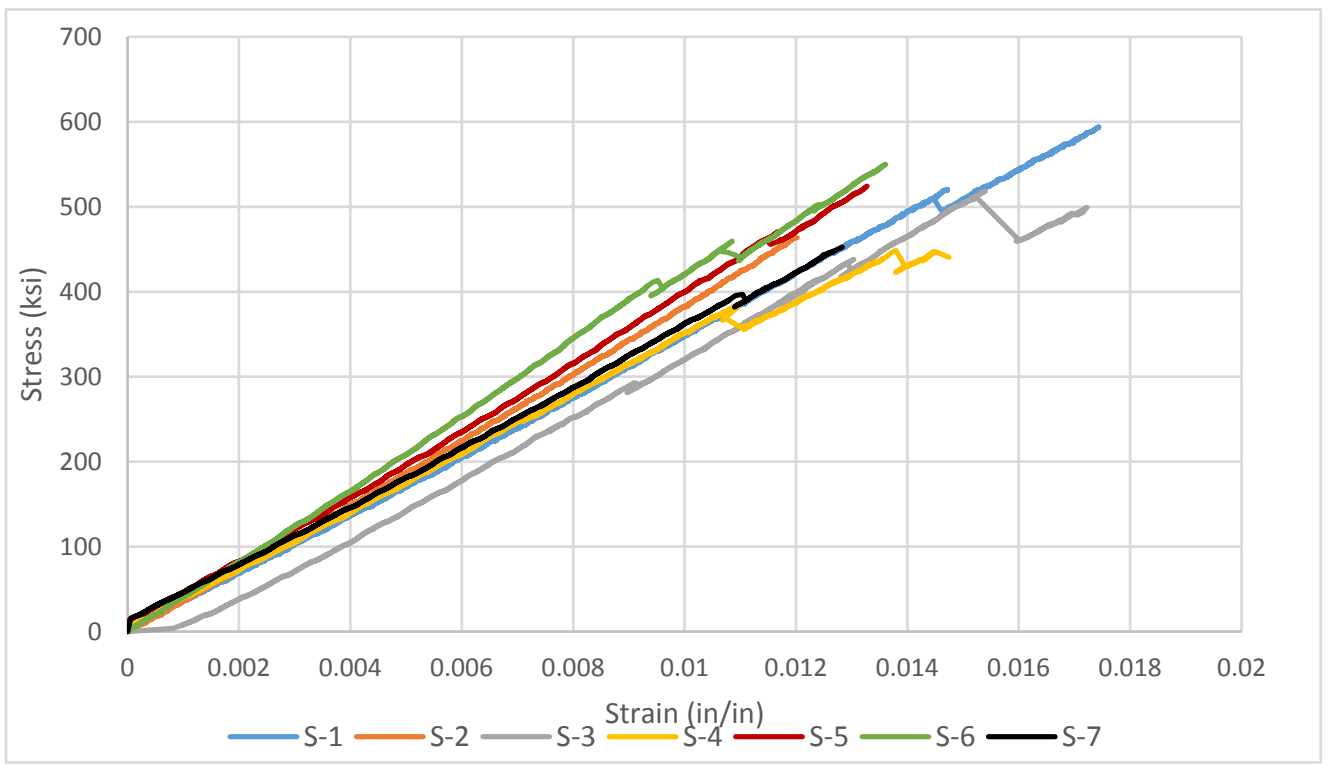

Figure 3-12: Stress-Strain curves of the test CFRP coupon

Table 3-12: Mechanical Properties of the CFRP fabric

\begin{tabular}{|c|c|c|c|c|c|}
\hline \multirow{2}{*}{ Material } & \multirow{2}{*}{ Source } & \multicolumn{4}{|c|}{ Mechanical Properties } \\
\cline { 3 - 6 } & & $f_{u}$ & $f_{y}$ & $\mathrm{E}$ & $\varepsilon f p$ \\
$\mathrm{ksi}$ & $\mathrm{ksi}$ & $\mathrm{ksi}$ & $\%$ \\
\hline \multirow{2}{*}{$\begin{array}{c}\text { MBrace }{ }^{\circledR} \text { FIB 300/50 CFS } \\
(\text { CFRP })\end{array}$} & Manufacture & 550 & --- & 33000 & 1.67 \\
\cline { 3 - 6 } & Coupon test & 508 & --- & 37202 & 1.45 \\
\hline
\end{tabular}




\subsection{Column Specimen Details}

\subsubsection{Fixed Parameters}

\section{Specimen Shape and Size}

All specimens were square columns with 5" x 5" cross section and 12" in height. The corners were rounded with a radius of about 0.75 " in order to minimize the stress concentration at the column corners when wrapped with CFRP composite. Figure 3-13 and Figure 3-14 show the specimen's details.

\section{Longitudinal Reinforcement}

The smallest reinforcing rebar available in the market is the \#3 rebar, and the least number of bars that can be used with square columns is four bars as per the ACI 318-14 Code. Therefore, to emulate columns with low reinforcement ratio, all of the specimens were longitudinally reinforced with 4-\#3 steel bars ( 0.375 " diameter) to provide a longitudinal reinforcement ratio of $\left(\rho_{g}=1.67 \%\right)$, which is close to the ACI Code minimum reinforcement ratio $\left(\rho_{g}=1 \%\right)$. Figure 3-13 and Figure 3-14 show the reinforcement details for both the $\mathrm{C} 2$ and the $\mathrm{C} 4$ series.

\section{$>$ Corner Radius}

The roundness degree of the corners of a column (corners' radii) when strengthened with CFRP jacket plays a significant role in the effectiveness of the jacket, as illustrated in Chapter 2. Current international design guidelines recommend different limit for the corner radius. For example, the ACI committee 440.2R recommends a minimum radius 0.5" when FRP sheets are wrapped around outside corners (ACI 440.2R, 2008). Because a great deal of research has studied the effect of this parameter, the researcher has fixed the corner radii at 0.75 " for all specimens in the current study. In most of the previous 
experimental studies, rounding the corners was performed with the formwork. However, in the present study, all of the specimens were cast in a perfect square cross section, whereas the corners were rounded later by grinding them until obtaining the desired radius. The reason for this was to emulate the real situation of having an existing square column that needs to be retrofitted with a CFRP jacket.

\subsubsection{Varied Parameters}

$>$ Concrete Compressive strength $\left(f^{\prime} c\right)$

Test specimens were set into two main series depending on the grade of concrete that was used. Specimens in series C2 were cast with 2000-psi concrete. This emulates old concrete columns in which concrete was weak to begin with, or concrete that may have lost some of its strength due to deterioration. On the other hand, specimens in series C4 were cast with 4000-psi concrete. This represents the currently common concrete strength. In other words, the two concrete grades are a good and reasonable representation of the lower and upper limit of the strength of concrete in structures built in 1920s-1960s. In addition, using two different concrete grades helps to bracket the effects of concrete compressive strength on the behavior of CFRP wrapped RC columns.

\section{$>$ Lateral (Confinement) Reinforcement}

According to the ACI 318 design requirements, lateral reinforcement of each type of specimens had a different pattern. C2NDC Specimens were reinforced with No. $9(\Phi$ $0.15 ")$ steel wire hoops spacing at $5 " \mathrm{o} / \mathrm{c}$, which is according to ACI rules (older as well as newer editions) that specifies spacing as the least dimension of the column cross section. The hoop ends were extended with 90-degree hooks for 1.8 ”. For specimen C2DC, No. 9 (Ф 0.15”) steel wire hoops spacing at 0.9” o/c were used. The end hooks 
were the 135-degree type, the so called "seismic hooks", with an extension of 1.5".For C4NDC specimen, which represent non-ductile RC column, \#9 ( $\Phi$ 0.15”) gage wire hoops spaced at 5" o/c were used, again, according to ACI rules (older as well as newer editions) that specifies spacing as the least dimension of the column cross section. The two ends of each hoop were extended with 1.8" 90-degree hooks. For C4DC specimen, which represent an ACI designed column that has the required seismic confinement reinforcement, \#2 gage wire hoops spaced at $1.25 \% \mathrm{o} / \mathrm{c}$ were used. The end hooks, in this case, were 135-degree type, the so-called "seismic hooks", with an extension of 1.5".

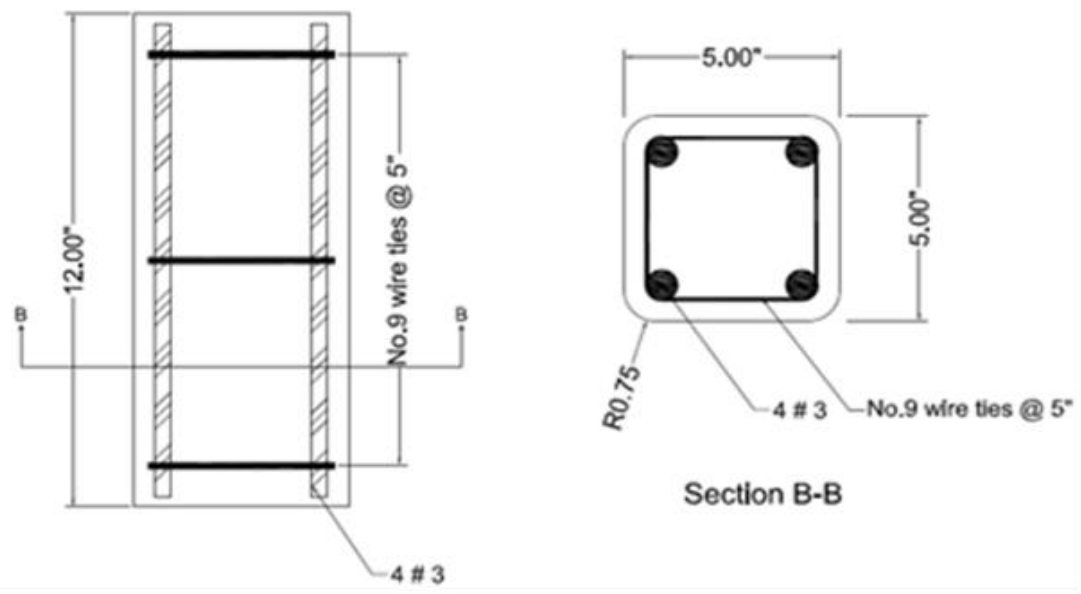

(a) Non-ductile column specimen

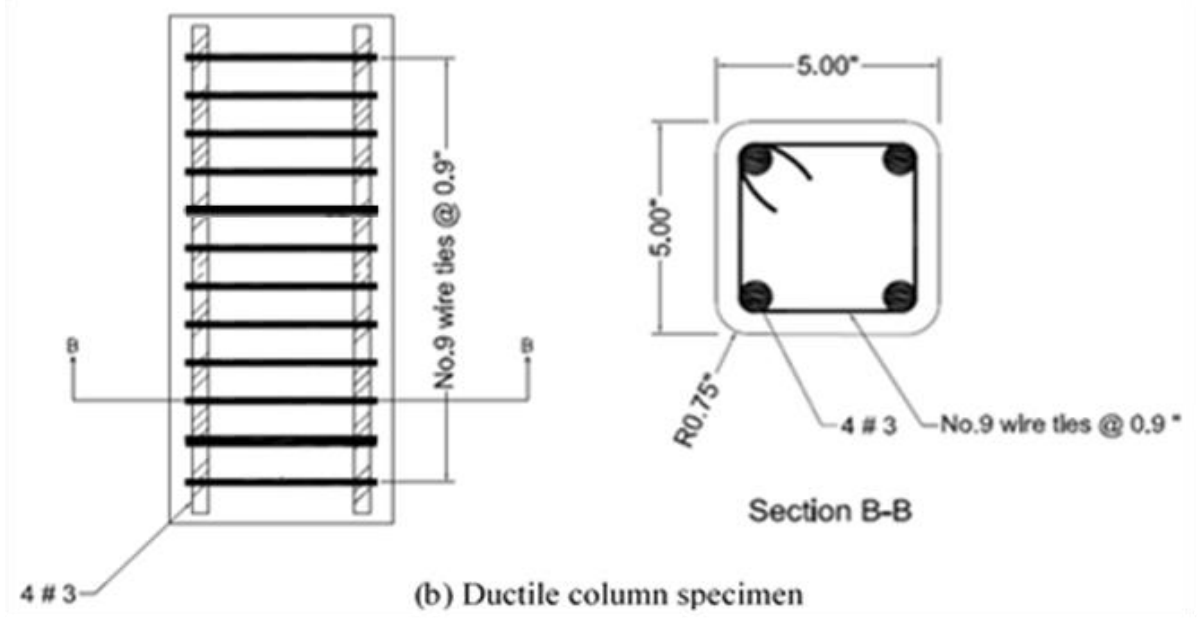

Figure 3-13: Specimen's details (C2 series) 


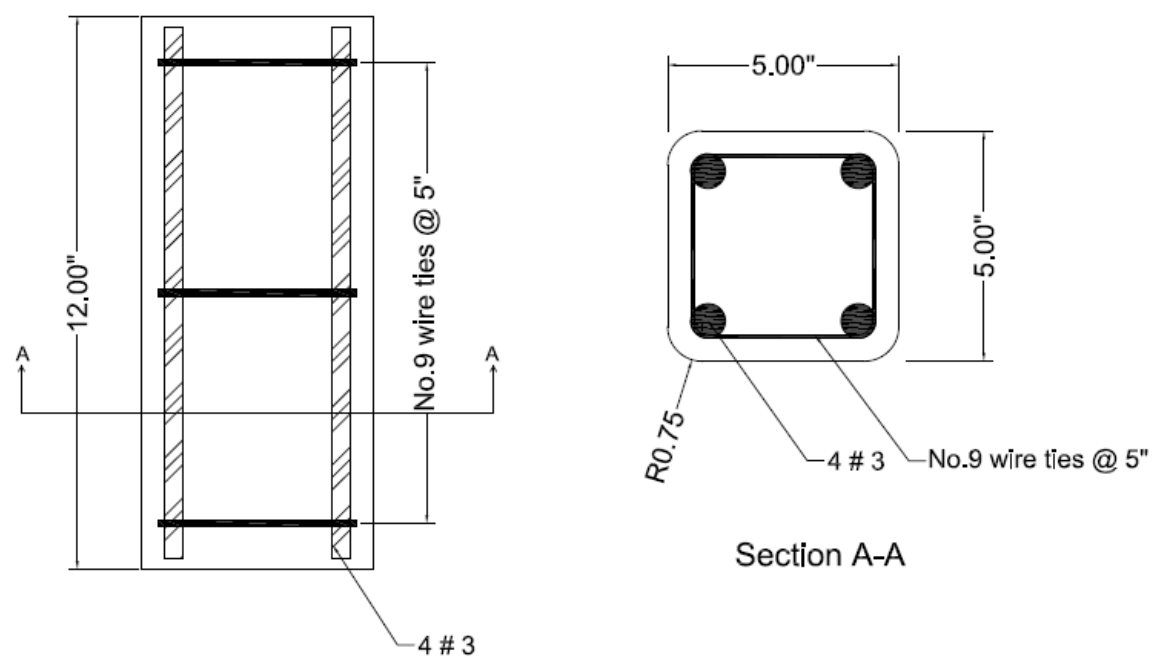

(a) Non-ductile column specimen
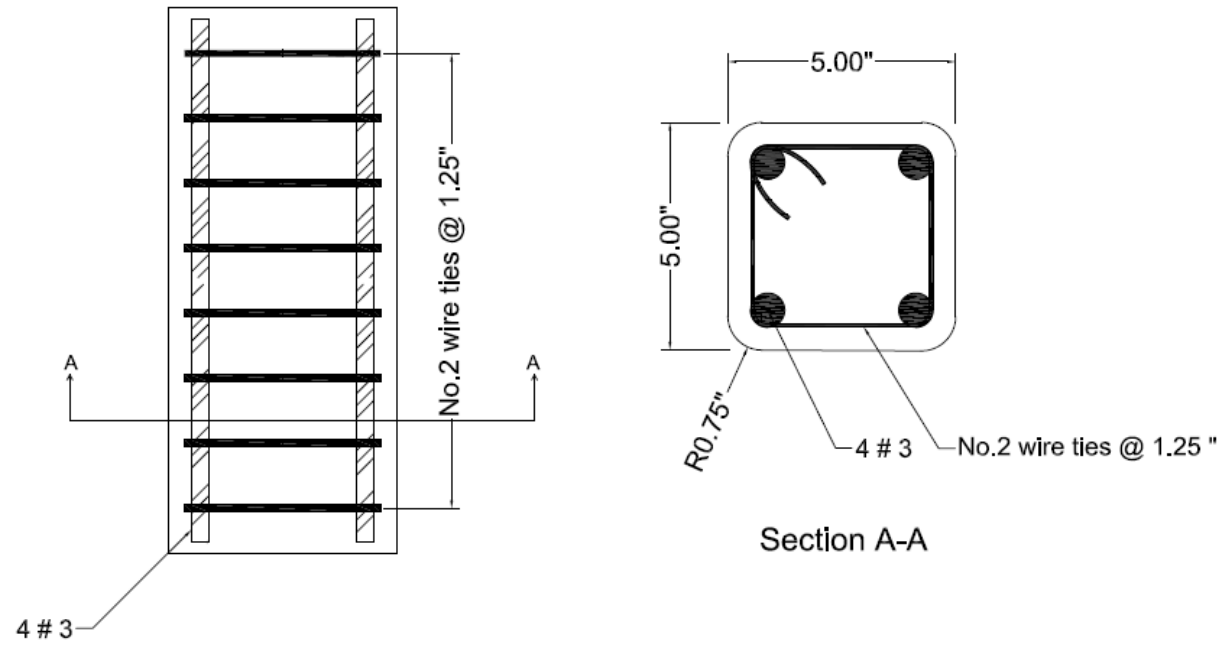

Section A-A

(b) Ductile column specimen

Figure 3-14: Specimen's Details (C4 series) 


\subsection{Specimens Fabrication}

\subsubsection{Fabrication of molds}

The test columns were constructed at the South Greenhouse Laboratory, PSU. The process of constructing these concrete square columns began with fabricating sixteen wooden molds. These molds were fabricated horizontally using $1 \frac{1 / 2}{2}$ " thick lumber. The lumber was cut to the appropriate dimensions, and secured using screws to form the molds that accommodated the test specimens. The mold fabrication process is shown in Figure 3-15.

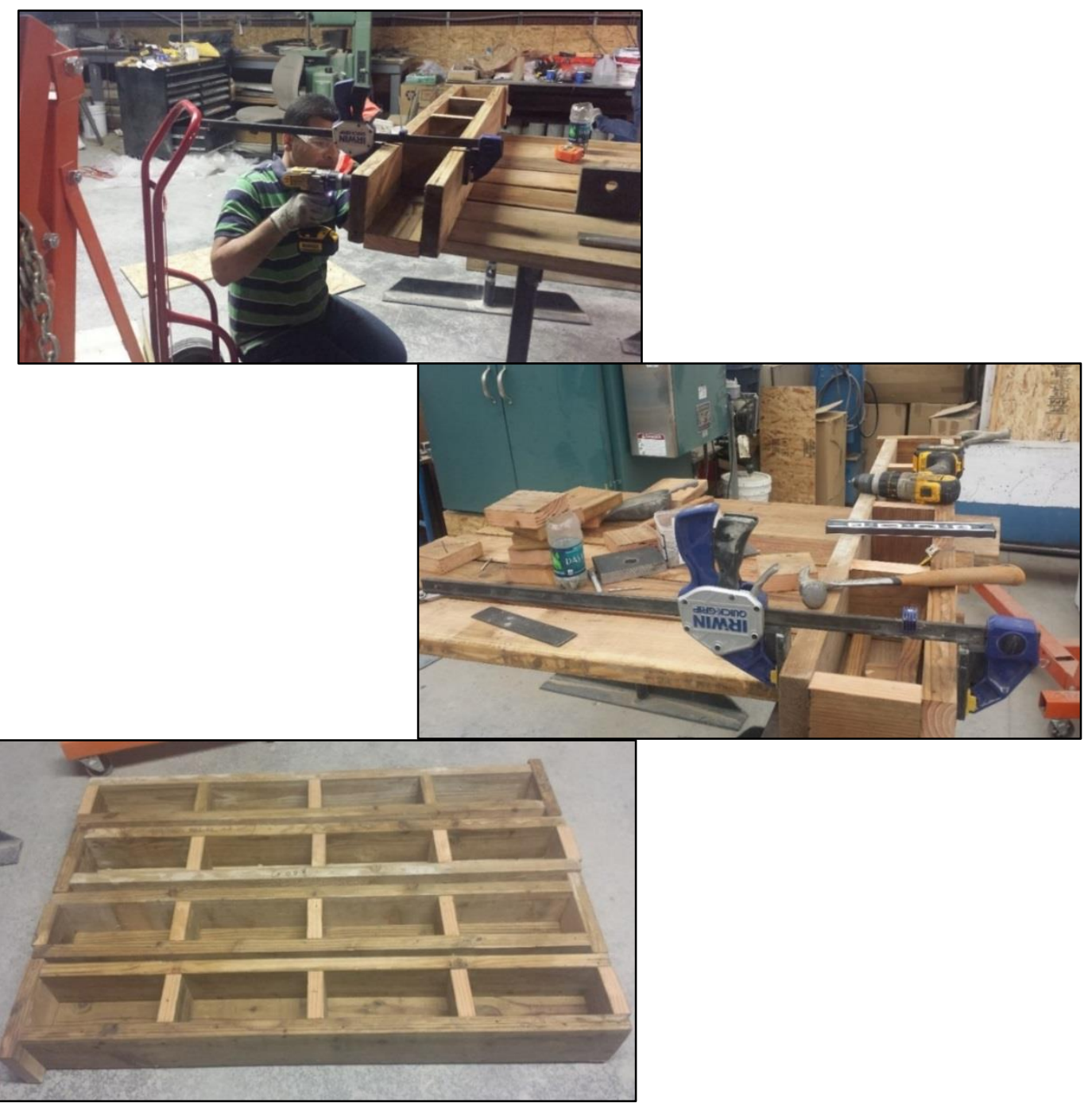

Figure 3-15: Fabrication of Molds 


\subsubsection{Fabrication of Steel Cages}

After completing the fabrication of the molds, a longitudinal steel reinforcement was prepared and cut to the required length by using an appropriate rebar cutter. A hand-made steel wire bender was used to form the lateral hoops with the proper dimensions. Then, those wire hoops were tied to the longitudinal bars at the specified spacing to form the reinforcing steel cages. Figure 3-16 illustrates the process of making the steel cages. 

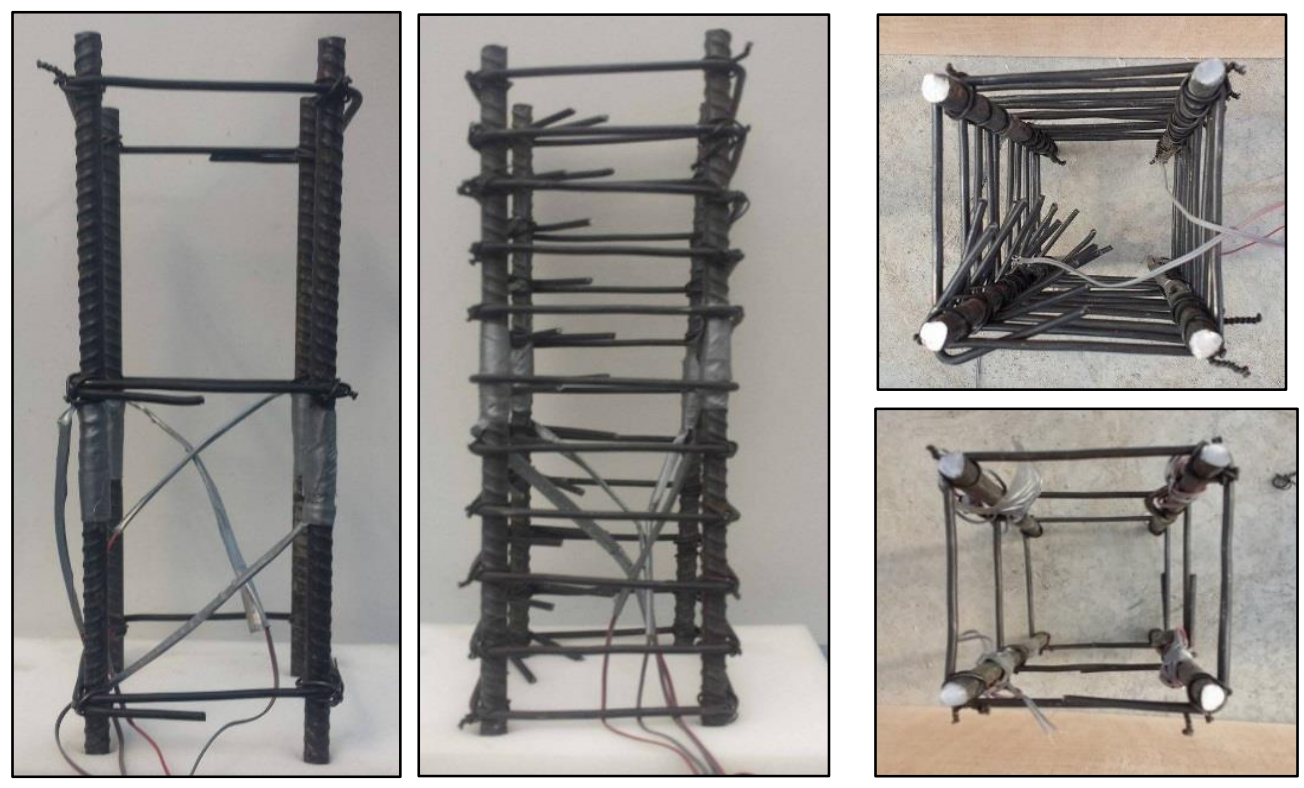

(a) C2 series
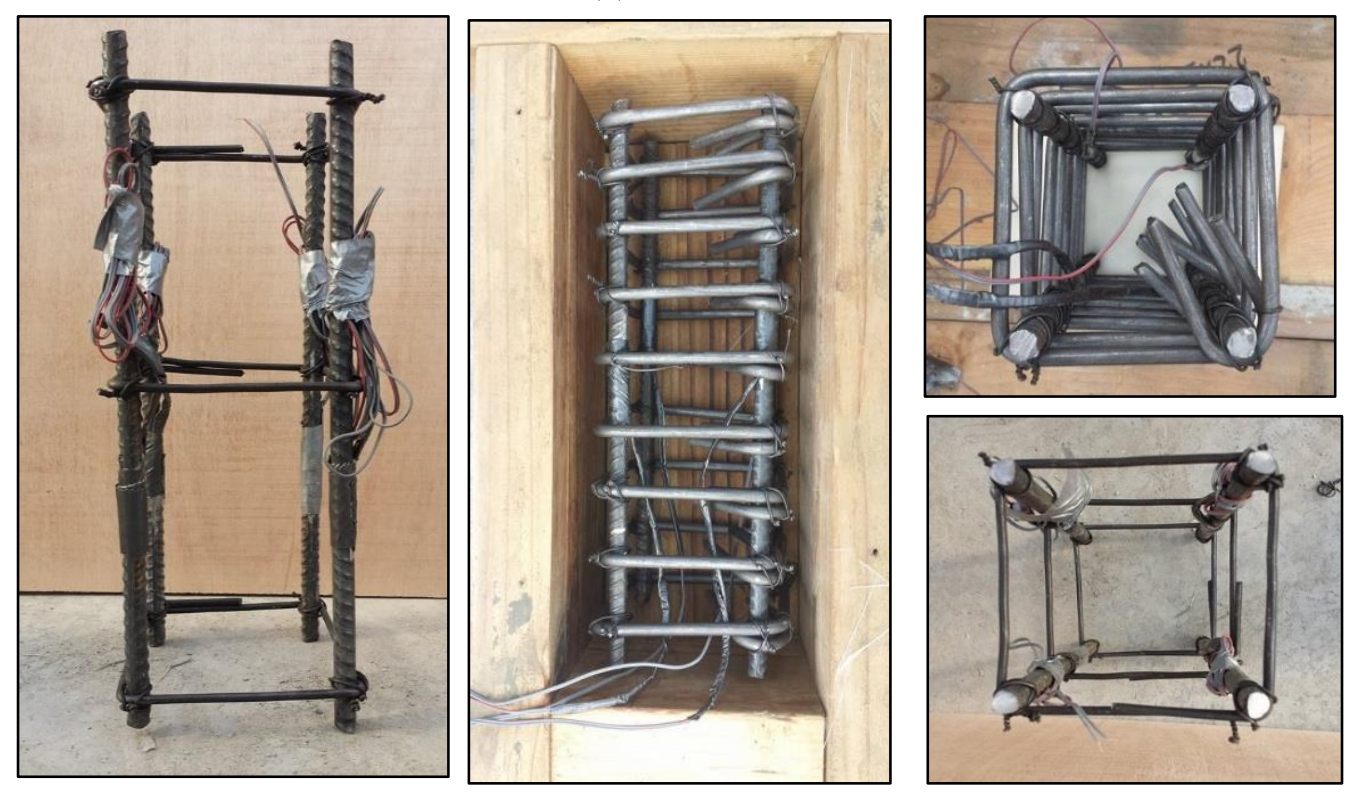

(b) C4 series

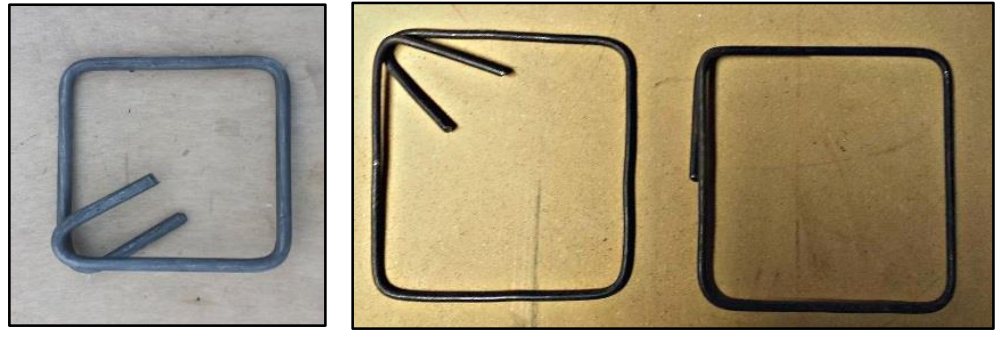

Figure 3-16: Reinforcing steel cages 


\subsubsection{Installation of strain gages}

The type of the strain gages used in this study were Omega KFH strain gages with a gauge length of $10 \mathrm{~mm}$. One strain gauge was installed on each longitudinal bar, so that there were four strain gages installed in each specimen. The strain gage was installed at about an inch above the mid-height of the longitudinal bar. The process of installing a strain gage began with grinding the surface of the rebar to get a leveled, smooth surface to place the strain gauge on. After that, the strain gauge was glued to the bar using a special adhesive that was recommended be the manufacturer. Then, it was covered with a

piece of duct tape to protect it from being scratched or cut during the next steps of specimen's fabrication. The process of placing the strain gauges is illustrated in Figure 3-17. 


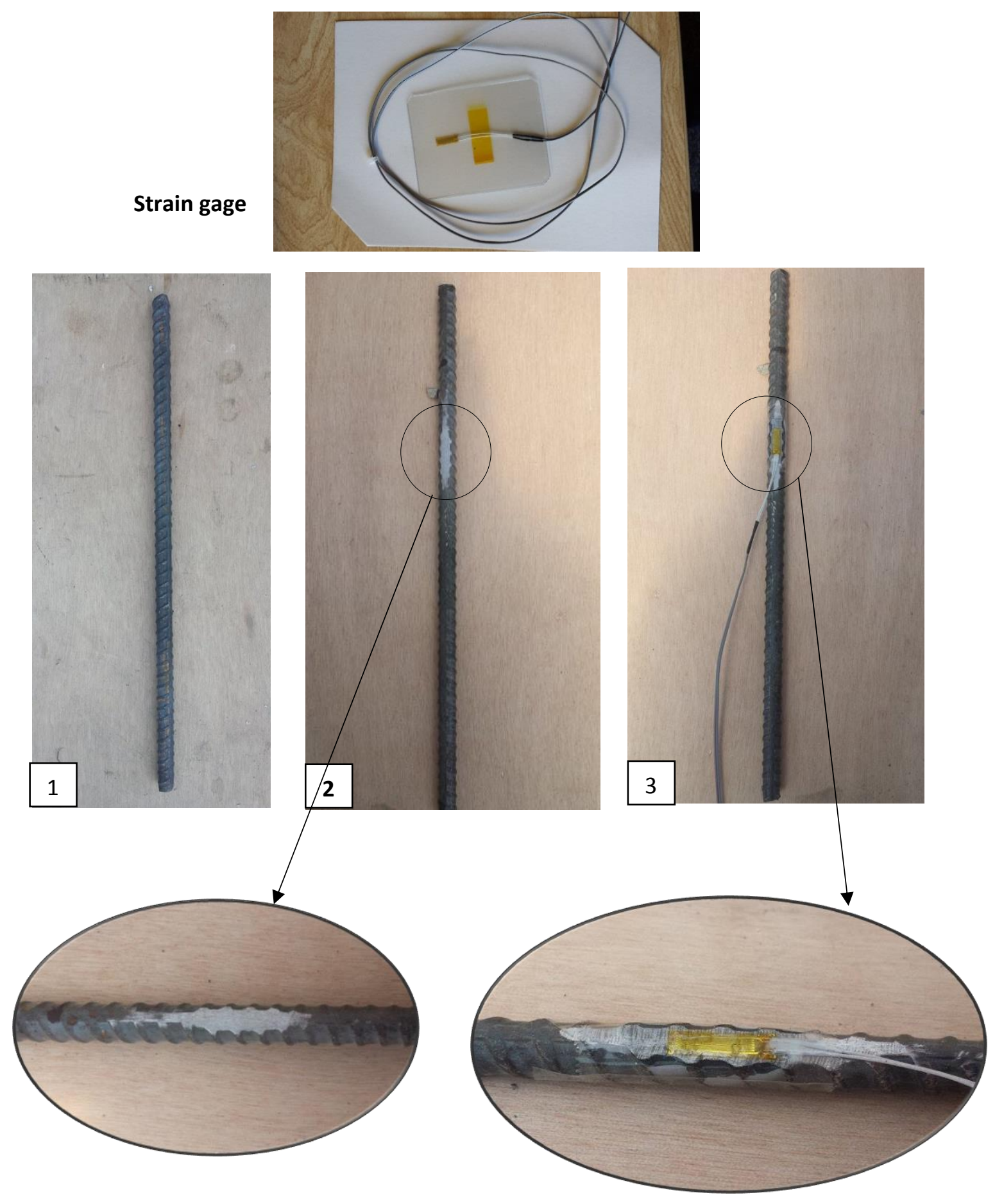

Figure 3-17: Installation of strain gages 


\subsubsection{Mixing, Casting, and Curing the Concrete}

The same procedure for preparing, mixing, casting, and curing the concrete was used with for both of the $\mathrm{C} 2$ and the $\mathrm{C} 4$ specimens.

Before mixing and pouring the concrete in the molds, the interior faces of the molds were oiled and then the steel cages were placed inside them. The proper concrete cover was provided by a number of plastic pieces and metal staples as shown in Figure 3-18. The concrete ingredients were mixed in a concrete mixer at the South Green House, PSU. First, the fine and coarse aggregates were mixed together for two minutes. Then, the cement was added and mixed with the other materials for other two minutes. After that, water was added to the mix. After five minutes of mixing, the concrete mixture was ready to be cast. Before casting the concrete, a slump test was performed to ensure that concrete mix attained the proper slump as per the design requirements. Finally, the concrete was poured in the molds. The concrete surface was leveled and smoothened using a appropriate trowel. At the time of casting the specimens, six standard ASTM concrete cylinders were cast for quality inspection. In terms of curing, after six hours of casting, the specimens' molds and cylinders were covered with wet burlap sheets for one day. Then, the column specimens and concrete cylinders were removed from the molds and kept together in the same place to ensure having the same curing conditions for both columns and cylinders. They were kept in a shaded area and covered with multiple layers of wet burlap sheets. In addition, they were covered with a layer of a plastic film to ensure that the concrete and the burlap sheets were kept moist for a longer time especially with knowing that the curing process was done during the summer time. Figure 3-18 and

Figure 3-19 show the process of casting and curing of the test specimens. 

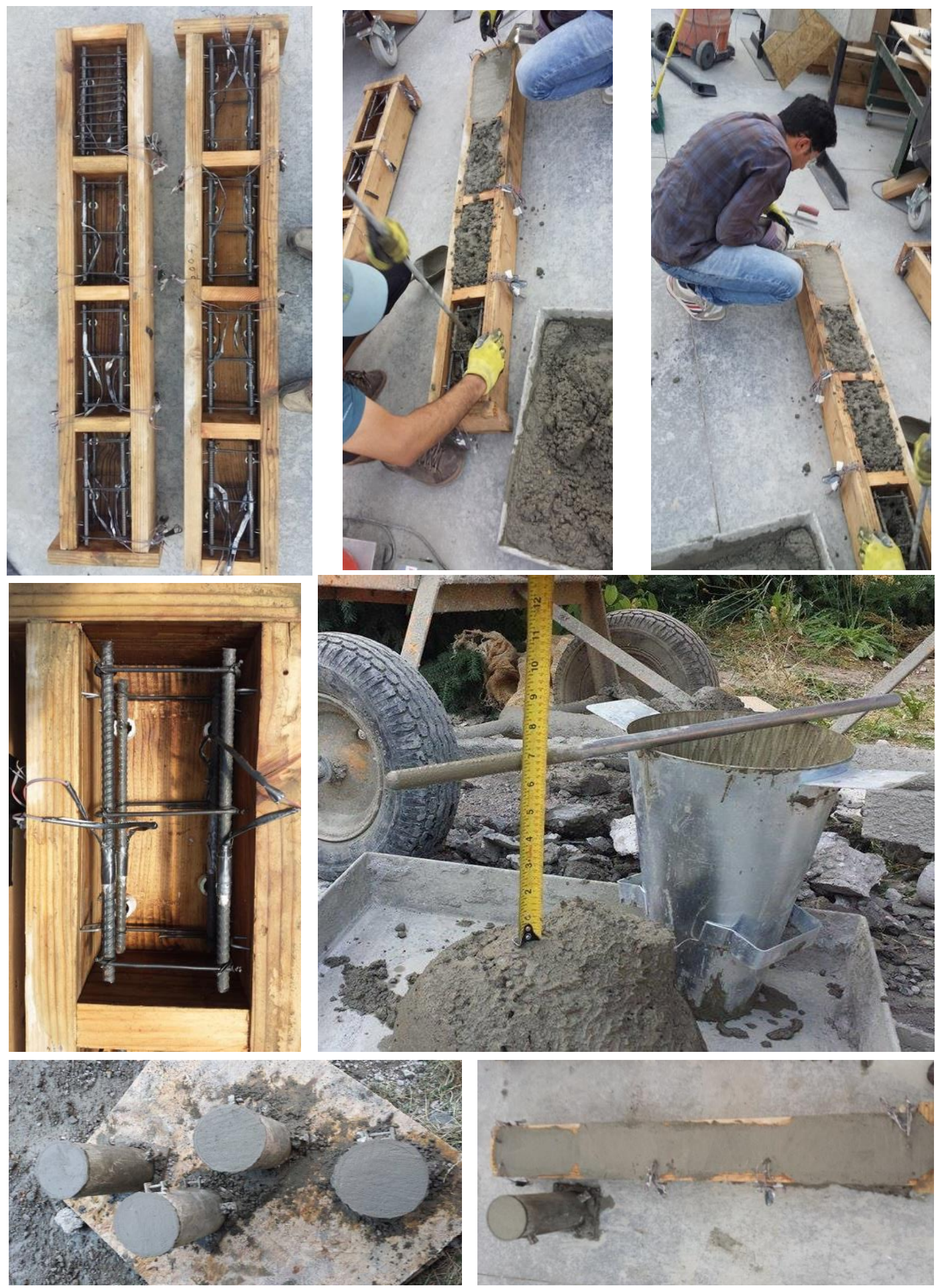

Figure 3-18: Casting the test's specimens 

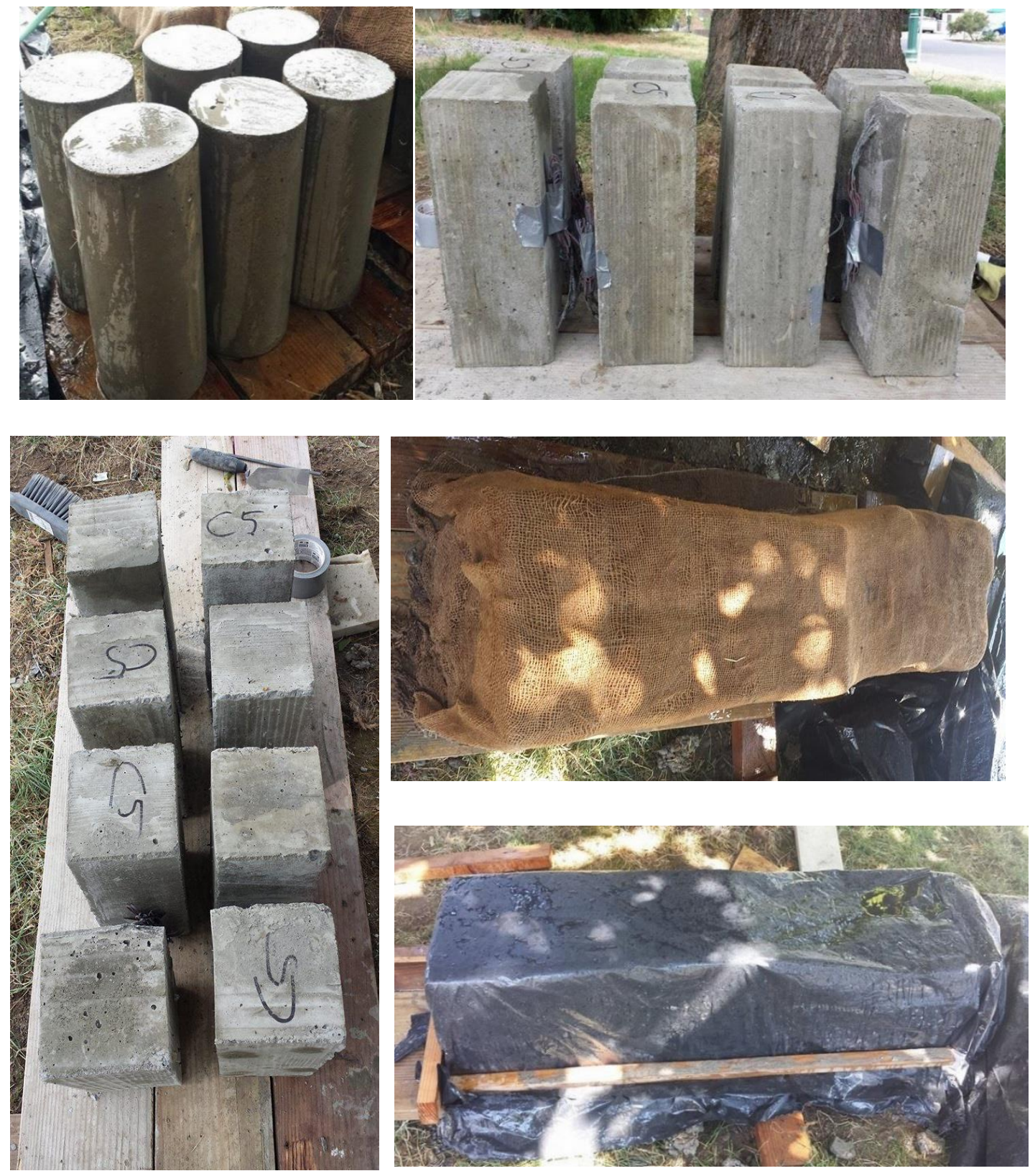

Figure 3-19: Curing the test's specimens 


\subsubsection{Installation of CFRP Wraps}

After twenty-eight days of curing, the column specimens were uncovered and prepared for installing the CFRP jacket. The procedure of wrapping them with CFRP sheets was done in several phases. These phases involved rounding the column's corners, repairing and preparing the concrete surfaces prior to applying the CFRP composite system, and applying the different layers of the epoxy materials that were used to install the CFRP sheets. These phases are explained thoroughly as follows:

\section{Phase I: Rounding the Corners}

This phase was done for all columns that were wrapped with CFRP sheets. The four corners of each column were rounded to have a corner radius of about 0.75 ". A grinder with a masonry disk was utilized to grind the concrete at the corners until the desired radius was obtained as shown in Figure 3-20.
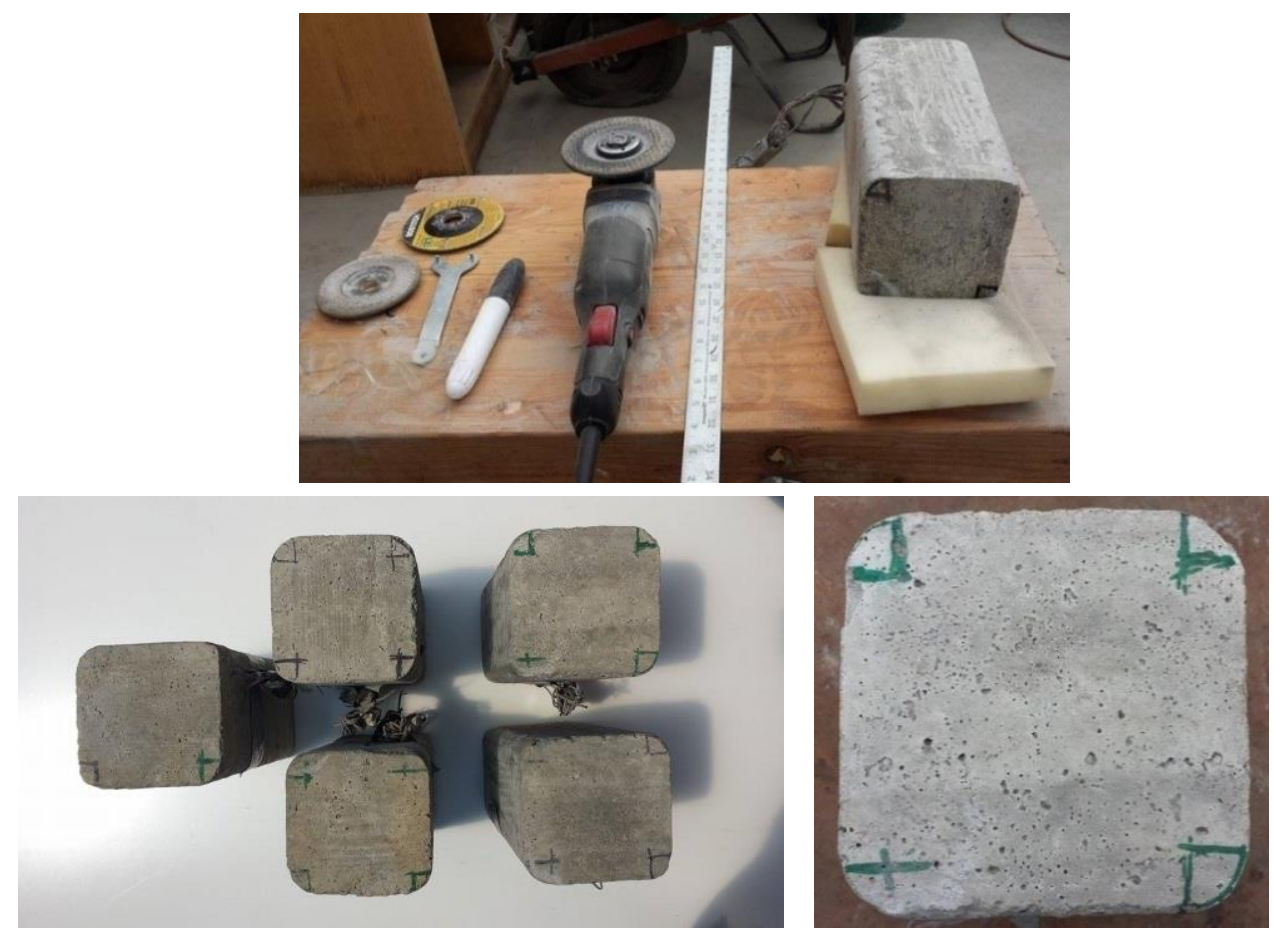

Figure 3-20: Rounding the column's Corners 


\section{Phase II: Repairing the Concrete surfaces}

For each column, the concrete surfaces were repaired before applying any epoxy-based material. This repair was done by filling any large to moderate- sized craters, voids and offsets using regular mortar with a mixing ratio of 1:2 (cement to sand). By using a proper trowel, the repaired areas were filled, pressed, and then smoothed to be level with the surrounding concrete. The repaired specimens were left to cure for two days in a moist atmosphere. After that, in order to roughen the concrete substrate surfaces and ensure that they are free of any contaminants and loose particles, they were abraded by a proper grinding wheel.

\section{Phase III: Constructing the CFRP Jacket}

The selected CFRP composite system for the present study consisted of the aforementioned components: primer, putty, saturant, and CFRP fabric. Prior to applying the first layer the strengthening system, the concrete surfaces were cleaned by brushing and then washing them with water to get rid of any dust and loose particles that could weaken the adhesion between the concrete and the primer. The cleaned column specimens were left for a day to dry completely.

a) MBrace $P 3500$ primer application

MBrace P 3500 is a two-part epoxy-based material as shown in Figure 3-21. Part A is the epoxy while part B is the hardener. The mix ratio is 100:30 (part A to part B) by weight. Once the two parts were mixed together, the primer was applied to the column surfaces by using a paint brush. While applying the primer, it was ensured that it was spread evenly over the concrete. The specimens were left to cure at the 
ambient temperature for one day before applying the subsequent layer of the CFRP strengthening system.
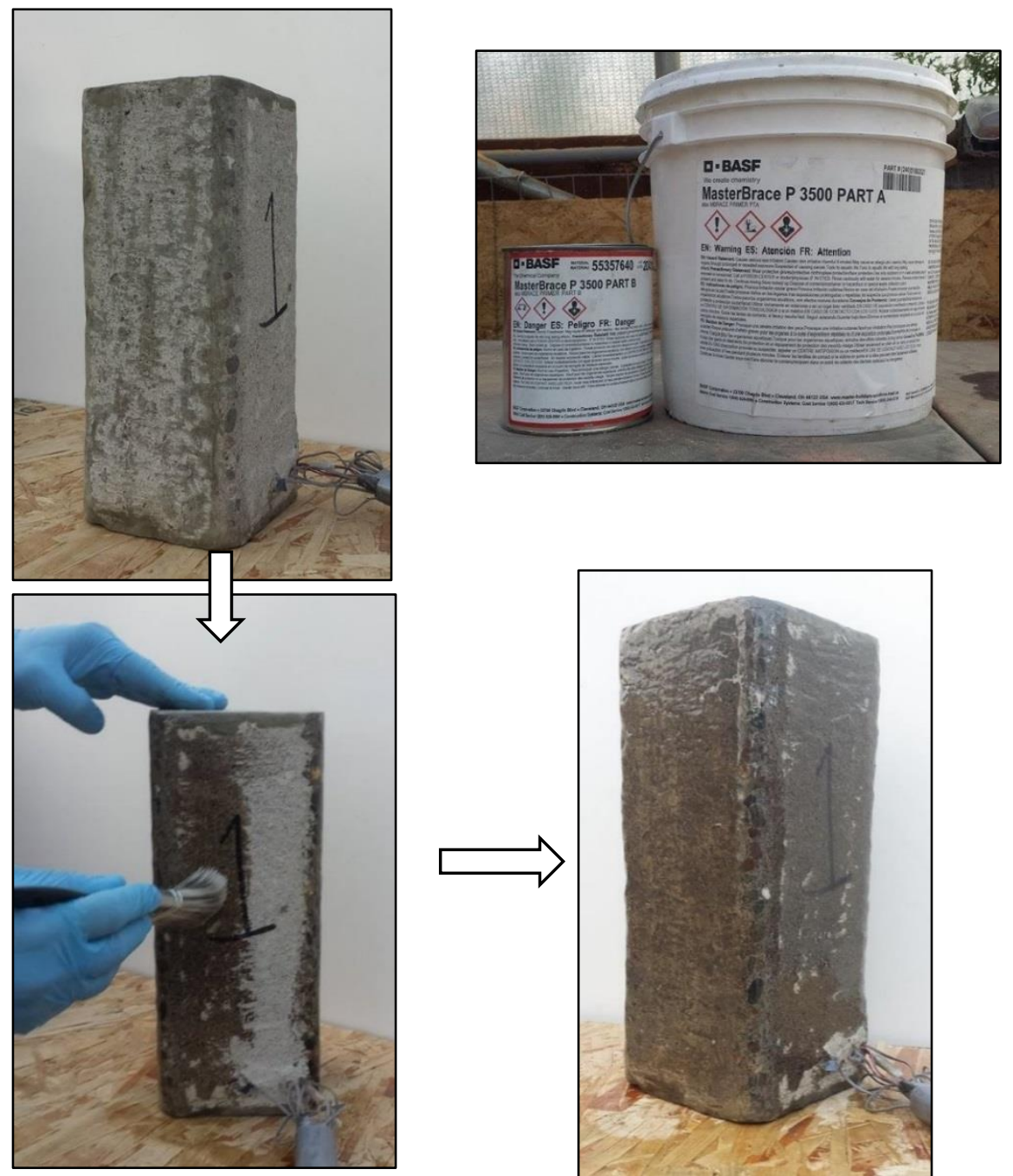

Figure 3-21: Primer coat application

b) MBrace F 2000 Putty application

MBrace F 2000 putty is also a two-part epoxy-based material. Part A is the resin while Part B works as a hardener. The mix ratio is 30:100 (Part A to Part B) by weight. After weighing the required amount of each part, Part A was mixed alone for about three minutes. Then Part B was added to Part A and mixed together using a low-speed drill with an appropriate mixing paddle for three minutes. The putty was 
applied to the primer substrate by using an appropriate trowel as shown in Figure 3-22. The application technique used here was the pressing and tightly pulling of the putty material on the surface to fill any tiny voids, to smoothing any small offsets or unevenness areas, and to ensure that there was not a thick layer of the putty on the specimens because it was not recommended by the manufacturer. The pressing and pulling technique was repeated until the surfaces were relatively smooth and level. The specimen was left for one day before applying the subsequent component of the CFRP system.
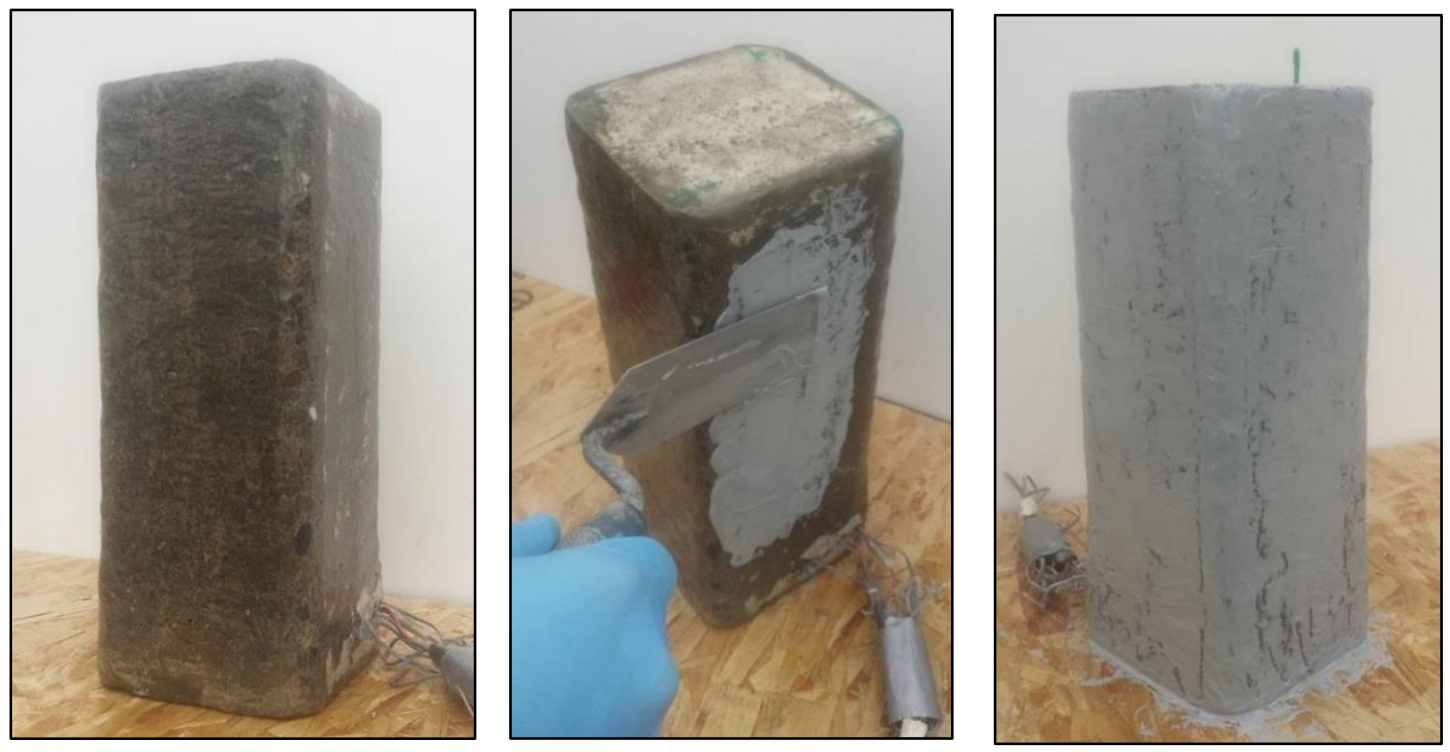

Figure 3-22: Putty coat application

c) Wrapping the CFRP fabrics

The CFRP fabric was installed following the wet lay-up procedure. The first step of this procedure was to cut the fabric to the required dimensions using a proper shear scissor as shown in Figure 3-23. The fabric was cut so that it would wrap the entire circumference 
of the specimens for the desired number of layers plus an additional overlap length of 5" at the end. For instance, for the specimen C4NDC-F1 (the column wrapped with one CFRP layer), the fabric was cut to a length of one perimeter plus a 5 " overlap. For the specimen C4NDC-F2, the fabric length was two perimeter length plus a 5" overlap at the end. A small rectangular opening was made in the fabric near the bottom end to let the existing strain gages' wires to pass through the CFRP jacket. In addition to that, a 1.25" wide CFRP strip was wrapped at both ends (top and bottom) of each column to avoid the premature failure that might happen at the ends during the test. This concept was applied to the other specimens.

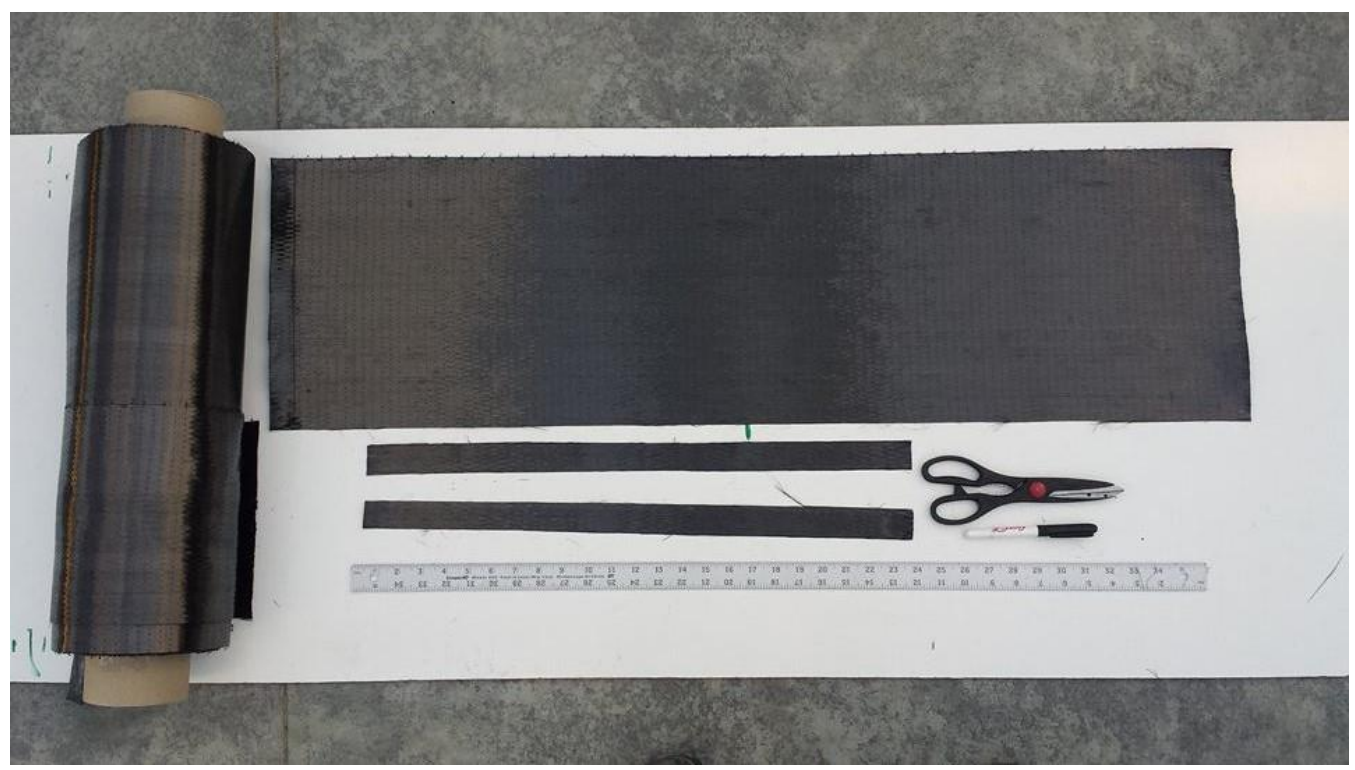

Figure 3-23: Cutting the CFRP Fabric

Before applying the epoxy, the column surfaces were cleaned by blowing out any residual dust using an air compressor. While blowing out the dust, the two-part epoxy (MBrace SAT 4500) was weighed. First, Part A was weighed and mixed alone for three minutes using an appropriate mixer. Then, Part B was weighed and added to Part A and 
mixed together for another three minutes. The mix ratio was 30:100 (Part A to Part B) by weight as stated at the product datasheet.

The first coat of the epoxy was applied to the column faces by using a short bristle brush. Immediately after that, the CFRP sheet was installed starting from the mid-width of one of the column faces as shown in Figure 3-24. The fabric was wrapped in the hoop direction of the specimen so that orientation of the fiber was perpendicular to the vertical axis of the column. Gentle hand pressure was applied to the CFRP sheet to initially squeeze some air pockets. Proper orientation of the fibers was inspected by the naked eyes and adjusted by hand as needed. By using a proper laminating roller, the fabric was firmly rolled in the direction of the fiber to squeeze any remaining air pockets. The rolling was continued until it was noted that there were visible signs of the epoxy bleeding out of the fabric. This was evidence that the fibers were impregnated (saturated) with the epoxy. A second coat of epoxy was applied to the fabric surfaces and pressed by the roller to ensure complete saturation. This second coat was the final coat for columns wrapped with one layer of the CFRP fabric. However, for columns wrapped with multiple layers of the fabric, it was the epoxy coat for the subsequent layer. The same aforementioned process was repeated on each layer of the jacket. After completing installing the CFRP jacket, the two CFRP strips were installed at the top and bottom ends of each column with same overlapping length. 

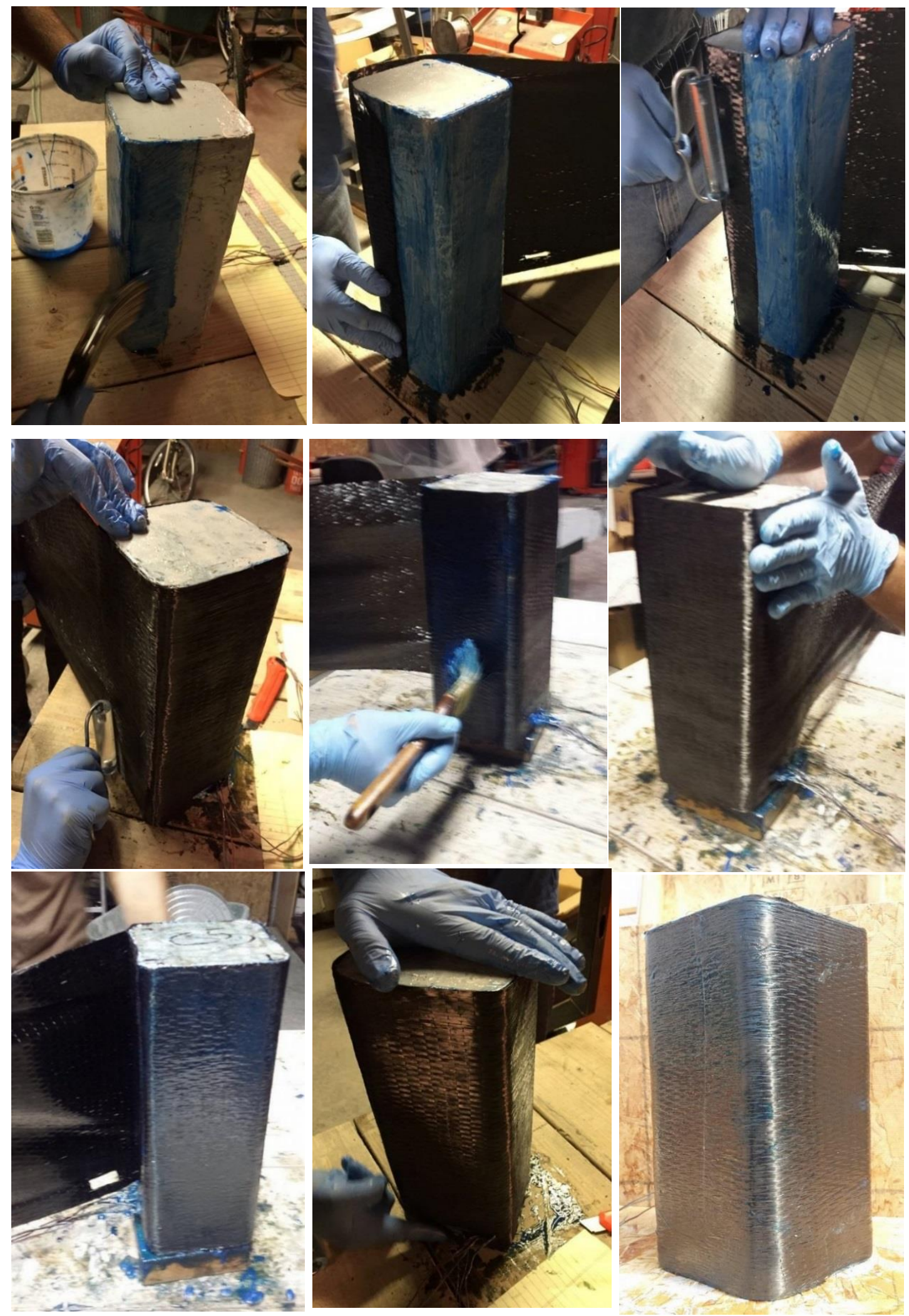

Figure 3-24: Construction of the CFRP jacket 


\subsubsection{Capping the Specimens' Ends}

In order to ensure that the two ends of each test specimen had smooth, parallel and uniform bearing surfaces, they were capped using a proper capping material. Having uniform parallel ends ensures that the applied load will be distributed evenly on the specimen ends, and that the possibility of having any eccentricity in the application of the load would be minimized. High-strength 9000 psi gypsum plaster was used as the capping material in this study. The capping process was performed according to the ASTM C617 / C617M guidelines. A 6" square glass plate was used as a capping plate. The thickness of that plate was 0.25 ”. A bull's-eye level was used to serve as an alignment device. First, the gypsum powder was weighed in a rubber bowl and then the water was added with a mixing ratio of $15.5 \%$ as recommended by the manufacturer. While mixing, the mixture was aggressively stirred using a plastic paddle. This step was important to ensure that the mix was homogenous which, in turn, affected the plaster strength. Since gypsum plaster sets very quickly, it was poured promptly on the concrete surface and pressed by the glass plate until the plaster covered all of the concrete surface evenly. The desired alignment was established by the bull's eye level that was mounted on the glass plate. The plate was left on the cap for twenty minutes until the plaster hardened. After that, the plate was gently removed, and the specimen was flipped upside down to repeat the same process on the cap on other end of the specimen. The average thickness of the cap was kept less than 0.25 " which is the maximum average cap thickness that the ASTM C617 recommends. The capping process is illustrated in Figure $3-25$. 

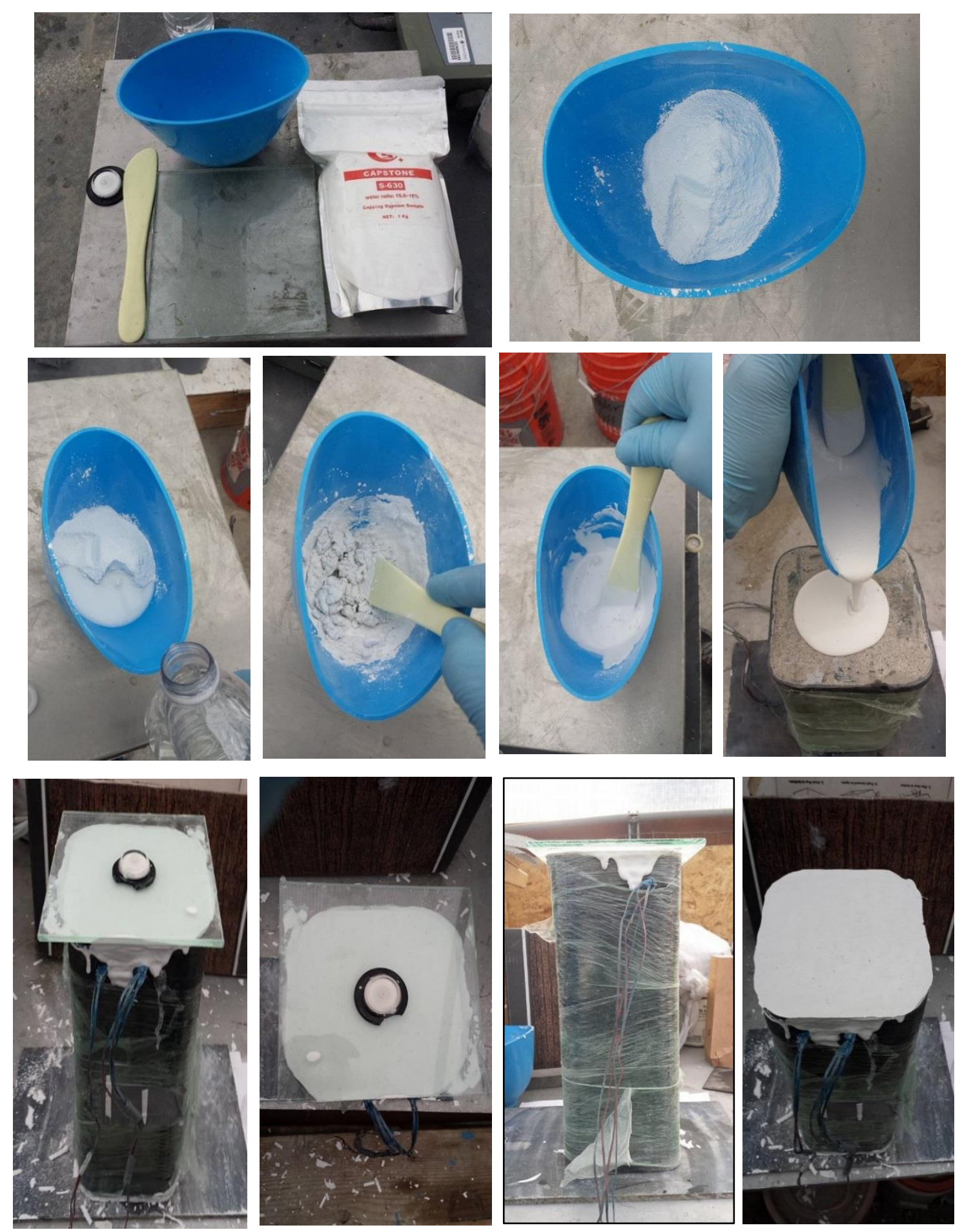

Figure 3-25: Capping process 


\subsubsection{Strain Gage Installation Procedure}

Phase I: Surface Preparation

Prior to installing the strain gages on the CFRP surface, the desired area where the gauge was to be installed, levelled, flattened, and smoothed. This was done by sanding the surface in the direction of the fibers using silicon carbide papers. The sanding process was done in multiple stages starting with using a rougher paper (grit 100) and ending with a smoother one (grit 220). This process was performed carefully in order to not harm the carbon fibers. After that, the sanded area was cleaned using isopropyl alcohol to ensure better bonding between the strain gage and the surface later.

\section{Phase II: Gage Mounting}

After the surface had been prepared and cleaned, the strain gage was ready to be mounted. First, a small piece of a normal Scotch ${ }^{\circledR}$ tape was cut out and placed upside down on a piece of cleaned cardboard. The size of that piece of tape was larger than the size of the strain gauge. Then, the strain gauge was taken out of its packet by handling it from its wires in order not to be contaminated by fingers. It was placed also upside down onto the tape. After that, some drops of a proper adhesive "Superglue ${ }^{\circledR ”}$ was placed on the gauge. Directly after this, the gauge was grabbed and mounted on the CFRP surface. Thumb pressure was applied over the gauge for thirty seconds in order to keep it flat, and to ensure proper bonding to the surface. Figure 3-26 demonstrate the strain gauge installation procedure. 

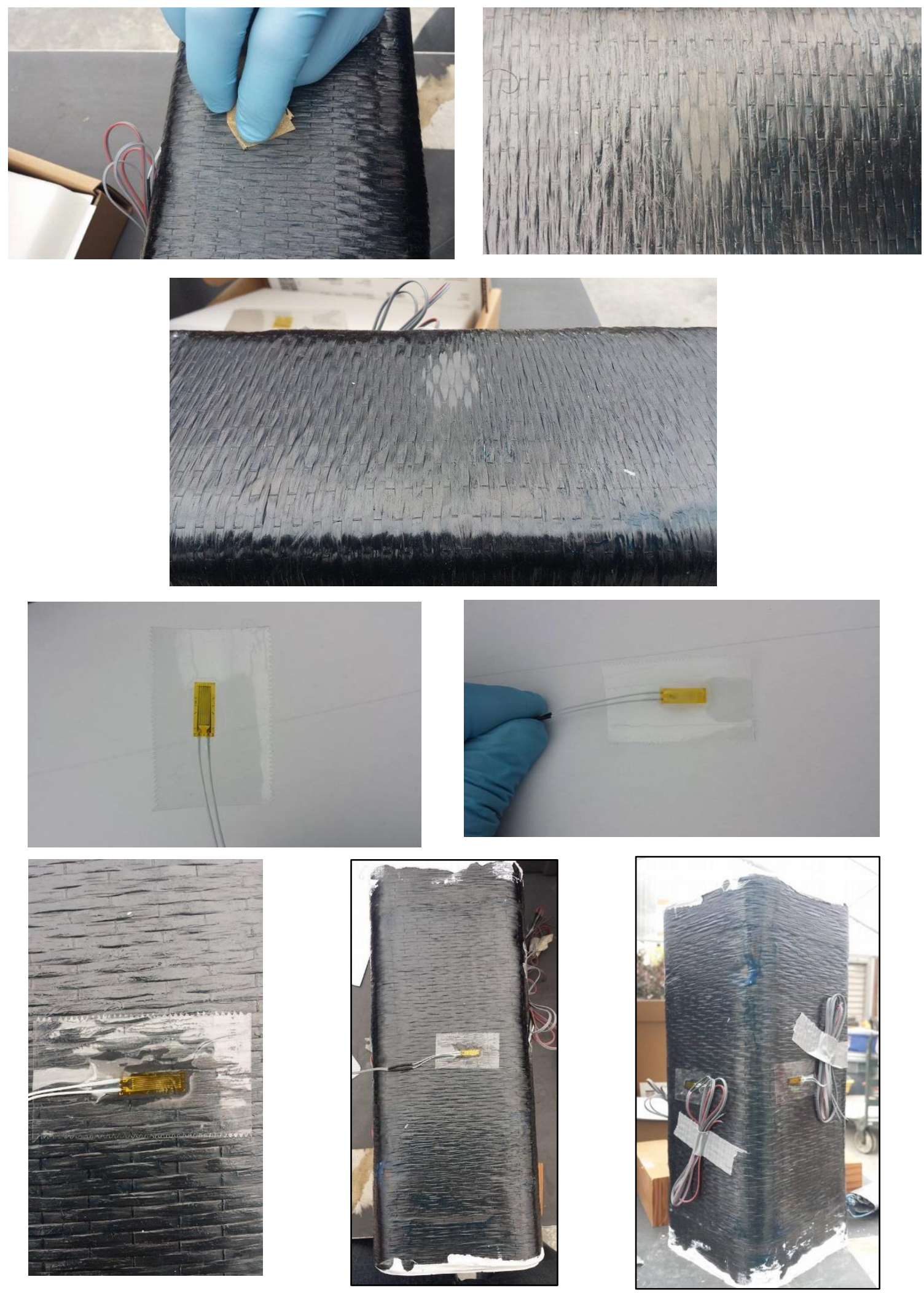

Figure 3-26: Strain gages installation 


\subsection{Instrumentation and Test Setup}

\subsubsection{Loading System}

All of the column specimens were tested using a hydraulic compression-loading machine shown in Figure 3-27 with a loading capacity of 250 kips. The load was applied manually using a hydraulic pump and measured using a pressure sensor that was connected to a data acquisition system.

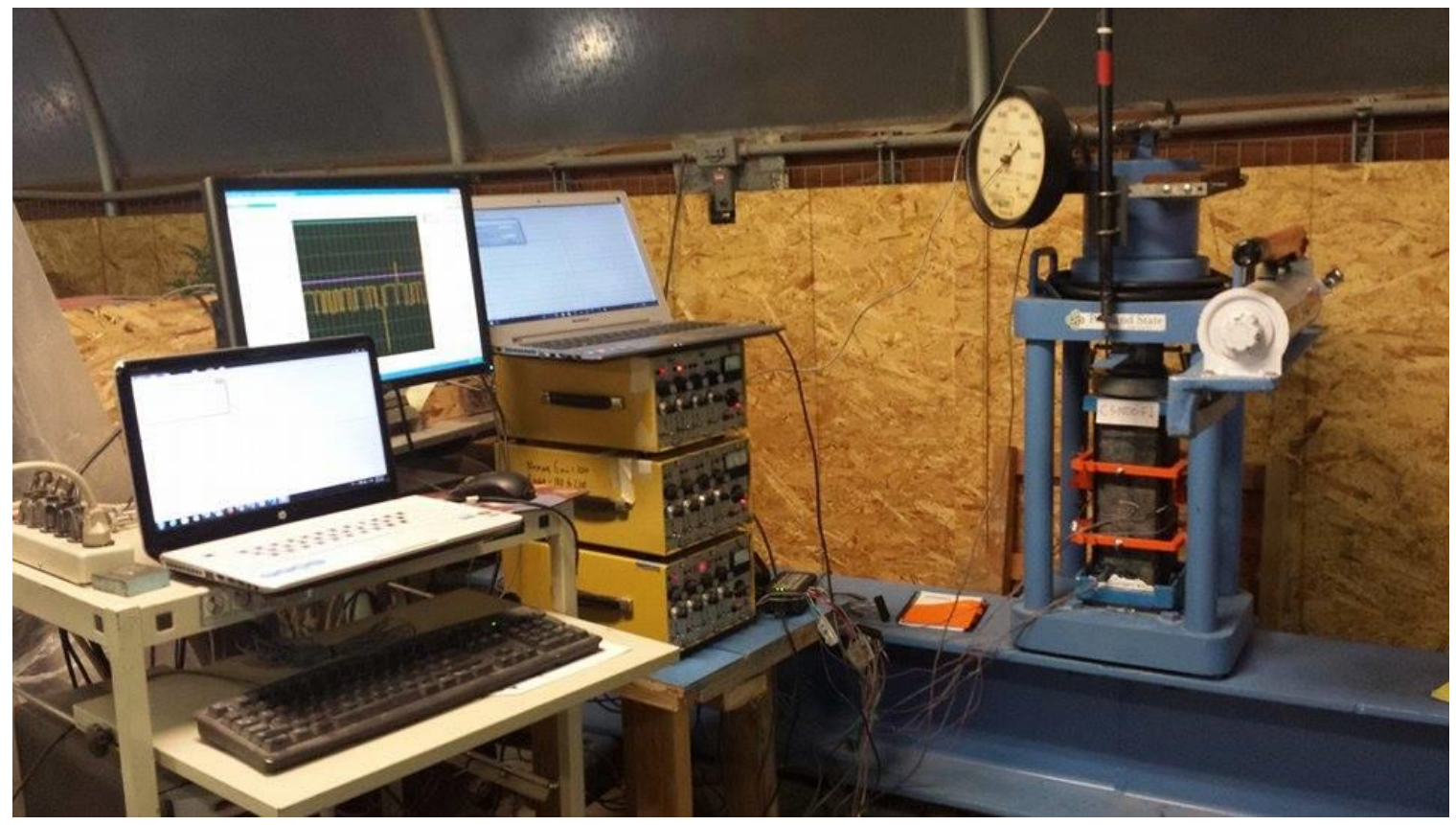

Figure 3-27: The loading system

\subsubsection{Instrumentation}

\subsubsection{Data Acquisition System}

The entire data acquisition system consisted of a set of computers, DATAQ USB data loggers, Signal Conditioning Amplifier boxes, and proper connection cords. This system collected both displacement and load data from the Leaner Variable Displacement Transducers (LVDT), strain gauges, and the load sensor in real time with a data logging 
step of $0.2 \mathrm{sec}$. The data logging software was able to run sixteen channels

simultaneously with no running time limits. Figure 3-28 shows the entire data acquisition system.

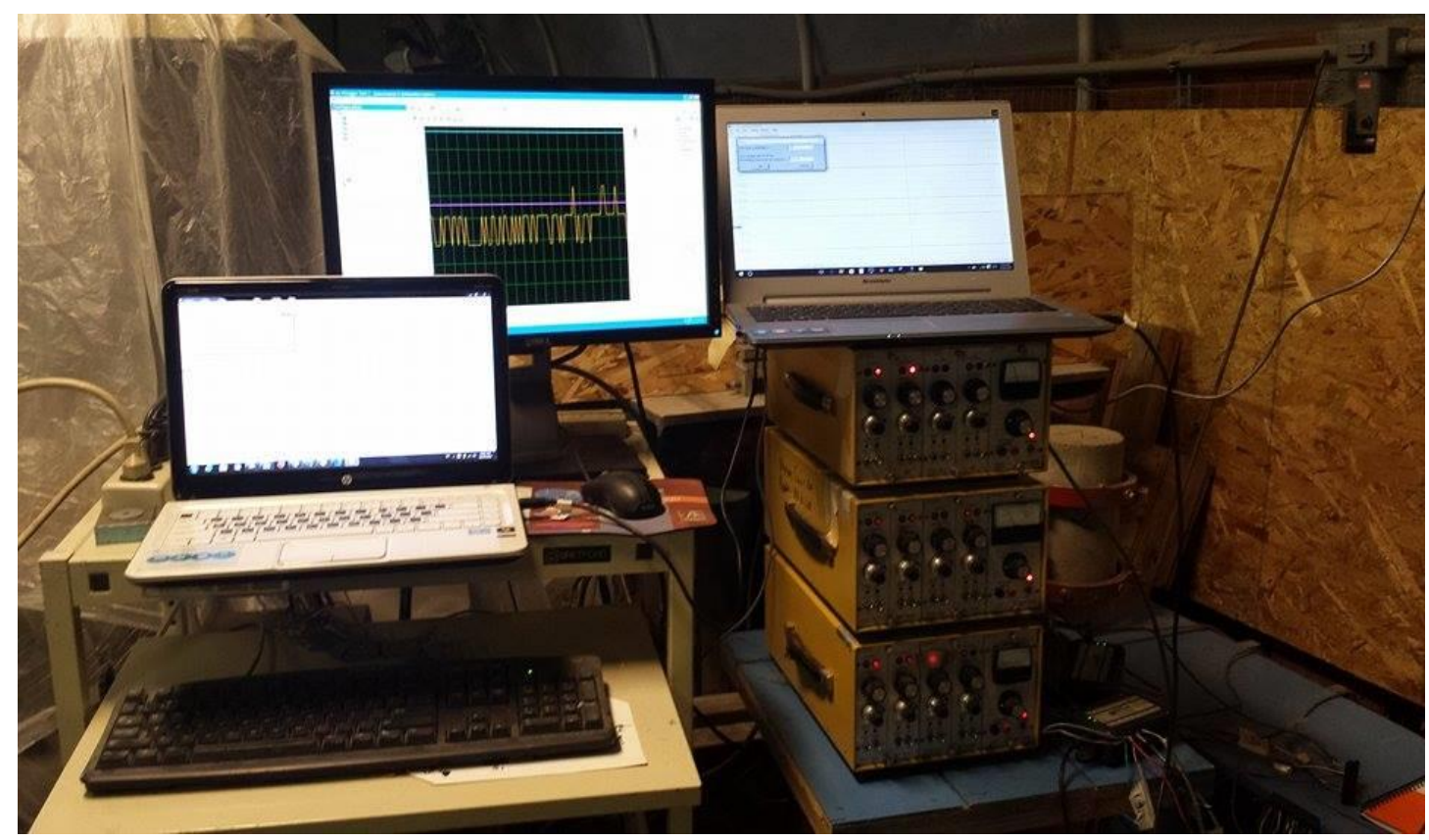

Figure 3-28: Data acquisition system

\subsubsection{LVDTs}

Two LVDTs were used to measure the longitudinal displacement at the mid-height region of each specimen. The two LVDTs were mounted on a specially designed steel frame with a gage length of $53 / 16$ ". The frame was fixed to the specimen at the mid-height area by a number of screws tightened to the surface of the concrete as shown in Figure 3-29. 


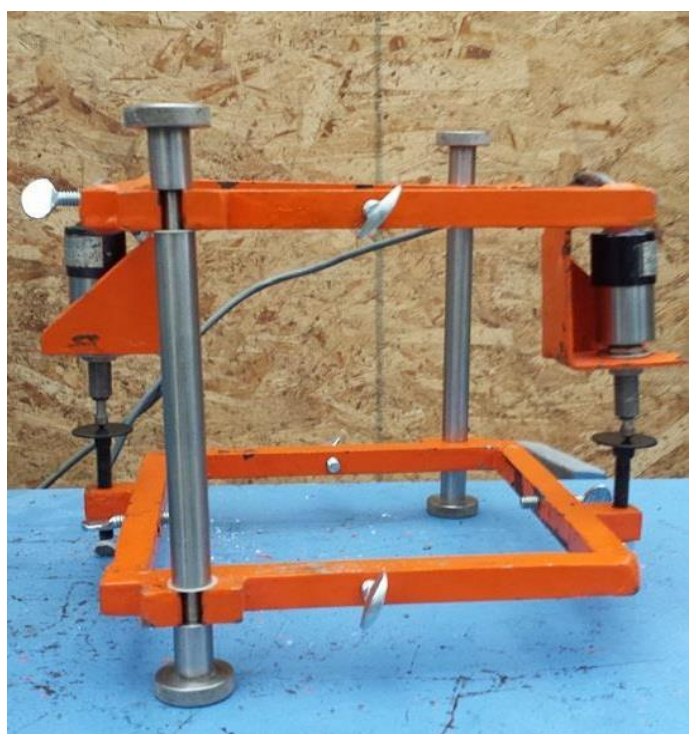

(a) Steel frame

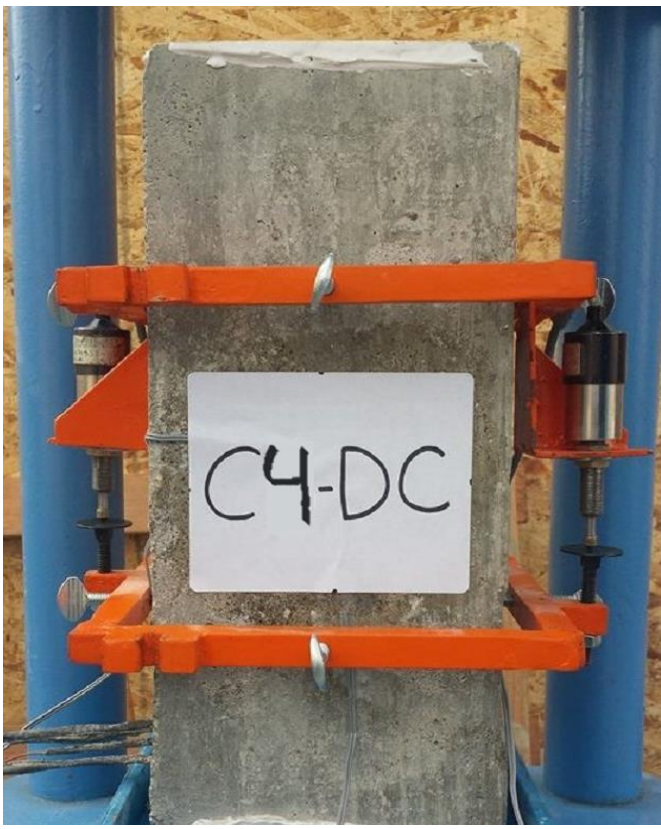

(b) The frame mounted on a specimen

Figure 3-29: The displacement measurement system

\subsubsection{Strain Gauges}

The types of strain gages used in this study were pre-wired electrical resistance strain gauges (Omega KFH series) with a length of $10 \mathrm{~mm}$. According to their function and location, two groups of strain gages were used. The first group consisted of four gages installed on each of the longitudinal reinforcing bars to measure their axial strain as illustrated previously in Section 3.5. The other group consisted of five strain gages mounted on the CFRP surface at the mid-height of each CFRP-wrapped specimen. These strain gages were oriented in the direction of the CFRP fibers perpendicular to the column axis to measure the composite hoop strain. Four of these five gages (S1, S2, S3, and S4) were placed outside the overlapping zone as close as possible to the four corners. 
In addition, one strain gage (So) was mounted on the overlapping zone. Figure 3-30 shows the location of the strain gages.

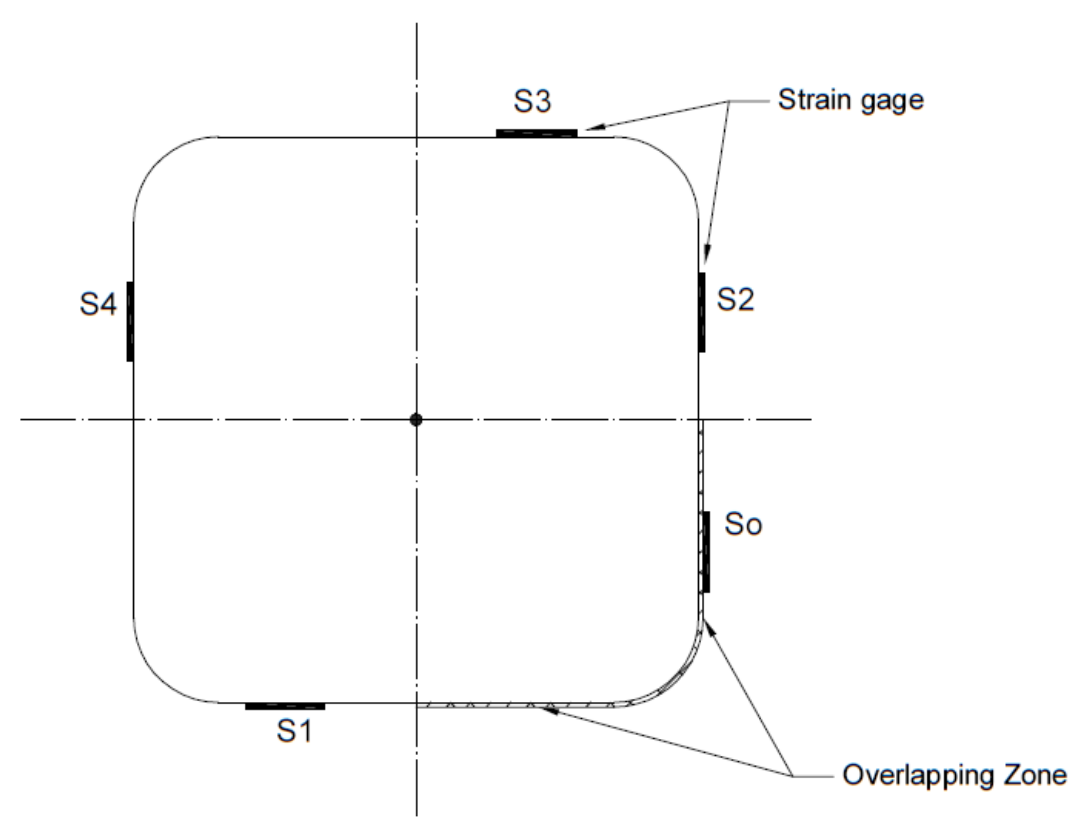

Figure 3-30: Location of the strain gages

\subsubsection{Test Setup and Loading Procedure}

After mounting and installing all of the required measuring instruments (LVDTs and strain gages), the specimen was ready for testing. The specimen was placed in the testing machine, and the measuring instruments were connected to the data logging system. A steel platen was placed underneath the specimen. Another platen was put on the top of the specimen in order to ensure that the applied load would be evenly distributed throughout the entire top face of the specimens. A number of shimming plates were added to fill any space between the top end of the specimen and the machine's loading head so that the machine's hydraulic ram would not run out of stroke during the test, when the specimen axially deforms. Since it was essential for loading to be concentric, prior to each test, 
careful calibration was made to ensure that the center of the loading head met the center of the column specimen in order to eliminate any accidental eccentricity.

All of the specimens in series $\mathrm{C} 4$ and $\mathrm{C} 2$ were tested under cyclic axial compression. The loading pattern that was used in this study was as follows:

First: The cyclic compression involved ten loading/unloading cycles at a prescribed load level. The load level that was selected was $70 \%$ of the designed axial capacity of the nonductile column, which was calculated by the following ACI equation:

$P_{n}=0.85{f^{\prime}}^{\prime}\left(A_{g}-A_{s t}\right)+F_{y} A_{s t} \quad$ Eq. 3-3

Where:

$P_{n}$ : Axial compression capacity

$f^{\prime}{ }_{c}$ : Concrete compressive strength

$F_{y}:$ Yield tensile strength of the longitudinal reinforcing bars

$A_{g}:$ Gross cross - sectional area

$A_{s t}$ : Total area of longitudinal reinforcement

For $C 2$ series: $P_{n}=76$ kips

For C4 series $P_{n}=96$ kips

The reason for choosing this load level was to emulate the impact of low-intensity earthquake $(\leq \mathrm{M} 5)$ on a building for several cycles.

Second: After finishing the first ten cycles, another ten loading/unloading compression cycles at another prescribed load level was performed. In this case, the load level that was selected was $90 \%$ of the designed axial capacity of the non-ductile column (i.e. $0.9 \mathrm{Pn}$ ). This load level emulates the impact of intermediate/high-intensity earthquake ( $\geq$ M5) on a building for several cycles as well. 
Third: At the end of the twentieth loading cycle, when the specimen was unloaded and the load was close to zero, the third stage of loading was initiated. In this stage, the load was monotonically increased to failure. For unwrapped specimens, the failure was determined by either excessive crushing of concrete, buckling of longitudinal bars, rupture the lateral hoops, or when a significant drop in the load was observed. For CFRP wrapped specimens, on the other hand, the test was terminated when excessive rupture of the CFRP jacket accompanied with a noticeable drop in the load was observed. 


\section{Chapter 4. Experimental Results and Discussion}

\section{Part 1. Experimental Results}

\subsection{Introduction}

This chapter presents observations from testing twelve reinforced concrete column specimens under cyclic compressive loading. As mentioned before in Chapter 3, the test specimens were classified into two main series ( $\mathrm{C} 2$ and $\mathrm{C} 4)$ in accordance to the concrete grade (2000 and 4000 psi, respectively). Each group had six specimens, two of them were unwrapped and the remaining four were wrapped with a different number of CFRP layers. However, the testing of C2NDC-F4 and C4NDC-F4 specimens were not completed due to acceding the loading capacity of the available testing machine. Therefore, they were excluded. Researchers have studied several variables that affect the behavior of the CFRP-wrapped RC columns, such as the concrete grade, specimen size, corner radius, CFRP material properties, the number of CFRP layers (i.e. jacket thickness). Two of these variables, the concrete grade, and the number of the CFRP layers were examined in this study. The effect of these two parameters on the stress-strain relationship, ultimate load, axial strain, and displacement corresponding to the ultimate load, ultimate strain, lateral (hoop) strain, confinement pressure, and the failure mode were investigated. The ultimate strain was defined as the strain at which the post peak load reached $50 \%$ of the peak load.

Graphical means were used to summarize the test results and to compare the performance of the test specimens in terms of the previously mentioned parameters. 


\subsection{Specimen C2NDC (Unwrapped Non-ductile RC Column)}

\subsubsection{General Behavior and Failure Mechanism}

It was planned that the loading scenario that was described previously in Chapter 3 was to be used in testing this specimen. However, the cyclic loading phase was not performed because the concrete cover had spalled, and the load had dropped to the half before completing the first cycle. This meant that the concrete cover had reached its axial capacity. A possible reason for this behavior was the fact that the concrete compressive strength is very low (2000 psi). This low compressive strength resulted in a very low concrete tensile strength $(\approx 10 \%$ of 2000 psi), which was not enough to resist the outward push of the longitudinal reinforcement. As a result, the concrete cover spalled earlier than expected. Consequently, the column was loaded monotonically until it achieved the peak loading level. To observe the post-peak behavior, the load was continually applied. The test was terminated when the longitudinal bars severely buckled and all the measuring instruments were no longer functional. Figure 4-1 shows the failure mode of specimen C2NDC.

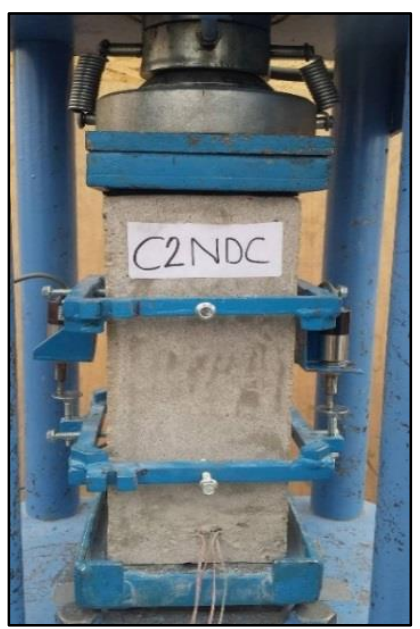

(a) Before Testing
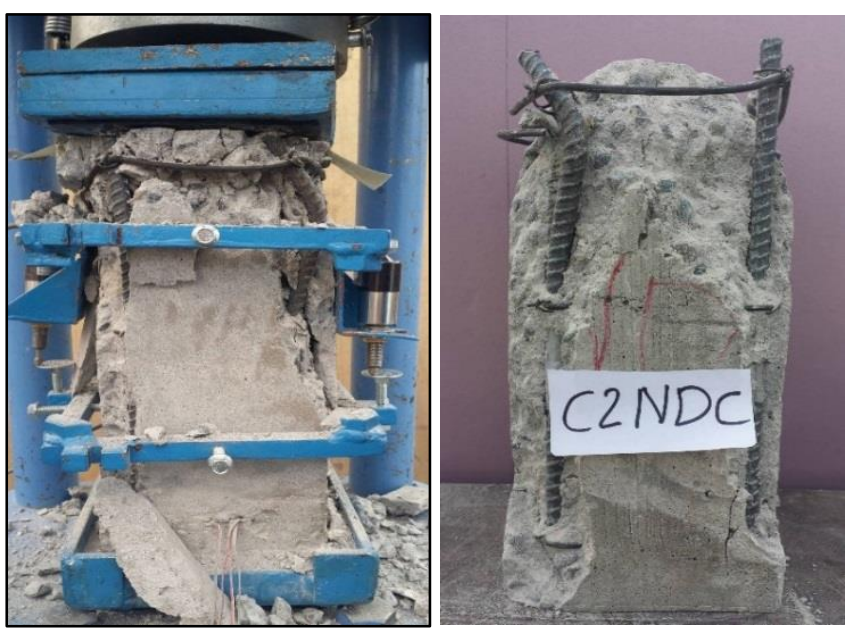

(b) At Failure

Figure 4-1: Failure mode of specimen C2NDC 


\subsubsection{Axial Load-Strain Relationship}

Figure 4-2 shows the obtained axial strain response for specimen C2NDC. It can be seen that the peak axial load was 52 kips and the corresponding axial strain was 0.001 (point A). This point coincided with the initiation of the concrete cover spalling process. The load had suddenly dropped about 50\% of the peak load (point B); however, the axial load was then recovered indicating that the load was mainly picked up by the undamaged concrete core. The axial strain response shows that the concrete core capacity was almost 51 kips and the corresponding axial strain was 0.005 (point $\mathrm{C}$ ). Beyond this point, the axial strain response showed a descending trend with an appreciated rate indicating that the column started to lose its capacity. It was believed that the post peak response was governed mainly by the buckling of longitudinal reinforcement.

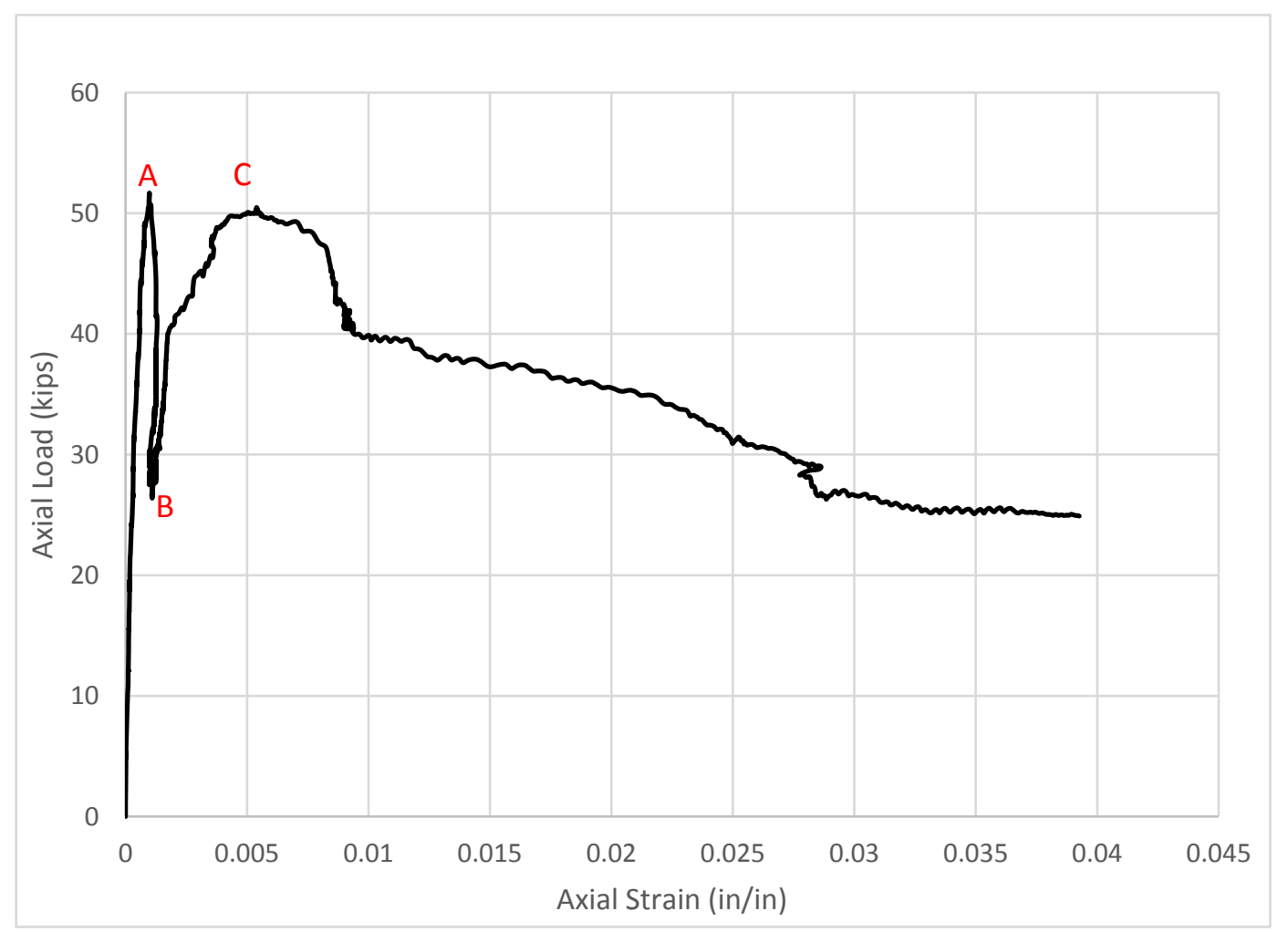

Figure 4-2: Axial load- Strain response of specimen C2NDC 


\subsubsection{Longitudinal Reinforcement}

The average axial compressive strain of the longitudinal reinforcing bars is depicted in Figure 4-3. By comparing the key points (A, B, and C) in Figure 4-2 with the points (A', B', and C') in Figure 4-3, it is noted that there was a good agreement in terms of the behavior of both the column and the steel reinforcement. To illustrate this in more depth, point $\mathrm{A}^{\prime}$ represents the average steel strain that corresponds to point $\mathrm{A}$ when the concrete cover started to spall off. Once the load dropped, the compressive steel strain started to decrease until reaching point B' when the concrete core started to pick up the axial load again. After that, the steel compressive strain increased until achieving the yield point of the reinforcing steel $(\approx 0.002)$ at point $C^{\prime}$ that coincides with point $\mathrm{C}$.

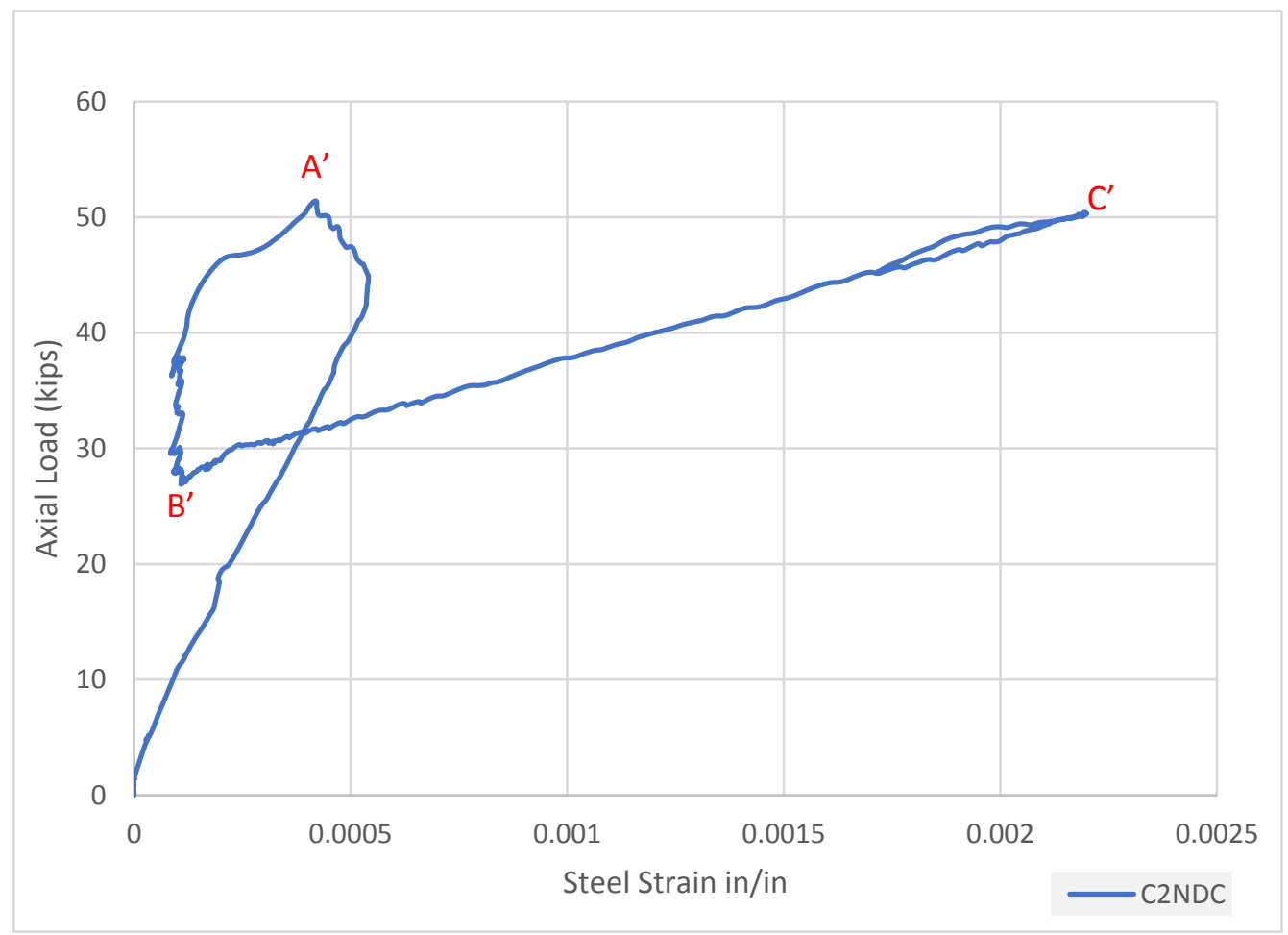

Figure 4-3: Reinforcing steel strain (C2NDC) 


\subsubsection{Concrete and Longitudinal Reinforcement Contribution}

The total axial load capacity of any unconfined reinforced concrete column is the sum of the contribution of both concrete and longitudinal reinforcement. To calculate the contribution of the steel reinforcement for a certain deformation, the average of the strain values that were obtained from the strain gages mounted on the longitudinal bars was transformed to an axial force using the following procedure:

$$
\begin{aligned}
& f_{s}=E_{s} \varepsilon_{s} \\
& P_{\text {steel }}=f_{s} A_{s t}
\end{aligned}
$$

Where:

$f_{s}$ : The steel stress corresponding to a certain value of strain.

$\varepsilon_{s}$ : The measured steel strain.

$E_{s}$ : The elastic modulus of the steel reinforcement.

$\mathrm{A}_{\mathrm{st}}$ : Total area of the longitudinal reinforcement.

$P_{\text {steel }}:$ Steel axial force (steel contribution).

Therefore, the concrete contribution $\left(P_{\text {conc }}\right)$ at a certain deformation was determined by subtracting the longitudinal reinforcement contribution from the measured applied load $\left(P_{t o t}\right)$ as follows:

$$
P_{\text {conc }}=P_{\text {tot }}-P_{\text {steel }}
$$

The concrete contribution was plotted against the overall column axial strain measured by the two LVDTs as shown in Figure 4-4. 


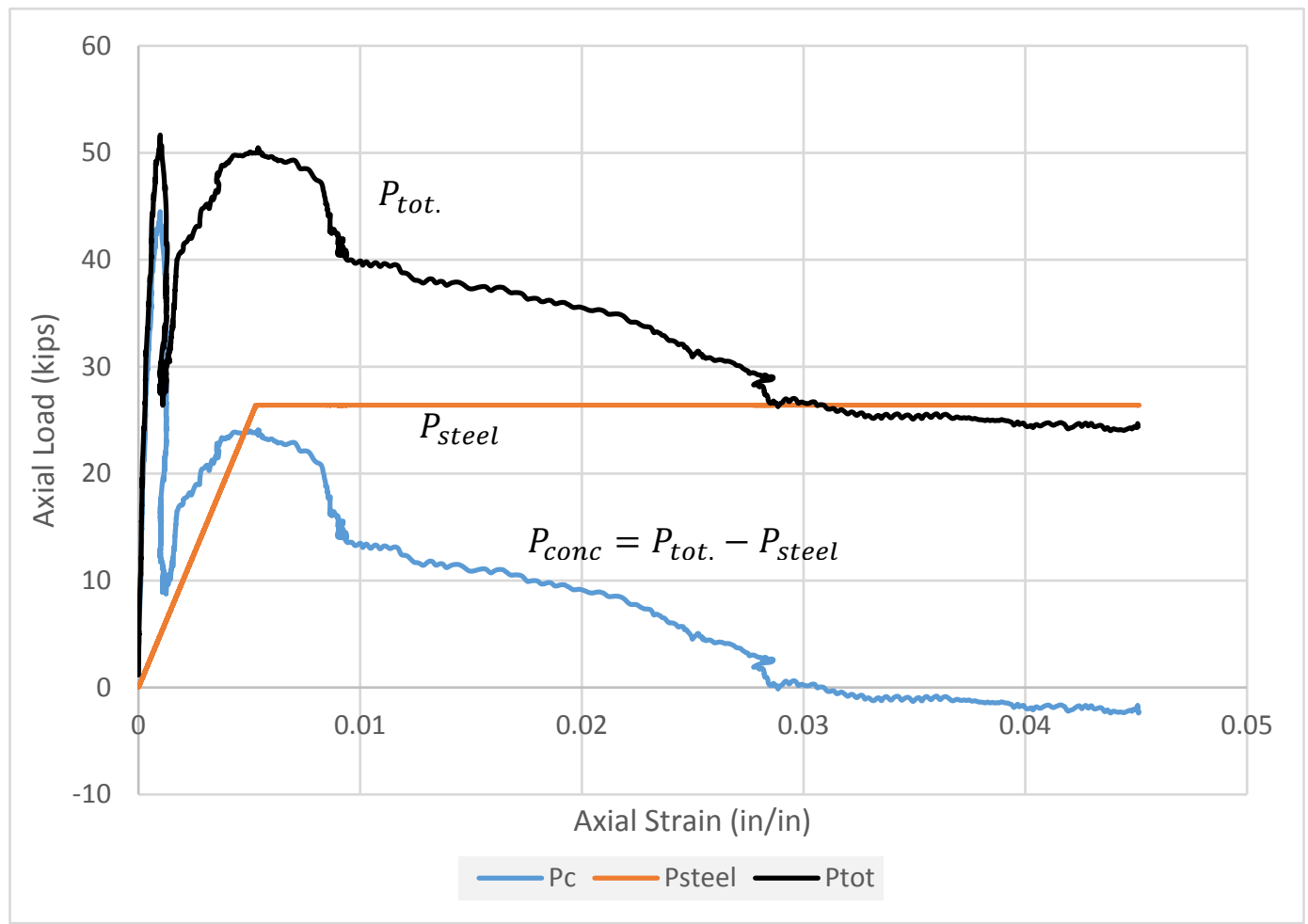

Figure 4-4: Concrete and Steel Reinforcement Contributions (C2NDC)

It is interesting to note that in the initial loading stages, the concrete was the main contributor to the total axial load since the steel strain in these initial stages was very small. In the initial loading stages, before the cover spalled, behaviors of the concrete cover and concrete core were similar, and had the same behavior as plain concrete with similar compressive strength obtained from the standard concrete cylinder test. After the concrete cover started to spall off at an axial strain around 0.002 , the column behavior was governed by the behavior of the concrete core while the concrete cover became ineffective. Consequently, the apparent concrete stress curve was calculated based on the concrete gross sectional area before reaching an axial strain of 0.002 , while the stress was calculated based on the concrete core area only for the rest of the curve. However, in reality, the loss of the concrete cover does not occur in an abrupt manner. The cover 
spalls off gradually (i.e. its contribution decreases gradually). Therefore, the transition from the concrete gross sectional area $\left(A_{c}\right)$ to the core sectional area $\left(A_{c c}\right)$ should be made in a practical way. Based on some observations during the test, a systematic methodology was used to make that transition. When the post-peak load reached about $70 \%$ of the peak load (i.e. $\mathrm{P}=80 \mathrm{kips}$ ), it was believed that the entire concrete cover became ineffective. Since it was hard to identify the rate of losing that concrete cover, the author proposed a linear transition from $A_{c}$ to $A_{c c}$.
$\sigma_{c}=\frac{P_{\text {conc }}}{A_{c}}$
$\left(\varepsilon_{c}<0.002\right)$
$\sigma_{c}=\frac{P_{c o n c}}{A_{c c}}$
$\left(\varepsilon_{c} \geq 0.002\right)$

Where:

$\sigma_{c}:$ Concrete apparent stress.

$A_{c}$ : Concrete gross sectional area.

$A_{c c}$ : The area of the concrete core.

In accordance with this methodology, the concrete's apparent stress response was determined from the $P_{\text {conc }}$ curve shown in Figure 4-4 and plotted in Figure 4-5. 


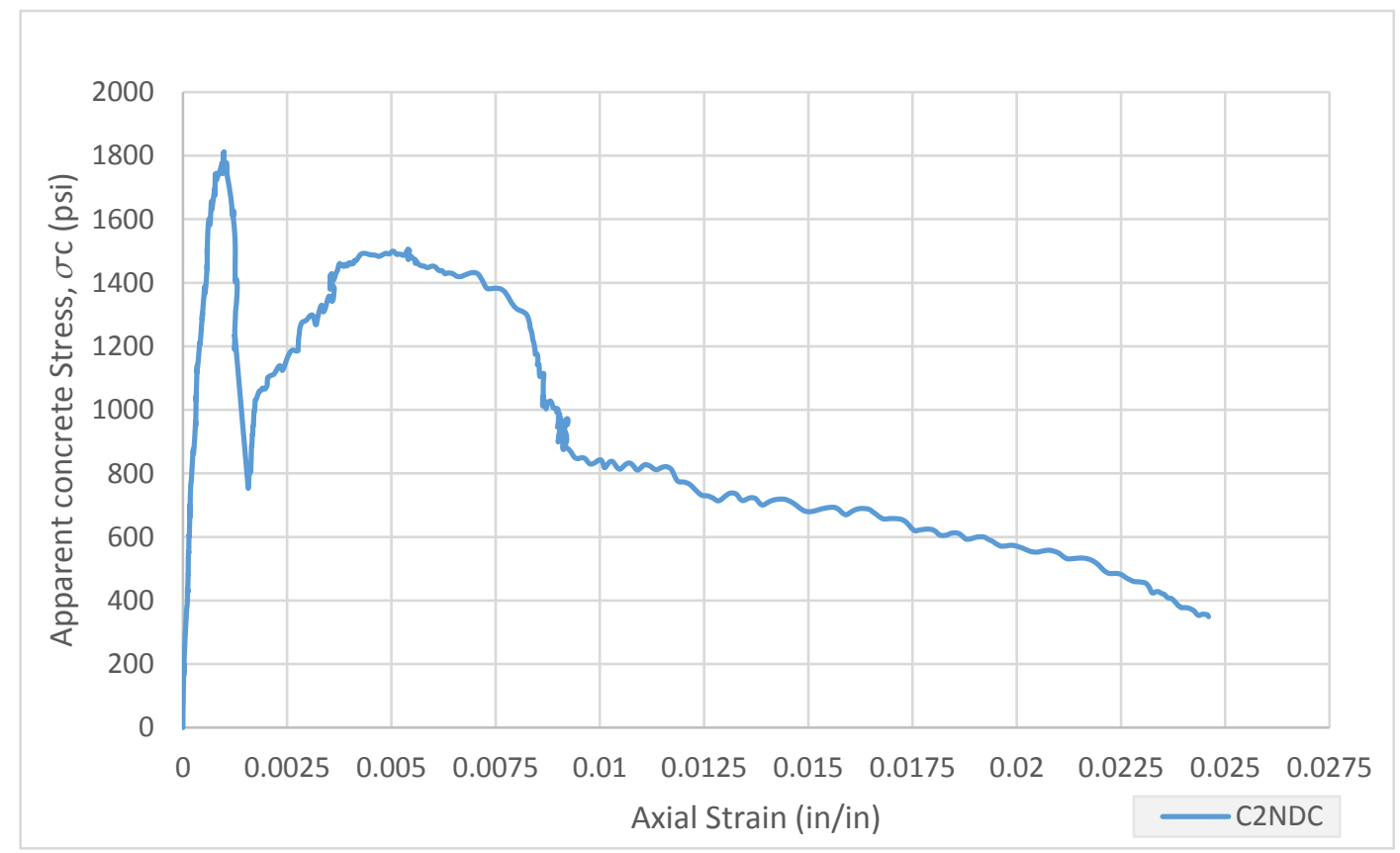

Figure 4-5: Concrete apparent strength (C2NDC)

\subsection{Specimen C2DC (Ductile RC Column)}

Two identical C2DC specimens were tested. Both specimens were designed and built according to the new ACI 318-14 design code with adequate confinement reinforcement. The first specimen was tested under a monotonic loading in order to examine the maximum loading capacity of this specimen configuration. This specimen achieved a maximum axial load $(\mathrm{Pn})$ of 77 kips with a corresponding axial strain of 0.004 . This load value was used to perform the cyclic loading phase on the second C2NDC specimen. In other words, ten loading cycles were performed with a maximum loading level of $70 \%$ Pn (i.e. $\mathrm{P}=54$ kips). Those cycles were followed by another ten cycles with a maximum loading level of $90 \%$ Pn (i.e. P = 69 kips). Then, it was monotonically loaded until failure. This loading sequence was also followed in the rest of the $\mathrm{C} 2$ series specimens. The second C2DC column specimen was prepared for testing. During the cyclic loading phase, no cracks, not even hairline cracks, were observed. During the second phase, the 
monotonic loading phase, longitudinal cracks started to develop, which initiated the concrete cover spalling phenomenon. The cracks extended and propagated as the load was increased as shown in Figure 4-6. It was noticed that the load did not drop when the concrete cover started to spall off. After achieving an axial load value of 86 kips and corresponding axial strain of 0.0045 , the load started to drop, but at a slow rate. However, the deformation was increasingly faster. This ductile behavior was because the confining action of the lateral reinforcement. Figure 4-6 shows the failure mode of specimen C2DC. It can be seen that that dominant failure mode was the severe buckling of the longitudinal bar, and crashing of the concrete core. 

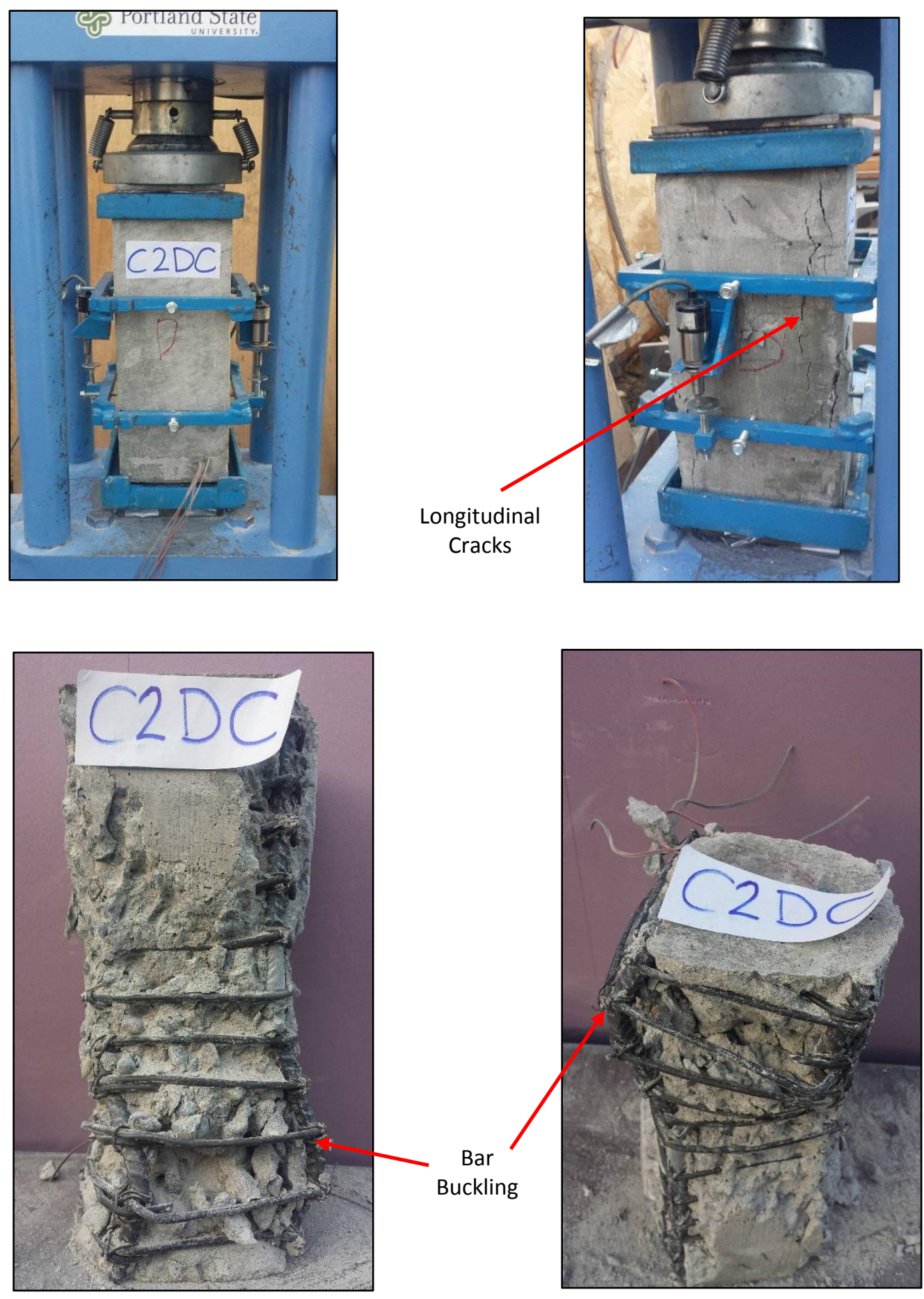

Figure 4-6: Failure mode of specimen C2DC 


\subsubsection{Axial Load-Strain Relationship}

Figure 4-7 shows the axial load versus the axial strain. By examining the post peak curve, it can be noted that this curve has a low slope indicating that the column experienced a great deal of axial strain with a slow degradation of the axial strength. The curve also shows that strain was increased while the load was almost constant. In other words, the column clearly demonstrated the post-peak ductile behavior, which was the main purpose of the seismically confining reinforcement.

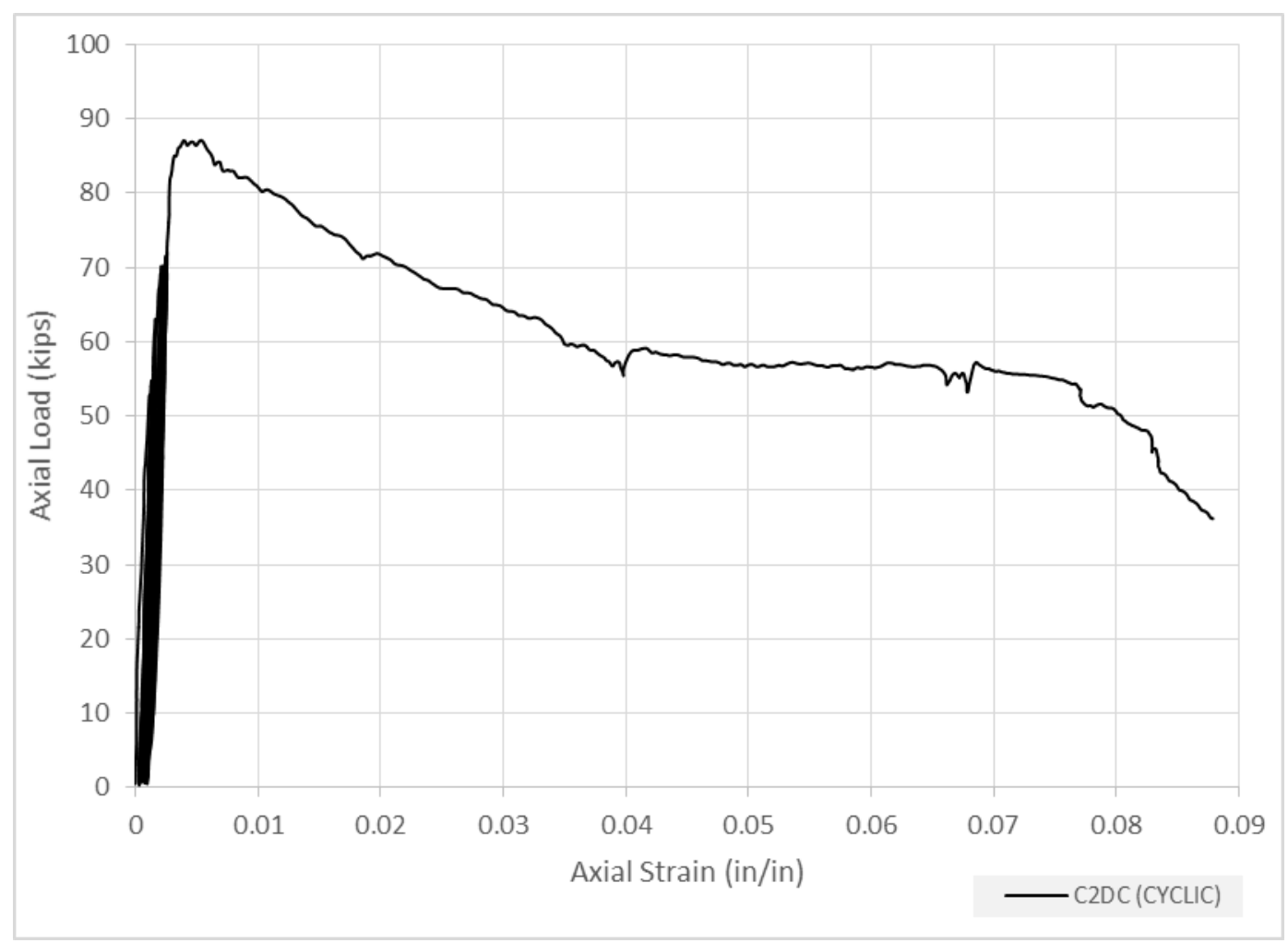

Figure 4-7: Axial load-Strain response of specimen C2DC

In order to have a better view of the cyclic loading phase of the axial strain response,

Figure 4-8 shows a close-up view of the cyclic loading phase. It can be seen that most of the loading cycles overlap and lay on each other indicating that there was no pronounced difference between a cycle and the subsequent one. 


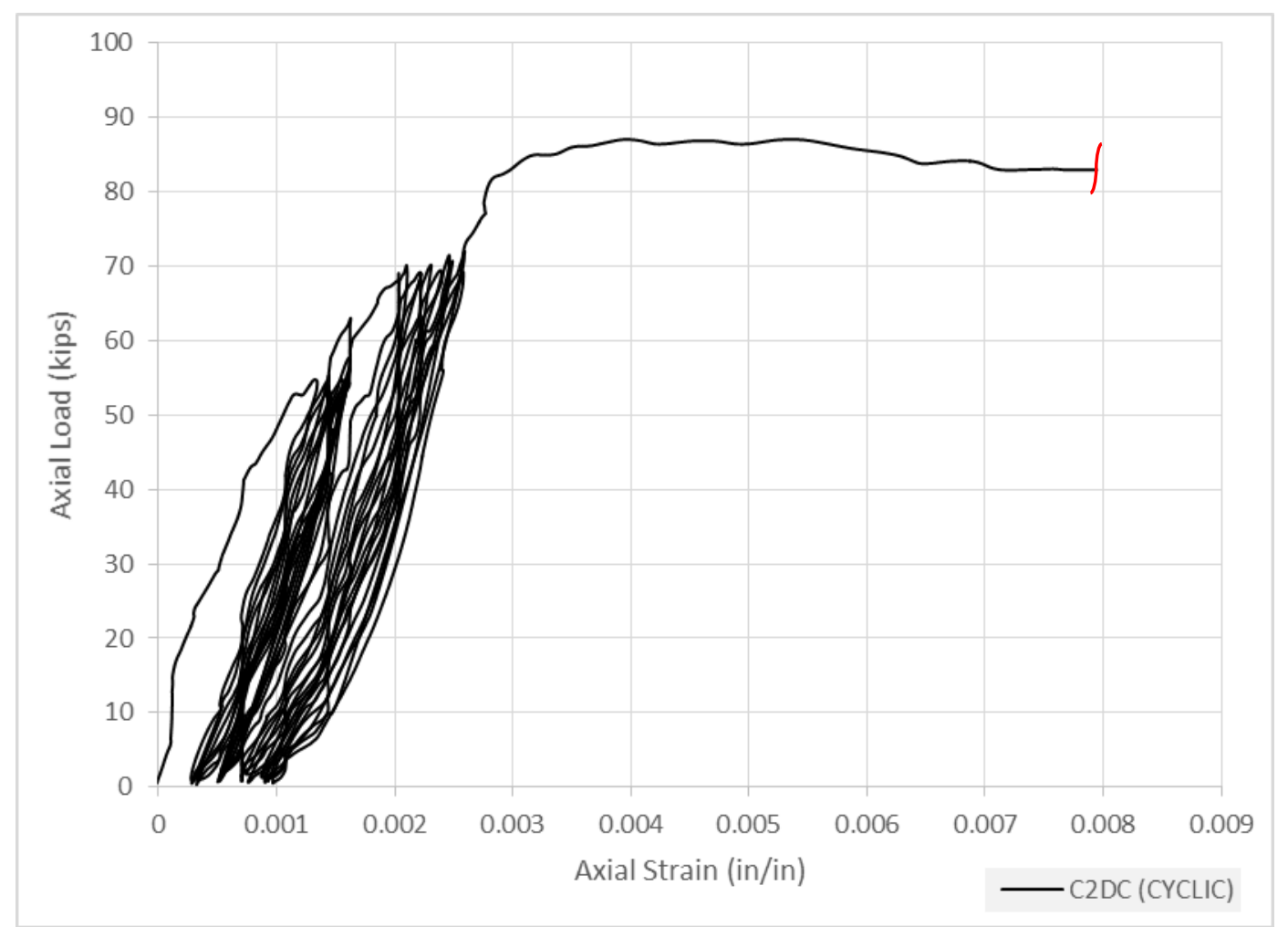

Figure 4-8: Close-up view for C2DC cyclic response

\subsubsection{Apparent Concrete Strength $\left(F_{c}\right)$}

The previously mentioned procedure to construct the apparent concrete stress curve is summarized in Figure 4-9 to Figure 4-11. It is worth noting that the total axial loading capacity of the column C2DC was mainly governed by the concrete core capacity. This might be explained by the fact that the concrete core was confined by closely spaced hoops. As a result, the unsupported length of the longitudinal reinforcing bars was very small, and resulted in a delay in the buckling of the longitudinal bars. Consequently, the column capacity increased. 


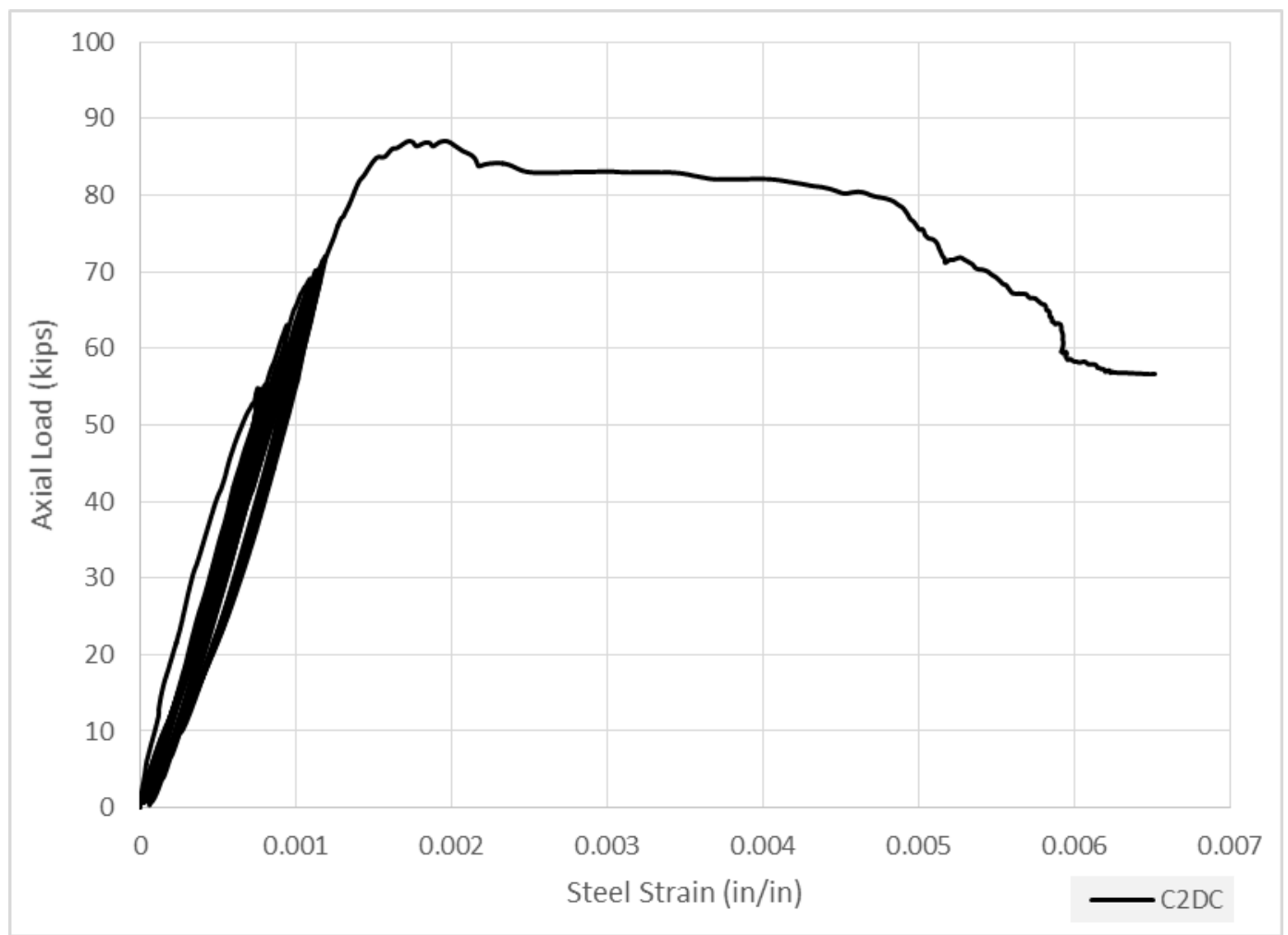

Figure 4-9: Reinforcing steel strain (C2DC)

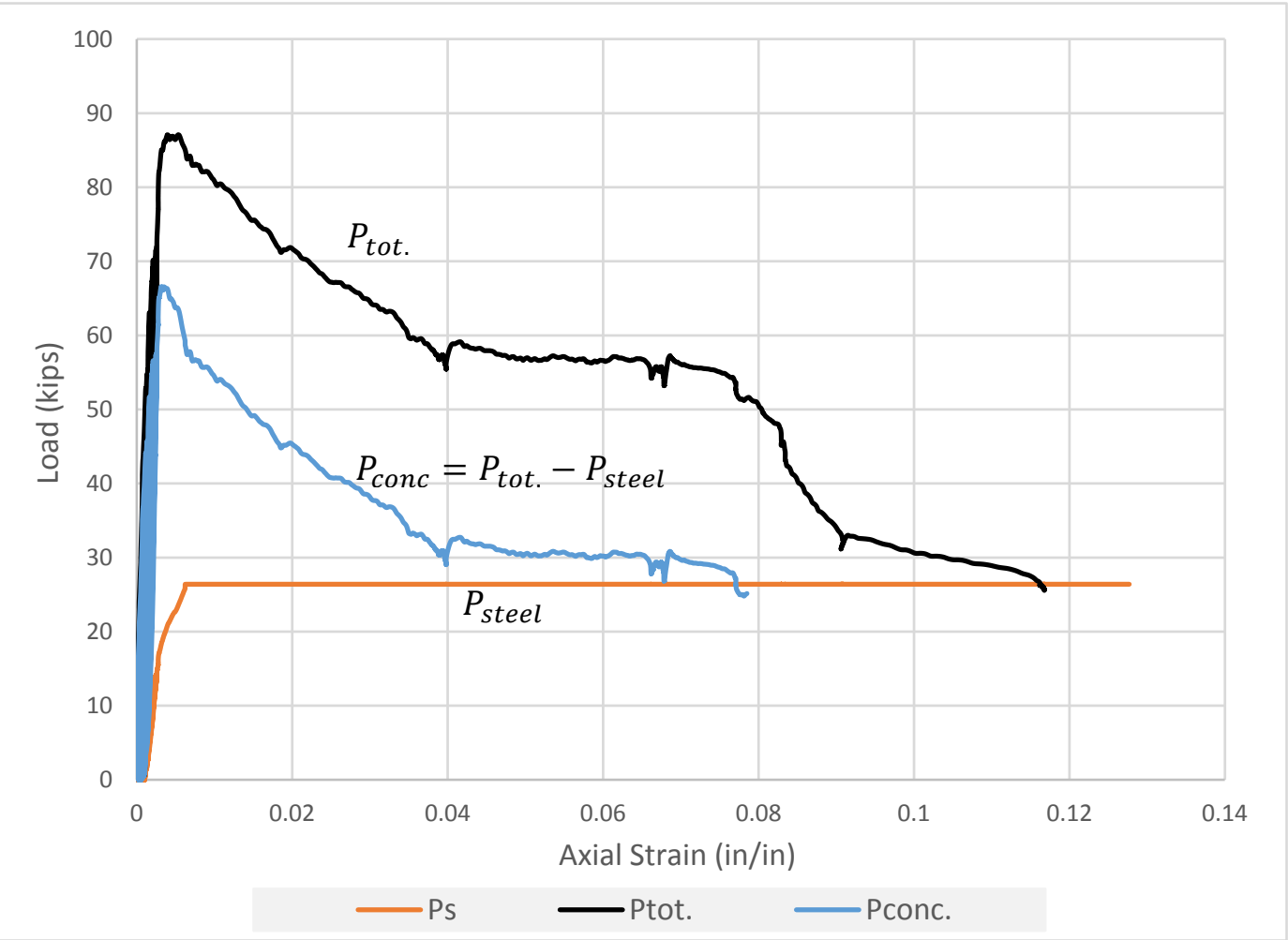

Figure 4-10: Concrete and Steel Reinforcement Contributions (C2DC) 


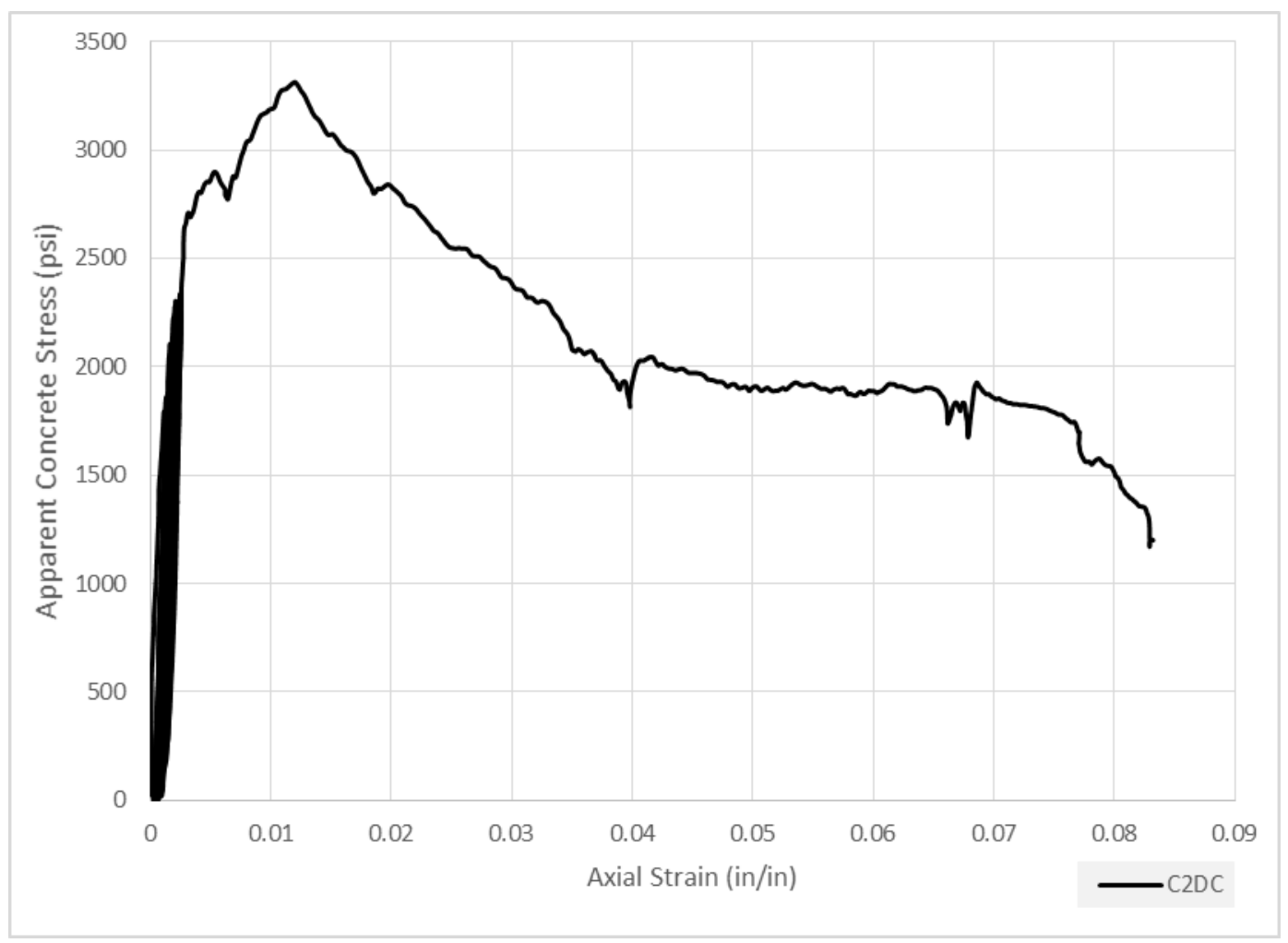

Figure 4-11: Concrete apparent strength (C2DC)

\subsection{Specimen C2NDC-F1 (Non-Ductile RC Column Wrapped with One CFRP}

\section{Layer)}

\subsubsection{General Behavior and Failure Mechanism}

The same loading sequence was followed with the C2NDC-F1 specimen. First, the specimen was subjected to ten loading cycles at a loading level of $70 \%$ of the expected axial loading capacity of the unwrapped column. Since this specimen was wrapped, it was impossible to know whether cracks developed in the concrete. By monitoring the LVDTs readings during those ten cycles, the residual axial deformation at the near-zero loading level was very small ranging between zero and 0.002 ". In addition, the readings of the strain gauges mounted on the CFRP jacket were almost zero. This meant that the concrete dilation was not enough to stress the CFRP jacket which, in turn, activated the 
confining action of the jacket. During the second ten loading cycles (up to $90 \%$ of the expected axial loading capacity), the column behaved almost similarly to its behavior during the first ten cycles with only one exception, which was that the residual axial deformation ranged between 0.002 " to 0.004 ". After that, the load was increased monotonically with a constant rate of $0.5 \mathrm{kip} / \mathrm{second}$. When the axial load approached a value around 85 kips, some noise was heard in the CFRP jacket. It was believed that this noise was due to cracking of the excessive epoxy on the CFRP surface. This noise was evidence that the CFRP confining action was activated. The other observation that supported this claim was the sudden increase in the measured hoop strain of the CFRP jacket that occurred simultaneously with that noise. While increasing the load, the axial and hoop strains increased and at the same time a louder noise was heard as well. Moreover, some small local buckling in the CFRP jacket was observed along the faces between the corners at the mid-height of the column. This phenomenon was also observed by Cole and Belarbi (2001). When the axial load reached a value of 142 kips, the CFRP jacket suddenly started to rupture at one of the corners at mid-height and the load dropped. The rupture mainly occurred at the lower half of the specimen Immediately, this CFRP jacket at this region de-bonded and extended horizontally around the circumference of the column. This rupture and the de-bonding process of the CFRP jacket was accompanied by continuous decrease of the measured axial load; however, the rate of the load dropping was slow. It was noticed that a thin layer of concrete was on the inside face of the de-bonded strips proving that a good bonding was achieved between the CFRP jacketing system and the concrete. To summarize, the C2NDC-F1 specimen failed by a sudden corner rupture of the CFRP jacket along lower half of the column as shown 
in Figure 4-12. The test was terminated when all of the instruments (LVDTs and strain gauges) ceased to function due to the extensive de-bonding of the CFRP jacket, and the crushing of the concrete at the rupture zone.

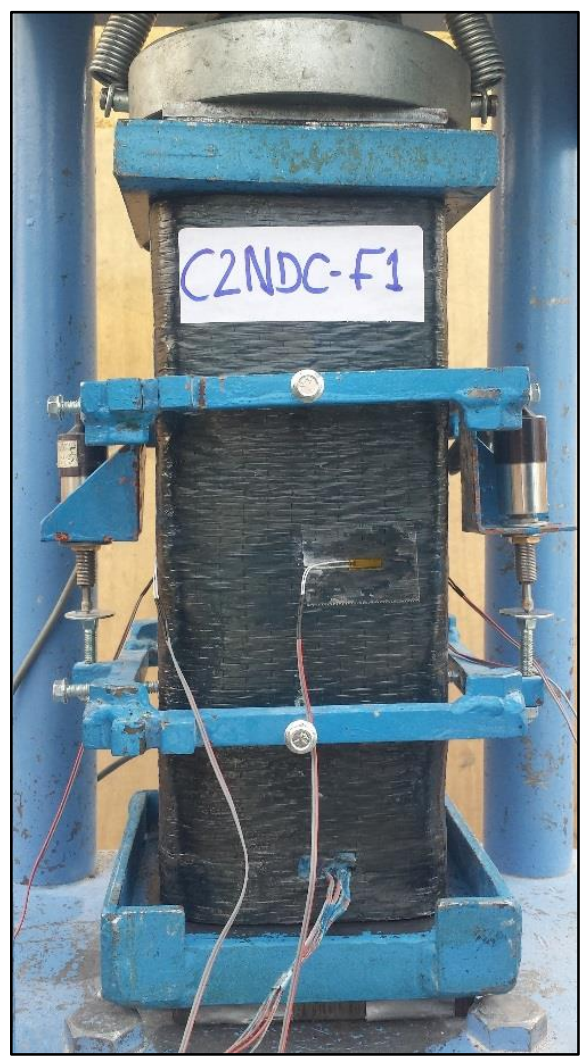

A) Before Testing

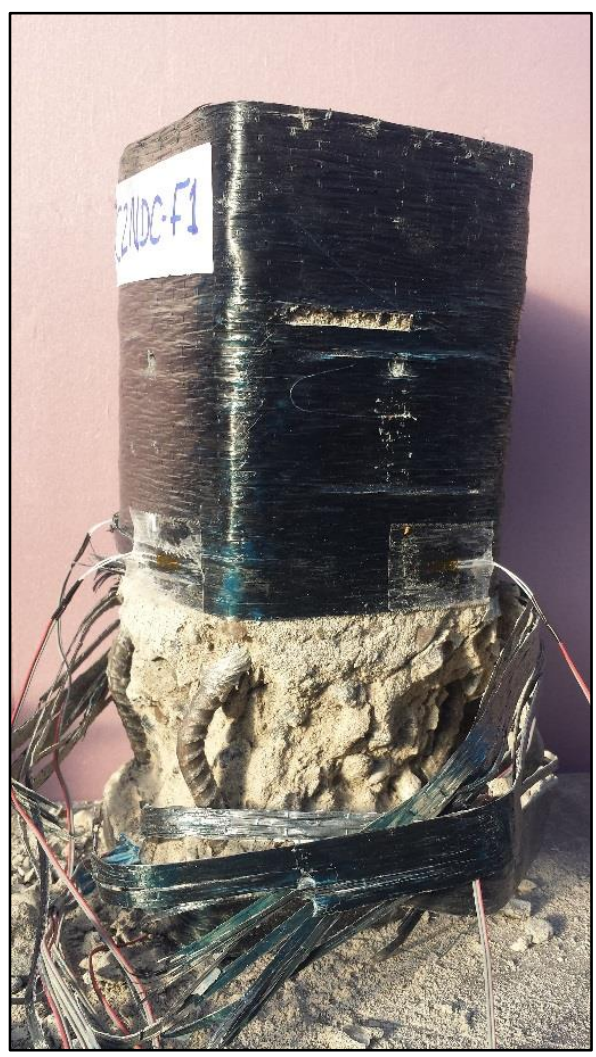

B) At Failure

Figure 4-12: Failure mode of specimen C2NDC-F1

Furthermore, after peeling off the remaining jacket and removing the inside crushed concrete at the rupture zone, it was found that the longitudinal bars experienced a local outward buckling as demonstrated in Figure 4-12. 


\subsubsection{Axial Load-Strain Relationship}

The experimental axial load-axial strain curve for column specimen C2NDC-F1 is reported in Figure 4-13. As formerly explained, the column axial compressive strain was calculated as the average readings of the two longitudinal LVDTs. It can be clearly noticed that the curve consists of four distinct regions. At the first region, the relationship is linear and ascending and ends at an axial load relatively higher than the peak load of the unconfined column (i.e. C2NDC specimen). The second region is a non-linear transitional region that connects the first region to the third region. This non-linear transition is generated due to the increasing lateral expansion of concrete. The third region is somewhat linear, but with a noticeably smaller slope as compared to that of the first region. The ascending trend of the curve in this region indicates the CFRP confining action was activated. Thus, both axial load capacity and the strain capacity were increased, but with higher rate. This region ended when the CFRP jacket significantly ruptured (i.e. the confinement action became practically ineffective). Therefore, beyond this point, the load has suddenly decreased because the load was sustained substantially by the CFRP confining action. The end of the curve is the point at which the test was terminated. As shown in Figure 4-16, the ultimate axial load at rupture is 142 kips. The maximum strain that corresponds to the peak load at rupture $(\varepsilon \mathrm{m})$ is 0.0380 . The ultimate strain $\left(\varepsilon_{\mathrm{cu}}\right)$ that was previously defined at the beginning of this chapter is 0.0464 , which is around 1.2 times the peak strain $\left(\varepsilon_{\mathrm{m}}\right)$. 


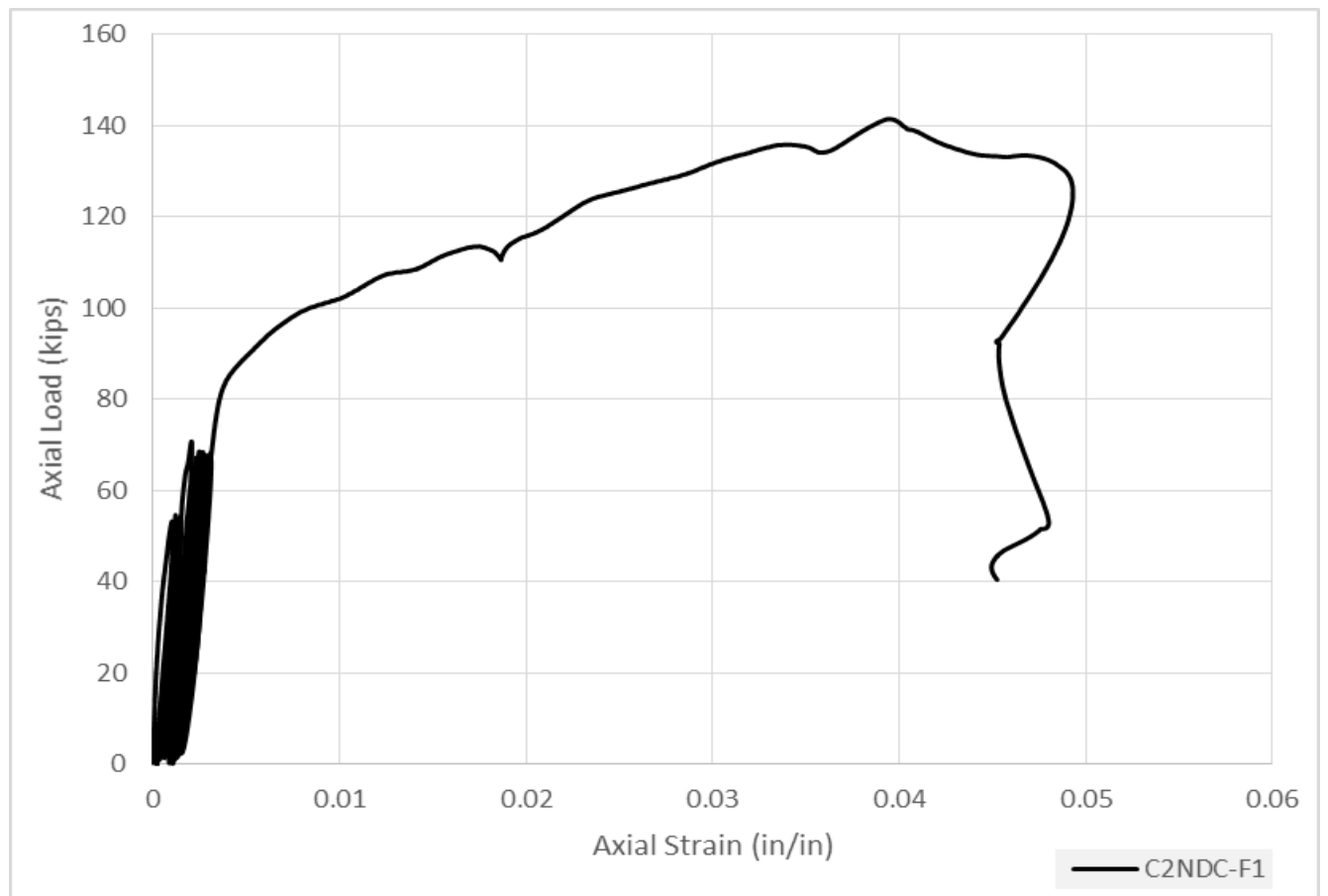

Figure 4-13: Axial load- Strain response of specimen C2NDC-F1

\subsubsection{CFRP Transverse Strain}

The CFRP transverse strain $(\varepsilon f)$ was measured by five strain gauges mounted in a transverse orientation on the surface of the CFRP jacket around the circumference of the column specimen. They were positioned as shown in Figure 3-26. Four of those strain gauges were mounted outside the overlapping zone near the corners. The fifth gauge was mounted inside the overlapping zone. The average of the strain values measured by the four gauges outside the overlapping zone was considered to be the overall CFRP transverse strain response in this section as depicted in Figure 4-14. It can be noted that this response is bilinear. It mainly constitutes two ascending branches, but with two different degrees of slope. It can be said that the initial branch represents the strain response before the activation of the CFRP confining action. The evidence of this claim is that this response branch ended when the concrete reached a concrete stress near its 
unconfined compressive strength (the strength corresponding to the peak load of the unconfined column specimen, C2NDC) with a measured transverse strain of less than 0.001. After the CFRP confinement was activated, the strain response continued to ascend at a faster rate as the axial load was increased. The end of this response was the point where the CFRP jacket was ruptured. The maximum average CFRP transverse strain at rupture $\left(\varepsilon_{f, \text { rup }}\right)$ is 0.0122 . However, the maximum transverse strain was measured by the strain gauge S2 (refer to Figure 3-26). The strain value was 0.0132 . It is worth noting that this strain gauge was the nearest gauge to the rupture region. In addition, the maximum CFRP transverse strain measured at the overlapping zone at rupture was 0.0055 , which was almost $40 \%$ of the average rupture strain. This phenomenon was expected since the thickness of the CFRP jacket at the overlapping zone was twice the thickness anywhere else. Table 4-1 presents the maximum CFRP transverse strain at first rupture (axial load = $142 \mathrm{kips}$ ) measured by each strain gauge.

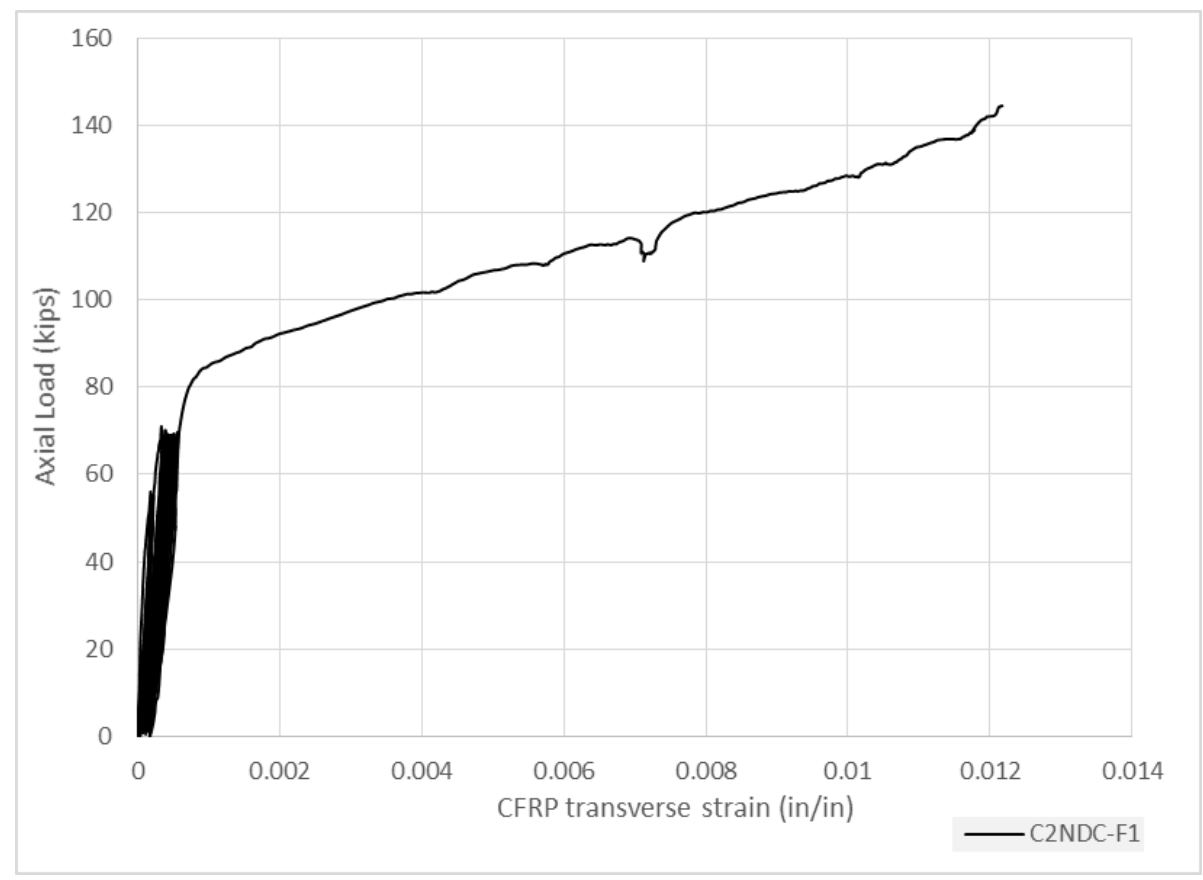

Figure 4-14: CFRP transverse strain response for C2NDC-F1 
Table 4-1: Maximum CFRP transverse strain of C2NDC-F1

\begin{tabular}{|c|c|}
\hline Strain Gauge ID. & Max. CFRP Transverse Strain, $\varepsilon_{f, \text { rup }}$ \\
\hline Outside overlapping zone & --- \\
\hline S1 & 0.0132 \\
\hline S2 & 0.0100 \\
\hline S3 & 0.0127 \\
\hline S4 & \\
\hline Inside overlapping zone & 0.0055 \\
\hline So & 0.0122 \\
\hline Avg. &
\end{tabular}

\subsection{Specimen C2NDC-F2 (Non-Ductile RC Column Wrapped with Two CFRP}

\section{Layers)}

\subsubsection{General Behavior and Failure Mechanism}

Again, the same loading sequence was followed. Similar to the specimen C2NDC-F1, during the twenty loading cycles, the axial strain measured by the two LVDTs was less than 0.001 . By monitoring the readings of the CFRP strain gauges, the CFRP transverse strain was almost zero. When the axial load reached a value close to 90 kips, suddenly, the measured CFRP transverse strain started increasing which indicated that CFRP confining action was activated. By increasing the applied axial load, the axial and transverse strain increased. While increasing the load, a cracking noise was heard several times. Similar to specimen C2NDC-F1, it was believed that this noise was due to the cracking of the excessive epoxy material in the CFRP jacket. When the load exceeded a value of $160 \mathrm{kips}$, some transverse cracks were observed on the surface of the CFRP jacket as shown in Figure 4-16. After few seconds, those cracks were developed into a small local buckling. This specimen failed with a sudden explosive tensile rupture of the CFRP jacket. The rupture occurred on the whole lower half of the specimen. It was believed that the rupture was initiated at a location near one of the column corners. Once 
the CFRP rupture occurred, the axial strength of column dropped significantly. The test was terminated when all of the measuring instruments were lost or ceased to function due to the severely extending rupture of the CFRP jacket and the extensive crushing of the concrete. After removing the ruptured part of the jacket at the failure region, it was noticed that the concrete core was severely crashed. In addition, two of the longitudinal bars were locally buckled as demonstrated in Figure 4-16.

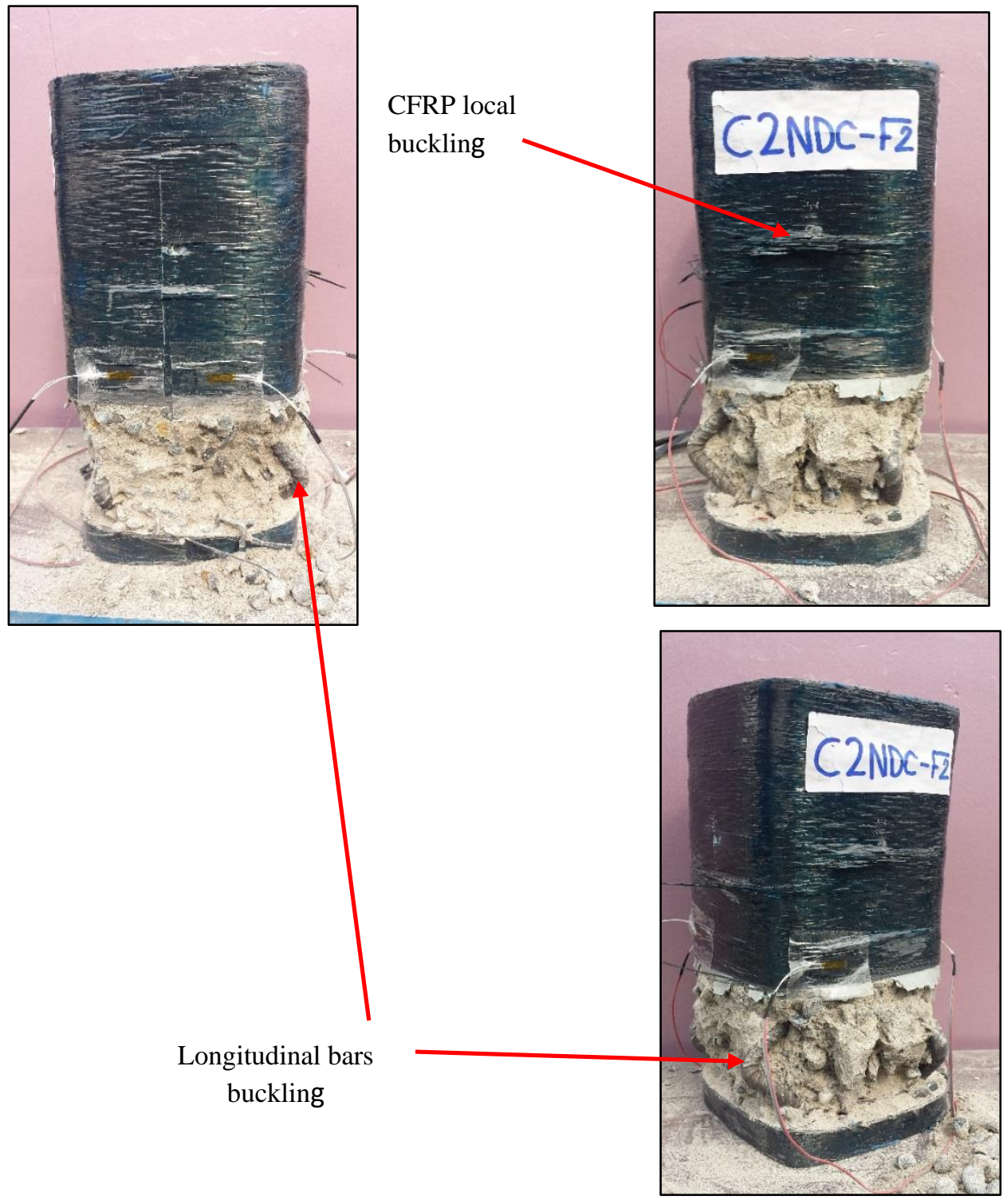

Figure 4-16: Failure mode of specimen C2NDC-F2 


\subsubsection{Axial Load-Strain Relationship}

Figure 4-17 shows the obtained axial load vs. axial strain curve for specimen C2NDC-F2. Similar to specimen C2NDC-F1, the curve consists of a linear ascending stage that is mainly governed by the stiffness of the unconfined concrete. After reaching a load value around the peak load of the unconfined column specimen, the curve shows a nonlinear transitional region indicating that the concrete expands laterally. This expansion results in an increase in the axial strain and reduction in the concrete stiffness. The third region of the curve is a linear response governed mainly by the stiffness of the CFRP jacket. The linear ascending trend of this response is evidence that the CFRP confining action is activated on the concrete core as a result of the excessive expansion of the concrete. In other words, the axial strain continues to increase while increasing the axial load due to the CFRP confinement. The curve shows a sudden drop in the load indicating the first rupture of the CFRP jacket. This means that the confinement action is lost beyond this point; therefore, the column started to show a degradation of its axial capacity. The peak axial load at rupture is $208 \mathrm{kips}$ and the corresponding axial strain is 0.058 . By magnifying the cyclic portion of the axial strain response as shown in Figure 4-18, it can be seen that the loading cycles lay on each other similarly to that of specimen C4NDCF1; however, it shows higher slope indicating that the column is stiffer in this case. 


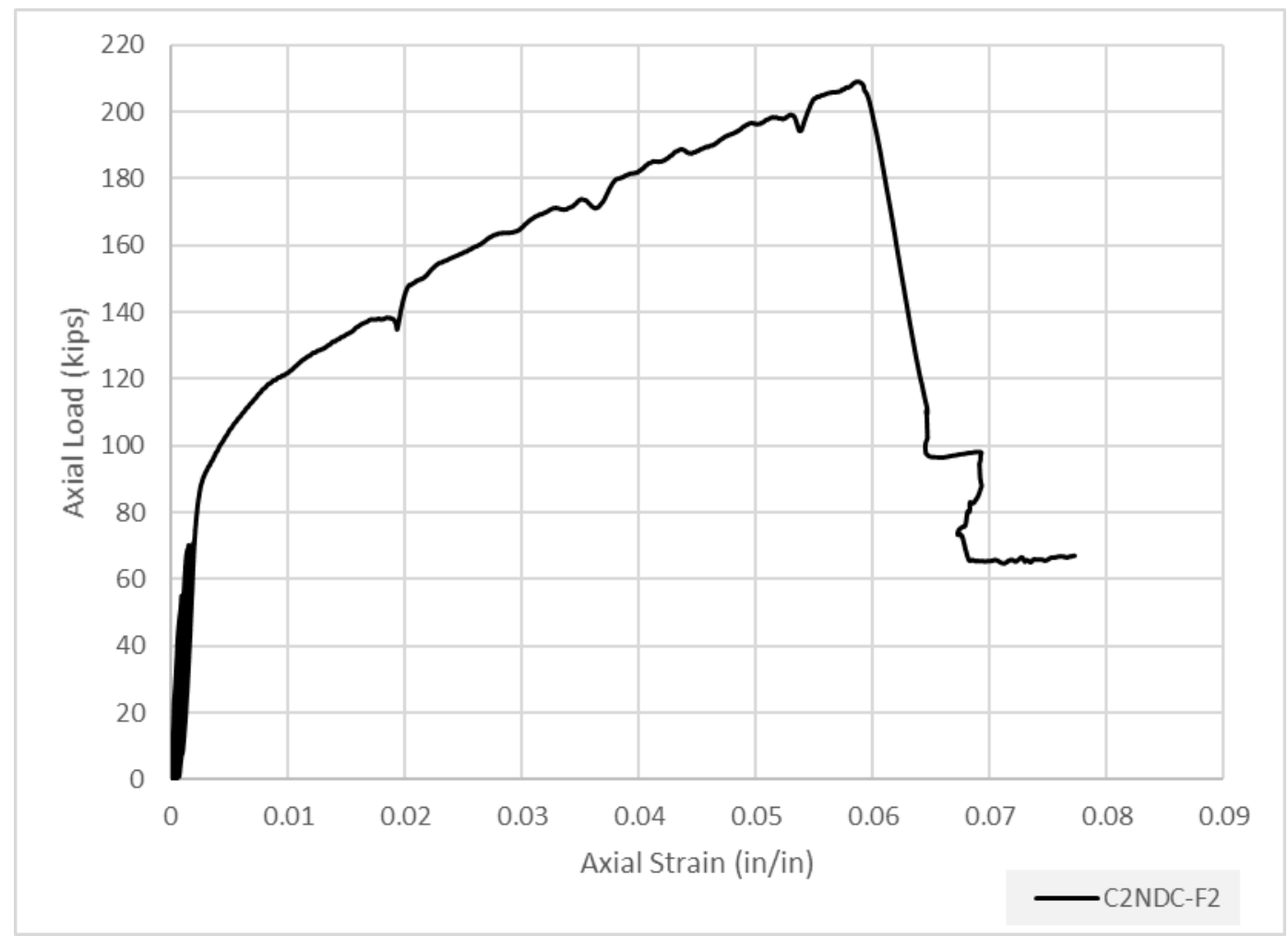

Figure 4-17: Axial load-Strain response of specimen C4NDC-F2

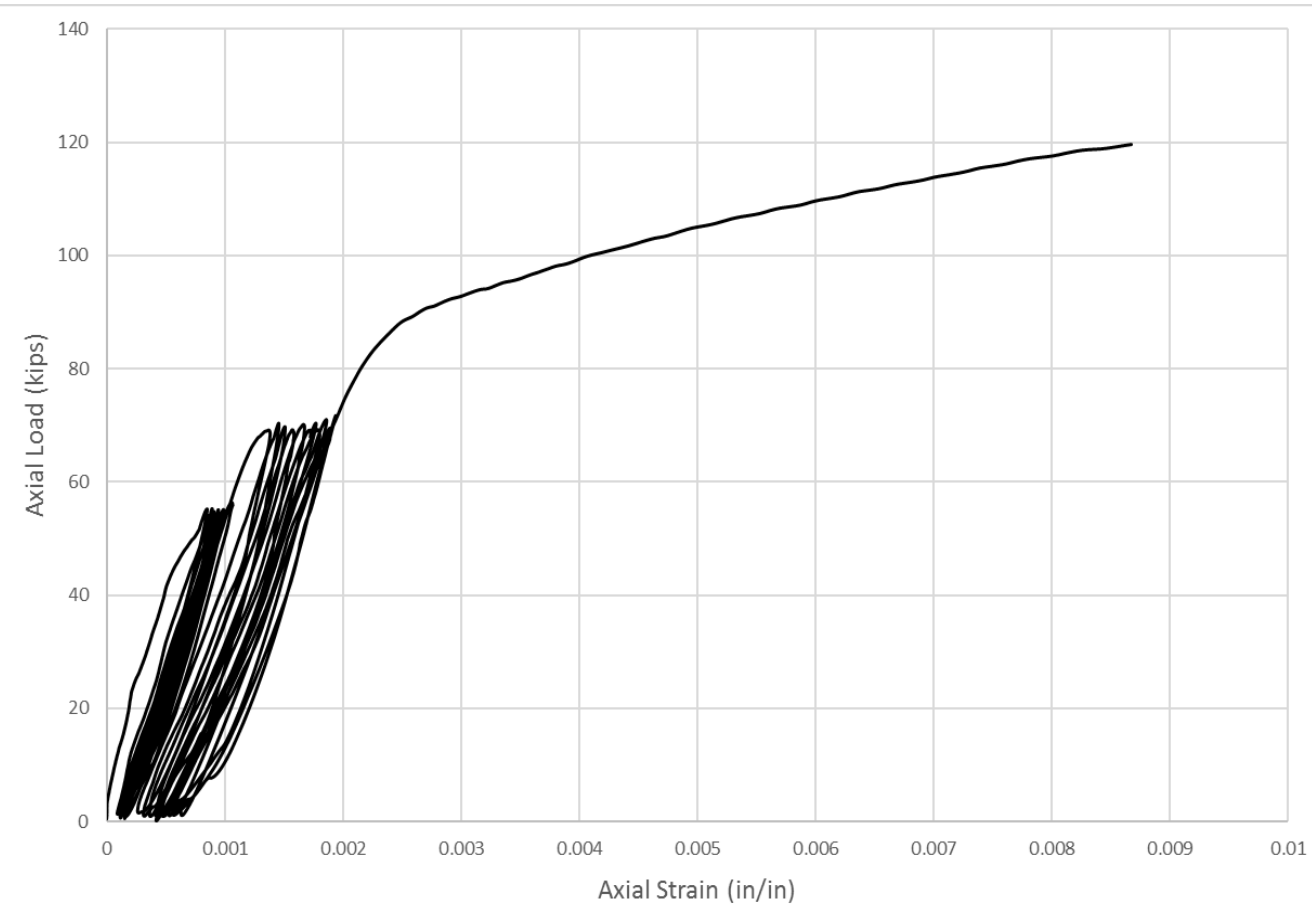

- C2NDC-F2

Figure 4-18: Close-up view for C4NDC-F2 cyclic response 


\subsubsection{CFRP Transverse Strain}

Similar to specimen C2NDC-F1, the CFRP transverse strain response is a bilinear response as shown in Figure 4-19. It is constructed as the average of the strain gauges outside the overlapping zone. The maximum average strain at the first CFRP rupture $\left(\varepsilon_{f, \text { rup }}\right)$ was 0.0131 when the axial load was 208 kips. However, the maximum strain value was 0.0143 . It was measured by the strain gauge $S 4$ (refer to Figure $3-26$ ). It is worth noting that the strain gauge S3 was lost before the rupture of the CFRP jacket. Table 4-2 illustrates the maximum CFRP transverse strain at first rupture (axial load = 208 kips) measured by each strain gauge.

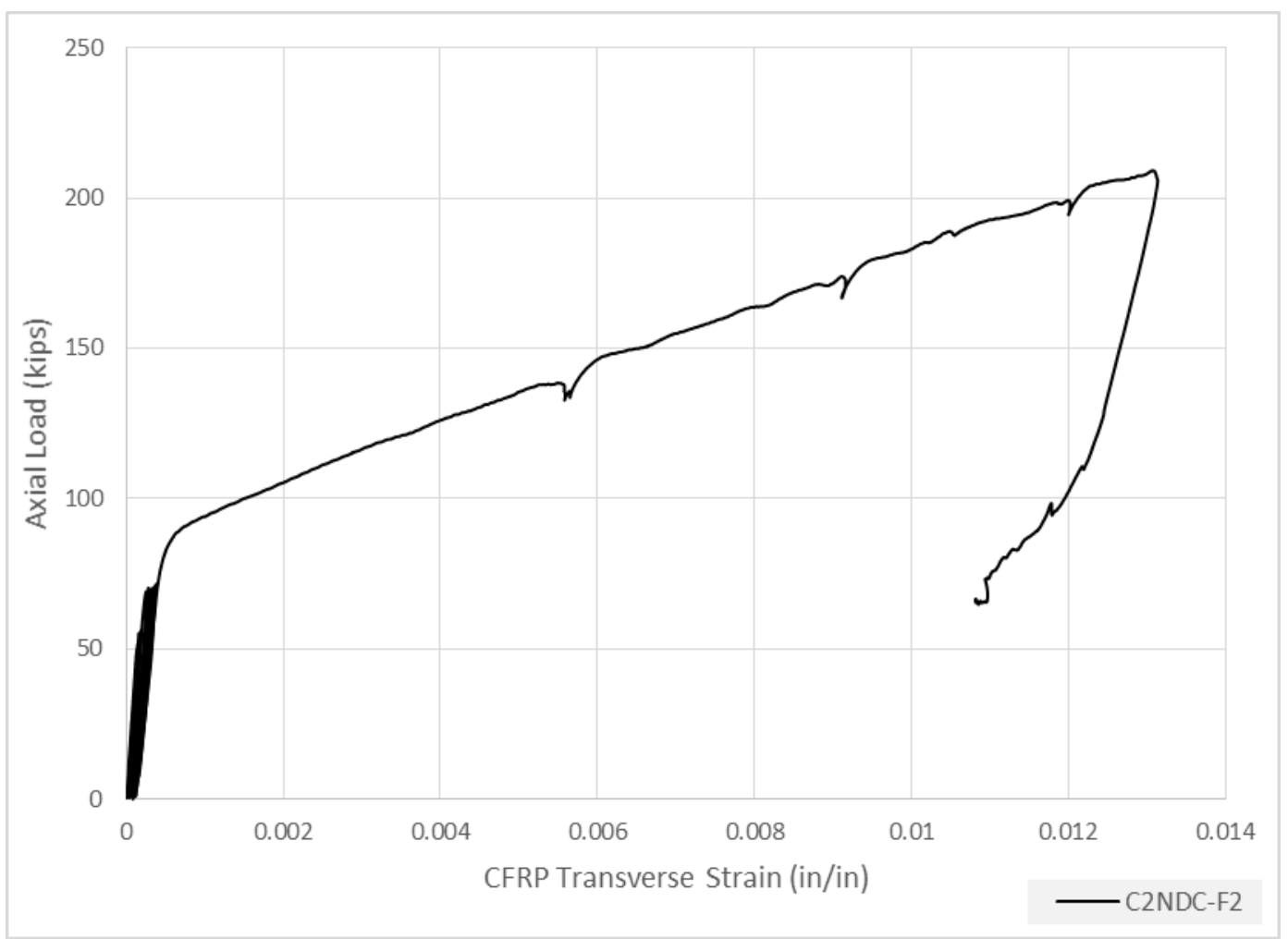

Figure 4-19:CFRP transverse strain response for specimen C2NDC-F2 
Table 4-2: Maximum CFRP transverse strain of C2NDC-F2

\begin{tabular}{|c|c|}
\hline Strain Gauge ID. & Max. CFRP Transverse Strain, $\boldsymbol{\varepsilon}_{f, r u p}$ \\
\hline Outside overlapping zone & \\
\hline S1 & 0.0136 \\
\hline S2 & 0.0116 \\
\hline S3 & --- \\
\hline S4 & 0.0143 \\
\hline Inside overlapping zone & \\
\hline So & 0.0095 \\
\hline Avg. & 0.0131 \\
\hline
\end{tabular}

\subsection{Specimen C2NDC-F3 (Non-Ductile RC Column Wrapped with Three CFRP Layers)}

\subsubsection{General Behavior and Failure Mechanism}

The same loading procedure was followed. Similar to the other wrapped column specimens, no significant behavior was observed during the cyclic loading phase. However, when the load was monotonically increased, a cracking noise was heard when the load approached the loading capacity of the unconfined concrete. In addition, some longitudinal local buckling was noticed in the CFRP jacket at the mid-height region as shown in Figure 4-20. The axial load and strain continued to increase until they dramatically dropped when the CFRP jacket suddenly ruptured at the lower half of the specimen. All of the measuring instruments were lost because of this explosive rupture. As a result, the test was terminated. Figure 4-20 shows the failure mode of the specimen C2NDC-F3. 

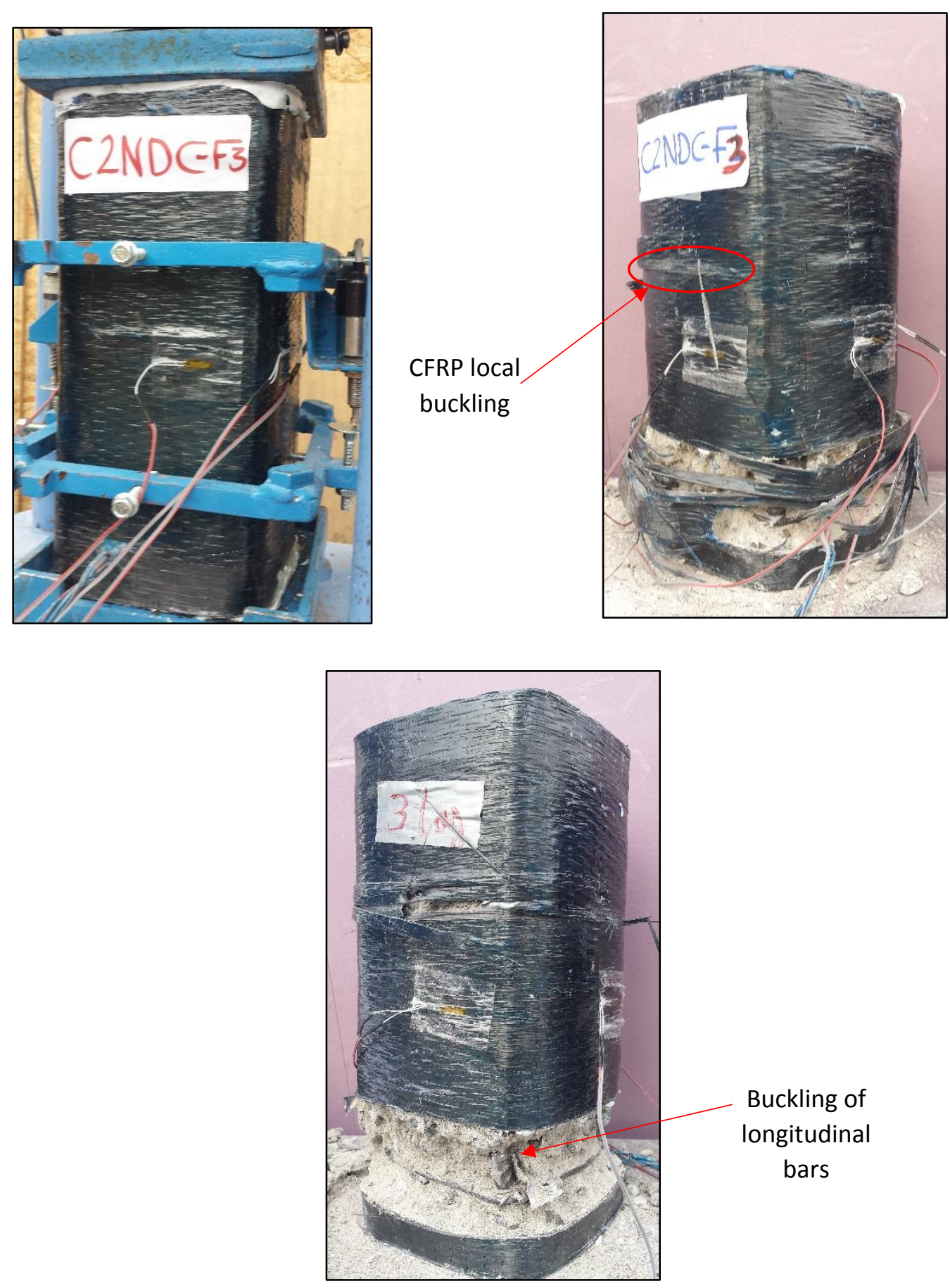

Figure 4-20: Failure Mode of Specimen C2NDC-F3 


\subsubsection{Axial Load-Strain Relationship}

The axial load versus axial strain relationship for specimen C2NDC-F3 is depicted in Figure 4-21. The axial strain response shows the same bilinear trend exhibited by the other CFRP wrapped column specimens. However, the peak axial load at CFRP rupture is 249 kips and the corresponding axial strain is 0.068 .

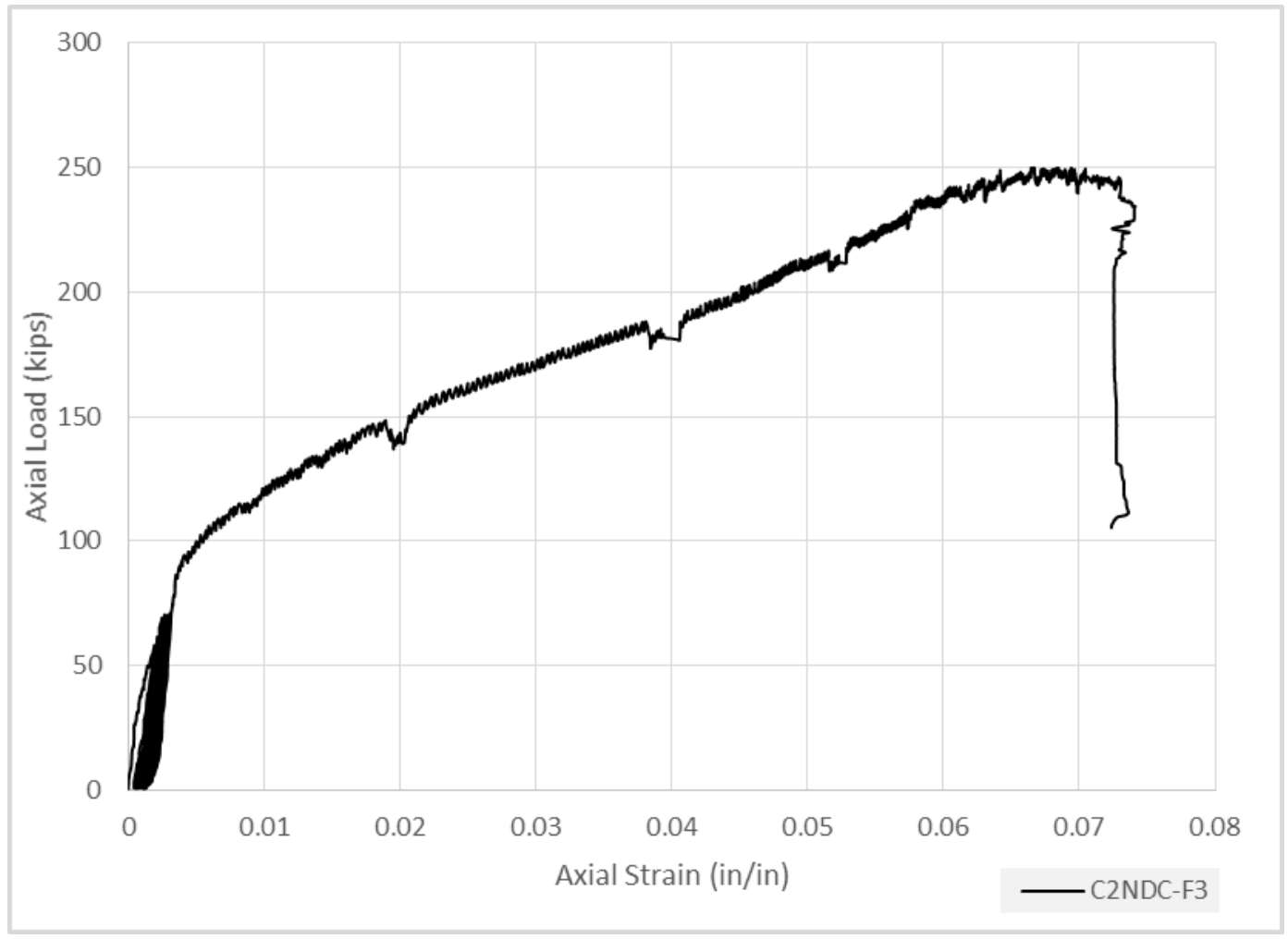

Figure 4-21: Axial load-Strain response of specimen C2NDC-F3 


\subsubsection{CFRP Transverse Strain}

The average CFRP transverse strain response is depicted in Figure 4-22. As it is expected, the response shows a bilinear trend with a non-linear transitional region. The maximum average strain at rupture $\left(\varepsilon_{f, \text { rup }}\right)$ is 0.0191 . However, the maximum strain value is 0.0194 . It was measured by the strain gauge S4 (refer to Figure 3-30). All of the strain gauges were lost due to the explosive rupture of the CFRP jacket. The maximum CFRP transverse strain measured by each strain gauge is reported in Table 4-3.

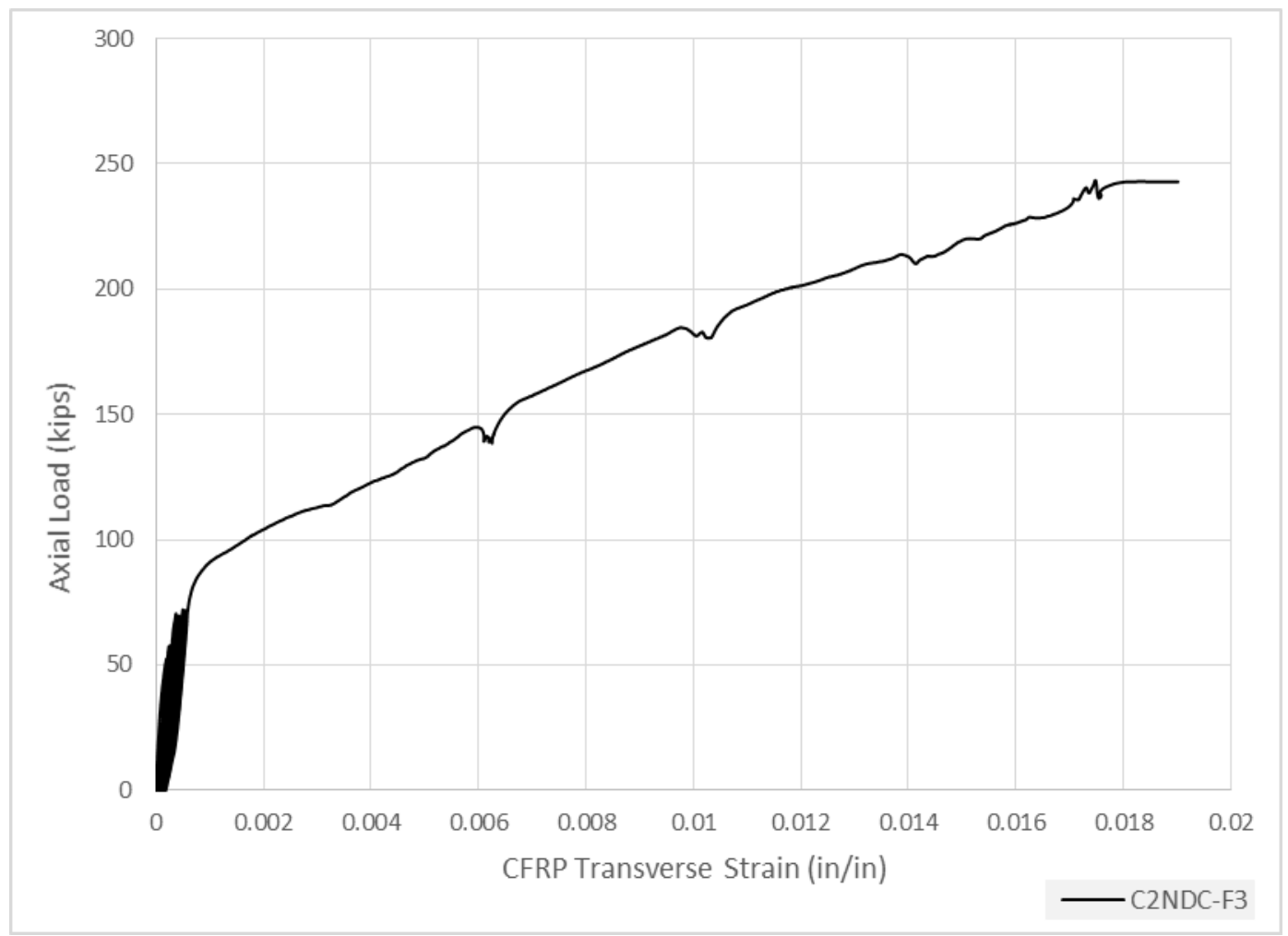

Figure 4-22: CFRP transverse strain response for specimen C2NDC-F3 
Table 4-3: Maximum CFRP transverse strain of C2NDC-F3

\begin{tabular}{|c|c|}
\hline Strain Gauge ID. & Max. CFRP Transverse Strain, $\boldsymbol{\varepsilon}_{\text {f,rup }}$ \\
\hline Outside overlapping zone & 0.0167 \\
\hline S1 & --- \\
\hline S2 & 0.0194 \\
\hline S3 & 0.0167 \\
\hline S4 & \\
\hline Inside overlapping zone & 0.0067 \\
\hline So & 0.0191 \\
\hline Avg. &
\end{tabular}

\subsection{Specimen C4NDC (Unwrapped Non-ductile RC Column)}

\subsubsection{General Behavior and Failure Mechanism}

Specimen C4NDC was tested. During the first ten loading cycles (up to $\mathrm{P}=0.7 \mathrm{Pn}=67$

kips), no cracks, not even hairline cracks, were observed. When the specimen was unloaded to the point that was considered at zero load, the residual deformation was between $0.002-0.003$ ". The very small residual deformation range and the absence of cracks proved that the concrete was still in its elastic stage. For the second ten cycles (up to $\mathrm{P}=0.9 \mathrm{Pn}=86 \mathrm{kips}$ ), the residual deformation was also between $0.002-003$ inch. Again, no cracks were observed except some longitudinal hairline cracks that developed at the mid-height of the specimens during the ninth and tenth cycles. These observations evidence the elastic behavior of the concrete in this level of loading. After the tenth loading cycle, the specimen was loaded monotonically until reaching the peak uniaxial loading capacity. As the axial load was increased, the cracks were extended and covered more area on the lower half of the column. When reaching the peak load, the concrete cover at the mid-height spalled off due to the propagated cracks. This was accompanied by a sudden drop in the measuring axial load. The loading process was kept beyond the peak-point to capture the post peak behavior of the column. While increasing the load, 
more concrete cover spalled off. The cover spalling was followed by extensive concrete crashing at the mid-height simultaneously with buckling of longitudinal reinforcing bars. At that time the measured axial load had dropped dramatically; therefore, the test was terminated. Figure 4-23 shows specimen C4NDC at failure.

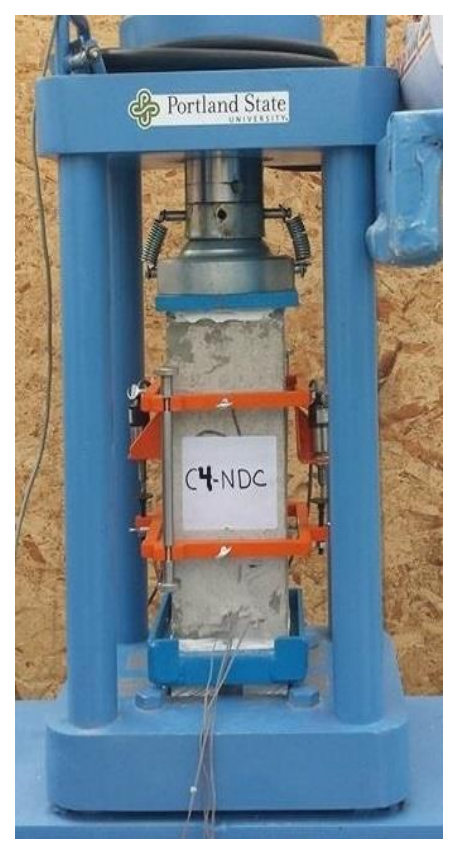

(a) Before the

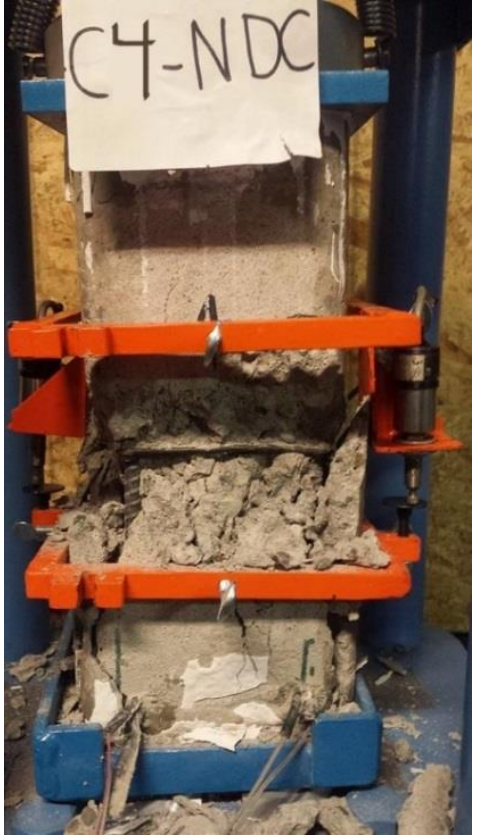

(b) At the end of the tes

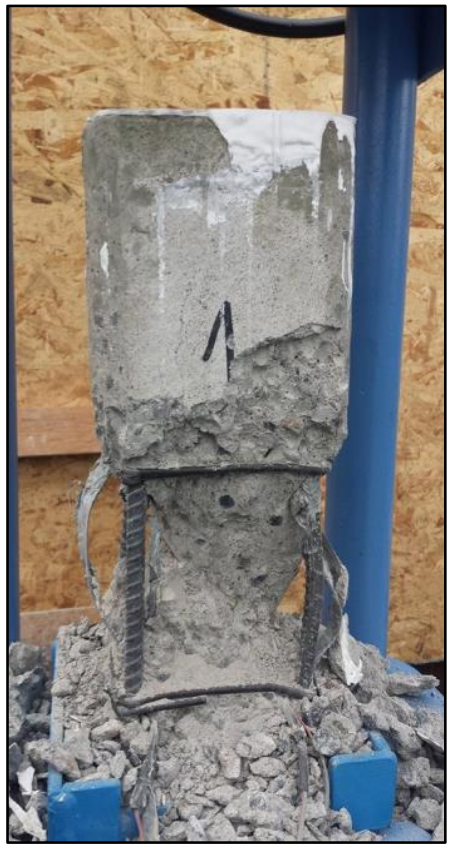

(c) After removing the crashed concrete

Figure 4-23: Failure mode of specimen C4NDC 


\subsubsection{Axial Load-Strain Relationship}

The axial load versus axial strain response is depicted in Figure 4-24. The axial strain was calculated as the average of the two LVDTs readings divided by the gauge length of LVDT. The axial load was the applied compressive load. It can be seen from Figure 4-24 that the overall load-strain curve can be divided into four portions. The initial linear portion starts from zero load up to $0.7 \mathrm{Pn}$ (67 kips). The second portion is the cyclic response where the loading/unloading cycles were performed. The beginning of that portion is when the load was released after achieving the first load level (67 kips). For better visualization, Figure 4-25 shows a close-up view of this portion and Figure 4-26 shows an individual cycle of each loading level. It can be noted that the reloading path has an almost linear trend while the unloading path is non-linear response. Its nonlinearity is more observable when the load approaches the zero value. In addition, it is worth noting that the degree of the unloading path is higher at the higher level of loading (i.e. at $0.9 \mathrm{Pn}$ ). Moreover, Figure 4-25 shows that most of the loading cycles almost lay on each other. In other words, there is no appreciable difference in the axial strain between a cycle and the subsequent one. A possible reason for this phenomenon is that the concrete and the reinforcing steel in the stage of cyclic response are in their elastic range so they do not undergo large residual strains. This hypothesis can be proven by the fact that the max residual strain is 0.0005 as shown in the Figure 4-25. The third portion (refer to Figure 4-25) is an ascending branch starting at the end of the twentieth cycle until achieving the peak load involving the short nonlinear transition zone near the peak load. The achieved axial peak load was 115 kips and the corresponding axial strain $\left(\varepsilon_{\mathrm{m}}\right)$ was 0.0019. Mander (1988) suggests a value of strain around 0.002 for the strain 
corresponding to the peak load in unconfined concrete. This is very close to the strain value recorded for this specimen (i.e. $\varepsilon_{\mathrm{m}}=0.0019$ ). The fourth portion of the response starts with the sudden drop in the load once reaching its peak value. This drop was accompanied by sharp increasing in the recording strain (deformation). To illustrate this in more depth, it can be noted that the strain corresponding to a load value of $50 \%$ of the peak loading capacity beyond the peak point (i.e. $\mathrm{P}=58 \mathrm{kips}$ ) is 0.0107 . This fastgrowing deformation can be explained by the fact that crushing the concrete cover initiated the outward buckling of the longitudinal reinforcement since there were not enough transverse confining ties.

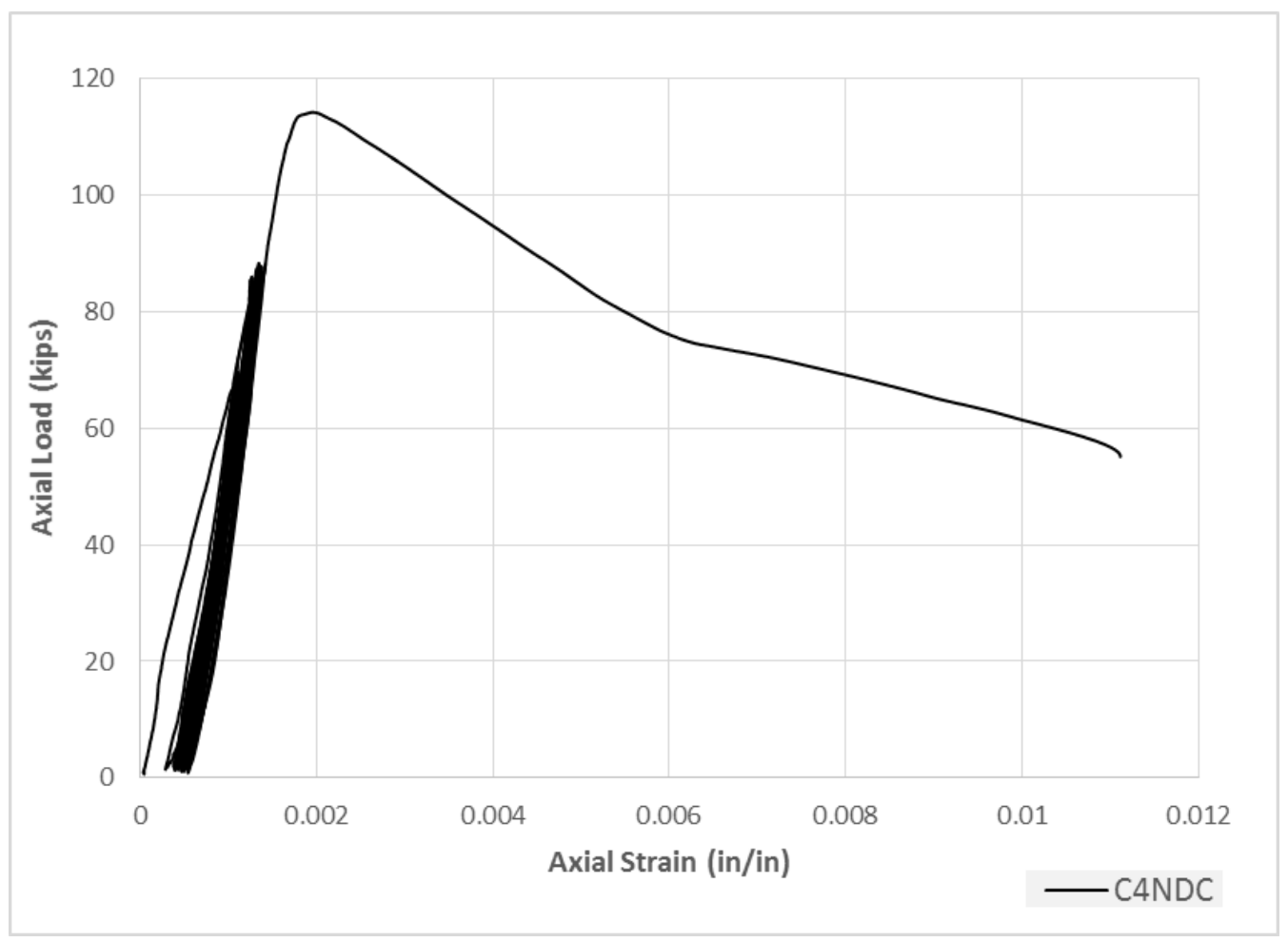

Figure 4-24: Axial load- Strain response of specimen C4NDC 


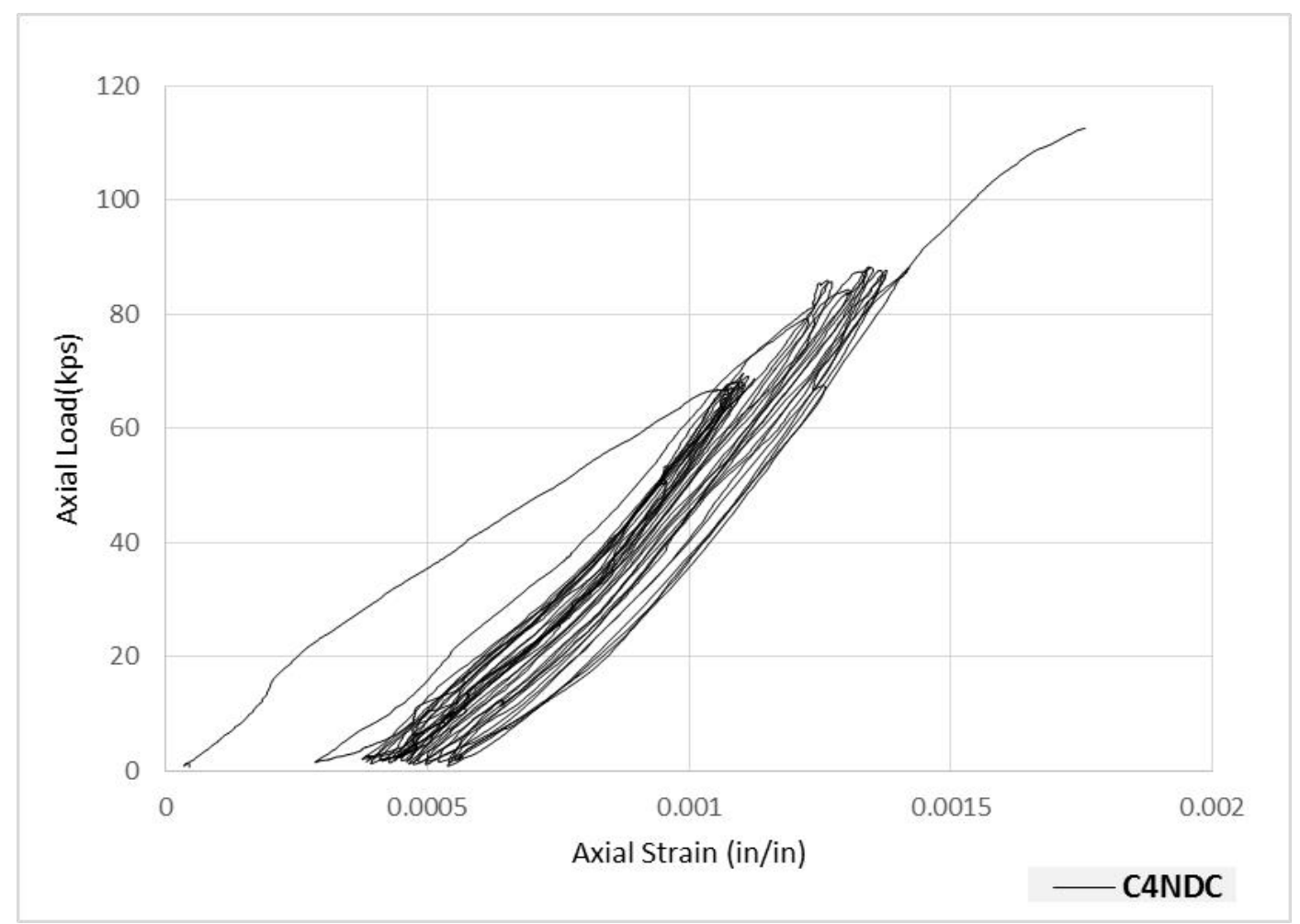

Figure 4-25: Close-up view for C4NDC cyclic response

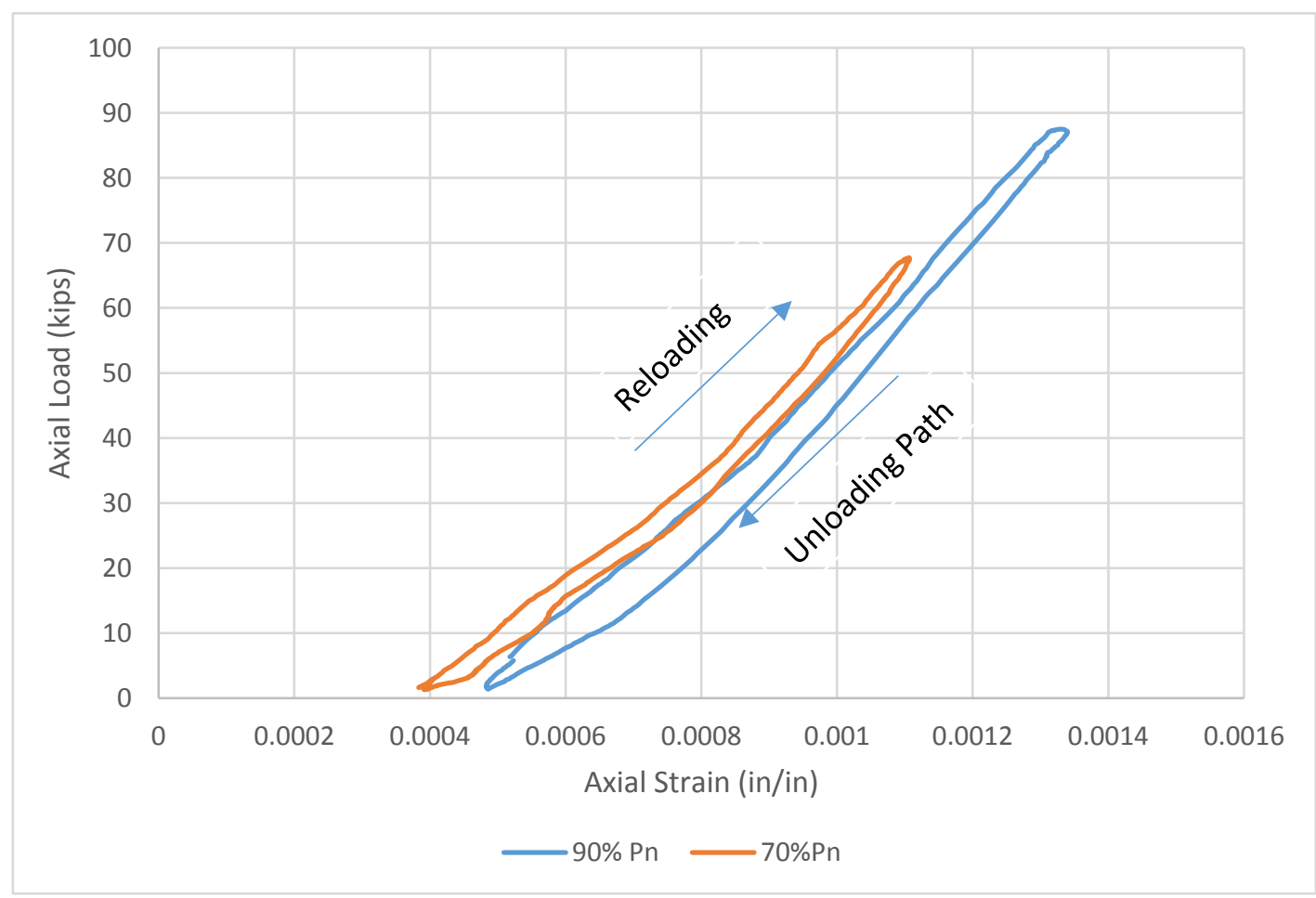

Figure 4-26: : Individual cycles (C4NDC) 


\subsubsection{Longitudinal Reinforcement}

As it was mentioned in the previous chapter, all column specimens including C4NDC specimen were reinforced with 4-\#3 bars providing a longitudinal reinforcement ratio of $1.76 \%$. Because of this low ratio, the expected contribution of the longitudinal reinforcement to the total loading capacity is small assuming that the steel reaches its yielding strength at failure. This fact is interpreted in the ACI 318-14 equation for designing reinforced concrete columns:

$P_{n}=0.85 f^{\prime}{ }_{c}\left(A_{g}-A_{s t}\right)+F_{y} A_{s t} \quad$ Eq. 4-1

This equation was the equation used for designing the test specimens. However, in specimen C4NDC, as shown in Figure 4-27 that presents the average measured steel strain, the maximum reinforcing steel strain that corresponded to the peak load was 0.001. This strain was almost $50 \%$ of the yield strain of the steel used in this study $\left(\varepsilon_{y}=\right.$ 0.0027). This observation explains the shape of the steel strain curve.

It can be seen in Figure 4-27 that there is only a linear portion with the absence of the post-yield plateau and strain hardening portions in comparison with the well-known shape of a steel stress-strain curve (refer to Figure 3-4). Developing that low steel strain might be caused partly by the following fact; when constructing the reinforcing steel cage, the longitudinal bars were cut 3/4" shorter than the column specimen's length. Therefore, there was about $3 / 8$ " concrete cap at the top and bottom ends (i.e. the concrete and steel reinforcing were not at the same level at the ends). Consequently, when compressing the column during the test, the concrete cap might have felt the load first, and after undergoing a certain amount of deformation, some of the load was then transferred to steel rebars. However, in columns, the ideal condition is when both the 
steel and the concrete feel the compressive load simultaneously so that they deform almost the same, but with different behavior.

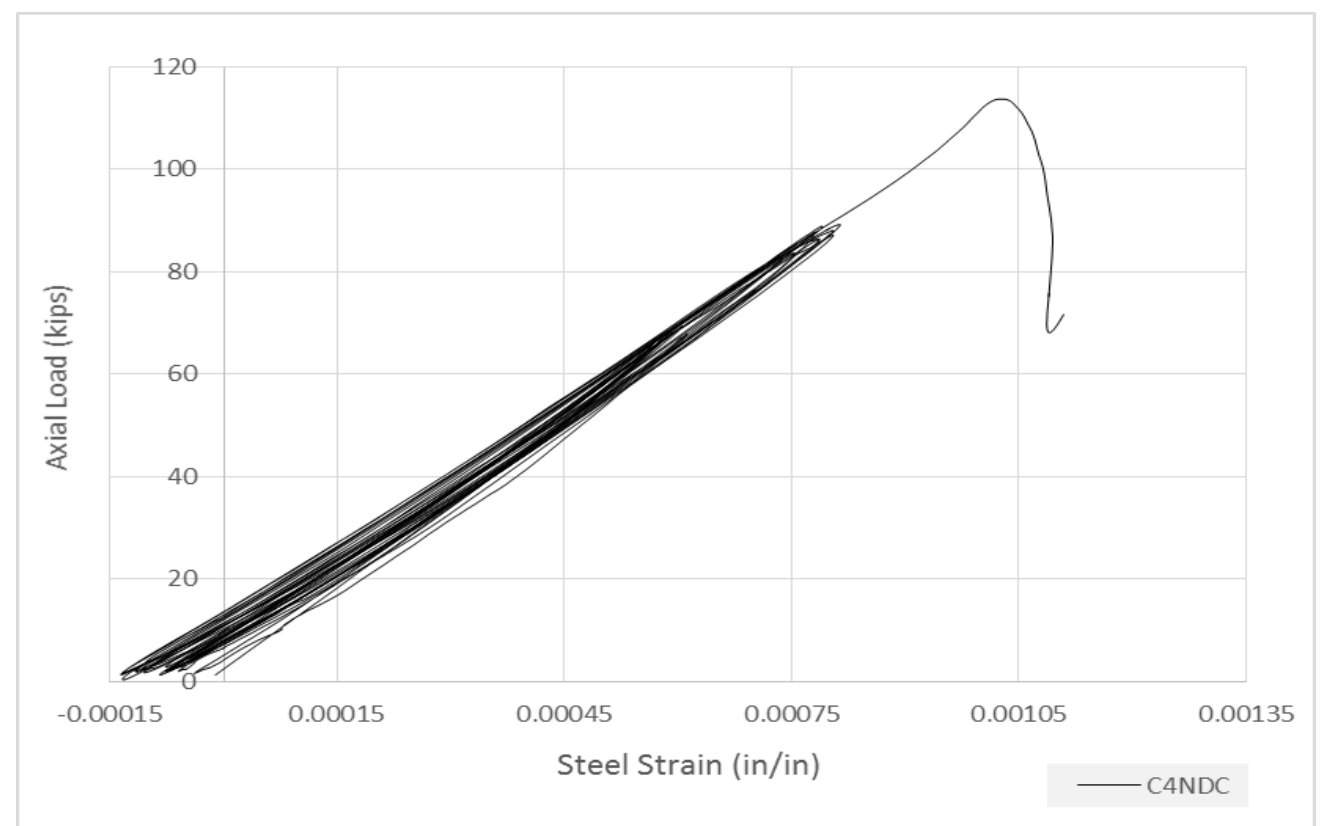

Figure 4-27: Reinforcing steel strain (C4NDC)

\subsubsection{Apparent Concrete Strength $\left(\mathbf{F}_{\mathbf{c}}\right)$}

The same procedure illustrated in Section 4.1.4 was followed to calculate the contribution of both the concrete and the reinforcing steel to the total compressive loading capacity as shown in Figure 4-28 


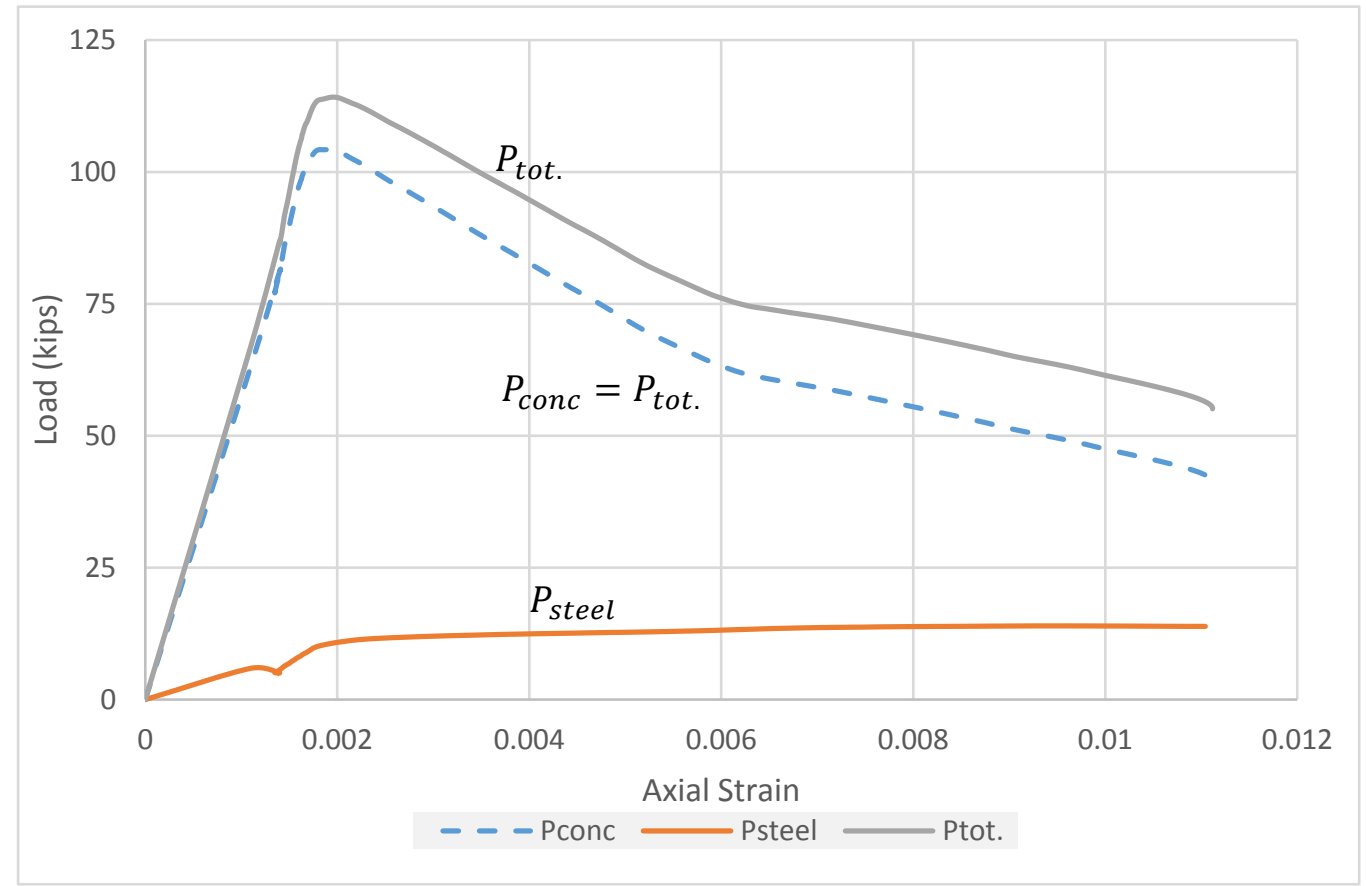

Figure 4-28: Concrete and Steel Reinforcement Contributions (C4NDC)

In addition, based on the $P_{\text {conc }}$ curve, the apparent concrete stress $\left(\sigma_{\mathrm{c}}\right)$ versus the axial strain curve was constructed and depicted in Figure 4-29.

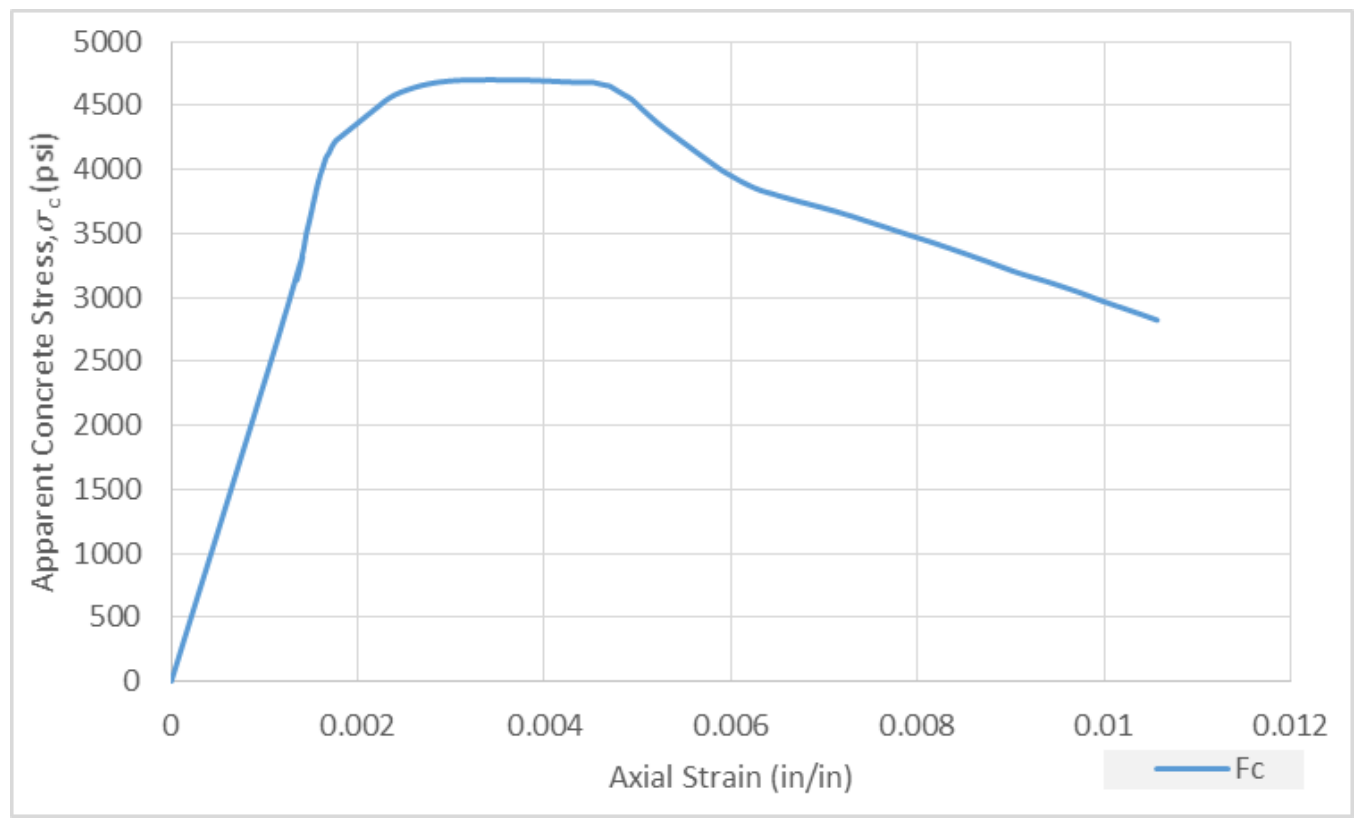

Figure 4-29: Apparent concrete stress (C4NDC) 


\subsection{Specimen C4DC (Ductile RC Column)}

\subsubsection{General Behavior and Failure Mechanism}

Specimen C4DC represented a reinforced concrete column with seismic reinforcement details (i.e. adequate lateral confining reinforcement). Similar to specimen C4NDC, specimen C4DC was subjected to ten loading cycles up to $70 \%$ Pn load level followed by another ten cycles up to $90 \% \mathrm{Pn}$ load level. Then, it was monotonically loaded until failure. During the cyclic loading stage, the column did not experience any noticeable cracking. The readings of the two vertical LVDTs were quite similar. This indicates that the specimen was well centered with the loading head, which means no appreciable rotation was induced at the ends. After that, the column was loaded monotonically. While increasing the load, some longitudinal cracks started to form at the upper end near the corners where the longitudinal bars were. Those cracks indicated the initiation of the concrete cover spalling. As the loading continued, the cracks began to extend and propagate as shown in Figure 4-30. A sudden drop in the measuring load was noticed after reaching a value of about 135 kips. This drop suggesting that a considerable portion of the concrete cover capacity was lost. Right after that, the load started to increase again indicating that the column recovered itself. However, the applied load was greatly carried by the confined concrete core. It achieved a loading capacity of about 134 kips. After that, the loading capacity started to decay, but with a slow rate. This gradual strength decay was accompanied by an increase in the measured axial deformation. As mentioned before, the axial deformation was measured by two vertical LVDTs. Nevertheless, one of the LVDTs was accidentally lost during the test due to the crashed concrete cover. It was hard to return it to its place again; therefore, it was relied on the other LVDT to measure 
the axial deformation then. While the axial deformation was increasing, the longitudinal bars were experiencing continuing buckling. Specimen C4DC failed with severe buckling of the longitudinal bars as demonstrated in Figure 4-30. The test was terminated when most of the measuring instruments were no longer functional, and when the load hugely dropped.

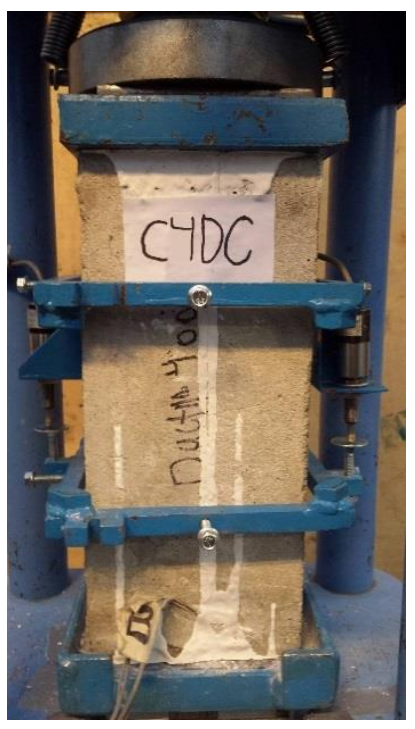

Before Testing

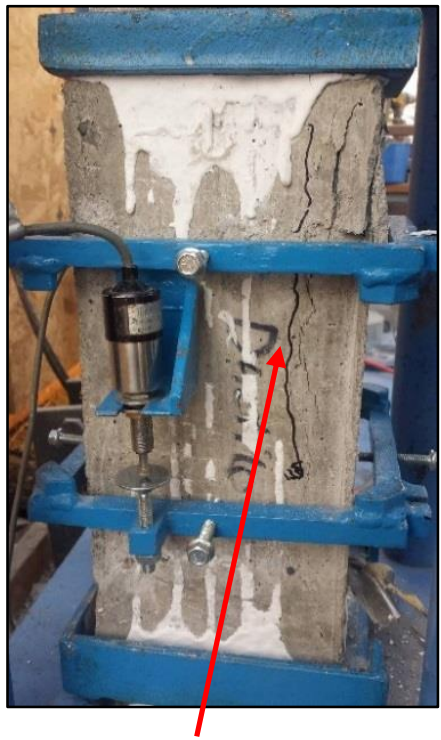

Longitudinal Cracking

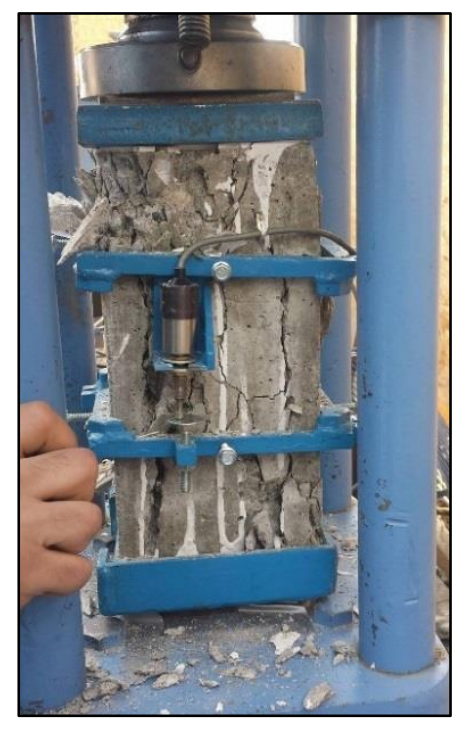

Prior to Failure

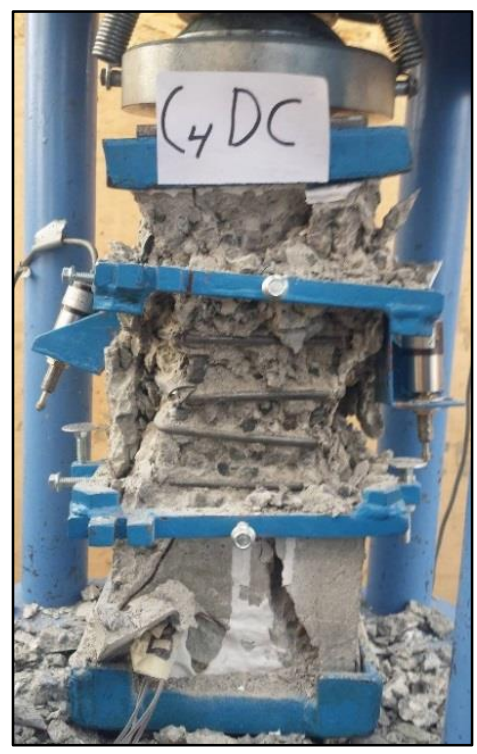

At Failure

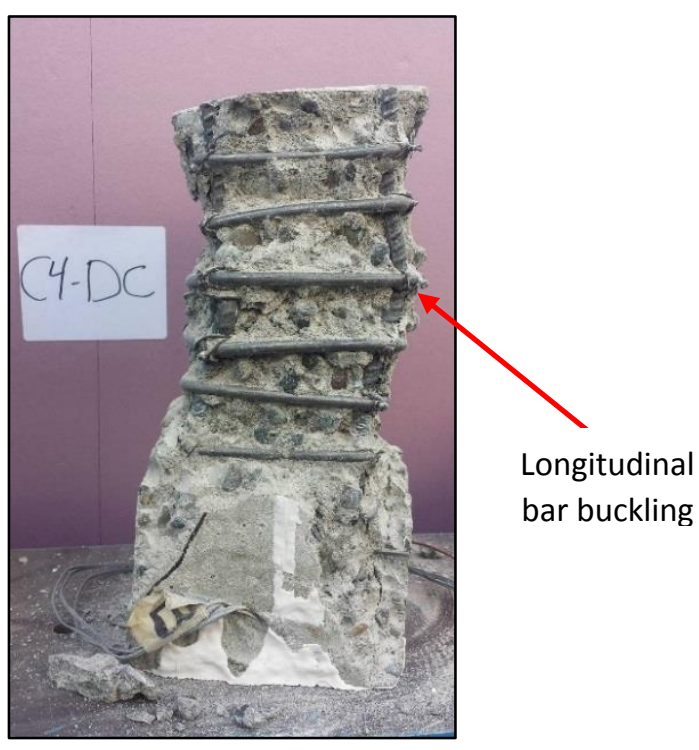

After Testing

Figure 4-30: Failure Mode of Specimen C4DC 


\subsubsection{Axial Load-Strain Relationship}

Figure 4-31 shows the axial strain response for specimens C4DC. It can be noted that post-peak response shows a gradual degradation of the axial loading capacity, but with a fast increase of the axial strain. This response proves the ductile behavior of the column that was basically designed for. In other words, the seismically-designed lateral reinforcement induced the ductile behavior of the column. The figure shows that column achieved a peak load of $135 \mathrm{kips}$, and a corresponding axial strain $(\varepsilon m)$ of 0.0044 . In addition, the ultimate strain $\left(\varepsilon_{c u}\right)$ is 0.044 which is ten times the $\varepsilon_{m}$.

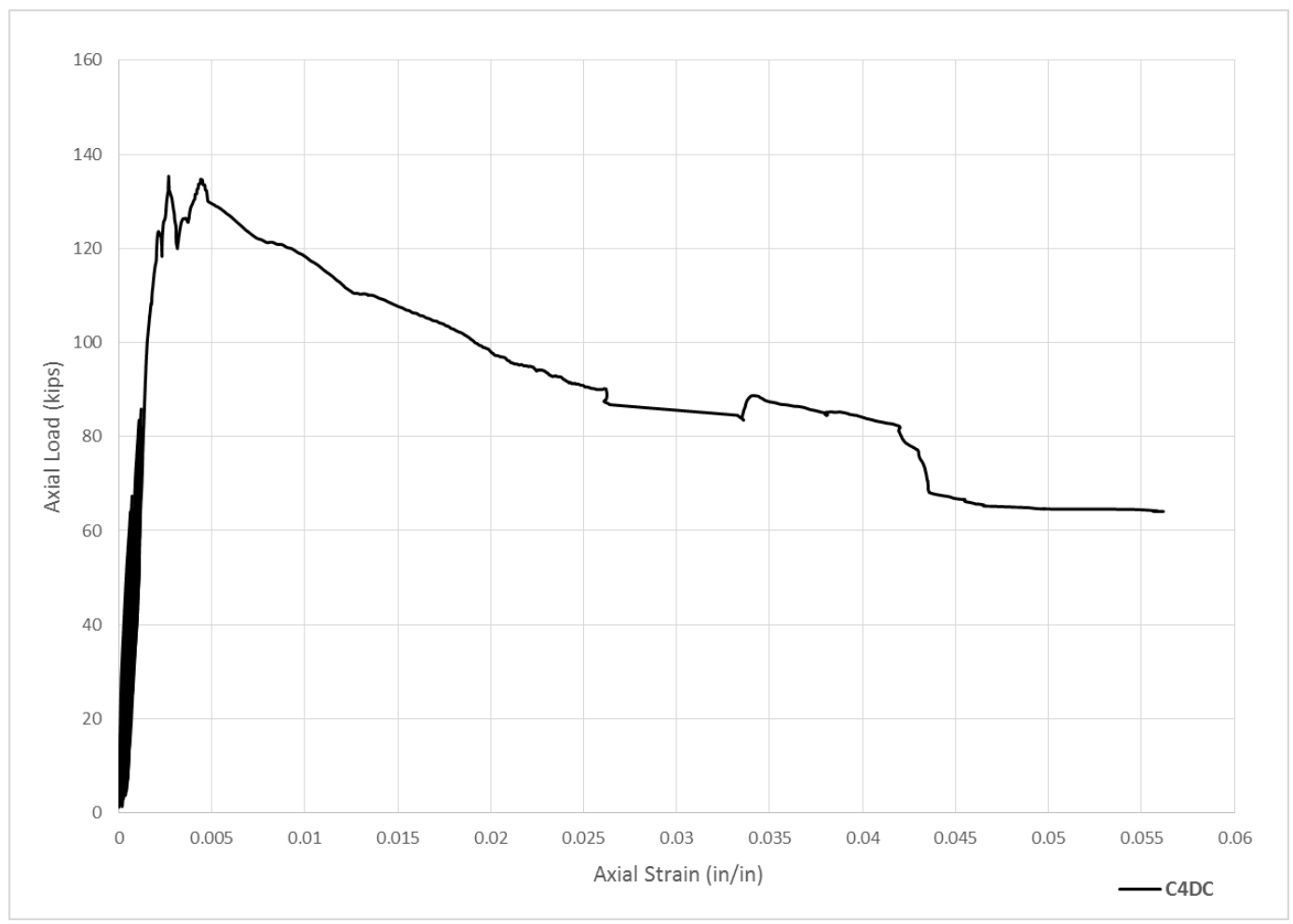

Figure 4-31: Axial load-Strain response of specimen C4NDC 


\subsection{CFRP-Strengthened C4 specimens}

Three non-ductile RC columns wrapped with a different number of CFRP layers were tested. The specimens were: C4NDC-F1 (wrapped with one CFRP layer), C4NDC-F2 (wrapped with two CFRP layers), and C4NDC-F3 (wrapped with three CFRP layers). When tested, it was observed that the general behavior and the failure mechanism of those three specimens were almost similar. Therefore, the intention was to not elaborate in describing the behavior of each specimen separately in order to avoid any unnecessary, prolix statements. Thus, the test results of the three specimens were presented in one section (Section 4.9). It was observed that all of the specimens failed with the rupture of the CFRP jacket as shown in Figure 4-32, Figure 4-33, and Figure 4-34. The specimens all experienced severe buckling of the longitudinal bars. All of the wrapped specimens had an almost bilinear axial load versus axial strain relationships as depicted in Figure 4-35, Figure 4-36, and Figure 4-37. In addition, the average CFRP transverse strain response of each specimen is shown in Figure 4-38, Figure 4-39, and Figure 4-40. 


\subsubsection{Failure Mechanism}

\subsubsection{C4NDC-F1}

After peeling off the remaining jacket and removing the inside crushed concrete at the rupture zone, it was found that the rupture occurred right above the middle steel hoop. Also, this hoop was bent outward in its horizontal plane. The other observation was that the longitudinal bars also experienced a local outward buckling as demonstrated in Figure 4-32. Those two observations might support the following proposed failure scenario for this specimen; in the mid-height area, where the steel hoop was placed, after the concrete core had reached its dilation limit, it started to push the hoop outward. This bulging action of the concrete and the steel hoop put the CFRP jacket under a higher stress at that area. Since one layer of CFRP was not stiff enough to resist that bulging over a long period of time, it ruptured exactly at that location and at that level of load (159 kips), which was much less than the rupture load of the specimens with more than one layer of CFRP, as it will be illustrated in the coming sections of this chapter. 

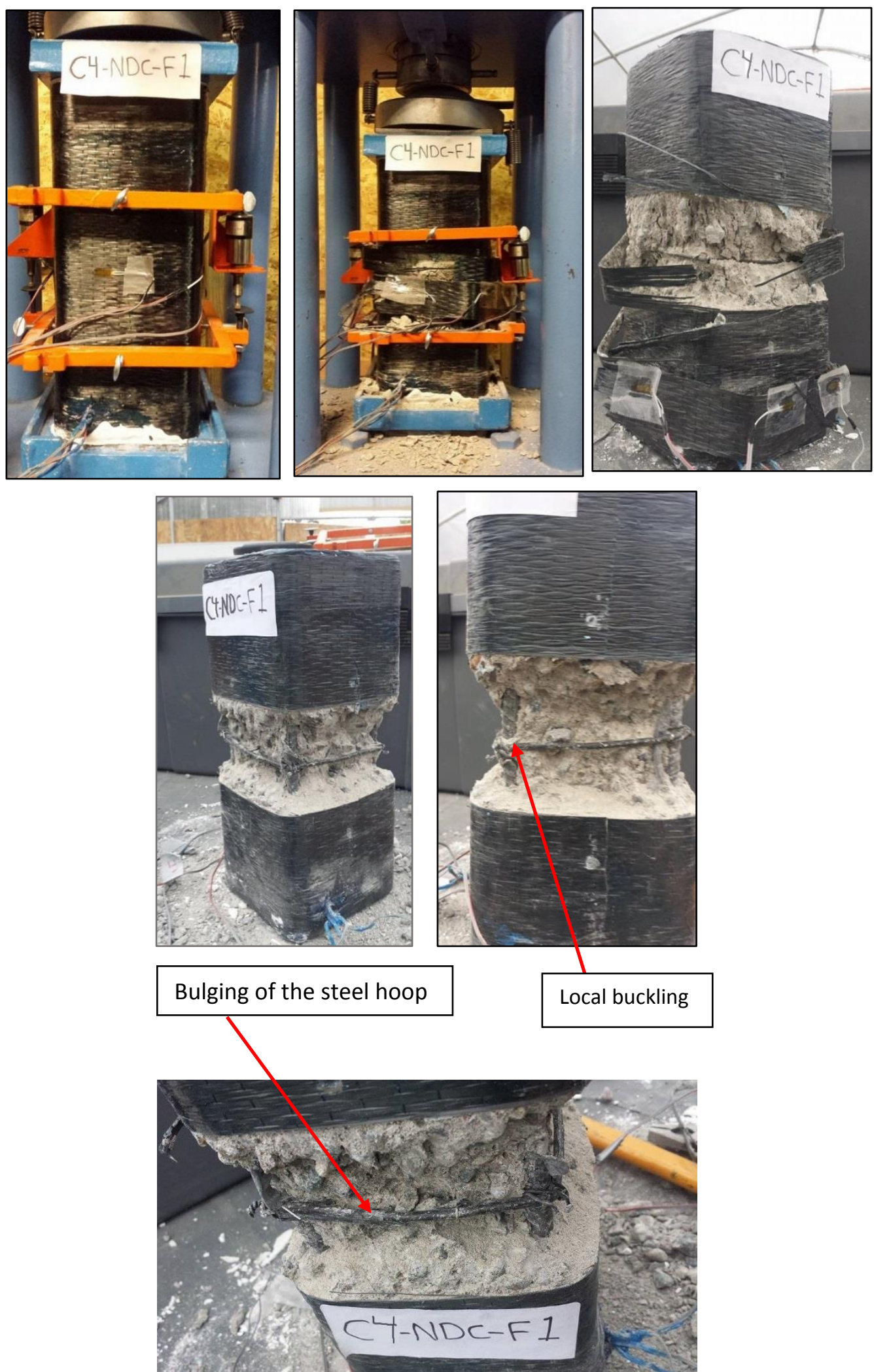

Figure 4-32: Failure mode of specimen C4NDC-F1 


\subsubsection{C4NDC-F2}

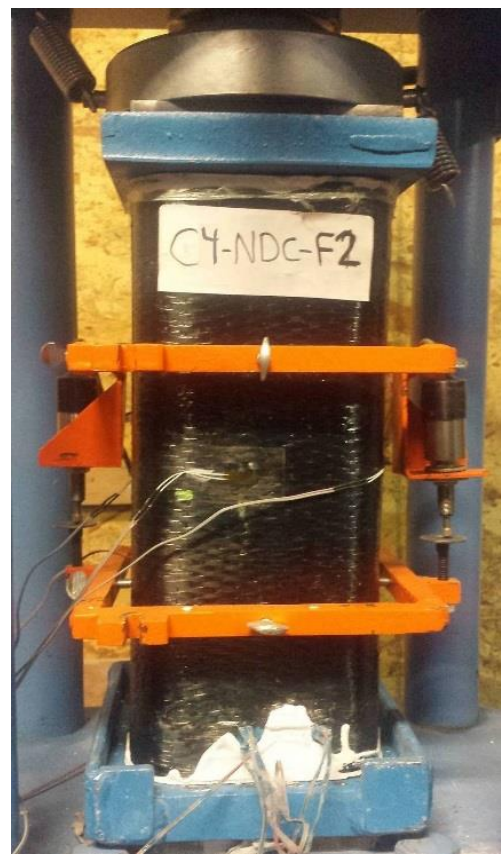

(a) Before Testing

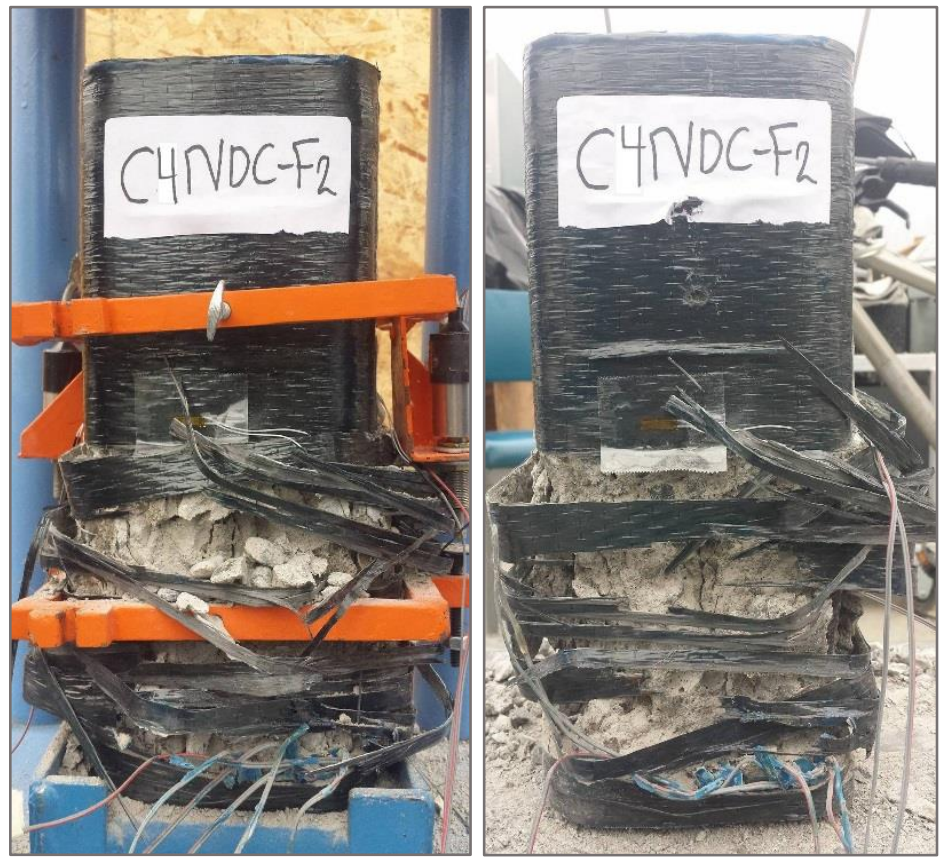

(b) At failure

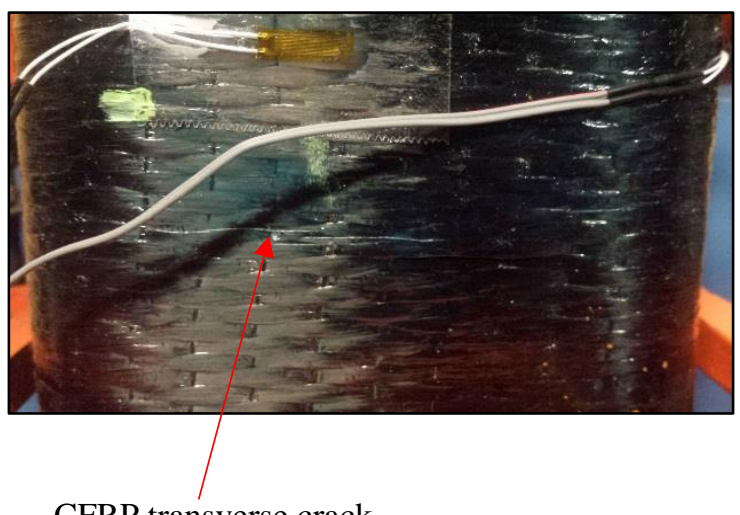

CFRP transverse crack

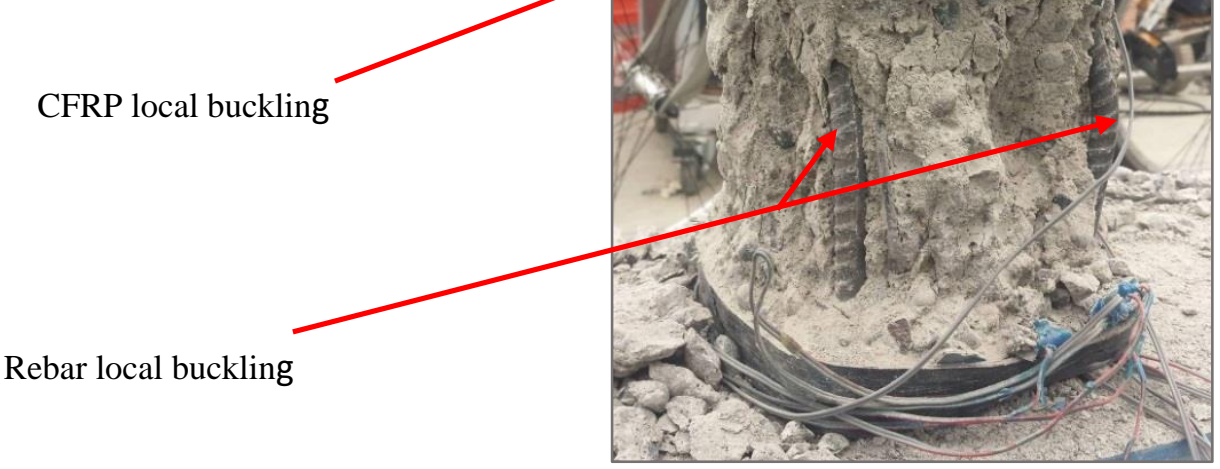

Figure 4-33: Failure mode of specimen C4NDC-F2 


\subsubsection{C4NDC-F3}

Unexpectedly, the first CFRP fracture occurred at the bottom end of the column although the ends were wrapped with an additional layer of CFRP. This early end failure might have occurred due to the lack of bonding between the jacket and concrete, yet the effect of this fracture was not noticeable on the loading capacity of the column. The axial load and strain continued to increase until they dramatically dropped when the CFRP jacket suddenly ruptured explosively at the mid-height region.

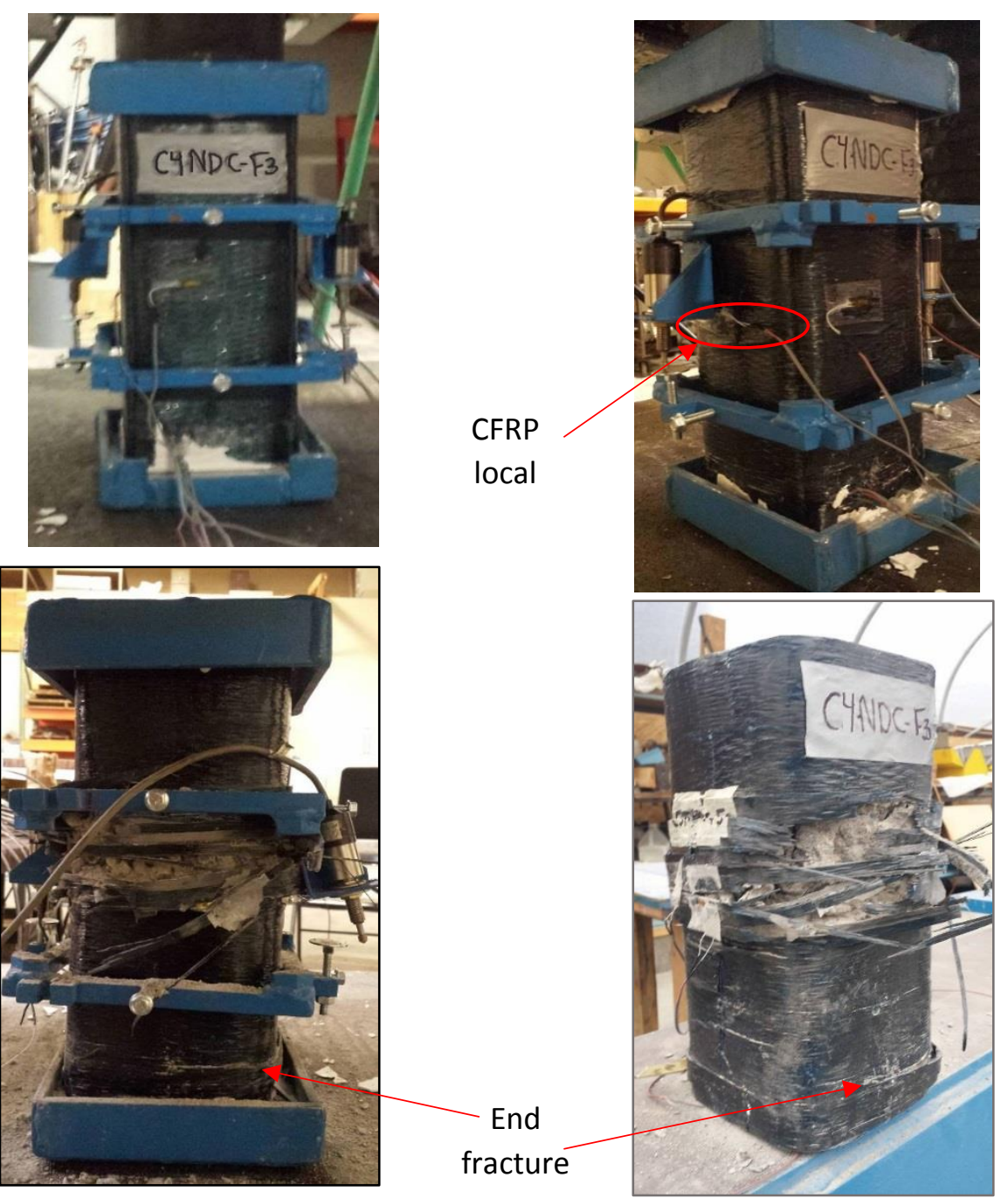

Figure 4-34: Failure Mode of Specimen C4NDC-F3 


\subsubsection{Axial Load-Strain Relationship}

\subsubsection{C4NDC-F1}

It can be seen in Figure 4-35that the maximum axial load at the rupture of the CFRP jacket was 159 kips and the corresponding axial strain was 0.0286 .

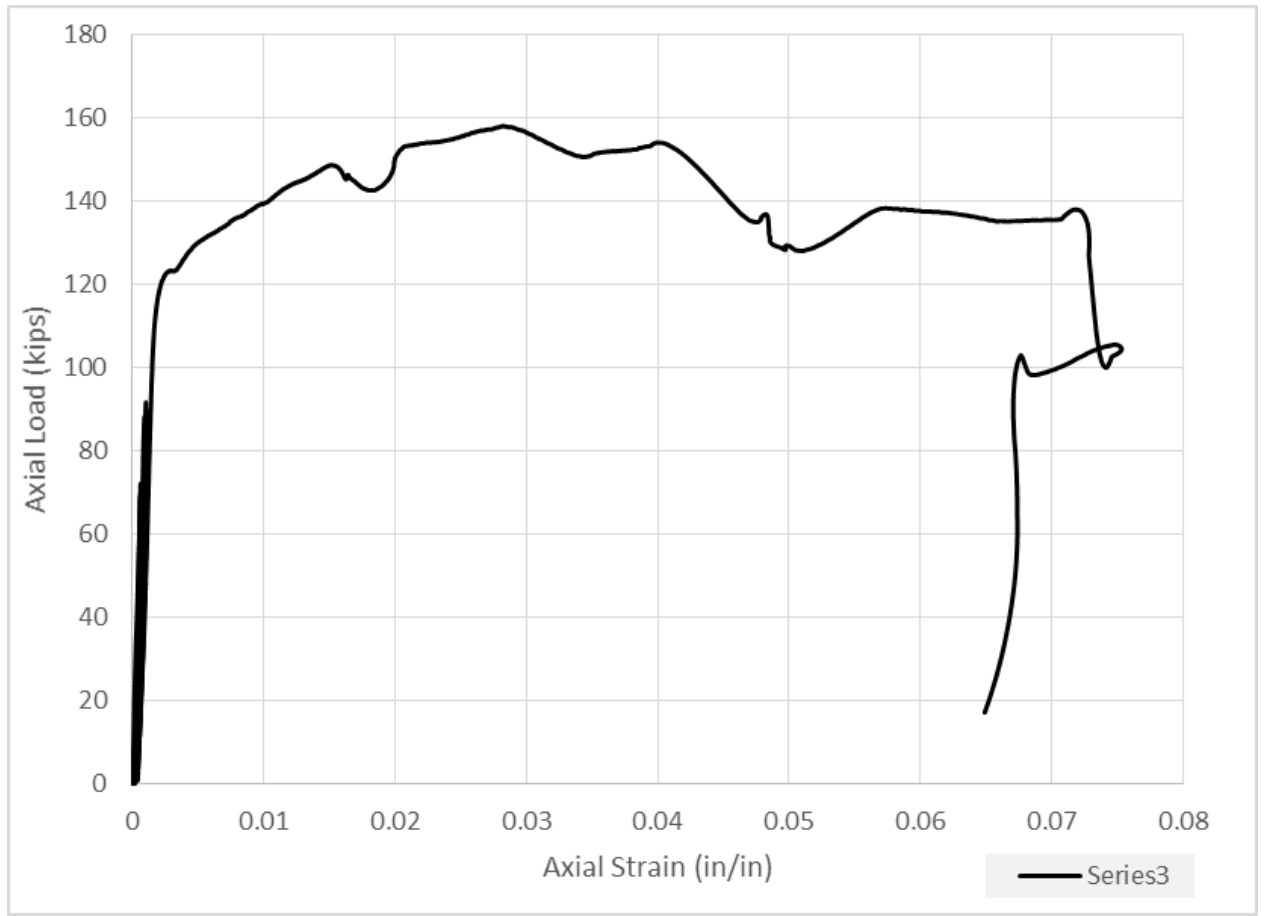

Figure 4-35: Axial load-Strain response of specimen C4NDC-F1 


\subsubsection{C4NDC-F2}

It can be seen in Figure 4-36 that the maximum axial load at the rupture of the CFRP jacket was 218 kips and the corresponding axial strain was 0.059 .

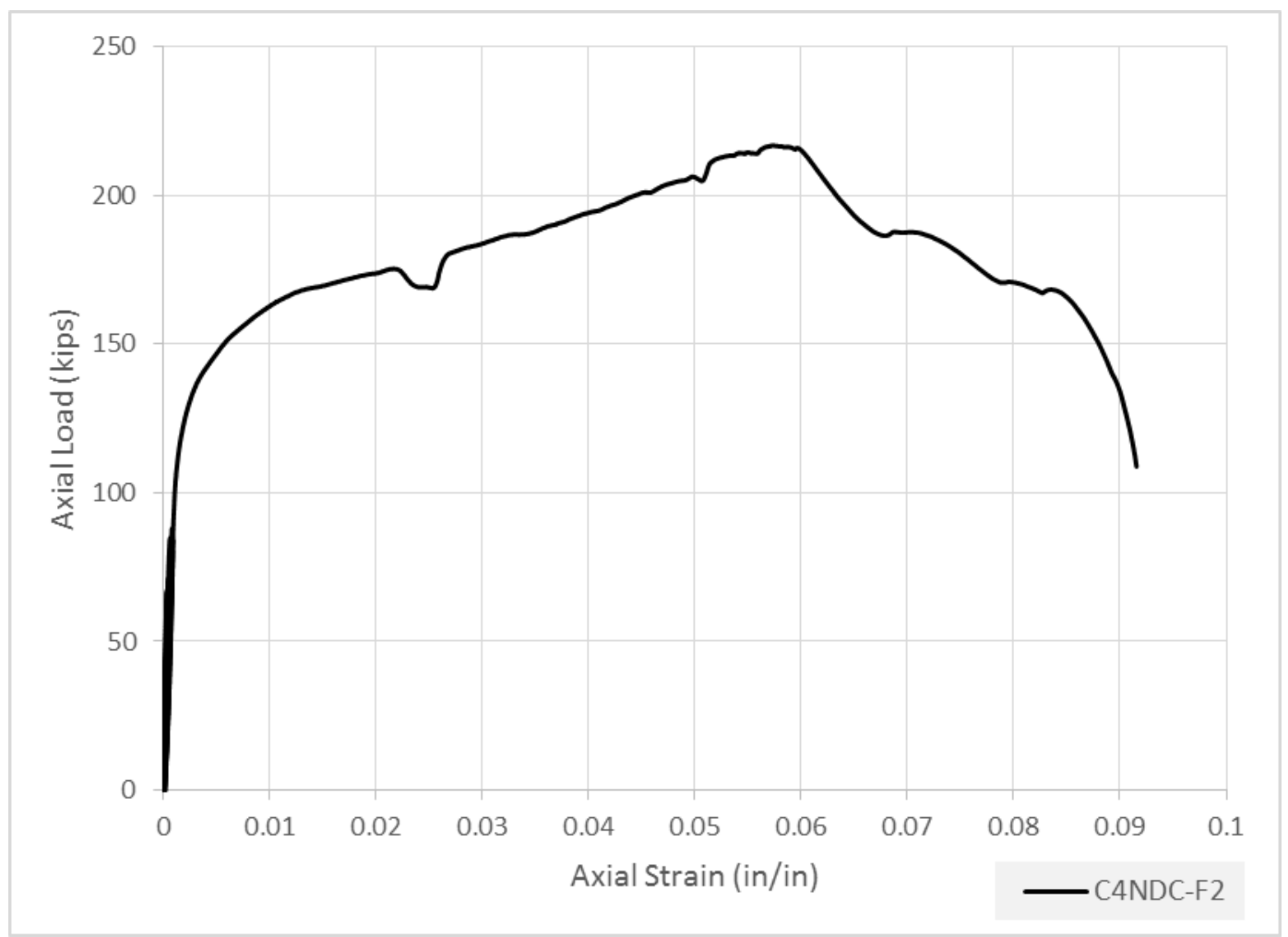

Figure 4-36: Axial load- Strain response of specimen C4NDC-F2 


\subsubsection{C4NDC-F3}

It can be noted in Figure 4-37 that the maximum axial load at the rupture of the CFRP jacket was 233 kips and the corresponding axial strain was 0.058 . it is worth noting that the post-peak response of this specimen was not shown because of the loss of the measuring instruments at the rupture of the CFRP jacket.

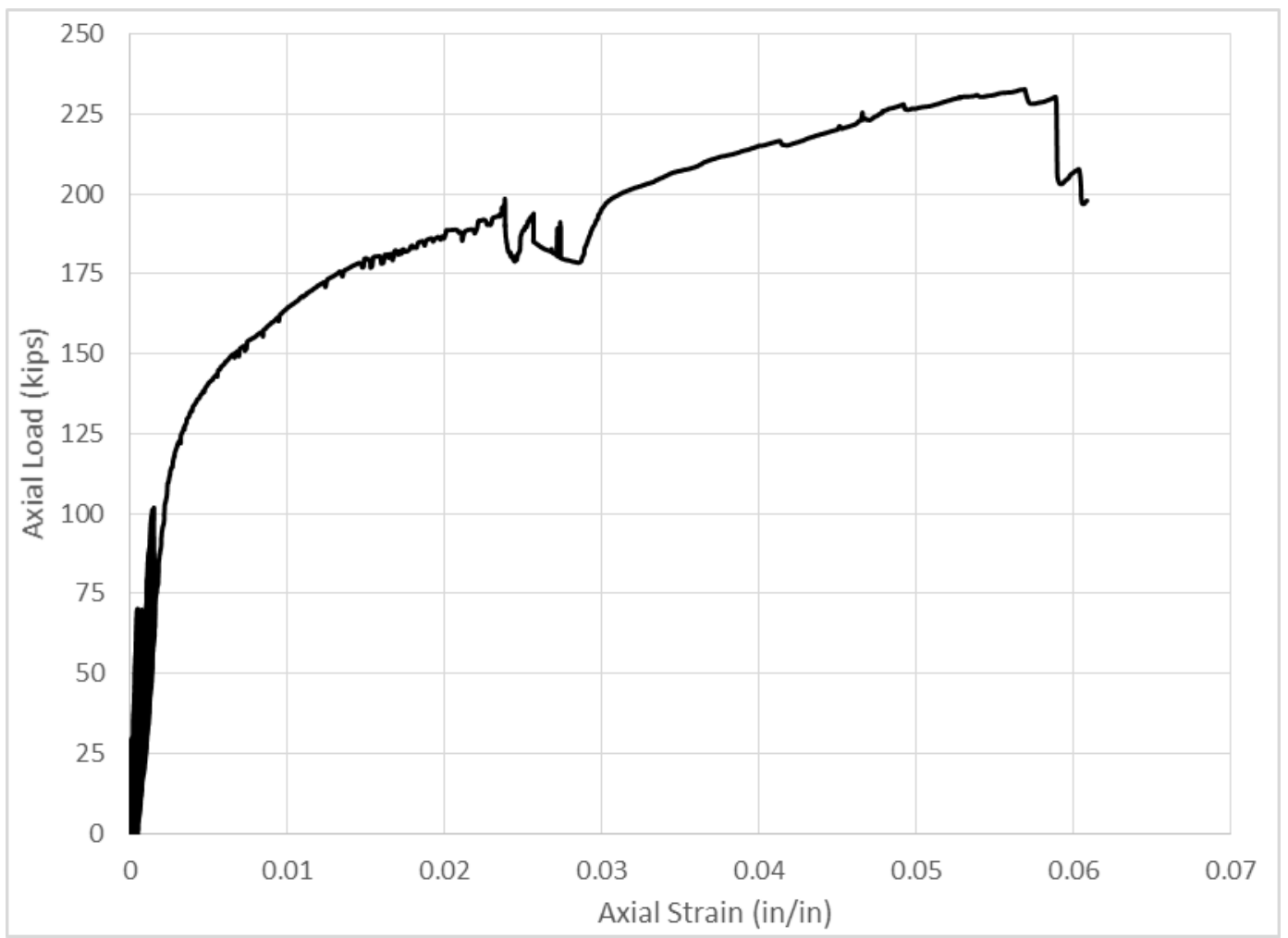

Figure 4-37: Axial load- Strain response of specimen C4NDC-F3 


\subsubsection{CFRP Transverse Strain}

\subsubsection{C4NDC-F1}

Figure 4-38 shows that the maximum average transverse strain at rupture $\left(\varepsilon_{f, \text { rup }}\right)$ is 0.0130. The maximum strain measured by each strain gauge at the maximum load is shown in Table 4-4.

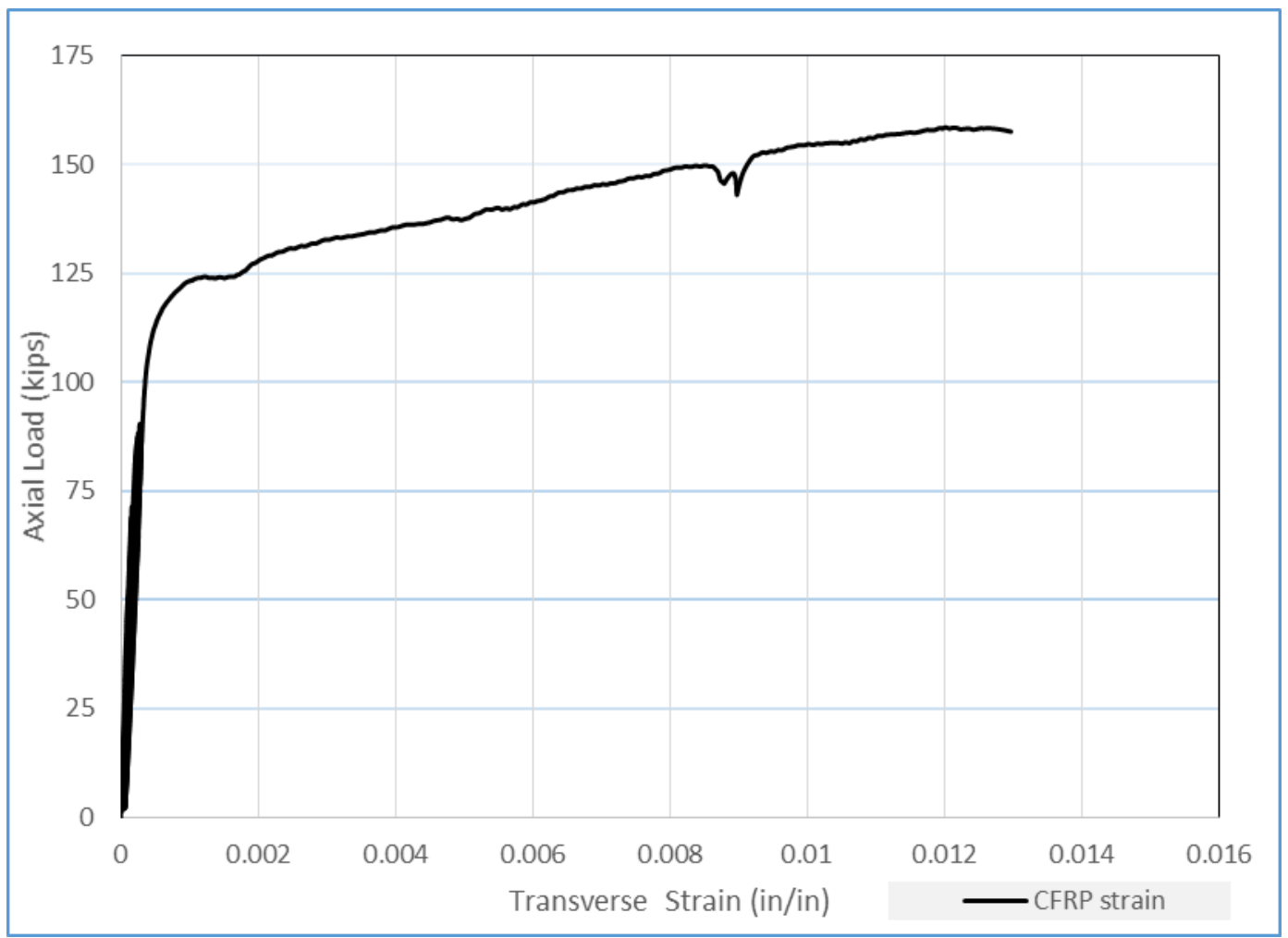

Figure 4-38: CFRP transverse strain response for C4NDC-F1

Table 4-4: Maximum CFRP transverse strain of C4NDC-F1

\begin{tabular}{|c|c|}
\hline Strain Gauge ID. & Max. CFRP Transverse Strain, $\varepsilon_{f, \text { rup }}$ \\
\hline Outside overlapping zone & 0.0142 \\
\hline S1 & 0.0123 \\
\hline S2 & 0.0113 \\
\hline S3 & 0.0120 \\
\hline S4 & \\
\hline Inside overlapping zone & 0.0073 \\
\hline So & 0.0130 \\
\hline Avg.
\end{tabular}




\subsubsection{C4NDC-F2}

Figure 4-39 shows that the maximum average transverse strain at rupture $\left(\varepsilon_{f, \text { rup }}\right)$ is 0.0130. The maximum strain measured by each strain gauge at the maximum load is shown in Table 4-5.

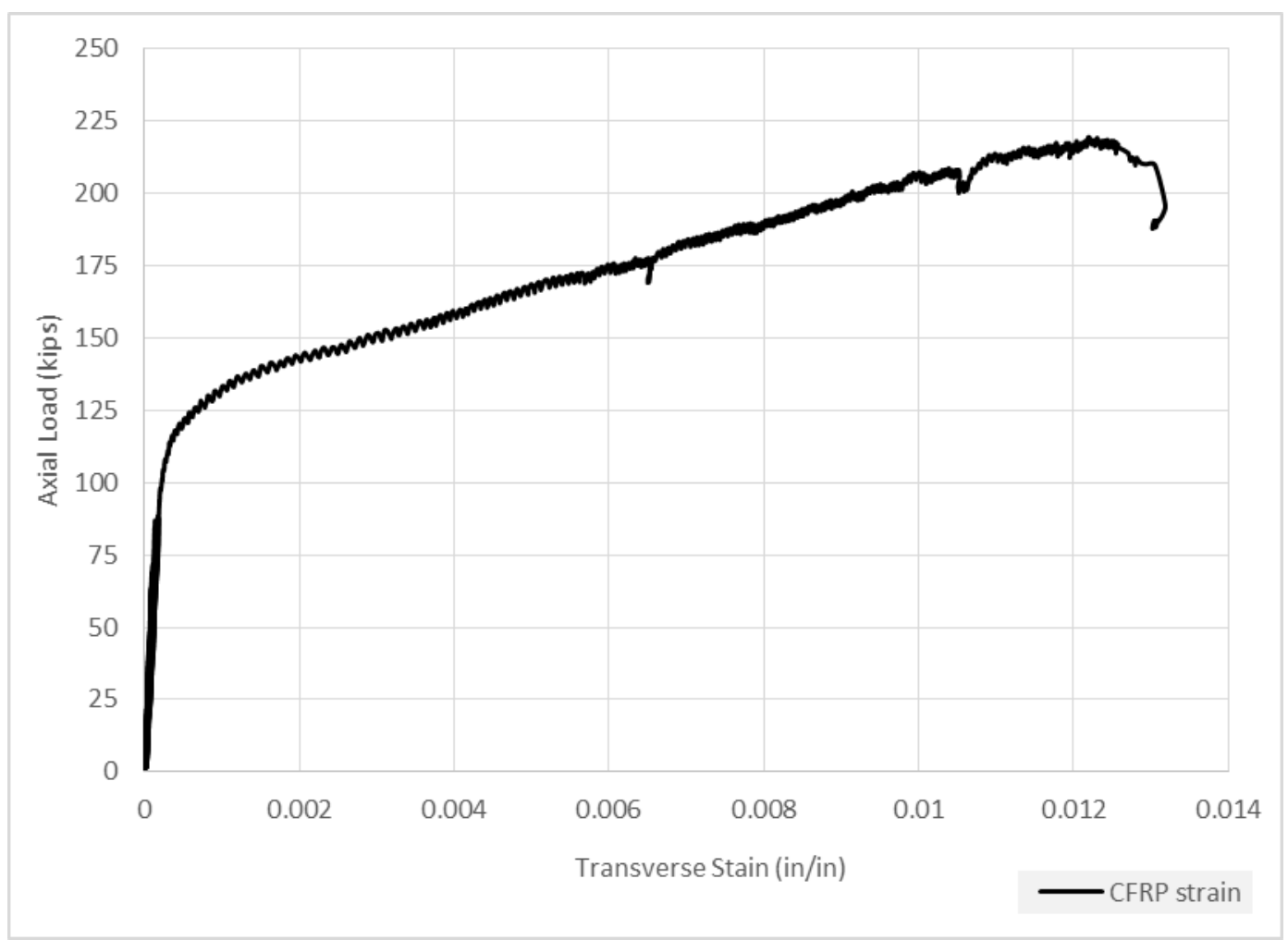

Figure 4-39: CFRP transverse strain response for specimen C4NDC-F2

Table 4-5: Maximum CFRP transverse strain of C4NDC-F2

\begin{tabular}{|c|c|}
\hline Strain Gauge ID. & Max. CFRP Transverse Strain, $\varepsilon_{f, \text { rup }}$ \\
\hline Outside overlapping zone & 0.0119 \\
\hline S1 & 0.0136 \\
\hline S2 & 0.0132 \\
\hline S3 & --- \\
\hline S4 & \\
\hline Inside overlapping zone & 0.0117 \\
\hline So & 0.0130 \\
\hline Avg. & \\
\hline
\end{tabular}




\subsubsection{C4NFC-F3}

Figure 4-40 shows that the maximum average transverse strain at rupture $\left(\varepsilon_{f, r u p}\right)$ is 0.0120 . The maximum strain measured by each strain gauge at the maximum load is shown in Table 4-6.

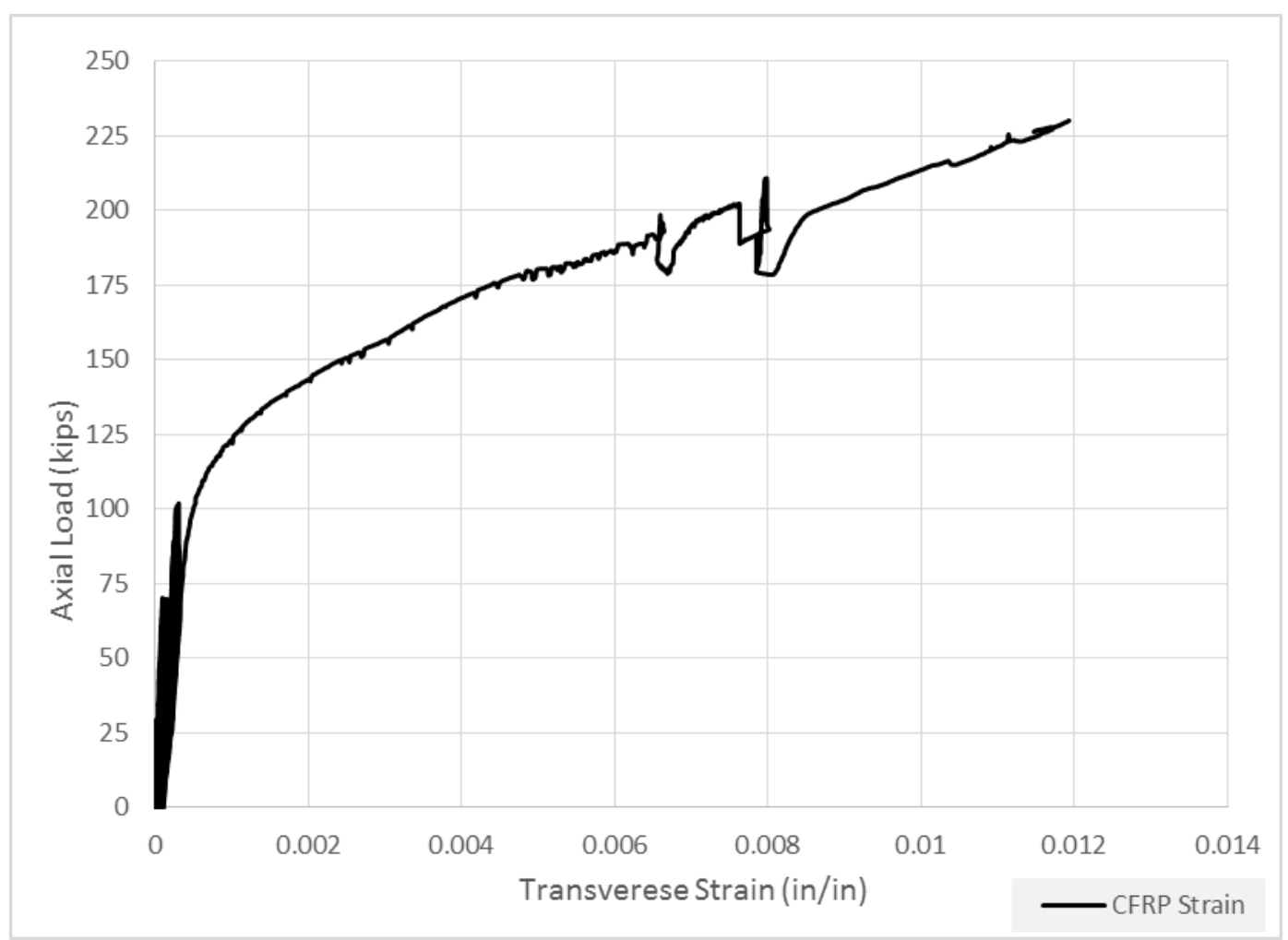

Figure 4-40: CFRP transverse strain response for specimen C4NDC-F3

Table 4-6: Maximum CFRP transverse strain of C4NDC-F3

\begin{tabular}{|c|c|}
\hline Strain Gauge ID. & Max. CFRP Transverse Strain, $\varepsilon_{f, r u p}$ \\
\hline Outside overlapping zone & 0.0114 \\
\hline S1 & 0.0123 \\
\hline S2 & 0.0120 \\
\hline S3 & 0.0131 \\
\hline S4 & \\
\hline Inside overlapping zone & 0.0107 \\
\hline So & 0.0120 \\
\hline Avg.
\end{tabular}




\section{Part 2. Discussion}

\subsection{Failure Mode}

In the case of the unwrapped specimens, the failure started with development of the longitudinal cracks that extended and propagated while continuing loading. Those cracks initiated the concrete cover spalling when the load approached the axial load carrying capacity of the specimen. With continuing the loading process, the longitudinal bars started to buckle and the axial load started to fall. Consequently, the unwrapped specimens failed with severe buckling of the longitudinal bars and relative crushing of the concrete core. The failure modes of the unwrapped specimens are shown in Figure 4-41 and Figure 4-42. On the other hand, all of the wrapped specimens failed by sudden tensile rupture of the CFRP jacket. The rupture originated near the corners of the columns. Figure 4-41 and Figure 4-42 interestingly show that the CFRP rupture mainly occurred at the lower half of the $\mathrm{C} 2$ specimen. In contrast, the rupture occurred at the mid-height region of the $\mathrm{C} 4$ specimens except the specimen C4NDC-F2, where the rupture occurred at the lower half of the specimen. In addition, it was noticed that there was no failure at the ends of wrapped specimens because the ends were strengthened with additional 1.25 " CFRP strips. However, the only exception was in specimen C4NDC-F3 where the first noticeable rupture occurred at the bottom end-specifically near the opening that was made for the internal strain gauges' wires. This end premature rupture might have occurred due to the inadequate bonding between the CRRP and the concrete surface at the opening region. Removal of the ruptured CFRP jacket after the test revealed that the longitudinal reinforcing bars had severely buckled and the single steel hoop had bent outward in most cases. In addition, the concrete core was noticeably 
cracked and crushed. In conclusion, the existence of the CFRP jacket prevented the spalling of the concrete cover and delayed the buckling of the reinforcing bars. Therefore, it resulted in significant deformability as shown in Figure 4-43. In this figure, some tested and untested specimens were placed next to each other to show the difference in their heights indicating that they were different in their deformation capacity.
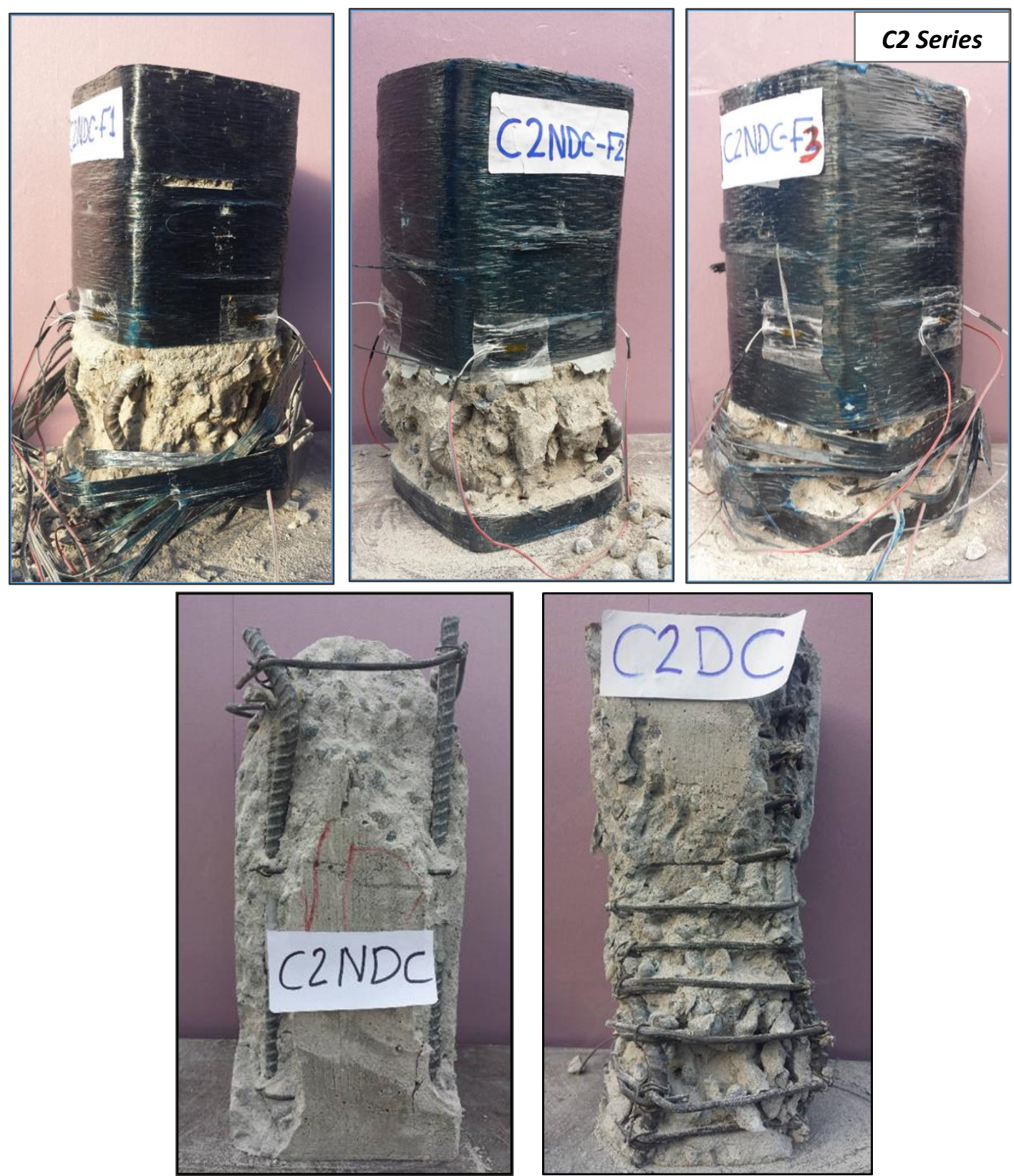

Figure 4-41: Failure Modes of C2 series specimens 

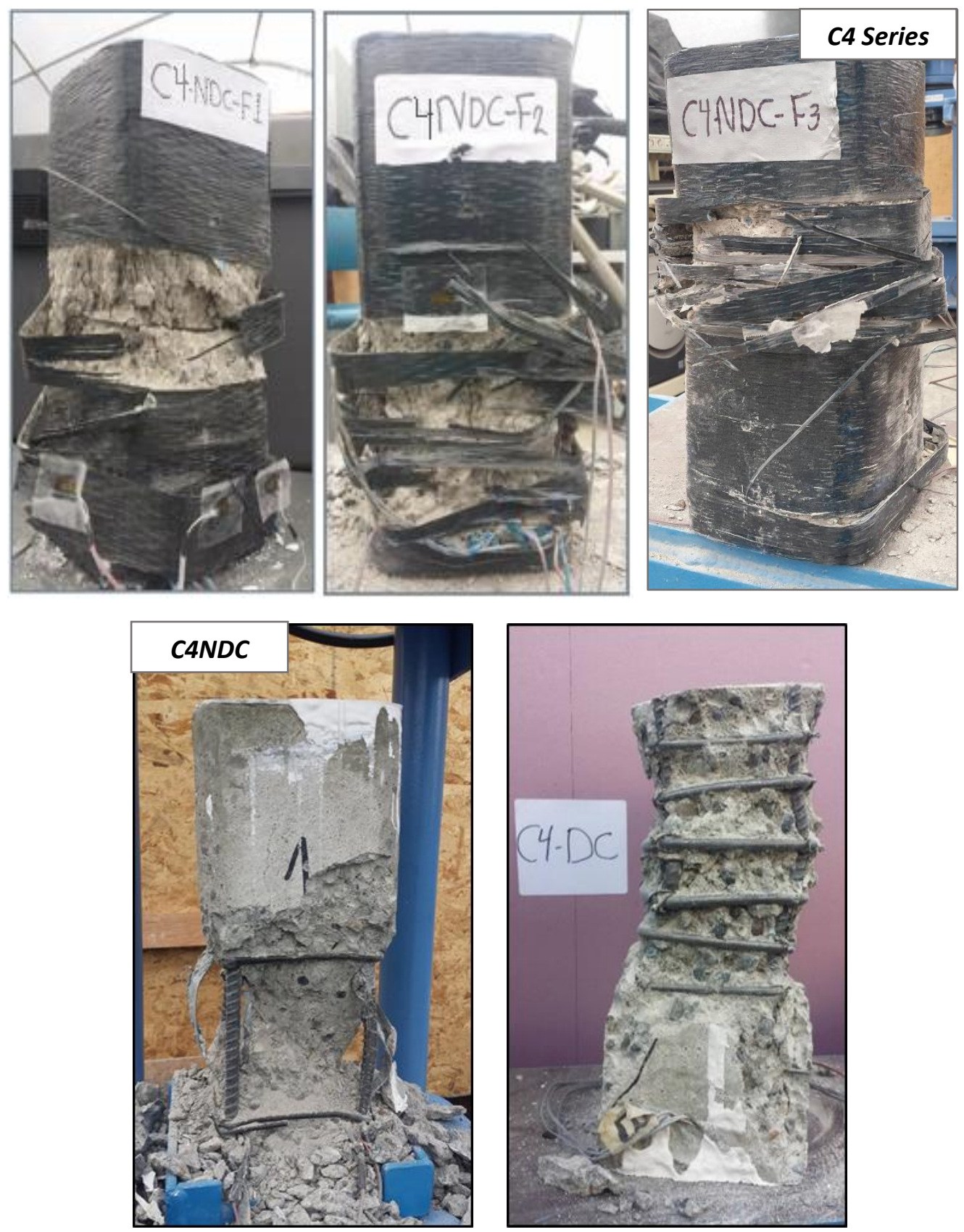

Figure 4-42: Failure Modes of C4 series specimens 


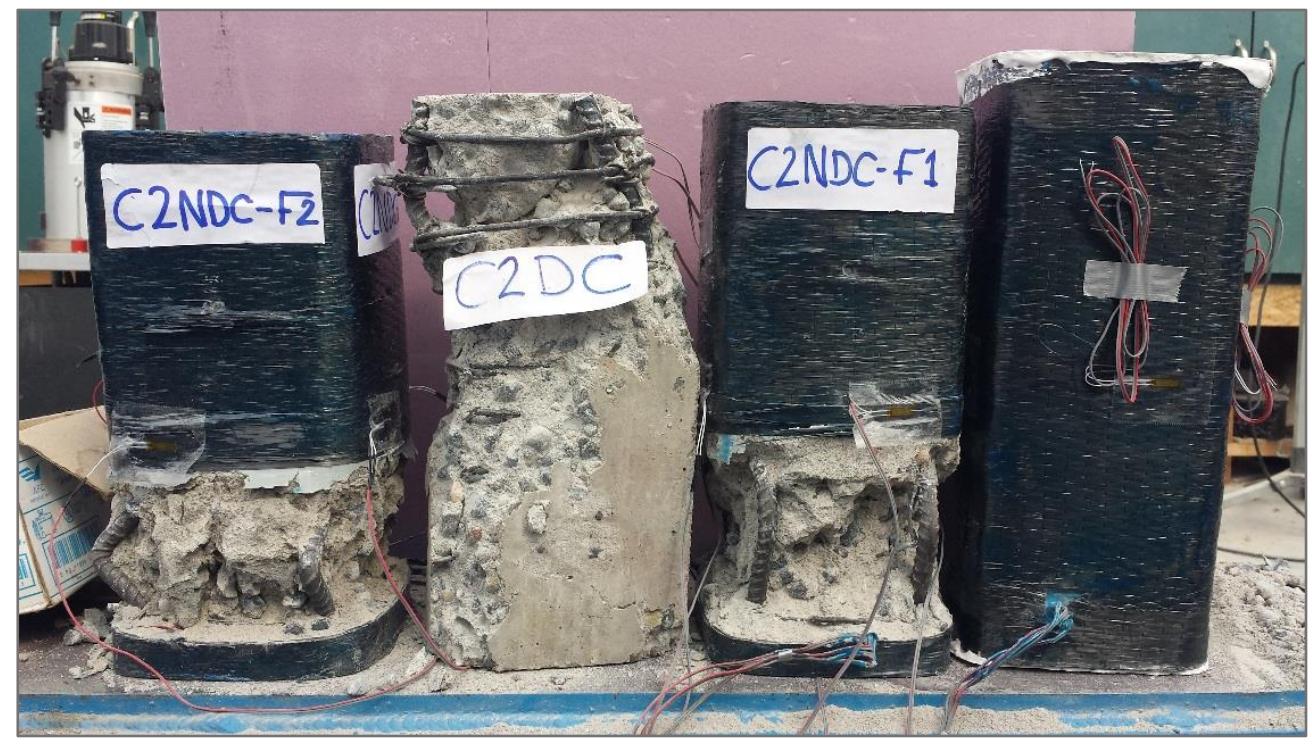

Figure 4-43: The height differences of some specimens after the test

\subsection{Axial Load-Axial Strain Relationship for Series C2}

Figure 4-44 shows the axial load vs. strain relationships of the five specimen of series C2. Inspecting the axial load vs. strain diagrams for the specimens C2NDC-F1, C2NDC-F2, and C2NDC-F3 reveals the effectiveness of the CFRP confining action due to the noticeable bilinear ascending response with the nonlinear transition zone around the peak axial load-carrying capacity of the non-ductile unconfined column (C2NDC). It is interesting to note that the first linear portions of the CFRP-wrapped specimens' responses have almost the same slope as the unwrapped specimens. The possible reason for this behavior is that this linear portion was mainly governed by the elastic properties of the concrete since the CFRP confining action was not active at this stage.

For the unwrapped specimens, it was decided that the effective axial load vs. strain curve should be ended when the post-peak axial load dropped to about $50 \%$ of the peak axial load. This decision was made based on the assumption that any column would be considered efficient if it was able to handle any sustained dead load after achieving its 
axial load- carrying capacity (assuming the sustained dead load is $50 \%$ of the peak axial load). For better presentation of the test results, they are summarized in Table 4-7. However, some terminology used in this table needs to be defined first:

- The transition load $\left(\mathbf{P}_{\mathbf{o}}\right)$ : It is the axial load where the CFRP confining action is believed to be activated. In other words, it is the load at which the axial load vs, strain changes the slope.

- $\varepsilon_{\boldsymbol{o}}$ : It the axial strain corresponding to the axial load $\mathrm{P}_{\mathrm{o}}$

- The ultimate load $\left(\mathbf{P}_{\mathbf{u}}\right)$ : For unwrapped specimens, it is the peak axial load carrying capacity that is achieved by the concrete core. For wrapped specimens, it is the axial maximum axial load that is achieved at the rupture of the CFRP jacket.

- $\varepsilon_{m}$ : It is the axial strain corresponding to the axial load $\mathrm{Pu}_{\mathrm{u}}$

- $\varepsilon_{c u}$ : It the axial strain corresponding to an axial load value where the maximum axial load drops $50 \%$. For the specimens where part of the post-peak curve was missing, it was assumed that $\boldsymbol{\varepsilon}_{\boldsymbol{c u}}$ would be the last recorded axial strain. 


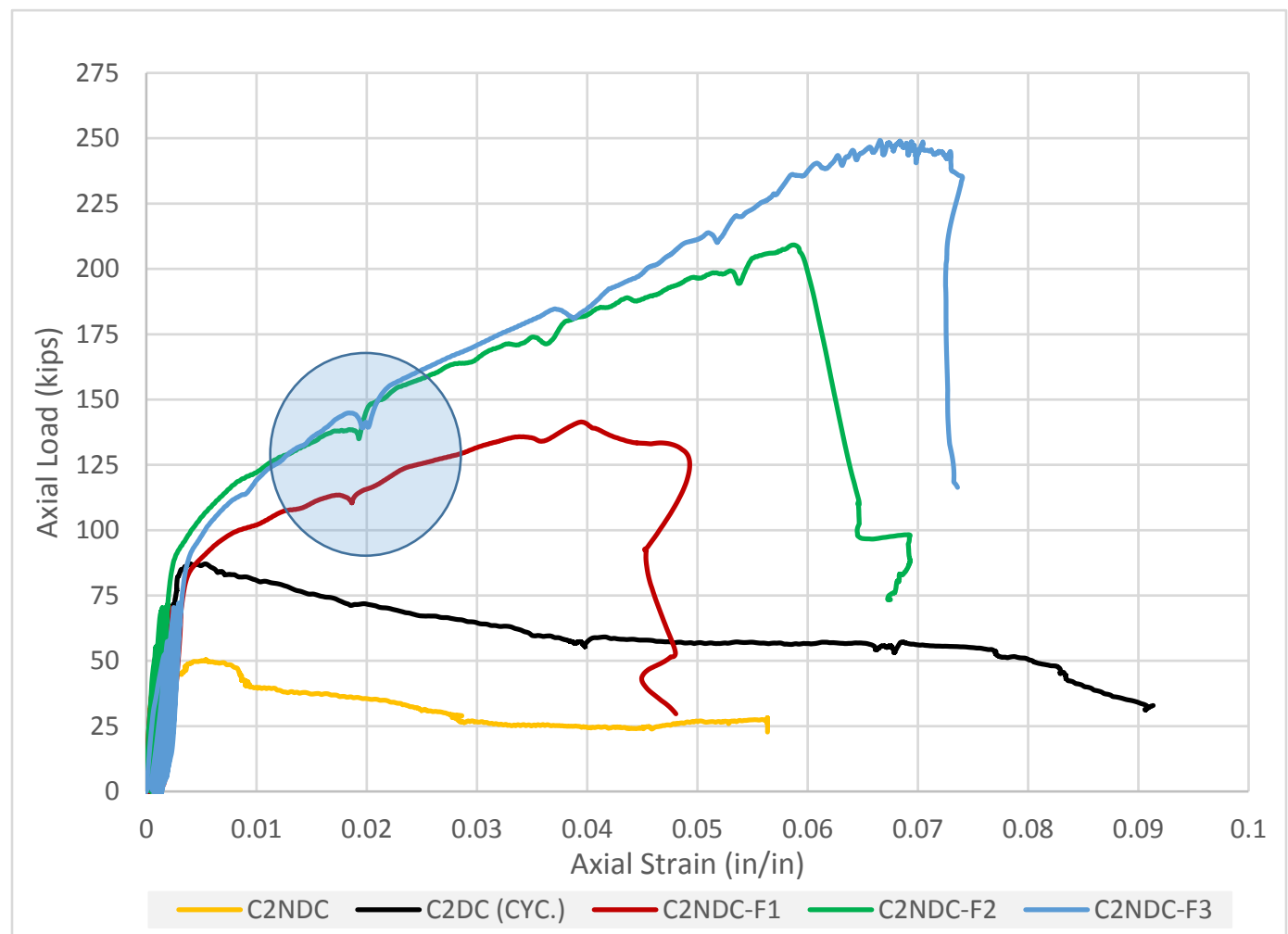

Figure 4-44: Axial load vs. strain response of series C2 specimens

Table 4-7: C2 series Test results

\begin{tabular}{|c|c|c|c|c|c|}
\hline Specimen & $\mathrm{P}_{\mathrm{o}}(\mathrm{kips})$ & $\mathrm{Pu}_{\mathrm{u}}(\mathrm{kips})$ & $\boldsymbol{\varepsilon}_{\boldsymbol{o}}(\%)$ & $\boldsymbol{\varepsilon}_{\boldsymbol{m}}(\%)$ & $\boldsymbol{\varepsilon}_{\boldsymbol{c u}}(\%)$ \\
\hline C2NDC & -- & 51 & -- & 0.10 & 2.90 \\
\hline C2DC & -- & 86 & -- & 0.48 & 8.34 \\
\hline C2NDC-F1 & 83 & 142 & 0.38 & 3.80 & 4.64 \\
\hline C2NDC-F2 & 86 & 208 & 0.26 & 5.80 & 6.47 \\
\hline C2NDC-F3 & 85 & 249 & 0.36 & 6.80 & 7.33 \\
\hline
\end{tabular}




\subsection{Axial Load-Axial Strain Relationship for Series C4}

Figure 4-45 shows the axial load vs. strain relationships of the five specimen of series $\mathrm{C} 4$. By examining the axial strain responses of wrapped specimens, it is noted they are similar to the responses of the specimens of series $\mathrm{C} 2$ in terms of the bilinear shape and the identical slope of the first linear portion. By comparing the curves of specimens C4NDC and C4DC, it can be clearly seen the effect of lateral confinement reinforcement on the significant enhancement in the axial strain capacity in addition to the enhancement in the axial load-carrying capacity. Table 4-8 summarizes the test results of series $\mathrm{C} 4$.

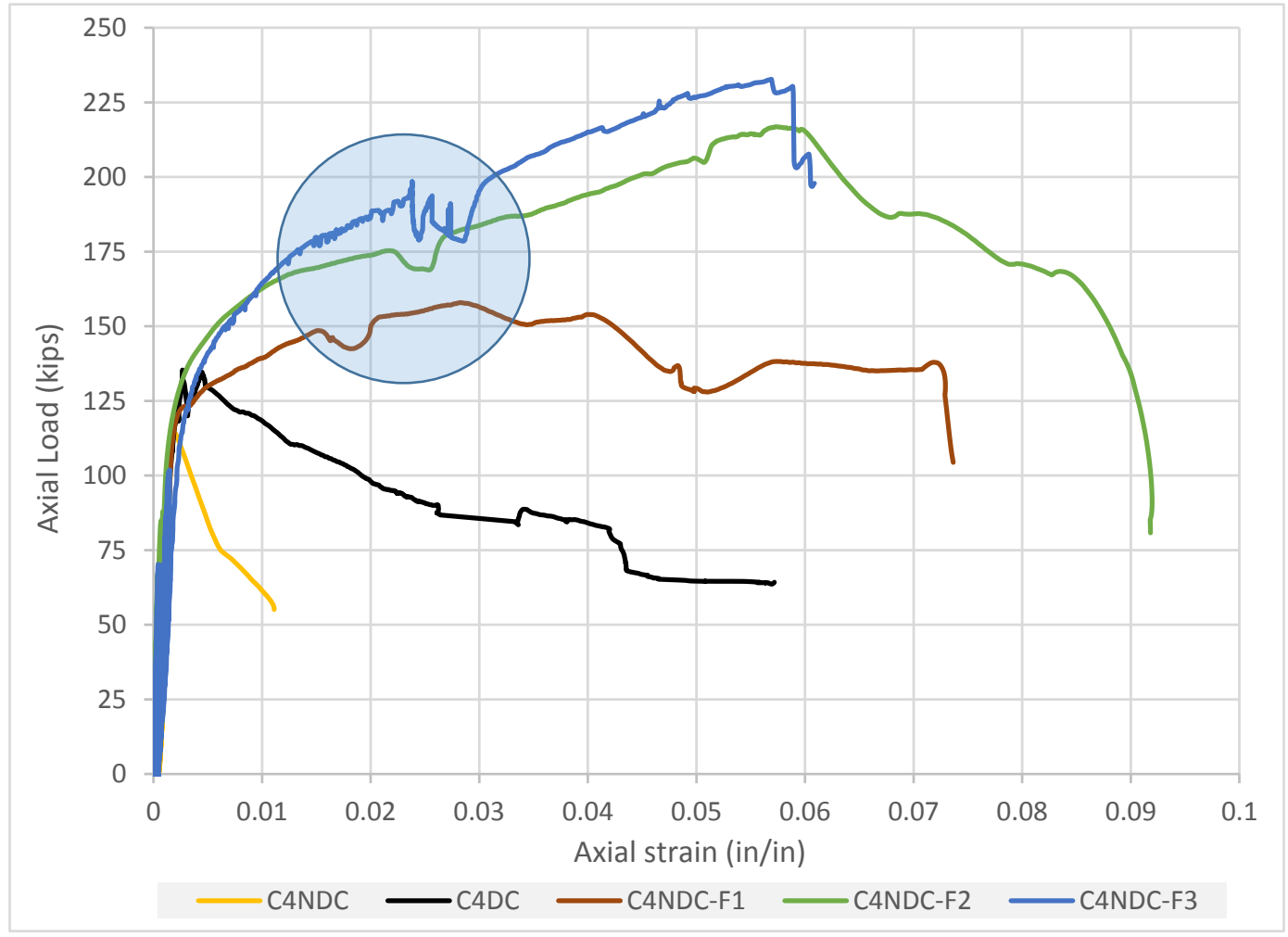

Figure 4-45: Axial load vs. strain response of series $C 4$ specimens 


\section{Table 4-8: C4 series Test results}

\begin{tabular}{|c|c|c|c|c|c|}
\hline Specimen & $\mathrm{P}_{\mathrm{o}}$ (kips) & $\mathrm{P}_{\mathrm{u}}(\mathrm{kips})$ & $\boldsymbol{\varepsilon}_{\boldsymbol{o}}(\%)$ & $\boldsymbol{\varepsilon}_{\boldsymbol{m}}(\%)$ & $\boldsymbol{\varepsilon}_{\boldsymbol{c u}}(\%)$ \\
\hline C4NDC & -- & 115 & -- & 0.19 & 1.07 \\
\hline C4DC & -- & 134 & -- & 0.44 & 4.40 \\
\hline C4NDC-F1 & 120 & 159 & 0.22 & 2.86 & 7.36 \\
\hline C4NDC-F2 & 140 & 218 & 0.40 & 5.90 & 9.12 \\
\hline C4NDC-F3 & 135 & 233 & 0.42 & 5.80 & 6.07 \\
\hline
\end{tabular}

It is worth noting that the slope of the second linear portion of specimen C4NDC-F3 is close to the slope of that of specimen C4NDC-F2. This observation is more pronounced when comparing the curve of specimen C2NDC-F3 with C2NDC-F2. This indicates that the stiffness of the column C4NDC-F3 and C2NDC-F3 are almost identical to that of column C4NDC-F2 and C2NDC-F2, respectively. Moreover, the test results show that ultimate strains of series $\mathrm{C} 2$ are more than those of series $\mathrm{C} 4$; however, the ultimate strain of specimen C4NDC-F2 is the same as that of specimen C2NDC-F2. This observation indicates that the axial strain capacity (ductility) of columns with low-grade concrete is higher than the strain capacity of columns with higher-grade concrete.

By inspecting the axial load-strain curves of both the C2 AND C4 specimens, it is interesting to note that all of the curves show a small drop in the axial load at an axial strain range of (0.02-0.03) in/in as highlighted in Figure 4-44 and Figure 4-45. By matching the corresponding axial load value on the CFRP transverse strain responses, the same drops can be clearly observed. The consistent existence of these drops indicates that there should be a scientific reason for these drops. A possible explanation might be that 
these sudden drops happened due to a sudden loss of the bonding action between the CFRP jacket and the concrete surface. This claim can be supported by the local buckling of the CFRP jacket that was observed during the testing of almost all the wrapped specimens.

\subsection{Idealized Axial Load-Deformation Relationship}

Figure 4-46 and Figure 4-47 show the experimental axial load-deformation curves of the CFRP-wrapped specimens in series $\mathrm{C} 2$ and $\mathrm{C} 4$. By inspecting each one of these curves, it can be seen that the curve could be simplified to a tri-linear curve consisting of three linear regions. The start and end points of each region were defined by the points at which the slope of the experimental curve changes. Those points are labeled on Figure 4-48 and Figure 4-49. The slope of each region of the idealized axial load-deformation curve can be interpreted as the stiffeners of the wrapped concrete column at that region. The slope of each region (i.e. stiffness) was computed by:

$$
K_{i}=\frac{\Delta P_{i}}{\Delta \delta_{c, i}}
$$

Where:

$K_{i}$ : The slope of each linear region (i.e. the stiffness of the CFRP-wrapped concrete column).

$\Delta \mathrm{P}_{\mathrm{i}}$ : The difference of the axial load between the start and end points of each region. $\Delta \delta_{c, i}:$ The difference of the axial deformation between the start and end points of each region.

Table 4-9 summarizes the slope of each linear region of the idealized axial loaddeformation curves of the CFR-wrapped specimens. 


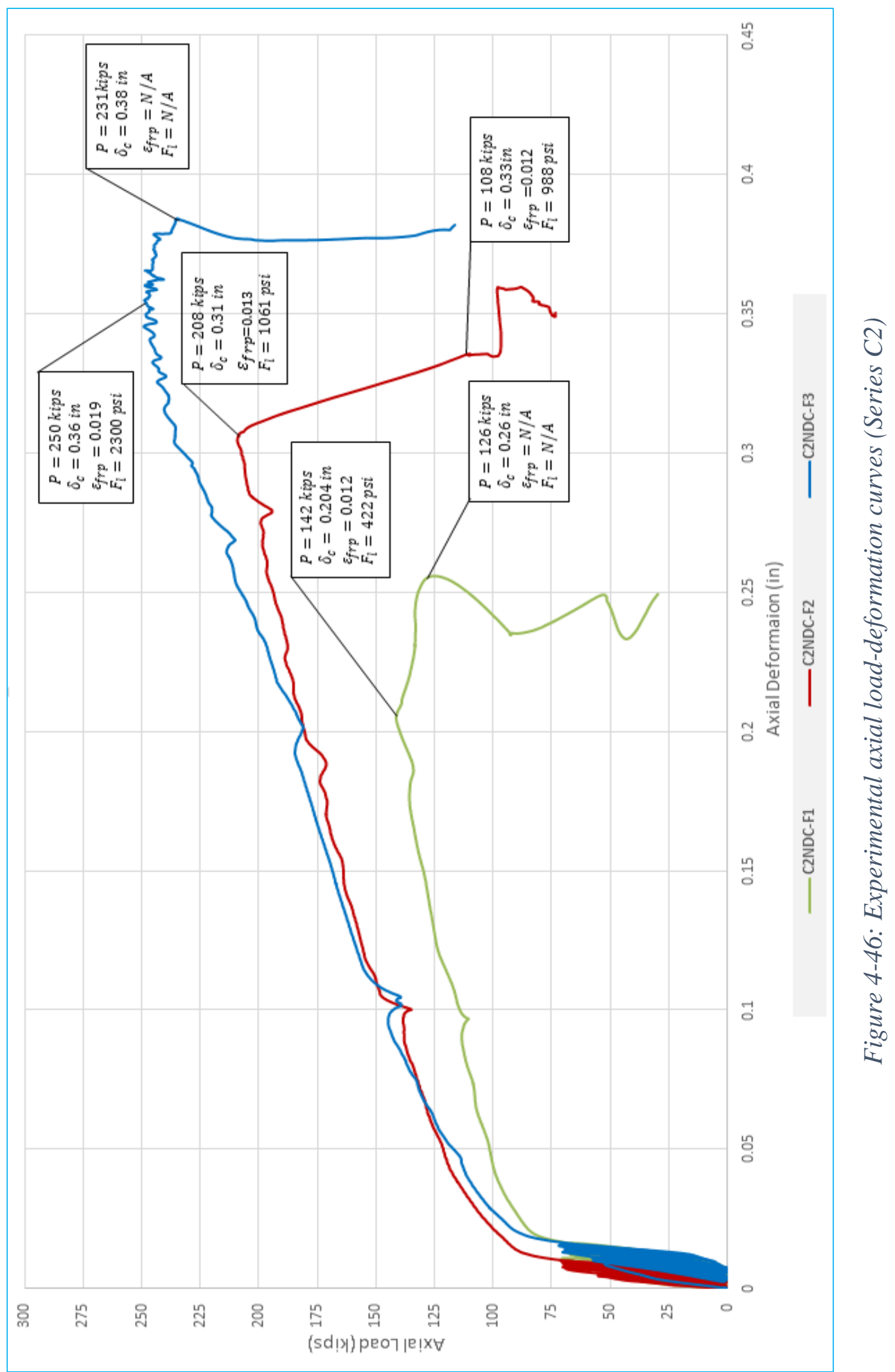




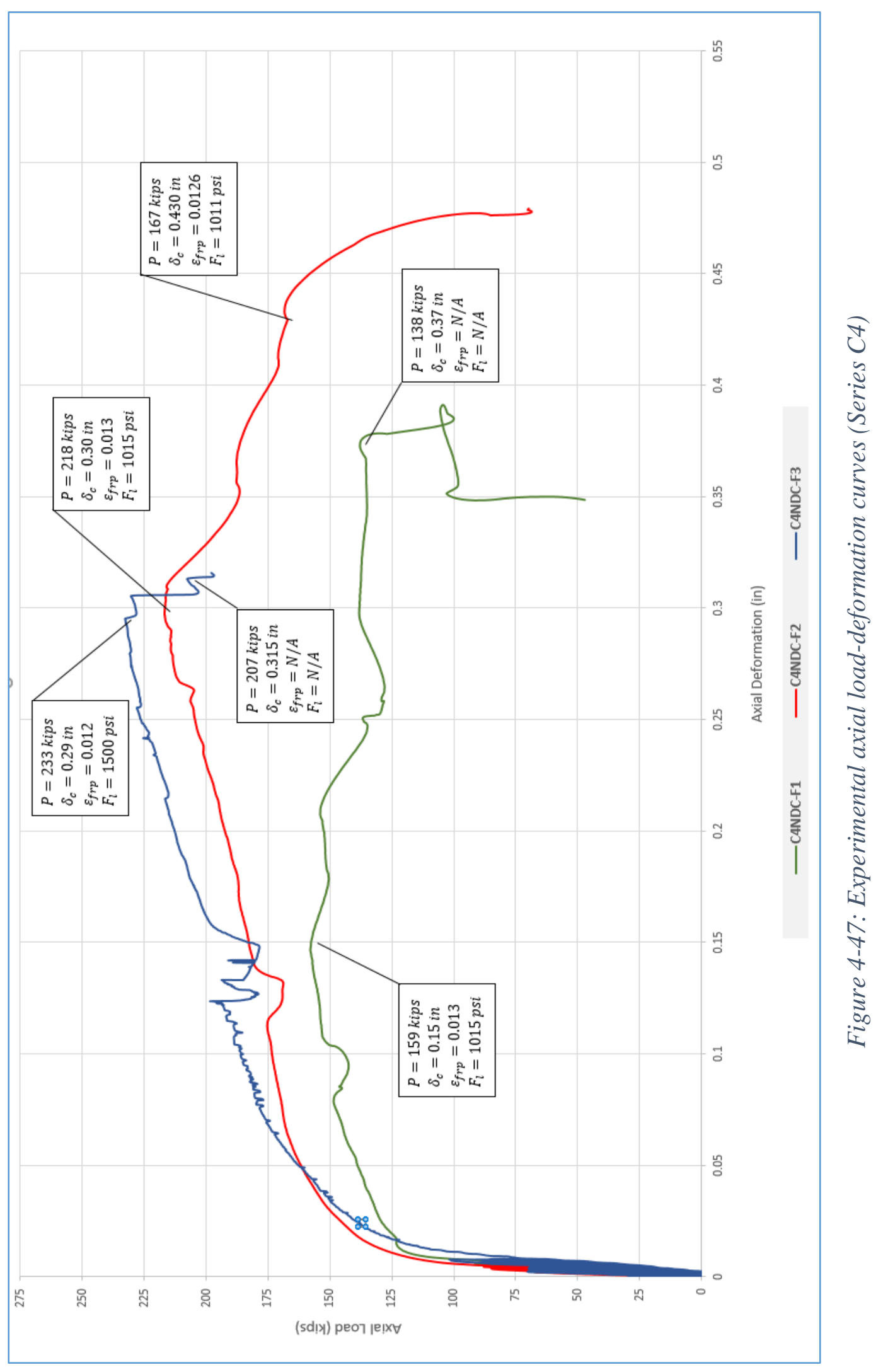


Table 4-9: Table of $K_{i}=\Delta P_{i} / \Delta \delta_{c, i}$

\begin{tabular}{|c|c|c|c|}
\hline \multirow{2}{*}{ Specimen } & \multicolumn{3}{|c|}{$K_{i}$ (kip/in) } \\
\cline { 2 - 4 } & Reg.(1) & Reg.(2) & Reg.(3) \\
\hline C2NDC-F1 & +4462.5 & +489 & -950 \\
\hline C2NDC-F2 & +6418 & +411 & -5000 \\
\hline C2NDC-F3 & +4213 & +320 & -286 \\
\hline C4NDC-F1 & +10515 & +281.5 & -95.5 \\
\hline C4NDC-F2 & +6747 & +279 & -392 \\
\hline C4NDC-F3 & +6196 & +365.5 & -1040 \\
\hline
\end{tabular}

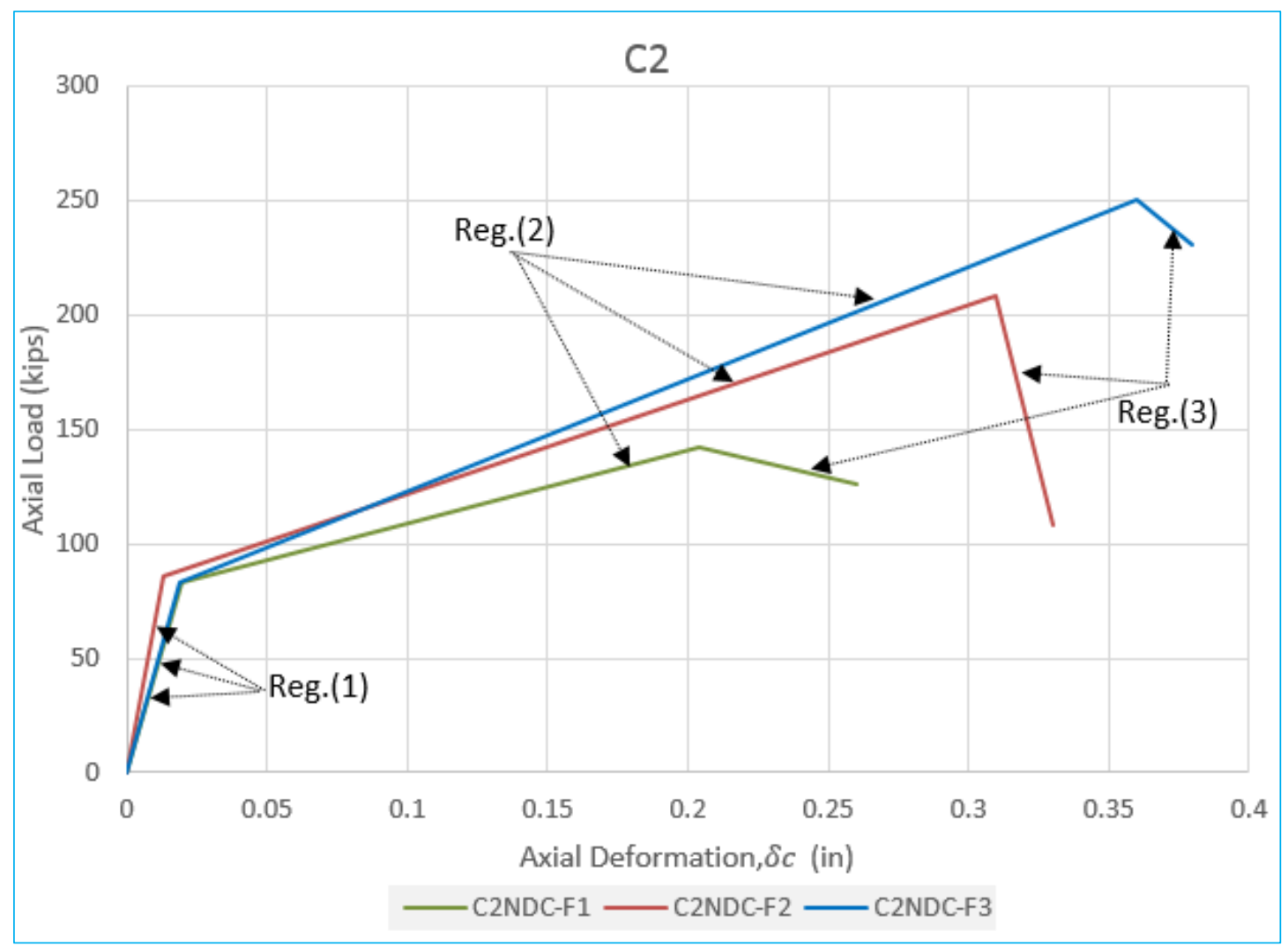

Figure 4-48: Idealized axial load-deformation relationships (series C2) 


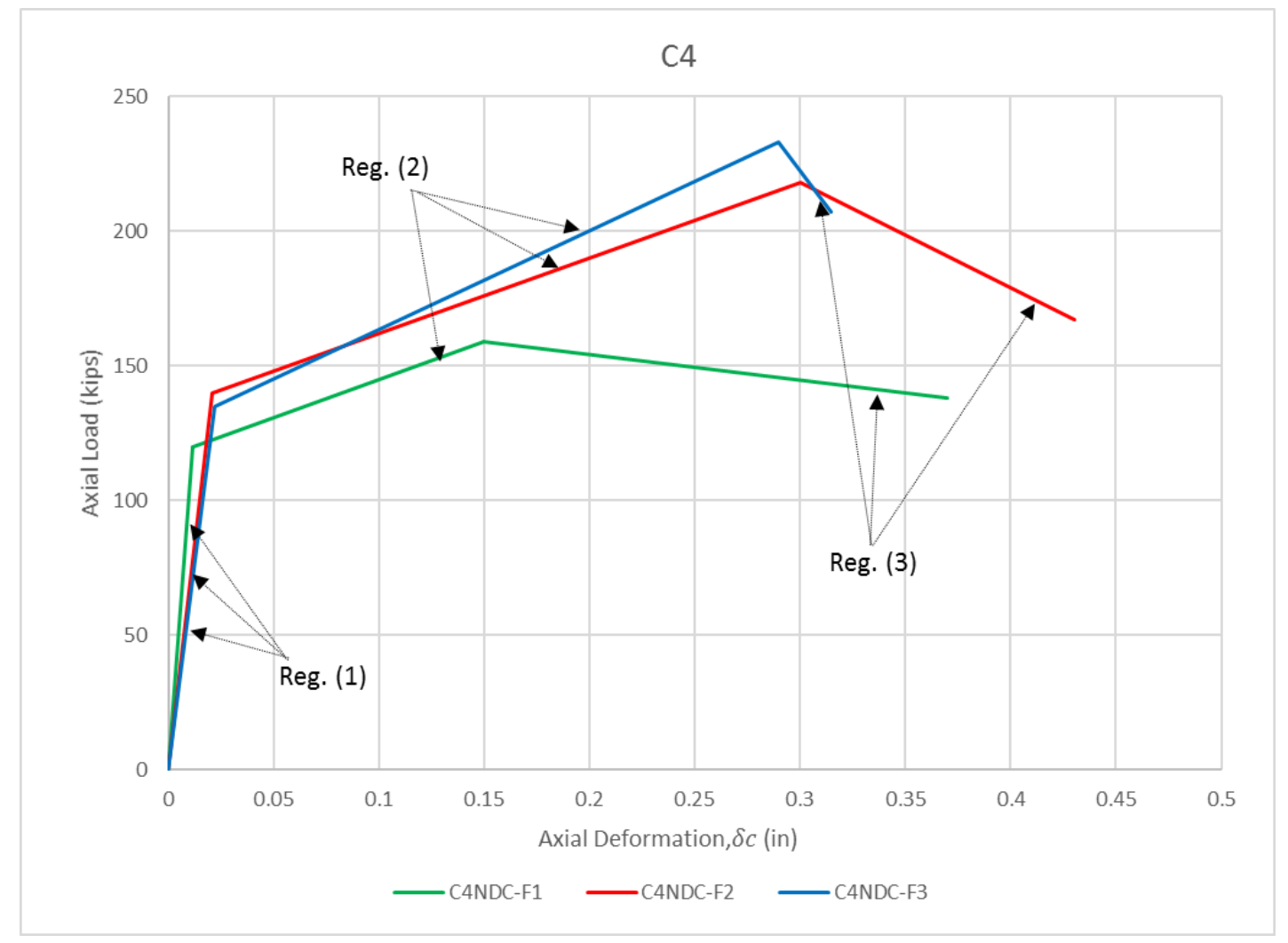

Figure 4-49: Idealized axial load-deformation relationships (series C4) 


\subsection{Apparent Concrete Strength of CFRP-Wrapped Columns}

By excluding the contribution of the longitudinal reinforcement to the axial load-carrying capacity of the confined columns, the apparent concrete strength was calculated using the same procedure that was mentioned earlier in this chapter. However, the calculated strength includes the effect of the CFRP confinement. For better illustration, an arbitrary confined concrete stress response for a wrapped column is depicted in Figure 4-50. In this figure, $f_{o}$ is the apparent confined concrete strength and it is denoted as $f_{c o}$ in the case of the actual unconfined concrete column (NDC columns). The apparent concrete strength $\left(f_{c c}\right)$ is the maximum concrete stress achieved by the wrapped column. In addition, $\varepsilon_{o}$ is the axial strain corresponding to $f_{o}$ while $\varepsilon_{m}$ is the axial strain corresponding to $f_{c c}$. Figure 4-51 and Figure 4-52 present the calculated confined concrete stress $\left(\boldsymbol{\sigma}_{\mathrm{c}}\right)$ for the wrapped and unwrapped specimens of series C2 and C4, respectively. Table 4-10 summarizes the apparent concrete strength of each specimen of series $\mathrm{C} 2$ and $\mathrm{C} 4$.

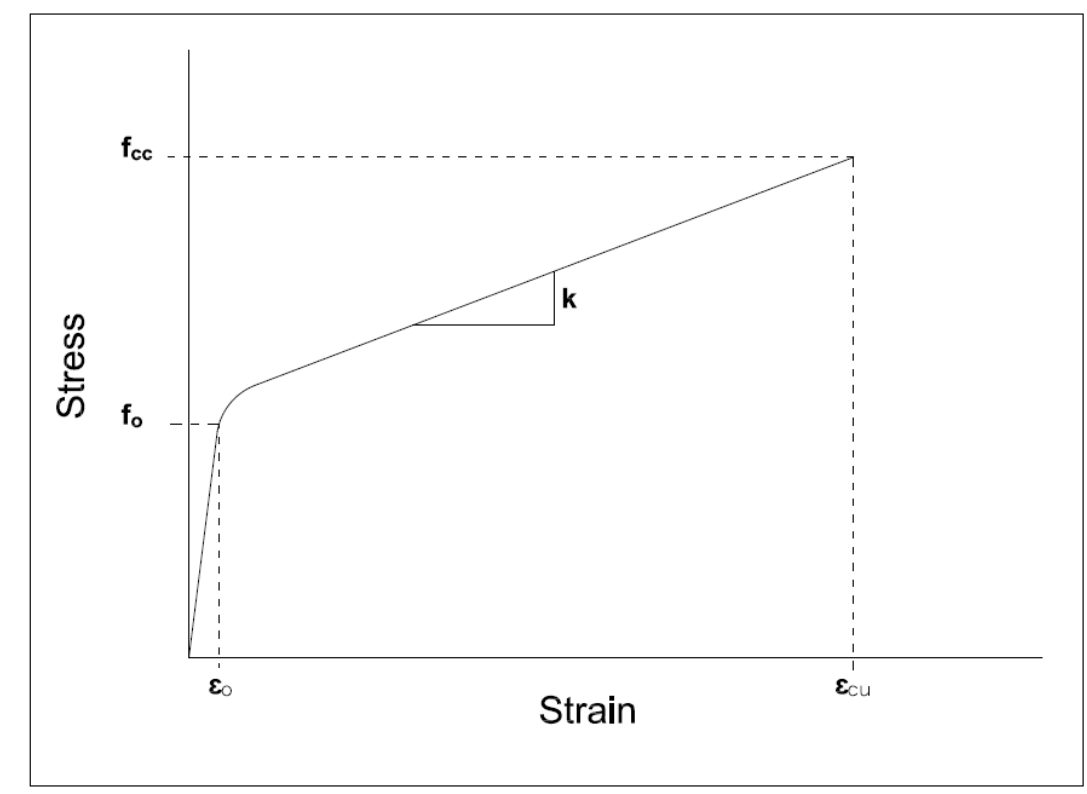

Figure 4-50: Typical stress-strain curve of FRP-confined concrete 


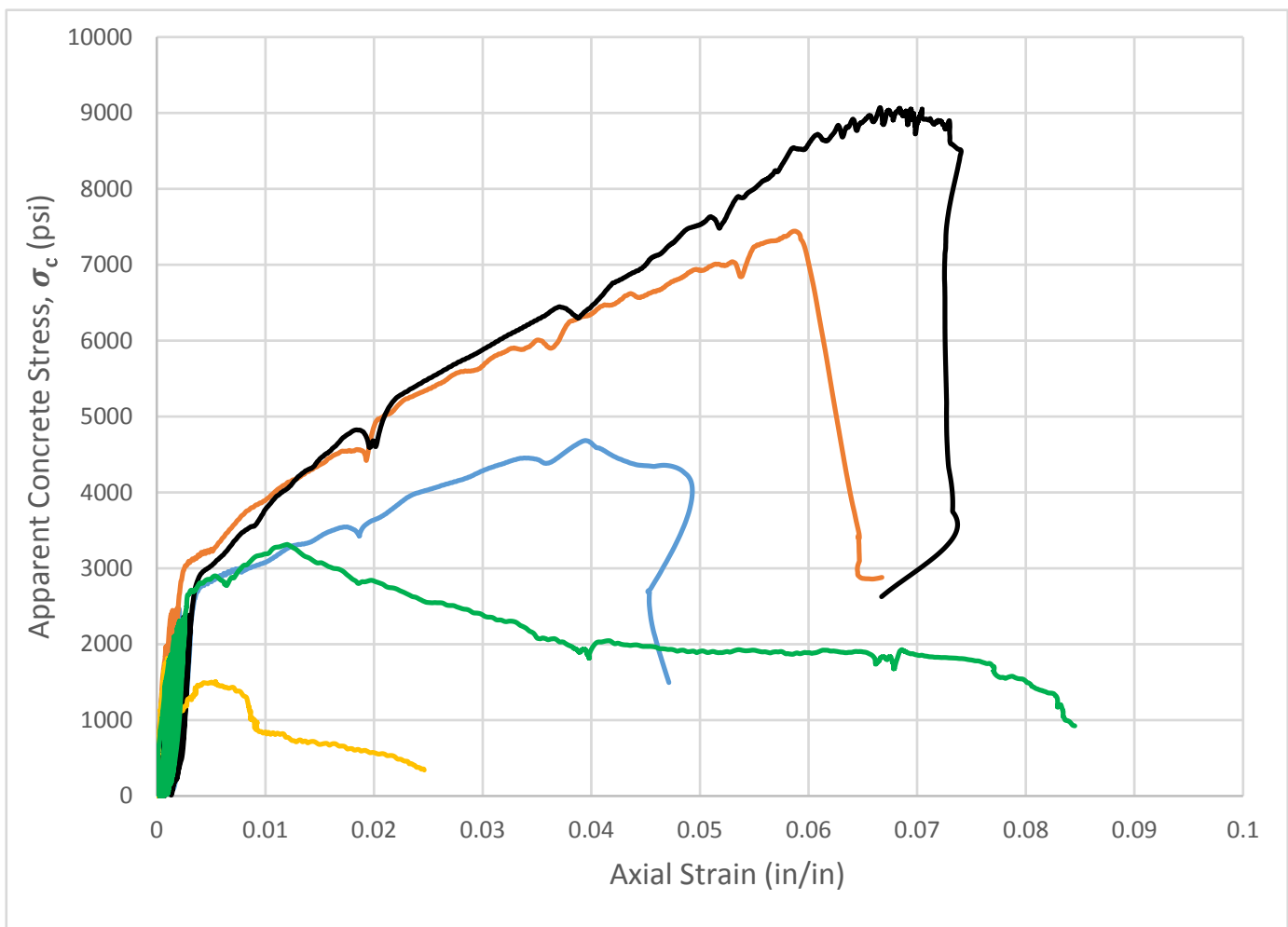

Figure 4-51: Apparent concrete stress (Series C2)

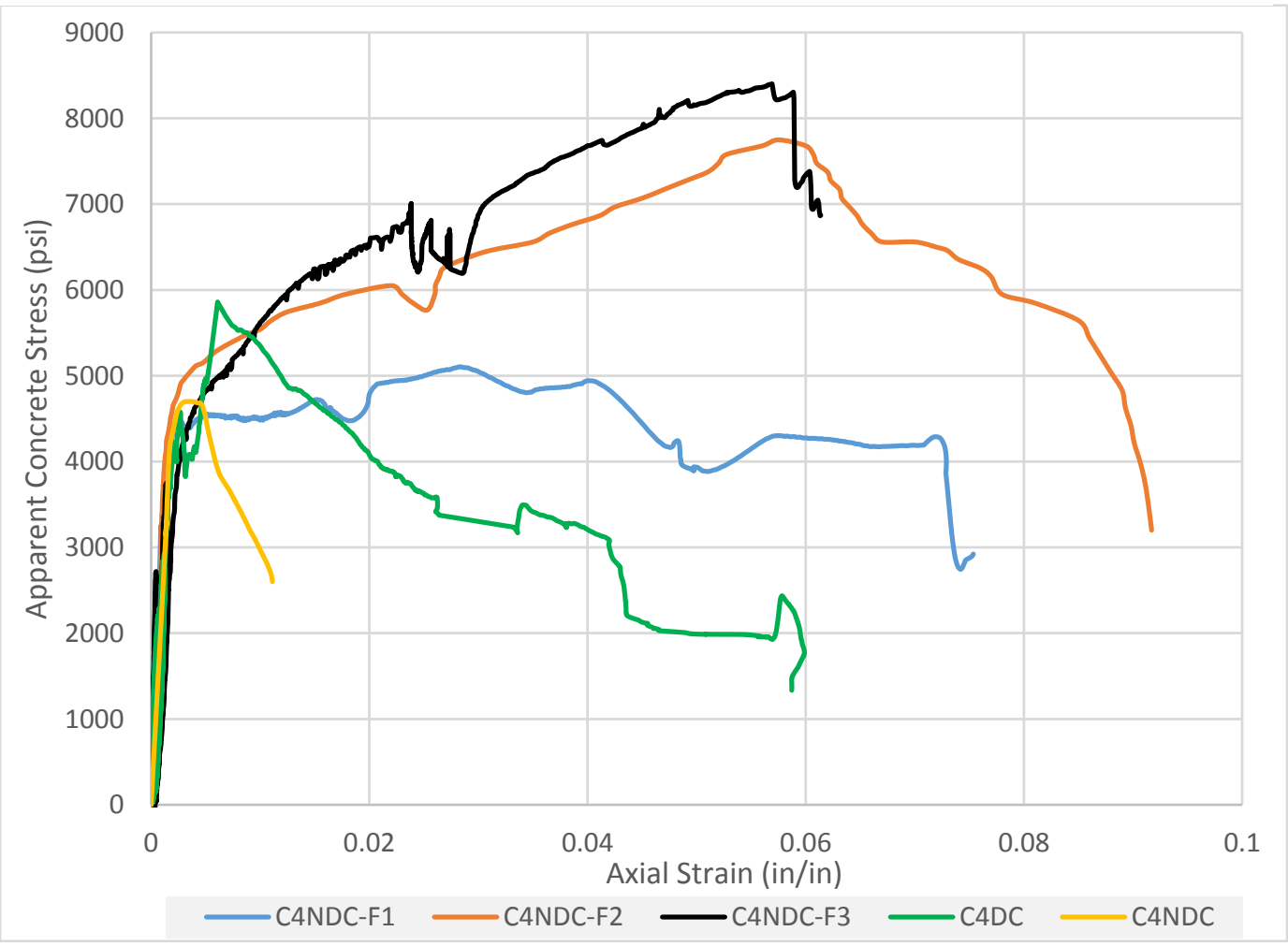

Figure 4-52: Apparent concrete stress (Series C4) 
Table 4-10: Apparent concrete strength

\begin{tabular}{|c|c|c|c|c|}
\hline Series & Specimen & $\begin{array}{c}f_{c o} \\
(\mathrm{psi})\end{array}$ & $\begin{array}{c}f_{o} \\
(\mathrm{psi})\end{array}$ & $\begin{array}{c}f_{c c} \\
(\mathrm{psi})\end{array}$ \\
\hline \multirow{4}{*}{ C2 } & C2NDC & 1800 & --- & --- \\
\cline { 2 - 5 } & C2DC & --- & --- & 3300 \\
\cline { 2 - 5 } & C2NDC-F1 & --- & 2650 & 4650 \\
\cline { 2 - 5 } & C2NDC-F2 & --- & 2800 & 7400 \\
\cline { 2 - 5 } & C2NDC-F3 & --- & 2630 & 9000 \\
\hline \multirow{4}{*}{ C4 } & C4NDC & 4800 & --- & --- \\
\cline { 2 - 5 } & C4DC & --- & --- & 5780 \\
\cline { 2 - 5 } & C4NDC-F1 & --- & 4250 & 5090 \\
\cline { 2 - 5 } & C4NDC-F2 & --- & 4500 & 7750 \\
\cline { 2 - 5 } & C4NDC-F3 & --- & 4200 & 8310 \\
\hline
\end{tabular}

\subsection{CFRP Rupture Strain $\left(\varepsilon_{f, \text { rup }}\right)$}

As formerly mentioned, the measured CFRP rupture strains for specimens C2NDC-F1 and C4NDC-F1 were $1.32 \%$ and $1.42 \%$, respectively. By comparing those two strain values with the tensile rupture strain of the CFRP material that was obtained by the direct tensile test of flat CFRP coupons (manufacturer: $\varepsilon$, rup $=1.67 \%$ ), it can be concluded that the CFRP jacket was able to utilize about 79-85\% of the strain capacity of the CFRP material. These results agree with the findings from literature that states that the maximum tensile strain of the CFRP material cannot be reached by the CFRP jacket (Xiao \& Wu, 2000; Pessiki et al., 2001; Micelli \& Modarelli, 2013). In addition, previous researchers found that 20-60\% of the CFRP tensile strain capacity can be utilized by the CFRP jacket. Therefore, some Theoretical design-oriented stress-strain models for FRPstrengthened concrete columns recommend using an FRP strain efficiency factor, $k_{\varepsilon}$ between 0.5 to 0.6 ( Lam \& Teng ,2003; Carey\& Harries,2005; ACI 440-2R, 2008). However, in this research, higher percentage of the CFRP strain capacity was achieved. 
Wu and Jiang (2013) also reported, as mentioned in Section 2.6, a high percentage of the utilized FRP strain (i.e. $k_{\varepsilon}=0.9$ ). Therefore, it can be said that most of the existing stress-strain models of the FRP-strengthened concrete underestimate the confinement effectiveness of the CFRP jacket.

\subsection{CFRP Confining Pressure $\left(F_{l}\right)$}

First, the lateral confining action developed by the single steel hoop at mid-height of the column was neglected. The FRP-confining jacket exerts circumferential pressure on the concrete specimen. This confining pressure is basically a reaction to the lateral dilation of the concrete when loaded uniaxially. However, it mainly depends on the tensile stress developed in the CFRP jacket. The maximum lateral confining pressure is attained when the CFRP circumferential tensile strain reaches its ultimate value (the rupture strain). The distribution of the FRP confining pressure around the circumference depends on the cross-sectional shape of the concrete specimen. It is well known that the distribution of the pressure is uniform in the case of the circular cross section. However, for square cross sections, the distribution of the confinement pressure is not uniform. It is concentrated at the corners and has a minimum value at the mid-width of the column sides. Figure 4-54 shows the effectively confined concrete area (Ae) that was adopted from Lam and Teng (2003). 


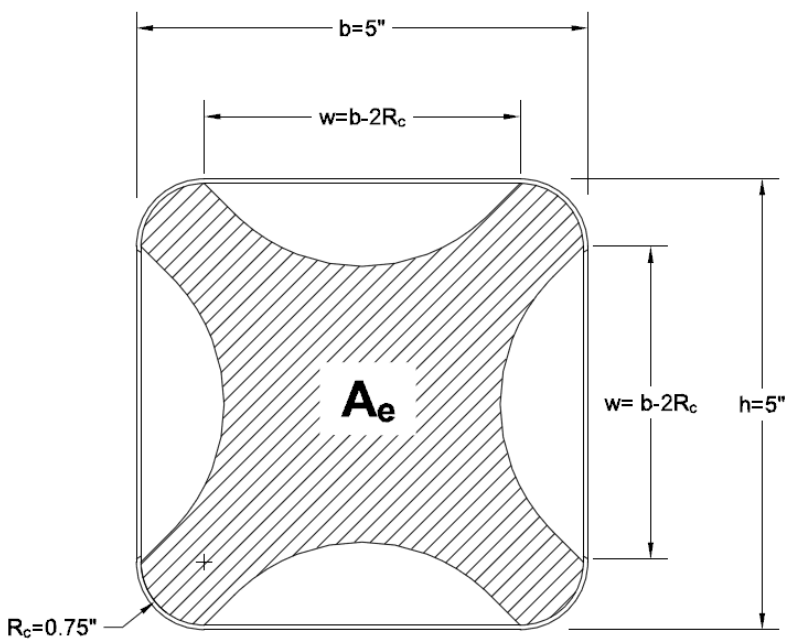

Figure 4-54: The effectively confined concrete area

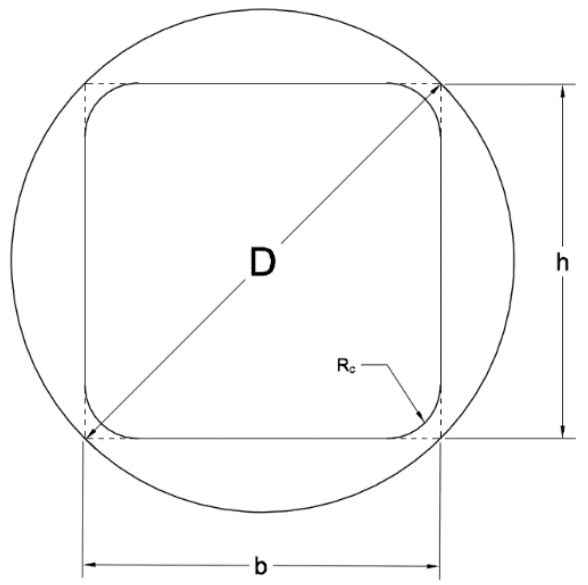

Figure 4-53: The equivalent circular cross section

The lateral confinement pressure was computed by performing a static force analysis on the free-body diagram of the equivalent circular cross section. A 1-in. strip of the CFRP jacket was taken to represent the entire jacket. Therefore, the calculated lateral confining pressure was basically evaluated per one longitudinal inch. Figure 4-55 demonstrates the free-body diagram of the 1-in. strip showing all the acting forces. By this analysis, the lateral confining pressure was evaluated in analogy to the following equation:

$$
F_{l}=\frac{2 E_{f r p} \varepsilon_{f r p} t_{f}}{D}
$$

Eq. 4-2 


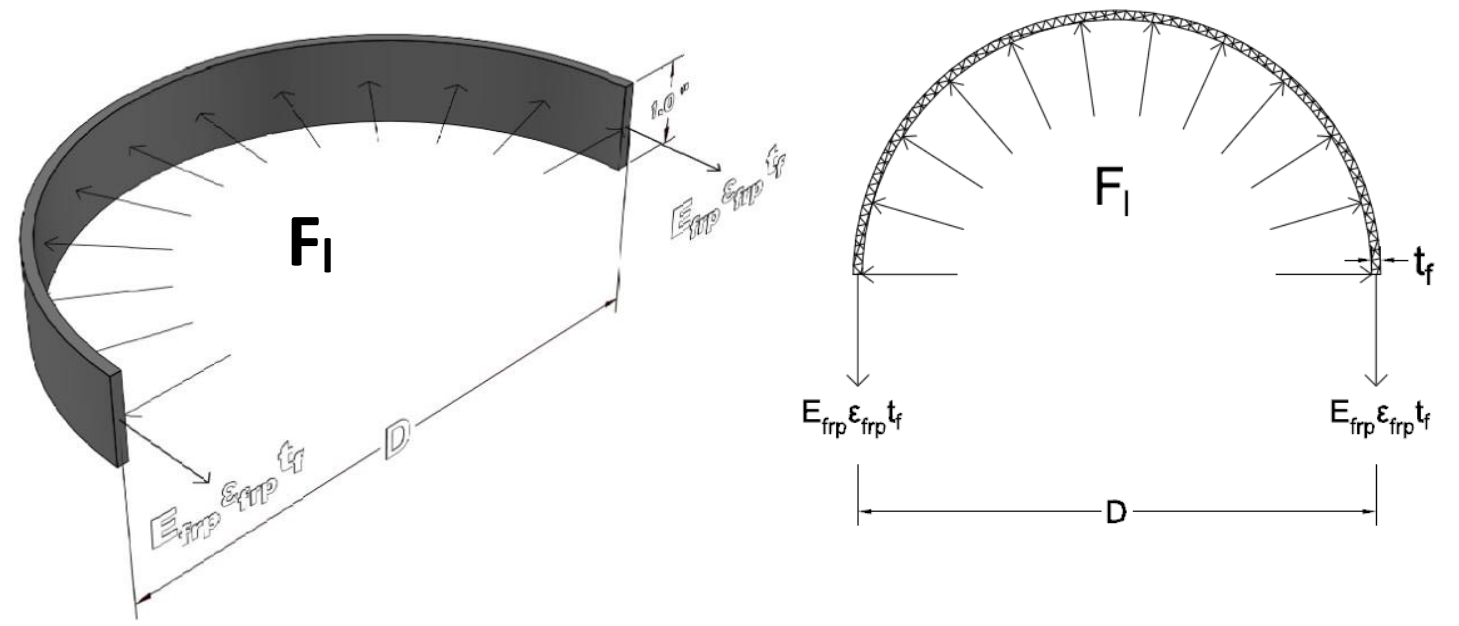

Figure 4-55: Confining action of the CFRP jacket

Where $F_{l}=$ the CFRP lateral confinement pressure, $E_{f r p}=$ the elastic modulus of the CFRP composite, $t_{f}=$ the total thickness of the CFRP jacket, $\varepsilon_{f r p}=$ the measured average CFRP transverse strain, $\mathrm{D}=$ the diameter of the equivalent circular cross section shown in Figure 4-53 according to Lam and Teng (2003). The equation is given by:

$$
D=\sqrt{h^{2}+b^{2}}
$$

Thus, the CFRP lateral confinement pressure $\left(F_{l}\right)$ response was constructed based on the measured average CFRP transverse strain $\left(\varepsilon_{f r p}\right)$. Figure 4-56 and Figure 4-57 show the CFRP lateral confining pressure versus the confined concrete axial stress for the wrapped specimens of series $\mathrm{C} 2$ and $\mathrm{C} 4$, respectively.

To calculate the maximum CFRP confining pressure $(f)$, the maximum measured average CFRP transverse strain at rupture $\left(\varepsilon_{f, \text { rup }}\right)$ was used in Eq 4-2 in place of the term $\left(\varepsilon_{f r p}\right)$ since $\varepsilon_{f, \text { rup }}$ was the actual CFRP rupture strain. 


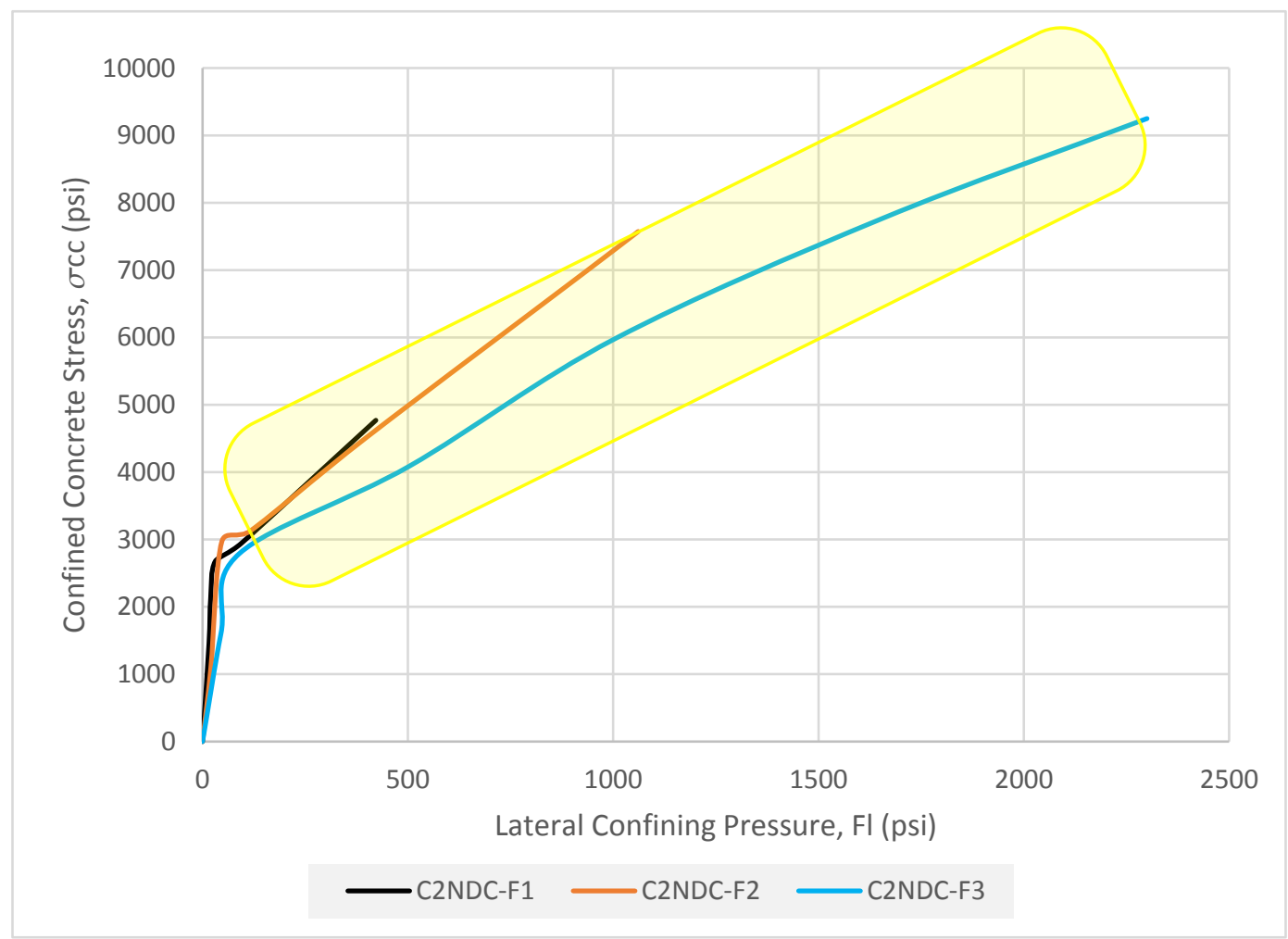

Figure 4-56: CFRP Lateral Confining Pressure responses (Series C2)

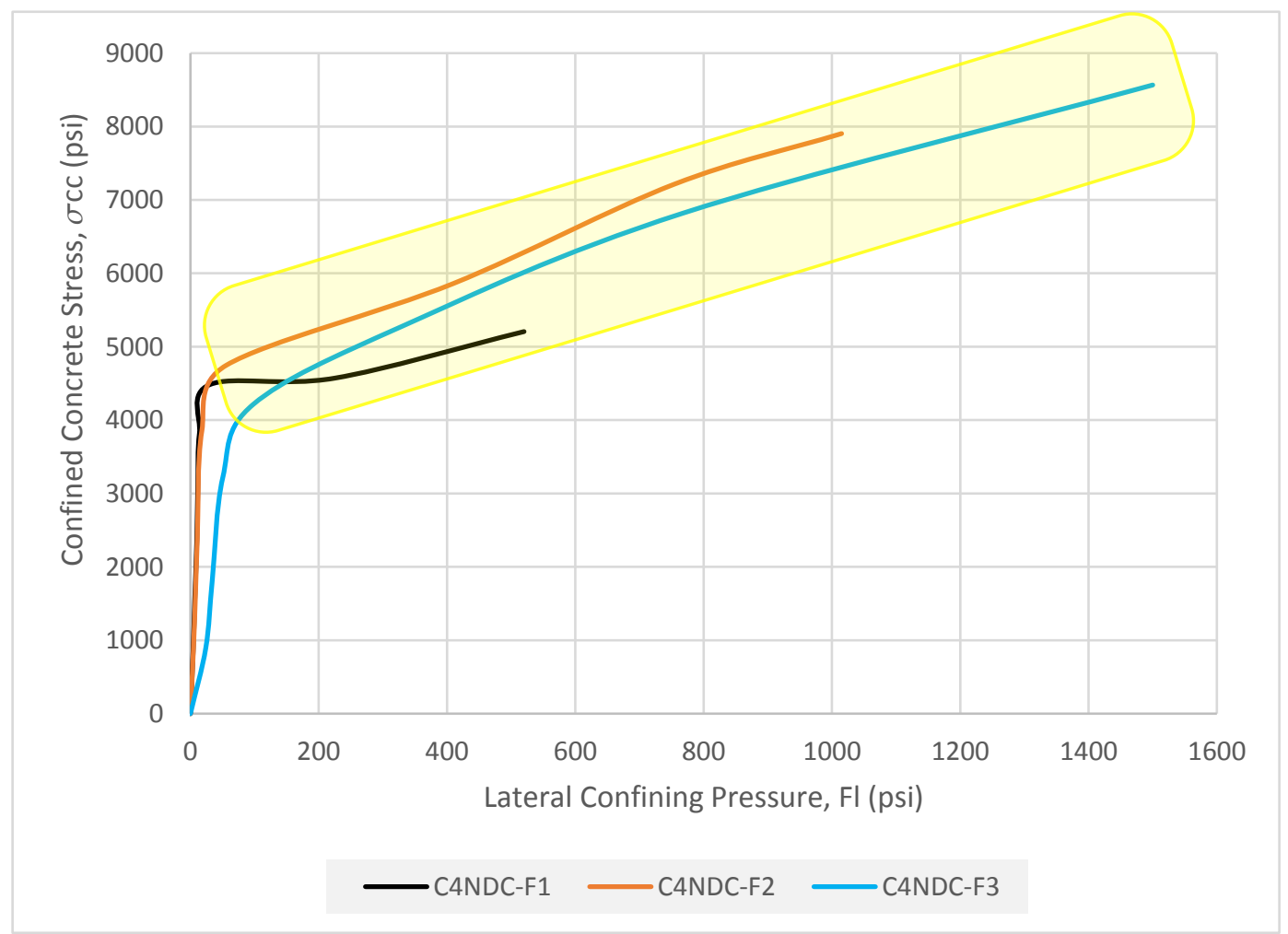

Figure 4-57: CFRP Lateral Confining Pressure responses (Series C4) 
It can be clearly seen that the lateral confining pressure exerted by the CFRP jacket significantly increased after achieving the apparent unconfined concrete strength $\left(f_{o}\right)$. This observation proves the fact that the CFRP confining action is activated after reaching the compressive strength of plain concrete. It can also be noted that the increase in the lateral confining pressure resulted in increasing the confined concrete axial strength. It is known that the lateral confining pressure increases with the increase of the of the CFRP jacket's thickness. Thus, increasing the number of the CFRP wraps resulted in enhancing the concrete strength. The gain of the concrete strength was proportional to the confining pressure by a confinement effectiveness coefficient $(k)$. The coefficient $k$ was calculated as the slope of the linear correlation between $F_{l}$ and $\sigma_{c}$ and it is given by:
$k=\frac{f_{C C}-f_{o}}{f_{l}}$
Eq. 4-3

Eq. 4-3 indicates that the coefficient $k$ has to be a constant value. It agrees with the constant value proposed by Lam and Teng (2003) for this coefficient $(k=3.3)$. Table 4-11 reports the calculated values of the coefficient $k$ for the test specimens.

Table 4-11: Confinement effective coefficient, $k$

\begin{tabular}{|c|c|c|c|c|c|}
\hline Series Code & Specimen Code & $\begin{array}{c}f_{l} \\
(\mathrm{psi})\end{array}$ & $\begin{array}{r}f_{c c}-f_{o} \\
\text { (psi) }\end{array}$ & $k$ & $\begin{array}{c}A v g . \\
k\end{array}$ \\
\hline \multirow{3}{*}{$\mathrm{C} 2$} & C2NDC-F1 & 422 & 2011 & 4.8 & \multirow{3}{*}{3.9} \\
\hline & C2NDC-F2 & 1061 & 4537 & 4.3 & \\
\hline & C2NDC-F3 & 2300 & 6405 & 2.8 & \\
\hline \multirow{3}{*}{$\mathrm{C} 4$} & C4NDC-F1 & 520 & 906 & 1.7 & \multirow{3}{*}{2.5} \\
\hline & C4NDC-F2 & 1015 & 3104 & 3.1 & \\
\hline & C4NDC-F3 & 1500 & 4196 & 2.8 & \\
\hline
\end{tabular}


Figure 4-58 and Figure 4-59 show that the slopes of the linear correlations between $F_{l}$ and $\sigma_{c c}$ for the specimens of both $\mathrm{C} 2$ and $\mathrm{C} 4$ series were very close. This observation indicates that if more than three specimens were tested in the current study, it is expected that the curves would lay within the yellow-highlighted regions. Therefore, general $F_{l}$ vs. $\sigma_{c c}$ curves were proposed for C2 and C4 and designated as "Gen." in Figure 4-58 and Figure 4-59, respectively. An average value of the coefficient $k$ and the apparent unconfined concrete stress $\left(\sigma_{o}\right)$ were used to construct those curves. The proposed correlations between Fl and $\sigma c c$ can be expressed by the following equations:

$$
\sigma_{c c}=\sigma_{o}+k F_{l}
$$

$$
\begin{array}{lll}
\text { For C2 Series } & \boldsymbol{\sigma}_{\boldsymbol{c c}}=\mathbf{2 5 0 0}+\mathbf{4} \boldsymbol{F}_{\boldsymbol{l}} & (\mathrm{psi}) \\
\text { For C2 Series } & \boldsymbol{\sigma}_{\boldsymbol{c c}}=\mathbf{4 2 0 0}+\mathbf{2 . 5} \boldsymbol{F}_{\boldsymbol{l}}
\end{array}
$$

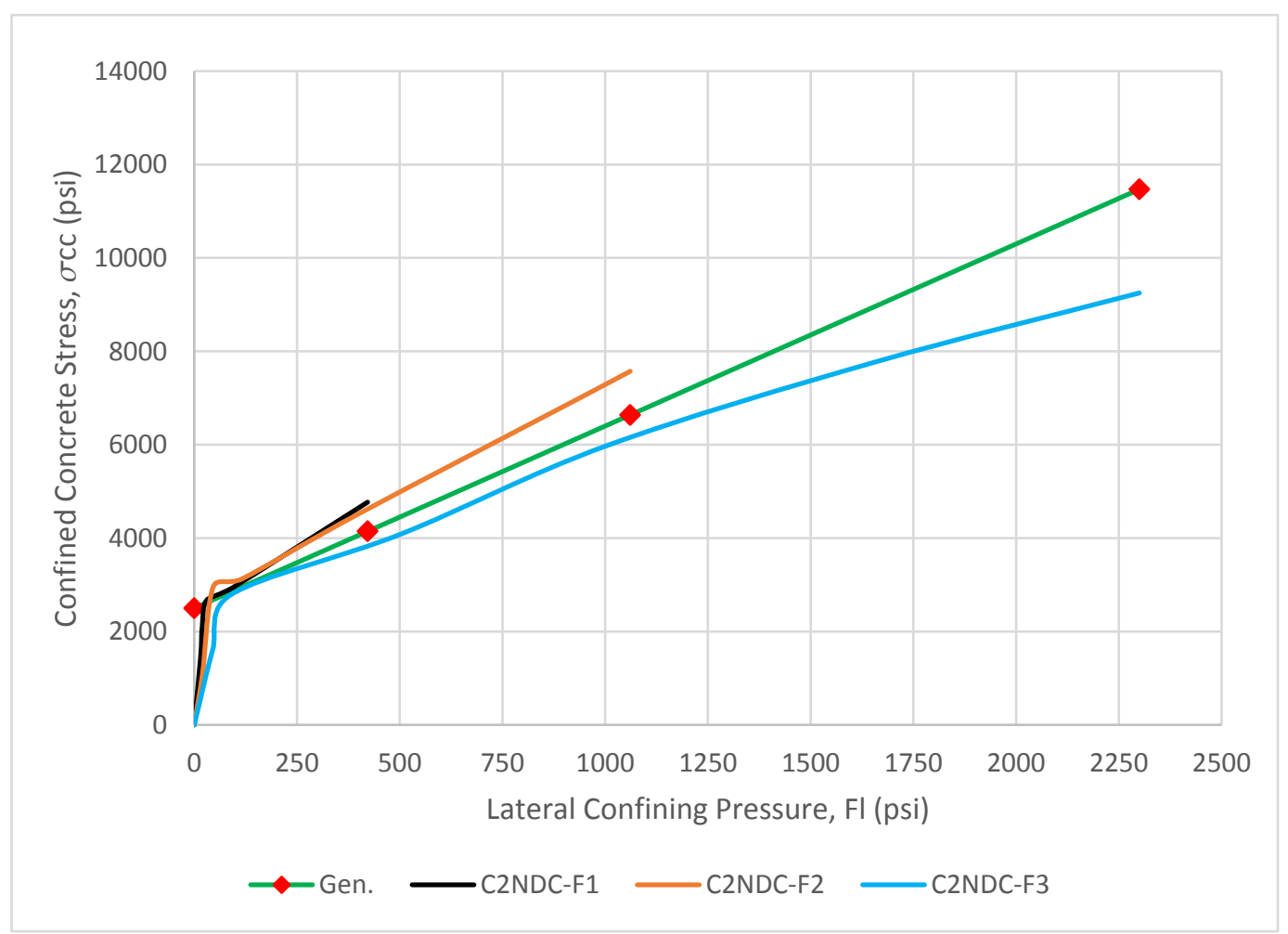

Figure 4-58: Proposed $F_{l}$ and. $\sigma_{c c}$ correlation (Series $C 2$ ) 


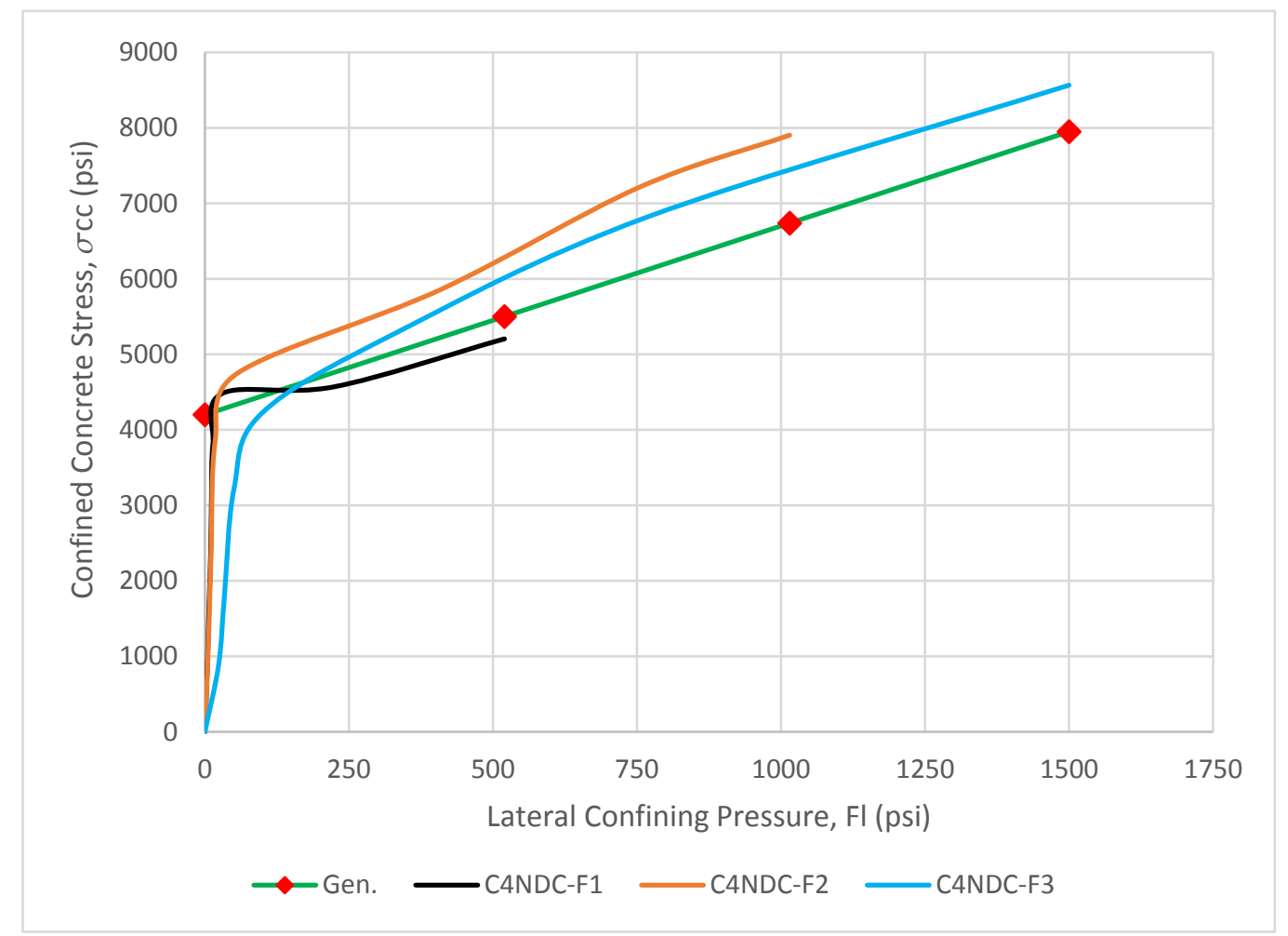

Figure 4-59: Proposed $F_{l}$ and. $\sigma_{c c}$ correlation (Series C4)

\subsection{Effect of CFRP Jacket Thickness}

In this section, comparisons were made among the test specimens to investigate the effect of varying the thickness of the CFRP jacket on different parameters, such as the maximum axial load-carrying capacity $\left(P_{u}\right)$, the maximum axial strain $\left(\varepsilon_{m}\right)$ that corresponds to $P_{u}$, the axial strain that corresponds to $50 \%$ post-peak load, and the apparent concrete strength (fc). The thickness of the CFRP jacket was defined by the number of the CFRP wraps (i.e. F1, F2, and F3). All of the comparisons were made by the means of Column Charts. The number labeled above each column is the value of the quality being compared. 


\subsubsection{Effect of CFRP Jacket Thickness on $P_{u}$}

A comparison among the test specimens in terms of the axial load $P_{u}$ was created by evaluating the increase in the axial load-carrying capacity achieved by each of the specimens with respect to the loading capacity of the unwrapped non-ductile concrete column (NDC). Figure 4-60 presents the increase of the load carrying capacity with respect to the non-ductile column. In this figure, $P_{c o}$ is the peak axial loading capacity of the non-ductile column. For $\mathrm{C} 2$ specimens, it can be seen that wrapping the non-ductile column with one, two, and three layers of CFRP enhanced the axial loading capacity by about 180\%, 300\%, and 380\%, respectively when compared to the column C2NDC. However, by comparing C2NDC-F1 with C2NDC-F2, the enhancement was about $44 \%$. On other hand, the enhancement was about $20 \%$ when comparing C2NDC-F2 with C2NDC-F3.

For C4 specimens, wrapping the non-ductile column by one, two, and three layers of CFRP resulted in a gain in the axial capacity of about $38 \%, 90 \%$, and $102 \%$, respectively. However, the gain was $37 \%$ and $46 \%$ when the CFRP jacket was upgraded from one layer to two layers and from two to three layers, respectively. These observations conclude that there was no linear correlation between the enhancement of the axial capacity and the thickness of the CFRP jacket. In other words, by doubling or tripling the jacket thickness, the gain in the axial capacity was not doubled or tripled. Consequently, it can be said that there might be a maximum effective jacket thickness (number of layers) that could result in a significant enhancement. 

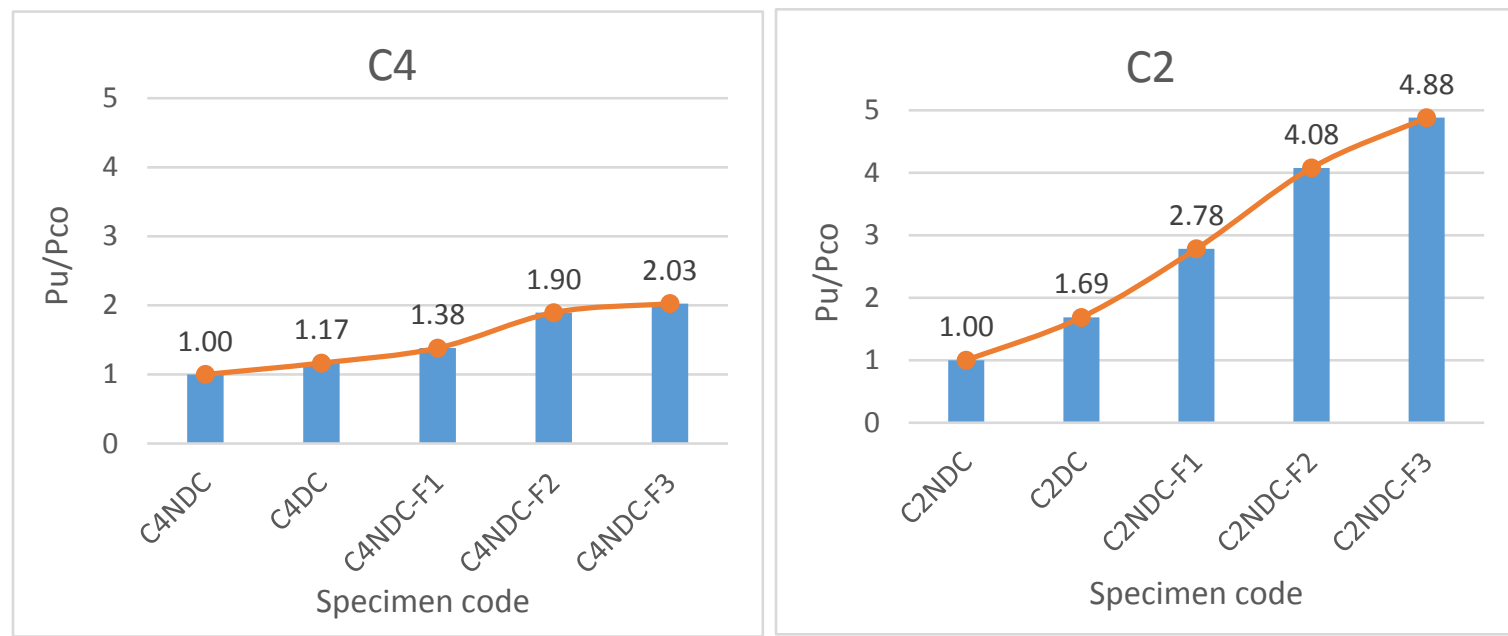

Figure 4-60: Comparison of the axial loading capacity (variable CFRP jacket thickness)

Moreover, by comparing the column C2DC with C2NDC, and C4D with C4NDC, it can be noted that the enhancement in the axial loading capacity was not significant. In other words, the main goal of the current ACI's seismic design provisions is not enhancing the axial loading capacity of the reinforced concrete columns.

The other observation was that the gain in the axial loading capacity due to varying jacket thickness was more pronounced in the series $\mathrm{C} 2$ specimens that in the series $\mathrm{C} 4$ specimens in most cases. The axial loading capacity was almost twice when comparing a specimen from series $\mathrm{C} 2$ with its corresponding specimen from series $\mathrm{C} 4$.

The effect of the CFRP jacket thickness on the axial loading capacity can be presented in another way, which is by comparing the axial loading capacity of the test specimens with respect to the ductile column (DC) as shown in Figure 4-61. In this figure, $\mathrm{PuDc}$ is the maximum axial load achieved by specimens C2DC or C4DC. 


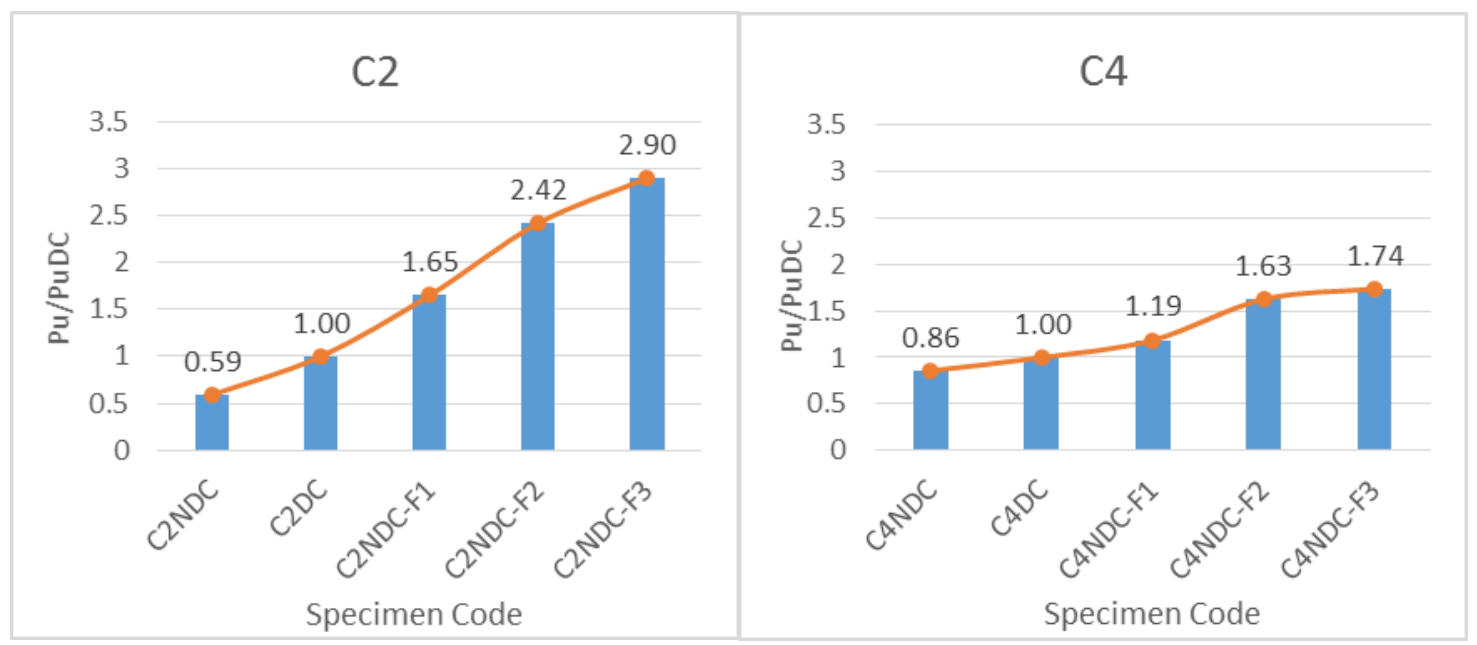

Figure 4-61: Comparison of the axial loading capacity (variable CFRP jacket)

This figure shows that specimens C2NDC-F1 and C4NDC-F1 achieved an axial loading capacity closer to the axial capacity exhibited by the ductile concrete columns C2DC and C4DC, respectively. Therefore, it can be concluded that strengthening the non-ductile column with one layer of CFRP $\left(\mathrm{t}_{\mathrm{f}}=0.165 \mathrm{~mm}\right)$ resulted in a behavior equivalent to the behavior of the adequately designed ductile column in terms of the axial loading capacity.

\subsubsection{Effect of CFRP Jacket Thickness on $f_{c}$}

To understand the effect of the CFRP jacket thickness on the apparent concrete strength $\left(f_{c}\right)$, a comparison was made between the test specimens by evaluating the enhancement in the apparent concrete compressive strength achieved by varying the jacket thickness (number of the CFRP wraps). For the sake of comparison, and in order to be consistent, the apparent concrete strength was calculated as:

$$
f_{c}=\frac{P_{\text {conc }}}{A_{c}}=\frac{P_{u}-P_{\text {steel }}}{A_{g}-A_{s}} \quad \text { Eq. } 4-4
$$


This equation indicates that the $f_{c}$ is basically the concrete axial force divided by the concrete net area excluding the contribution of the longitudinal reinforcement; however, this definition is not totally true for the case of the unwrapped columns since the concrete cover spalls at a certain level of loading which means that the acting concrete area is smaller (concrete core area). In contrast, for the wrapped columns, all of the concrete net area is acting during the test. Therefore, to be consistent when comparing wrapped and unwrapped columns, $f_{\mathrm{c}}$ was calculated as described in Eq 4-4 for both wrapped and unwrapped columns.

Figure 4-62 demonstrates the apparent concrete strength of the test specimens $\left(f_{c c}\right)$ normalized with respect to the apparent concrete strength of the non-ductile column $\left(f_{c o}\right)$.
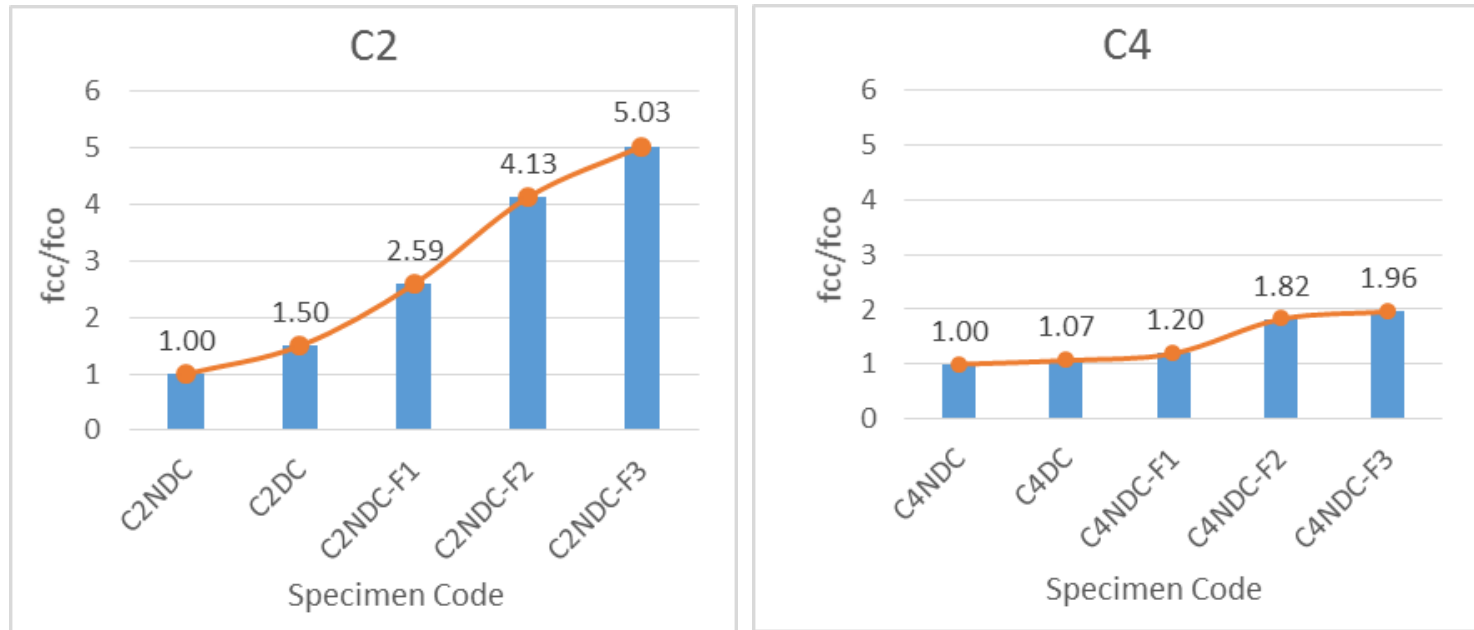

Figure 4-62: Comparison of the apparent concrete compressive strength (variable CFRP jacket) 
It can be clearly seen that increasing the CFRP jacket thickness increased the concrete apparent concrete compressive strength. In other words, wrapping the non-ductile concrete column with one, two, and three of layers CFRP enhanced the apparent concrete strength by about $160 \%, 313 \%$, and $403 \%$, respectively for series C2. On other hand, the gain was $20 \%, 82 \%$, and $96 \%$, respectively for series $\mathrm{C} 4$. It is obvious that the gain in the concrete compressive strength in series C2 specimens was more significant than that in series $\mathrm{C} 4$ specimens.

The gain in the apparent concrete compressive strength was presented in a different way in Figure 4-63. In this figure, the apparent concrete strength of each of the specimens was normalized with respect to the apparent concrete strength of the ductile column $\left(f_{c D C}\right)$.

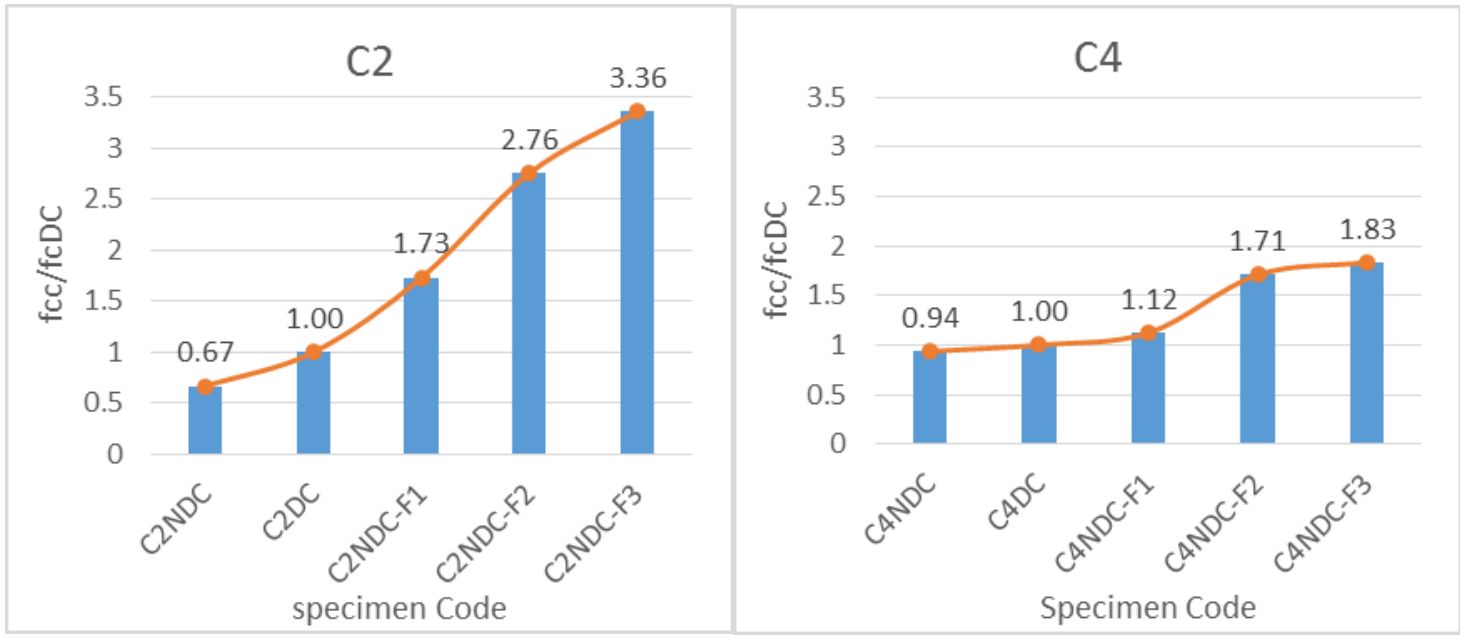

Figure 4-63: Comparison of the apparent concrete compressive strength (variable CFRP jacket)

This figure shows that, specimens C2NDC-F1 and C4NDC-F1achieved a concrete compressive strength closer to the strength exhibited by the ductile concrete columns C2DC and C4DC, respectively. Therefore, it can be concluded that strengthening the non-ductile column with one layer of CFRP $\left(t_{f}=0.165 \mathrm{~mm}\right)$ resulted in a behavior 
equivalent to the behavior of the adequately designed ductile column in terms of the apparent concrete compressive strength.

\subsubsection{Effect of CFRP Jacket Thickness on $\varepsilon_{m}$}

The effect of the CFRP jacket thickness on the measured maximum axial strain $\left(\varepsilon_{m}\right)$ is depicted in Figure 4-64 for both series C2 and C4 specimens. It is obvious that strengthening the non-ductile column significantly enhanced its axial strain capacity. Specifically speaking, wrapping the non-ductile column with one layer of CFRP greatly increased the axial strain capacity. However, the gain in the axial strain by doubling or tripling the thickness of the CFRP jacket was less than that gained by the one-layer CFRP jacket. For better illustration the correlation between the jacket thickness and the axial strain $\left(\varepsilon_{m}\right)$, Figure 4-65 shows the axial strain of each specimen with respect to the maximum axial strain exhibited by the non-ductile column $\left(\varepsilon_{c o}\right)$.

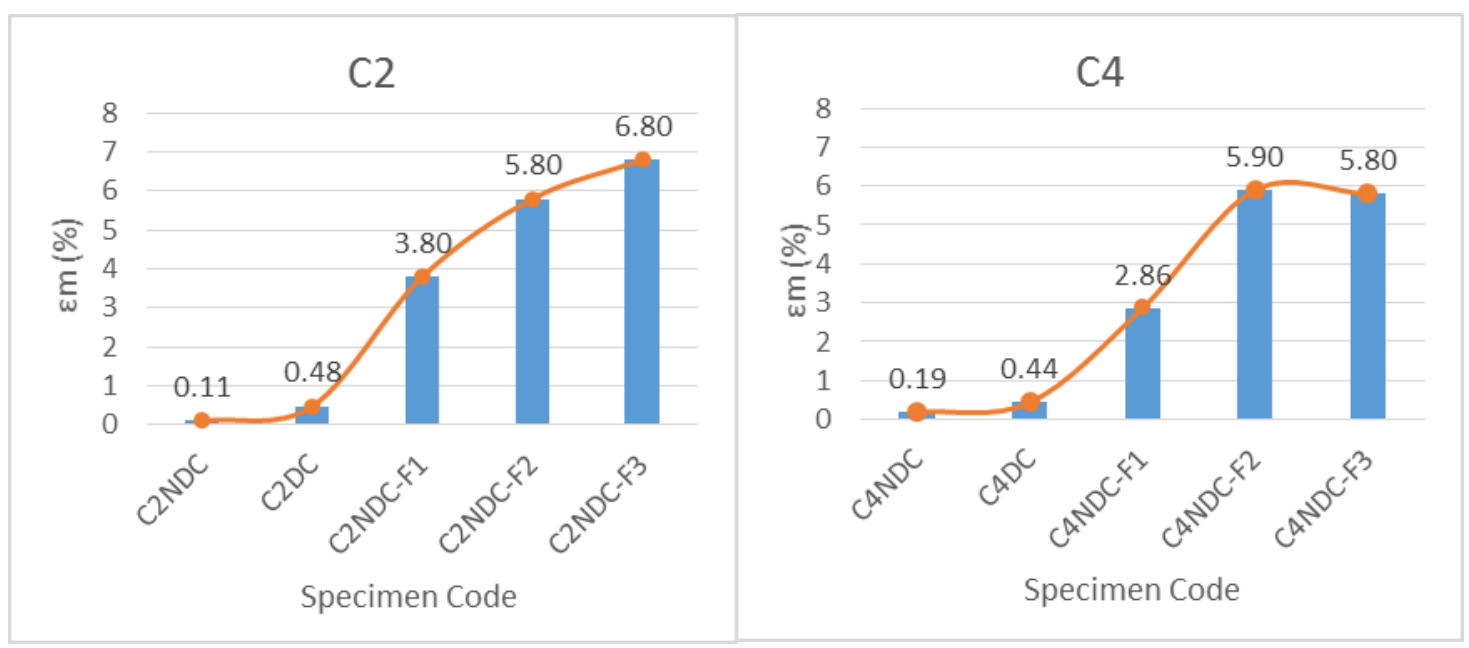

Figure 4-64: Maximum axial strain values of test specimens 

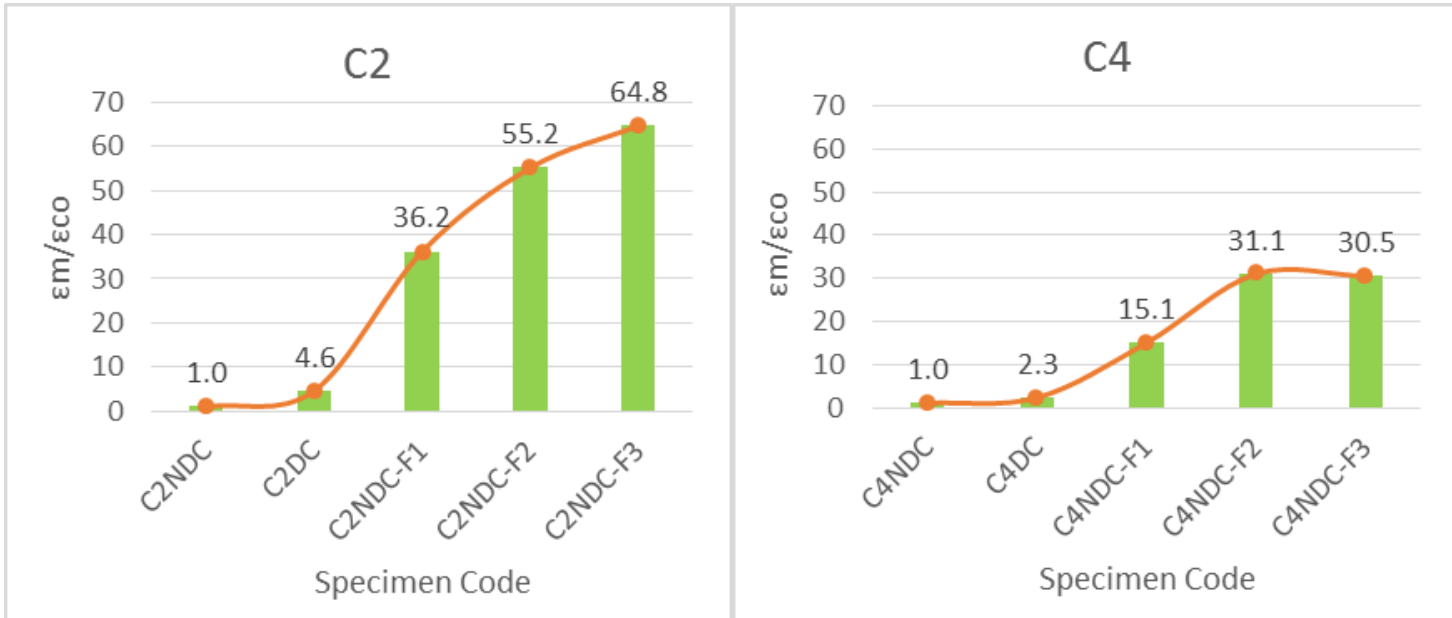

Figure 4-65: Comparison of the maximum axial strain (variable CFRP jacket)

This figure shows that for series C2, columns wrapped with one, two, and three layers of CFRP experienced an axial strain capacity that was about 36,55 , and 65 times the axial strain achieved by column $\mathrm{C} 2 \mathrm{NDC}$, respectively. On the other hand, for series $\mathrm{C} 4$, the enhancement in the axial strain was noticeably less than that exhibited by series $\mathrm{C} 2$ specimens. For instant, wrapping a non-ductile column with one layer of CFRP enhanced the axial strain by 15 times, which is almost half the value achieved by the corresponding specimen in series C2 (i.e. C2NDC-F1). It is worth mentioning, that the values of the axial strain achieved by wrapping the non-ductile column with two and three layers of CFRP were very close to each other in both C2 and C4 series. However, it was more obvious in the case of C4NDC-F2 and C4NDC-F3. As it was mentioned in Section 4.17.1, this observation indicates that there should be a maximum effective CFRP jacket thickness that results in a significant enhancement in the behavior of the confined concrete columns. 


\subsection{Evaluation of Ductility}

Ductility is an essential property of any well-designed concrete structure, especially for the FRP-confined confined concrete columns because of the brittle nature of the FRP composites (Vasumathi et al., 2014). One possible definition of ductility is the ability of a structural member to experience a plastic deformation without a huge loss of its strength (Rochette \& Labossiere, 2001). There is no consensual approach to evaluate ductility. One of the well-accepted approach to measure ductility is based on the concept of the axial strain energy. The strain energy is defined as the energy absorbed by the structural member during the loading process. In this approach, for an axially loaded column, the ductility is calculated as the area under the axial load-deformation curve $(A U C)$, which represents the absorbed axial strain energy (pham \& Hadi, 2013). However, defining the effective axial load-deformation curve (i.e. specifying the ultimate axial deformation, $\delta_{c u}$ ) varied depending on the researcher. Some researchers defined the ultimate deformation as the axial deformation of the column, which is when the load drops to $80-85 \%$ of the ultimate load, $P_{u}$ (Lokuge \& Karunasena, 2015). In the current study, two definitions were used for the ultimate deformation. The first definition of the ultimate deformation was as the axial deformation, which is when the axial load falls $50 \%$ of the ultimate load. As previously mentioned, the 50\%-limit was specified based on the hypothesis that the column would be efficient if it could handle any sustained dead load. Figure 4-70 demonstrates the axial load-deformation curves of both series C2 and C4' specimens. In this figure, the green vertical line represents the limit of the effective axial loaddeformation curves based on the first definition. For specimens, where there was no 
available data for the descending curve after the achieving the ultimate load, $P_{u}$, the ultimate deformation limit was selected as the last recorded axial deformation value.
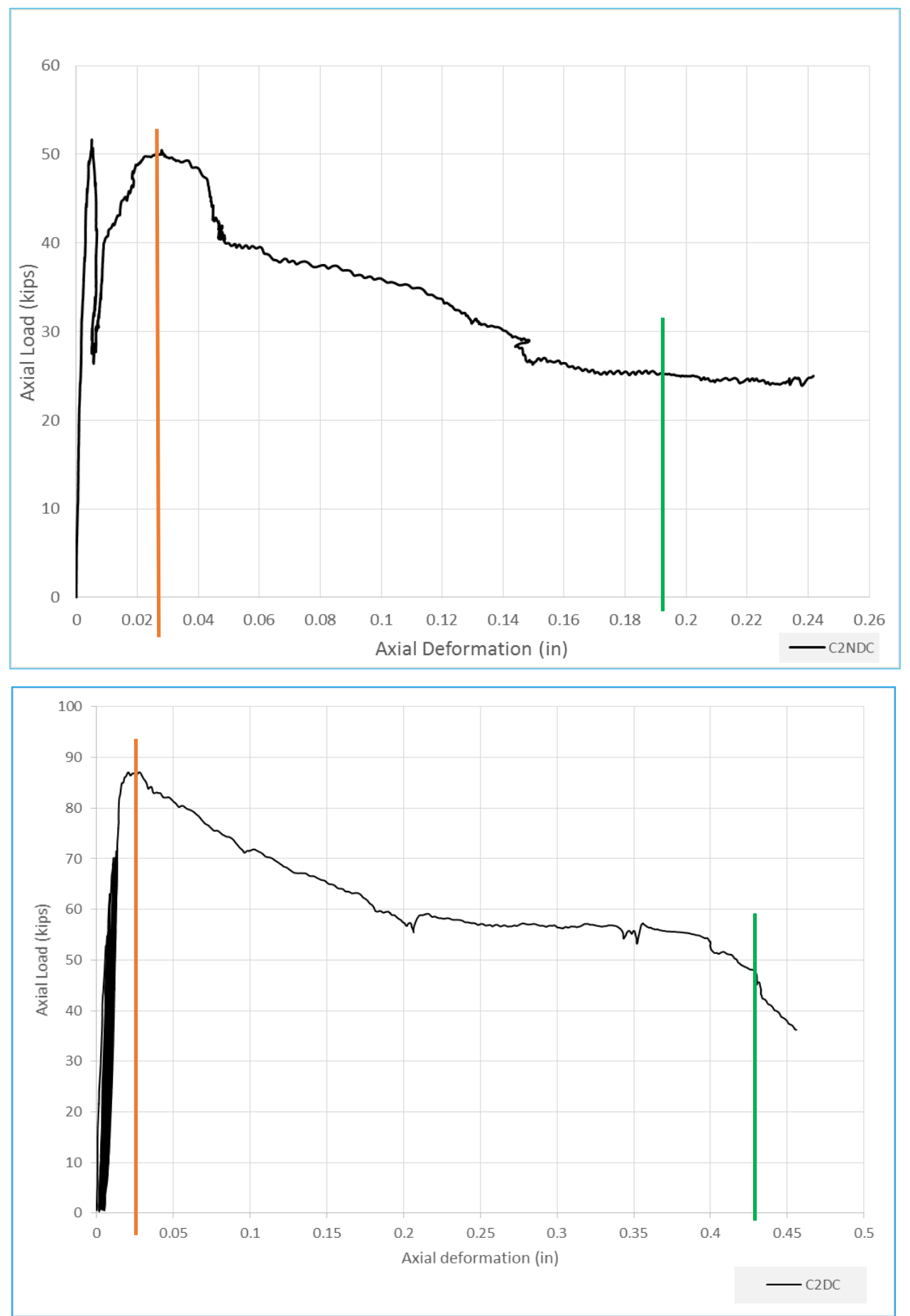

Figure 4-66: Effective axial load-deformation curves for ductility evaluation 

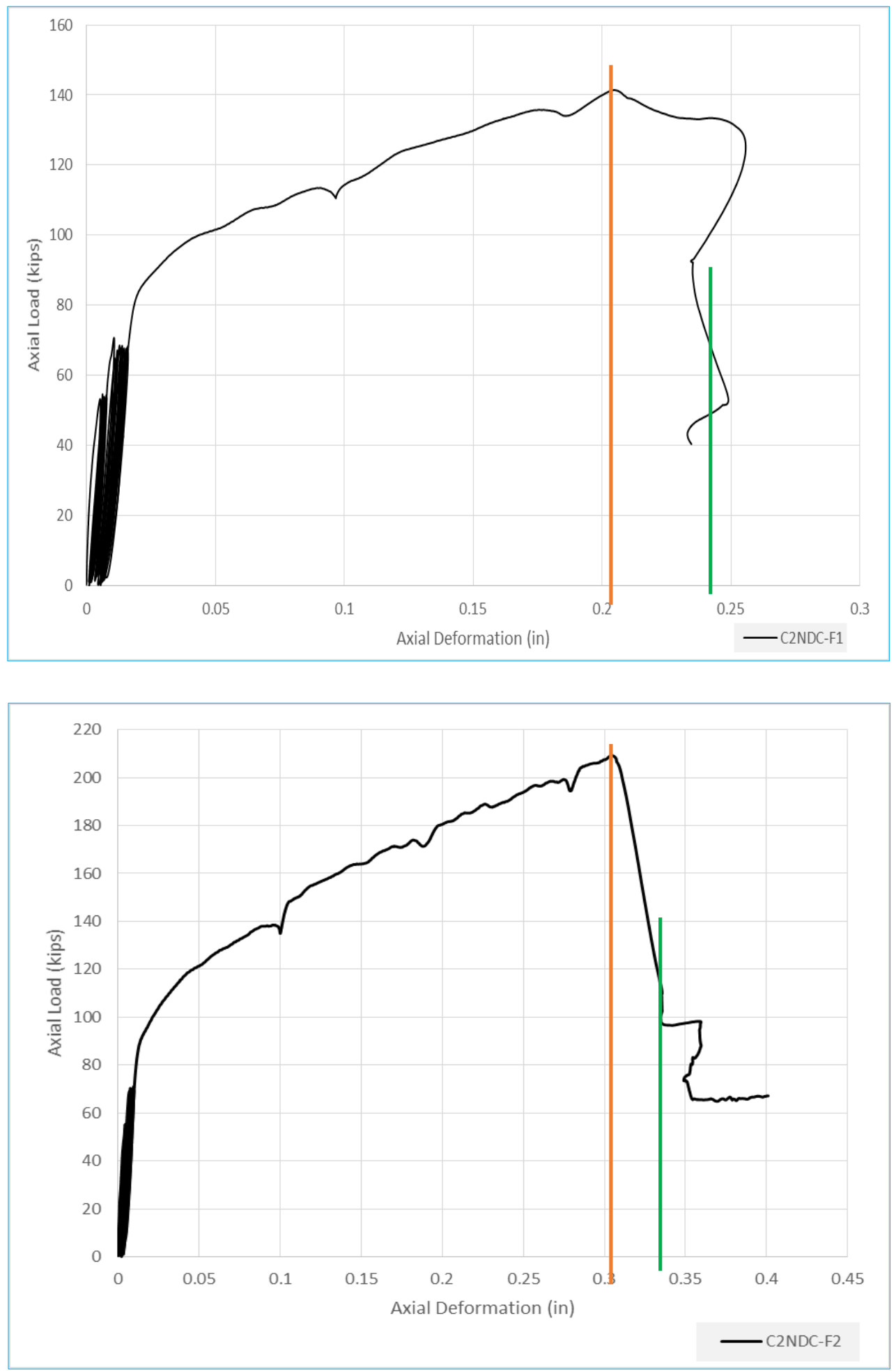

Figure 4-67: Effective axial load-deformation curves for ductility evaluation (Cont.) 

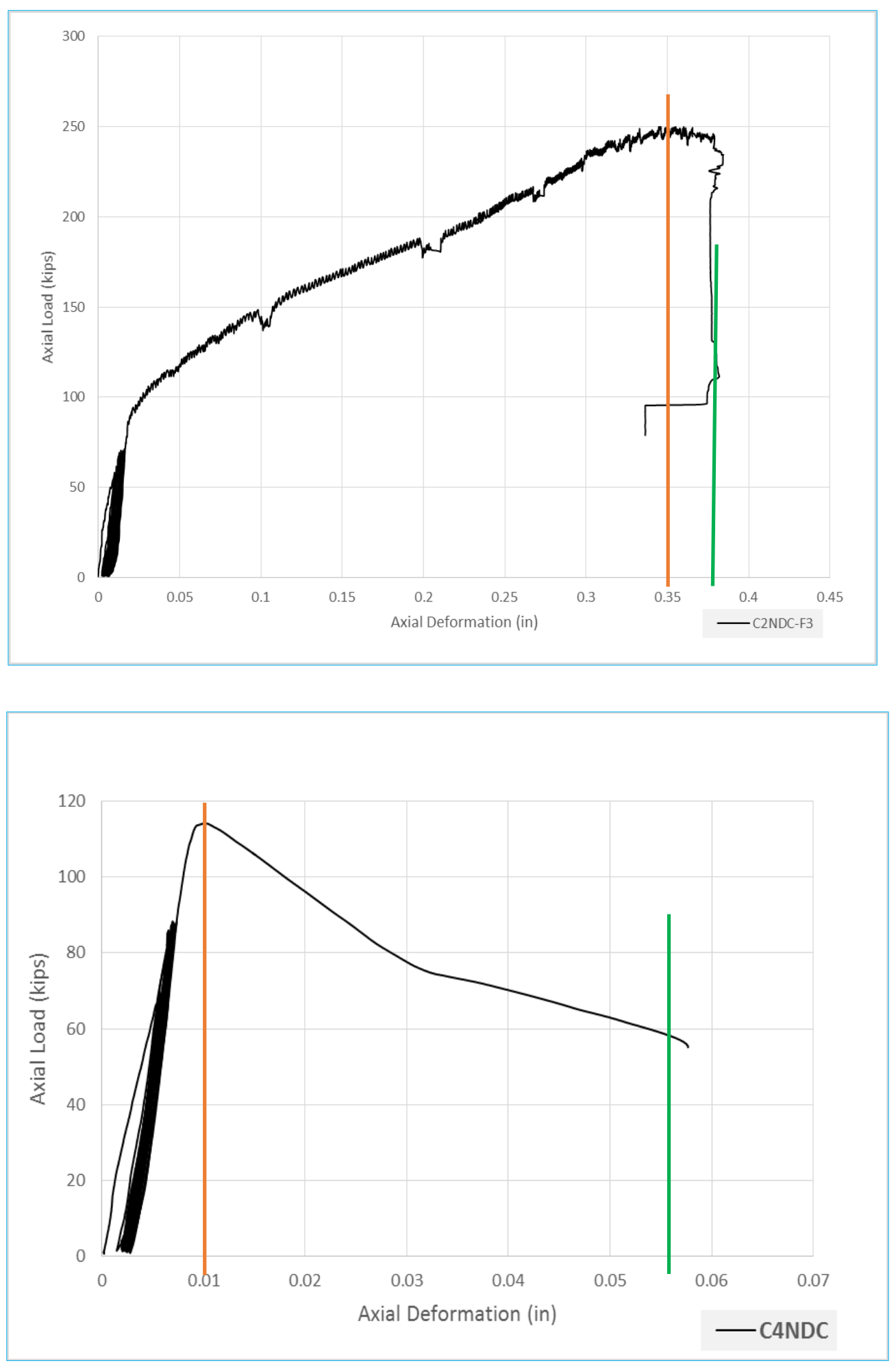

Figure 4-68: Effective axial load-deformation curves for ductility evaluation (Cont.) 

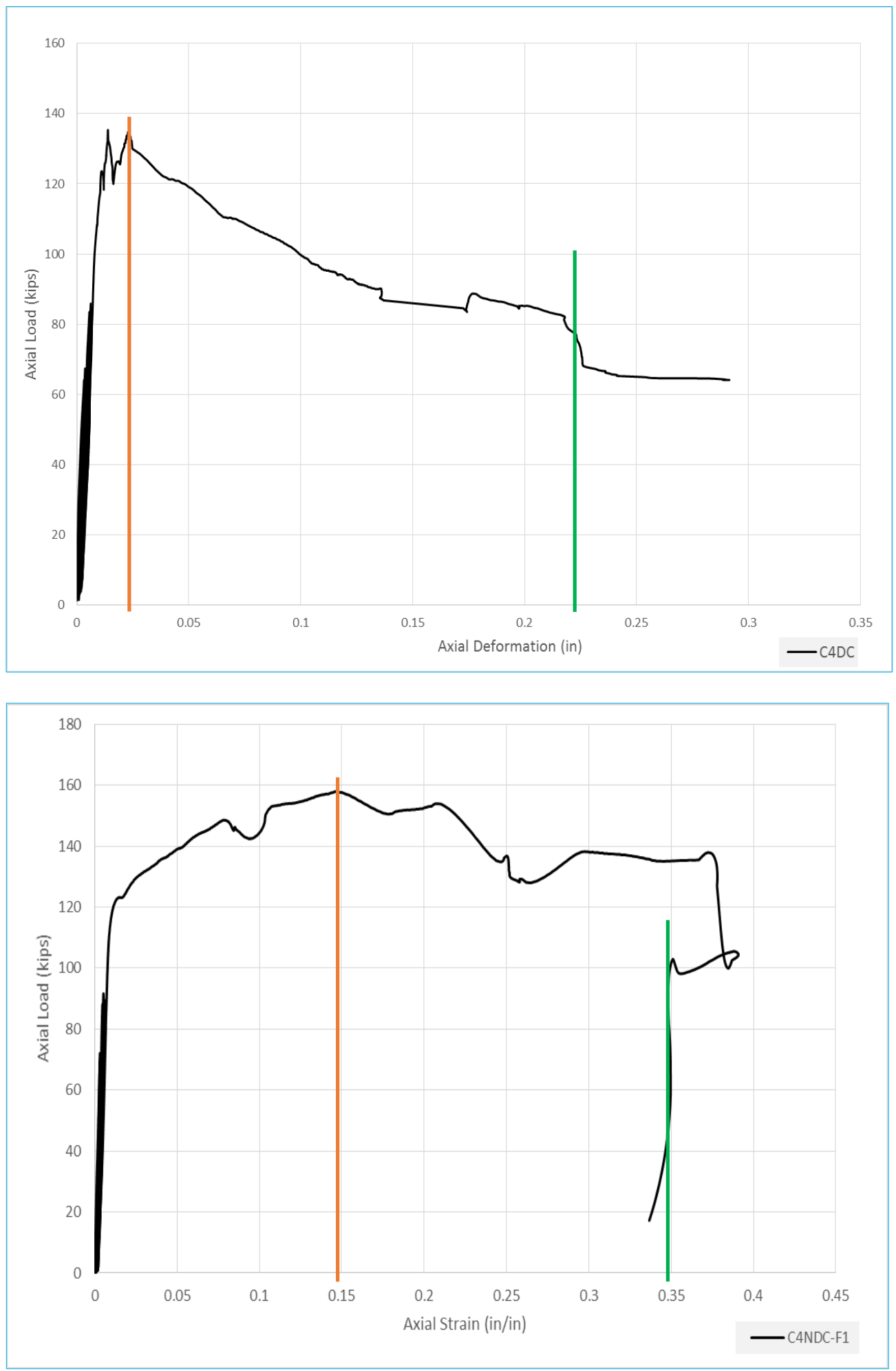

Figure 4-69: Effective axial load-deformation curves for ductility evaluation (Cont.) 

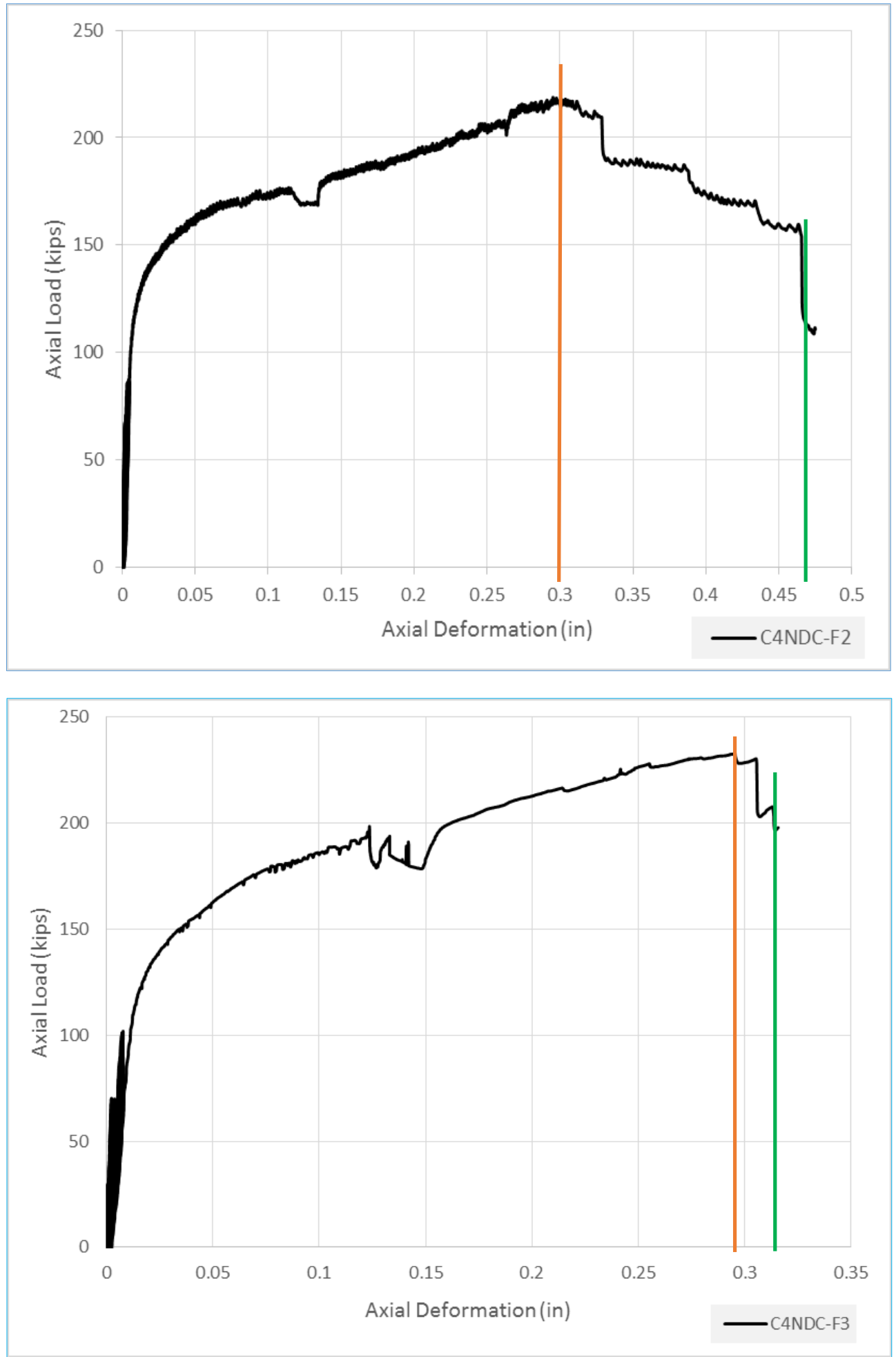

Figure 4-70: Effective axial load-deformation curves for ductility evaluation (Cont.) 
Based on the first definition of the ultimate axial deformation, the area enclosed by the axial load-deformation curve of each specimen and the green vertical line as shown in Figure 4-70 was computed and listed in Table 4-12

Table 4-12: The ductility values of test specimens (first definition)

\begin{tabular}{|c|c|}
\hline \multicolumn{2}{|c|}{ First Definition } \\
\hline Specimen & AUC (kip.in) \\
\hline C2NDC & 7.85 \\
\hline C2DC & 27.68 \\
\hline C2NDC-F1 & 28.97 \\
\hline C2NDC-F2 & 53.64 \\
\hline C2NDC-F3 & 68.06 \\
\hline C4NDC & 4.73 \\
\hline C4DC & 23.08 \\
\hline C4NDC-F1 & 53.19 \\
\hline C4NDC-F2 & 85.44 \\
\hline C4NDC-F3 & 59.90 \\
\hline
\end{tabular}

The second definition of the ultimate axial deformation is the axial deformation corresponding to the ultimate axial load, $P_{u}$. The vertical orange line in Figure 4-70 represents the limit of the effective axial load-deformation curves. Based on this second definition, the computed values of AUC are listed in Table 4-13. 
Table 4-13: The ductility values of test specimens (second definition)

\begin{tabular}{|c|c|}
\hline \multicolumn{2}{|c|}{ Second Definition } \\
\hline Specimen & AUC (kip.in) \\
\hline C2NDC & 1.65 \\
\hline C2DC & 2.74 \\
\hline C2NDC-F1 & 24.26 \\
\hline C2NDC-F2 & 49.93 \\
\hline C2NDC-F3 & 69.26 \\
\hline C4NDC & 1.09 \\
\hline C4DC & 2.13 \\
\hline C4NDC-F1 & 21.19 \\
\hline C4NDC-F2 & 57.75 \\
\hline C4NDC-F3 & 55.74 \\
\hline
\end{tabular}

For better illustration, the values of AUC of all of the test specimens that were computed based on both first and second definitions are presented in Figure 4-71 and Figure 4-72. In this figure, a comparison was made among the test column specimens in terms of AUC, which interpreted to mean the axial ductility. 


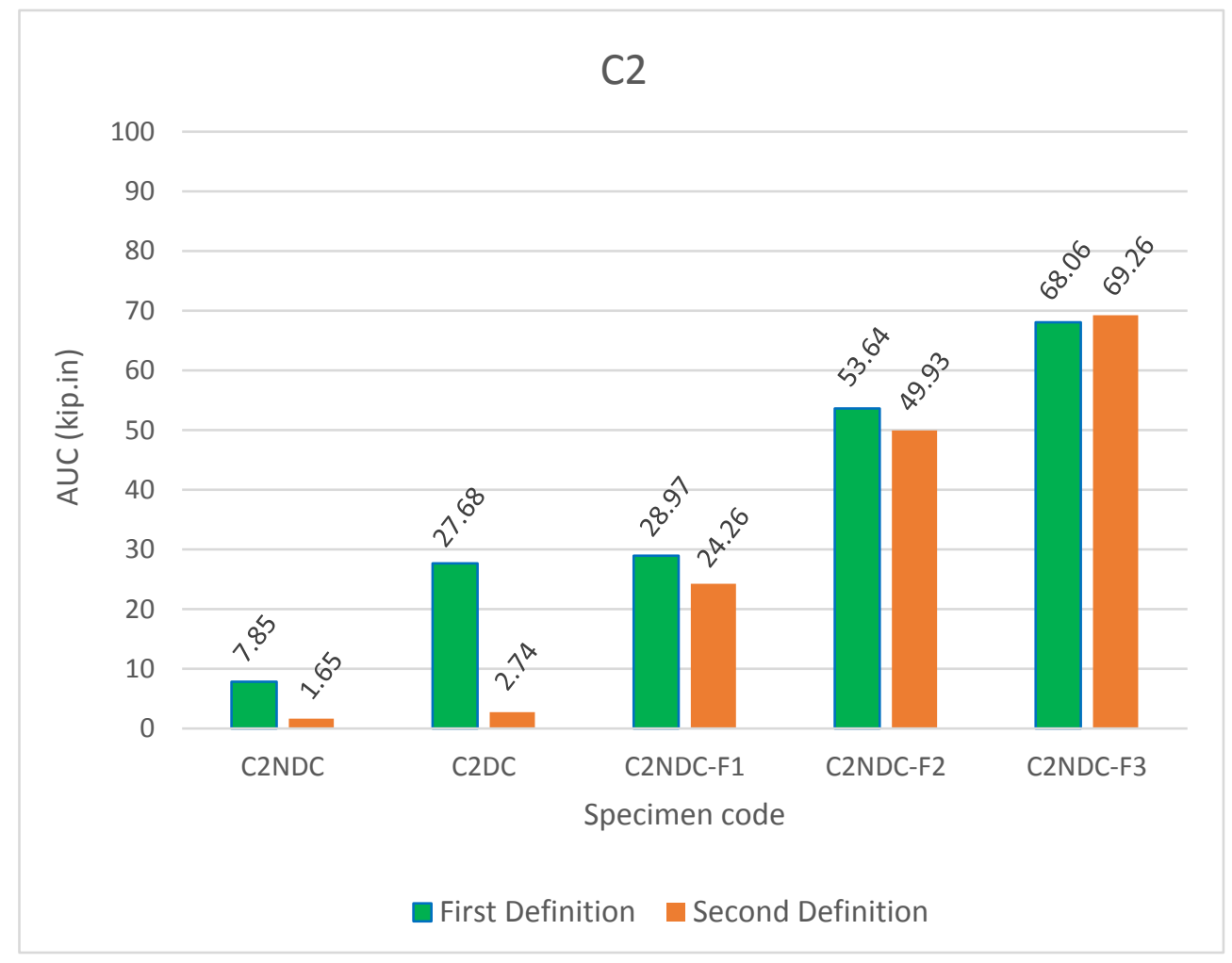

Figure 4-71: Ductility evaluation (C2 series)

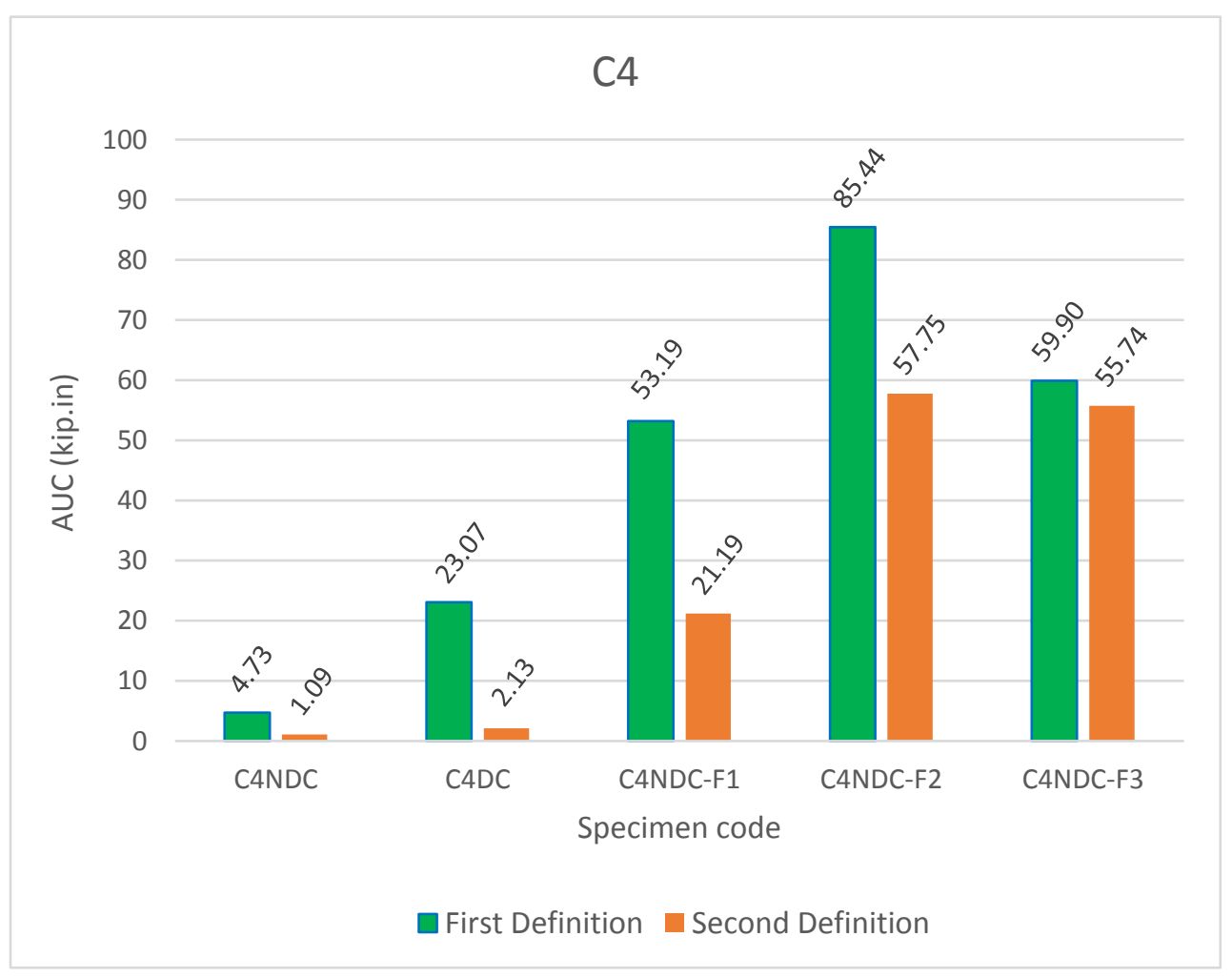

Figure 4-72: Ductility evaluation (C4 series) 
The second definition of the ultimate axial deformation was employed in evaluation of ductility in order to overcome the fact that some of the axial deformation data in the descending curve after the ultimate load point of some specimens (e.g. C4NDC-F3) was missing. Therefore, the ductility was computed as the area under the axial loaddeformation curve up until the ultimate axial load point since all of the data within this region of the curve was available and trustworthy.

It can be clearly seen that increasing the thickness of the CFRP jacket enhanced the ductility. In series C2, wrapping the non-ductile concrete columns with one, two, and three layers of CFRP enhanced the ductility of the non-ductile concrete column 15, 30, 42 times, respectively. In series C4, wrapping the non-ductile concrete columns with one, two, and three layers of CFRP enhanced the ductility of the non-ductile concrete column 19, 53, 51 times, respectively. For better illustration of the effect of varying the CFRP jacket thickness on the axial ductility, the relative enhancement in the axial ductility of each column with respect to the non-ductile column was evaluated based on the first and second definitions of the ductility as shown in the Figure 4-69 and Figure 4-70.
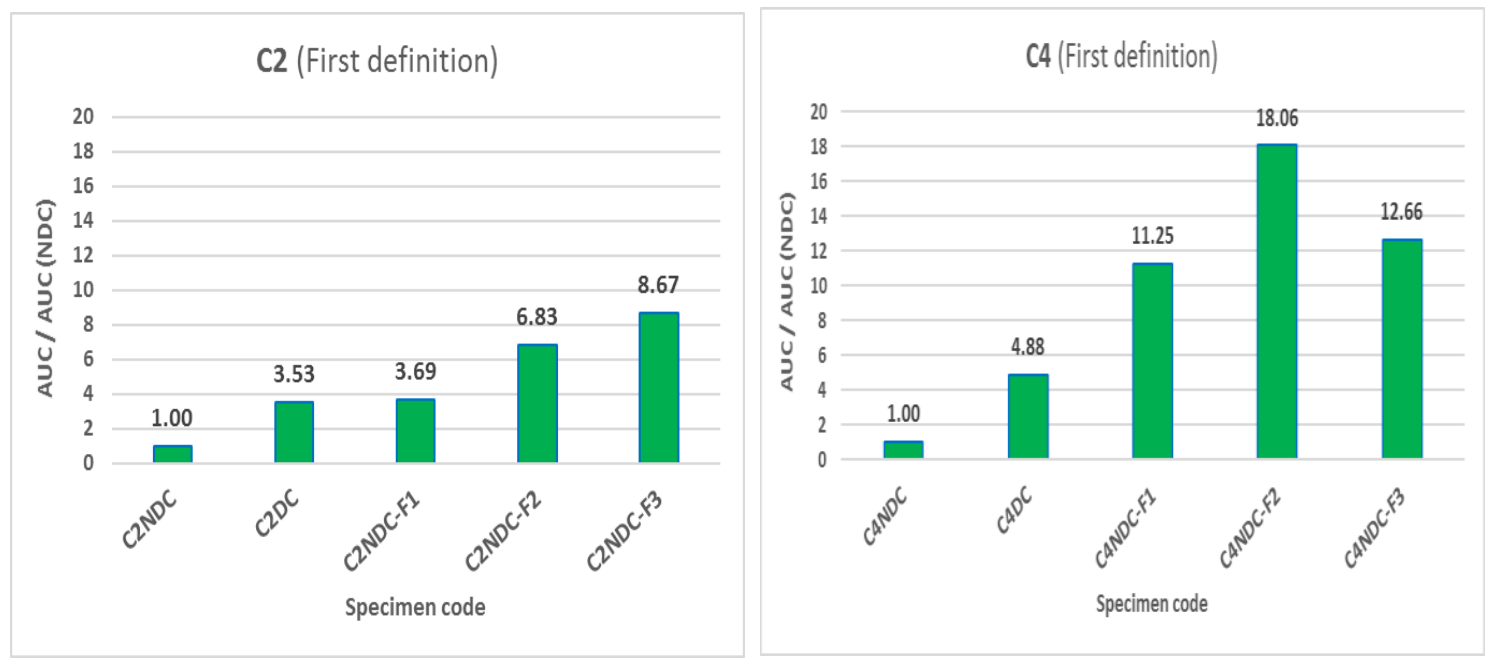

Figure 4-73: Relative enhancement in axial ductility based on First Definition (variable CFRP jacket) 

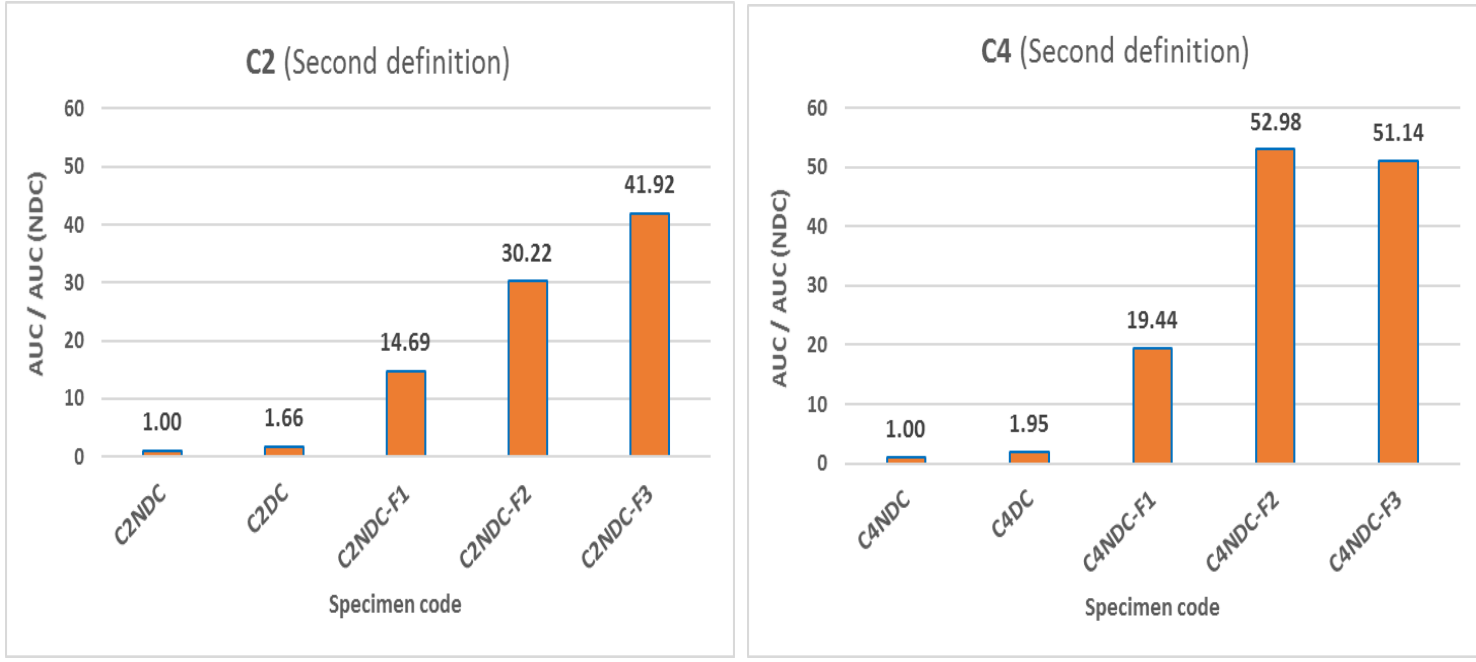

Figure 4-74: Relative enhancement in axial ductility based on Second Definition (variable CFRP jacket)

\subsection{Effect of Concrete Compressive Strength}

The effect of the concrete strength was investigating by comparing the CFRP wrapped specimens in series C2 (i.e. 2000- psi concrete) with the corresponding specimens in series C4 (i.e. 4000-psi concrete). The comparisons were performed in terms of the enhancement in the axial load carrying capacity and axial strain that was attained due to the confinement action of the CFRP wraps. These comparisons were illustrated in previous sections (i.e. in Figure 4-60 and Figure 4-65). By fixing the thickness of the CFRP jacket (e.g. one wrap of CFRP), the enhancement in the axial loading capacity was higher for the case of lower concrete strength. The effect is more evident on the axial strain corresponding to the ultimate load $\left(\varepsilon_{m}\right)$. For example, the enhancement in the axial loading capacity by wrapping the C2-non-ductile column with one CFRP layer was $180 \%$ while the enhancement was $37 \%$ for the case of the C4-non-ductile column wrapped with one CFRP layer. In conclusion, the efficiency of the CFRP confinement action is higher if lower concrete strength is used in structural members. A possible reason for this 
phenomenon is that the stiffness of the concrete increases with the increase of its compressive strength. Higher stiffness limits the lateral expansion of the concrete, which, in turn, activates the confinement action of the CFRP jacket. This finding was also addressed by other authors such as Micelli and Modarelli, 2012 and Belouar et.al, 2013. Figure 4-75 shows the concrete compressive strength on the level of the enhancement in the axial loading capacity.

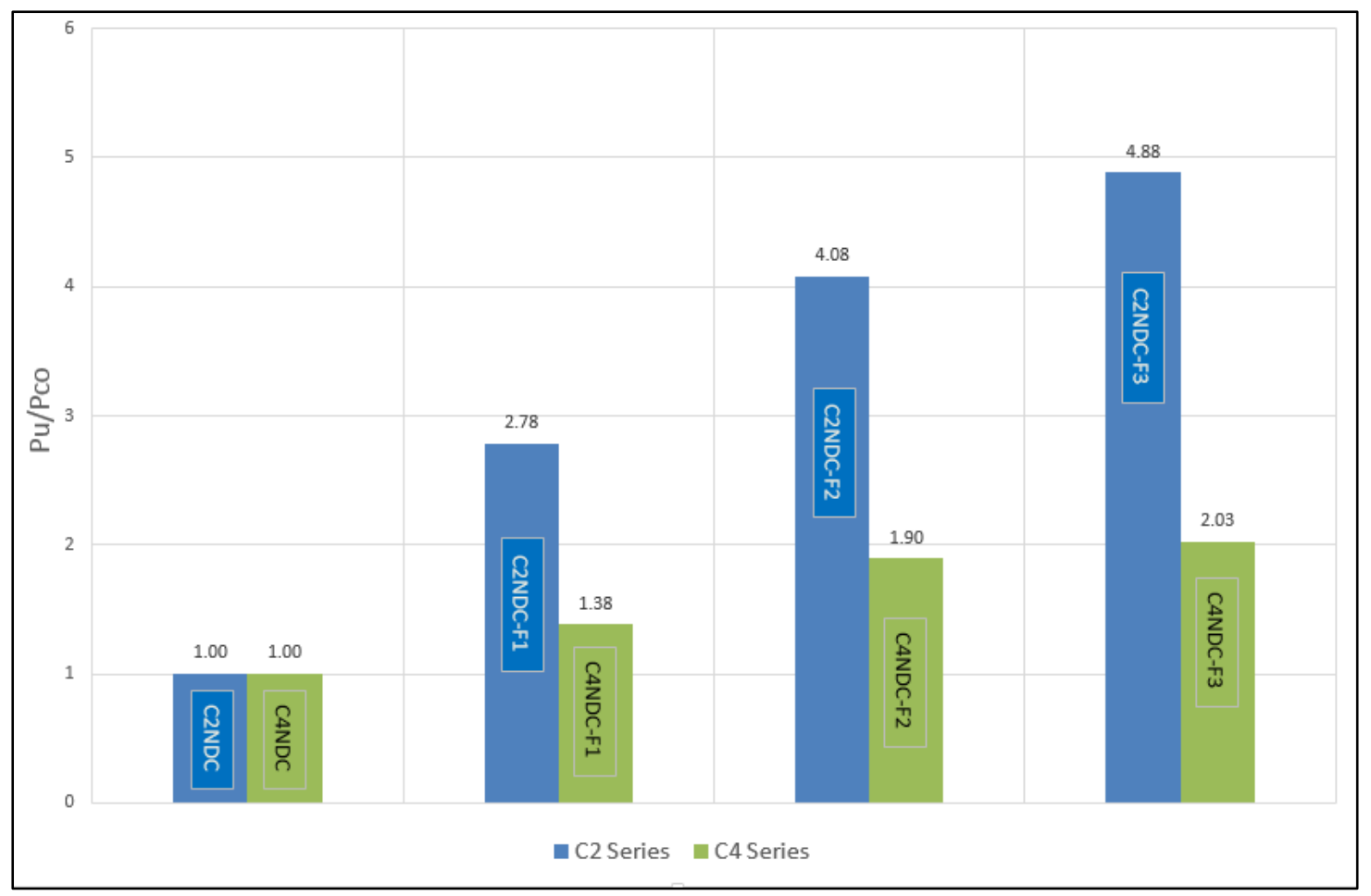

Figure 4-75: Effect of concrete compressive strength 


\section{Chapter 5. Conclusions and Recommendations}

The main purpose of the experiment work in this study was to investigate the effectiveness of strengthening non-ductile square RC columns with CFRP composites. The first section of this chapter presents the main conclusions from this study. The second section provides recommendations and suggestion for future studied to further improve the knowledge on the FRP-confined concrete columns.

\subsection{Conclusions}

Based on the experimental results presented in this study, several conclusions were drawn:

1. The confinement action provided by the CFRP jacket improved the axial load carrying capacity and the axial ductility.

2. The CFRP jacket of RC columns wrapped with one layer of CFRP was able to utilize about $79-85 \%$ of the strain capacity of the CFRP material.

3. Failure of all CFRP-wrapped columns was identified by a sudden rupture of the CFRP jacket. In most cases, the failure was initiated near the corners.

4. Increasing the thickness of the CFRP jacket resulted in enhancing the axial load carrying capacity and the axial ductility.

5. The values of the maximum axial load carrying capacity, $\mathrm{Pu}$ and axial strain, $\varepsilon_{m}$ for the columns wrapped with three layers of CFRP were very close to the values of the columns wrapped with two layers of CFRP. This suggests that the relationship between increasing the thickness of the CFRP jacket and the level of the resulted enhancement in $\mathrm{P}_{\mathrm{u}}$ and $\varepsilon_{m}$ is not continuously linear. In other words, increasing the 
thickness for the CFRP jacket will reach a maximum level of effectiveness and no more.

6. In both series $\mathrm{C} 2$ and $\mathrm{C} 4$, the performance of the non-ductile column wrapped with one CFRP layer was close to the performance of the corresponding ductile column. In other words, wrapping non-ductile columns with one layer of the CFRP sheet that was used in the current study was enough to achieve the performance of the well-designed (ductile) columns.

7. The enhancement in the axial load capacity, apparent concrete strength, and axial strain due to CFRP confinement was more pronounced in specimens with lower concrete grade (C2 series) than those with higher concrete grade (C4 series).

\subsection{Recommendations for future research}

1. Further research to confirm the observation regarding the maximum effective thickness for the CFRP jacket.

2. More experimental work to investigate the interaction between the internal lateral reinforcement and the external CFRP jacket. The amount of the lateral steel reinforcement may have an influence on the rupture strain of the CFRP jacket which, in turn, affect the confinement effectiveness of the CRRP jacket.

3. Further study to investigate the effect of the amount and distribution of the FRPtransverse strain measuring devices on the actual FRP rupture strain $(\varepsilon f$, rup $)$ and the FRP strain efficiency factor, $k \_\varepsilon$. 
4. In order to simulate the real situation of an old existing RC column, it is recommended pre-loading the column specimens before strengthening them with the CFRP sheets. Then, reloading the columns to failure.

5. Developing an analytical FEM model to predict the performance of the CFRP strengthened columns. 


\section{References}

Abegaz, A. Z. (2013). Advanced Fiber Reinforced Composites as Confining Systems for RC Columns.

Al-Lami K. (2015). Experimental Investigation of Fiber Reinforced Concrete Beams (master's thesis). Retrieved from Dissertations and Theses. Paper 2296. http://pdxscholar.library.pdx.edu/open_access_etds/2296

Al-Obaidi S. (2015). Behavior of Reinforced Concrete Beams Retrofitted in Flexure Using CFRP-NSM Technique (master's thesis). Retrieved from Dissertations and Theses. Paper 2294. http://pdxscholar.library.pdx.edu/open_access_etds/2294

American concrete institute (2008). ACI 440.2R -08: Guide for the Design and Construction of Externally Bonded FRP Systems for Strengthening Concrete Structures. ACI Manual of Concrete Practice, Farmington Hills, Michigan.

American concrete institute (2014). ACI 318 -14: Building Code Requirements for Structural Concrete and Commentary. ACI Manual of Concrete Practice, Farmington Hills, Michigan.

ASTM A370-05, Standard Test Methods and Definitions for Mechanical Testing of Steel Products, ASTM International, West Conshohocken, PA, 2005, www.astm.org. ASTM C617-98(2003), Standard Practice for Capping Cylindrical Concrete Specimens, ASTM International, West Conshohocken, PA, 1998, www.astm.org.

ASTM C49 / C49M-14, Standard Test Method for Compressive Strength of Cylindrical Concrete Specimens, ASTM International, West Conshohocken, PA, 2014, www.astm.org. 
ASTM C469-02, Standard Test Method for Static Modulus of Elasticity and Poisson's Ratio of Concrete in Compression, ASTM International, West Conshohocken, PA, 2002, www.astm.org.

ASTM D3039 / D3039M-08, Standard Test Method for Tensile Properties of Polymer Matrix Composite Materials, ASTM International, West Conshohocken, PA, 2008, www.astm.org.

Au C. (2001). Behavior of FRP-confined Concrete (Master's thesis). Retrieved from IST selected thesis http://web.mit.edu/istgroup/ist/documents/2001_master_Behavior\%20of\%20FRPConfined\%20Concrete_Au.pdf

Belouar, A., Laraba, A., Benzaid, R., \& Chikh, N. (2013). Structural performance of square concrete columns wrapped with CFRP sheets. Procedia Eng, 54, 232-40.

Benzaid, R., \& Mesbah, H. A. (2013). Circular and square concrete columns externally confined by CFRP composite: experimental investigation and effective strength models (pp. 167-201). INTECH.

Benzaid, R., Mesbah, H., \& Chikh, N. E. (2010). FRP-confined concrete cylinders: axial compression experiments and strength model. Journal of Reinforced plastics and composites, 29(16), 2469-2488.

Brandtzaeg, A., Richart, F., \& Brown, R. The Failure of Plain and Spirally Reinforced Concrete in Compression. Bulletin, (190).

Carey, S. A., \& Harries, K. A. (2005). Axial behavior and modeling of confined small-, medium-, and large-scale circular sections with carbon fiber-reinforced polymer jackets. ACI Structural Journal, 102(4), 596. 
Cole,C., Belarbi, A. (2001). FRP Jacketed Reinforced Concrete Columns (Master's thesis). Retrieved from University of Missouri - Rolla, USA.

https://myfiles.pdx.edu/stuhome/h/hayder/RESEARCH\%20NEW/THESIS\%20AND\%20 DESERTATION/thesis\%20FRPJacketedReinforcedConcreteColumns.pdf

Doan, V. (2013). Behaviour of shape-modified columns confined with carbon fiberreinforced polymer under eccentric loading (Master's thesis). Retrieved from University of Wollongong collections.

http://ro.uow.edu.au/cgi/viewcontent.cgi?article=4931\&context=theses

Elsanadedy, H. M., Al-Salloum, Y. A., Alsayed, S. H., \& Iqbal, R. A. (2012).

Experimental and numerical investigation of size effects in FRP-wrapped concrete columns. Construction and Building Materials, 29, 56-72.

Hadi, M. N., \& Widiarsa, I. B. R. (2012). Axial and flexural performance of square RC columns wrapped with CFRP under eccentric loading. Journal of Composites for Construction, 16(6), 640-649.

Jiang, T. (2008). FRP-confined RC columns: Analysis, behavior, and design (Doctoral dissertation). Retrieved from https://www.researchgate.net/publication/277741021_FRPconfined_RC_columns_analysis_behavior_and_design

Lam, L., \& Teng, J. G. (2003). Design-oriented stress-strain model for FRP-confined concrete. Construction and building materials, 17(6), 471-489.

Lam, L., \& Teng, J. G. (2003). Design-oriented stress-strain model for FRP-confined concrete in rectangular columns. Journal of Reinforced Plastics and Composites, 22(13), 1149-1186.

Liang, M., Wu, Z. M., Ueda, T., Zheng, J. J., \& Akogbe, R. (2012). Experiment and modeling on axial behavior of carbon fiber reinforced polymer confined 
concrete cylinders with different sizes. Journal of Reinforced Plastics and Composites, 31(6), 389-403.

Micelli, F., \& Modarelli, R. (2013). Experimental and analytical study on properties affecting the behaviour of FRP-confined concrete. Composites Part B: Engineering, 45(1), 1420-1431.

Pessiki, S., Harries, K. A., Kestner, J. T., Sause, R., \& Ricles, J. M. (2001). Axial behavior of reinforced concrete columns confined with FRP jackets. Journal of Composites for Construction, 5(4), 237-245.

Pham, T. M., \& Hadi, M. N. (2013). Strain estimation of CFRP-confined concrete columns using energy approach. Journal of Composites for Construction, 17(6), 04013001.

Saatcioglu, M., \& Razvi, S. R. (1992). Strength and ductility of confined concrete. Journal of Structural engineering, 118(6), 1590-1607.

Subramanian, N. (2011). Design of confinement reinforcement for RC columns. The Indian Concrete Journal, 85(6), 19-29.

Teng, J. G., Jiang, T., Lam, L., \& Luo, Y. Z. (2009). Refinement of a design-oriented stress-strain model for FRP-confined concrete. Journal of Composites for Construction, 13(4), 269-278.

Vasumathi, A. M., Rajkumar, K., \& Ganesh Prabhu, G. (2014). Compressive behaviour of RC column with fibre reinforced concrete confined by CFRP strips. Advances in Materials Science and Engineering, 2014. 
Wang, L. M., \& Wu, Y. F. (2008). Effect of corner radius on the performance of CFRPconfined square concrete columns: Test. Engineering structures, 30(2), 493505.

Wang, Z. Y., Wang, D. Y., \& Smith, S. T. (2012, February). Size effect of square concrete columns confined with CFRP wraps. In Proceedings of the 3rd AsiaPacific Conference on FRP in Structures, Hokkaido University, Sapporo, Japan (pp. 2-4).

Wu, Y. F., \& Jiang, J. F. (2013). Effective strain of FRP for confined circular concrete columns. Composite Structures, 95, 479-491.

Xiao, Y., \& Wu, H. (2000). Compressive behavior of concrete confined by carbon fiber composite jackets. Journal of materials in civil engineering, 12(2), 139-146. 


\section{Appendix}

\section{Column Specimen Design}

\section{C2 Series}

\section{a) Non-ductile reinforced concrete column (C2NDC)}

$f^{\prime}{ }_{c}=2000 p s i$

$f_{y}=$ Yield tensile strength of longitudinal rienfocement $=74 \mathrm{ksi}$

$f_{y t}=$ Yield tensile strength of transverse rienfocement $=31 \mathrm{ksi}$

$A_{g}=$ column cross - sectional area $=25 \mathrm{in}^{2}$

Using 4 No. 3 rebar as longitudinal reinforcement $\left(\mathrm{A}_{s b}=0.11 \mathrm{in}^{2}\right)$; therefore:

$A_{s t}=4 \mathrm{~A}_{s b}=0.44 \mathrm{in}^{2}$

$\rho_{g}=\frac{\mathrm{A}_{s t}}{A_{g}}=\frac{0.44}{25}=0.0176$

Thus, the expected nominal axial load carrying capacity, Pn is:

$P_{n}=0.85 f^{\prime}{ }_{c}\left(A_{g}-A_{s t}\right)+A_{s t} f_{y}=95.2$ kips

For transverse reinforcement:

$>$ No.9 steel wire $\left(d_{w}=0.159 \mathrm{in}, \mathrm{A}_{s b}=0.02 \mathrm{in}^{2}\right)$ was used

$>$ Square steel hoops were used as transverse reinforcement.

$\mathrm{ACl} 318-14$ code states that the steel hoops should be spaced at:

$$
\begin{aligned}
& \text { Spcing }(S) \leq\left\{\begin{array}{c}
16 d_{b} \\
48 d_{w} \\
\text { Min col.cim. }
\end{array}\right. \\
& \therefore S=5 \mathrm{in}
\end{aligned}
$$

\section{Summary:}

Longitudinal reinforcement: 4 No. 3 rebar

* Transverse reinforcement: No.9 steel wire hoops @ 5 in 


\section{b) Ductile reinforced concrete column (C2DC)}

For longitudinal reinforcement: 4 No. 3 rebar

For lateral Confinement Reinforcement:

The required lateral confining reinforcement was determined in accordance with the ACI 318-14 seismic design provisions.

The minimum cross sectional area of the lateral hoops $\left(A_{s h}\right)$ is the smallest of :

$$
\begin{array}{ll}
A_{s h 1}=0.3\left(S b_{c} \frac{f^{\prime}{ }_{c}}{f_{y t}}\right)\left[\frac{A_{g}}{A_{c h}}-1\right] & \text { ACI Eq? } \\
A_{s h 2}=0.09 S b_{c} \frac{f^{\prime}{ }_{c}}{f_{y t}} & \text { ACI Eq? }
\end{array}
$$

Where:

$$
\begin{array}{ll}
b_{c}=b-2\left(\operatorname{cov}-\frac{d_{w}}{2}\right) & b_{c}=3.84 \mathrm{in} \\
A_{c h}=b-2(\operatorname{cov})^{2} d & A_{c h}=16 \mathrm{in}^{2}
\end{array}
$$

$S$ : The spacing of transverse reinforcement and it is limited to:

$$
\begin{aligned}
& \text { - } \quad 1 / 4 \text { of the smallest member dimension (i.e. } S=\frac{1}{4}(b)=1.25 \mathrm{in} \text { ) } \\
& \text { - } \quad 6 d_{b}=6 * 0.375=2.25 \mathrm{in} \\
& \text { - } \quad S_{o}=4+[(14-h x / 3] \quad \text { Does not apply because there are no } \\
& \text { crossties }
\end{aligned}
$$

Thus, $S=1.25$ in

$$
\begin{aligned}
\therefore \quad A_{s h 1} & =0.0365 \mathrm{in}^{2} \\
A_{s h 2} & =0.0194 \mathrm{in}^{2}
\end{aligned}
$$

So, $A_{s h}=0.0365 \mathrm{in}^{2}$

Use N0.9 wire hoops

$$
A_{s w}=0.04 \mathrm{in}^{2}>0.0365 \mathrm{in}^{2} \quad O K
$$

\section{Summary:}

* Longitudinal reinforcement: 4 No. 3 rebar

* Transverse reinforcement: No.9 steel wire hoops @ 0.9 in 


\section{C4 Series}

\section{a) Non-ductile reinforced concrete column (C4NDC)}

${f^{\prime}}_{c}=4000 \mathrm{psi}$

$f_{y}=$ Yield tensile strength of longitudinal rienfocement $=74 \mathrm{ksi}$

$f_{y t}=$ Yield tensile strength of transverse rienfocement $=38 \mathrm{ksi}$

$A_{g}=$ column cross - sectional area $=25 \mathrm{in}^{2}$

Using 4 No. 3 rebar as longitudinal reinforcement $\left(\mathrm{A}_{s b}=0.11 \mathrm{in}^{2}\right)$; therefore:

$A_{s}=4 \mathrm{~A}_{s b}=0.44 \mathrm{in}^{2}$

$\rho_{g}=\frac{\mathrm{A}_{s t}}{A_{g}}=\frac{0.44}{25}=0.0176$

Thus, the expected nominal axial load carrying capacity, Pn is:

$P_{n}=0.85 f^{\prime}{ }_{c}\left(A_{g}-A_{s t}\right)+A_{s t} f_{y}=116$ kips

For transverse reinforcement:

$>$ No.9 steel wire $\left(d_{w}=0.159 \mathrm{in}, \mathrm{A}_{s b}=0.02 \mathrm{in}^{2}\right)$ was used

$>$ Square steel hoops were used as transverse reinforcement.

$\mathrm{ACl}$ 318-14 code states that the steel hoops should be spaced at:

$$
\begin{aligned}
& \text { Spcing }(S) \leq\left\{\begin{array}{c}
16 d_{b} \\
48 d_{w} \\
\text { Min col.cim. }
\end{array}\right. \\
& \therefore S=5 \mathrm{in}
\end{aligned}
$$

\section{Summary:}

* Longitudinal reinforcement: 4 No. 3 rebar

* Transverse reinforcement: No.9 steel wire hoops @ 5 in 


\section{b) Ductile reinforced concrete column (C2DC)}

For longitudinal reinforcement: 4 No. 3 rebar

For lateral Confinement Reinforcement:

The required lateral confining reinforcement was determined in accordance with the ACI 318- 14 seismic design provisions.

The minimum cross sectional area of the lateral hoops $\left(A_{s h}\right)$ is the smallest of :

$$
\begin{array}{ll}
A_{\text {sh1 }}=0.3\left(S b_{c} \frac{f^{\prime}{ }_{c}}{f_{y t}}\right)\left[\frac{A_{g}}{A_{c h}}-1\right] & \text { ACI } 318-14 \text { Table 18.7.5.4 } \\
A_{\text {sh } 2}=0.09 S b_{c} \frac{f^{\prime}{ }_{c}}{f_{y t}} & \text { ACI } 318-14 \text { Table 18.7.5.4 }
\end{array}
$$

Where:

$$
\begin{array}{ll}
b_{c}=b-2\left(\operatorname{cov}-\frac{d_{w}}{2}\right) & b_{c}=3.84 \mathrm{in} \\
A_{c h}=b-2(\operatorname{cov})^{2} d & A_{c h}=16 \mathrm{in}^{2}
\end{array}
$$

$S$ : The spacing of transverse reinforcement and it is limited to:

$$
\begin{aligned}
& \text { - } \quad 1 / 4 \text { of the smallest member dimension ( i.e. } S=\frac{1}{4}(b)=1.25 \mathrm{in} \text { ) } \\
& \text { - } \quad 6 d_{b}=6 * 0.375=2.25 \mathrm{in} \\
& \text { - } \quad S_{o}=4+[(14-h x / 3] \quad \text { Does not apply because there are no } \\
& \text { crossties }
\end{aligned}
$$

Thus, $\quad S=1.25$ in

$$
\begin{aligned}
\therefore A_{s h 1} & =0.0855 \mathrm{in}^{2} \\
A_{s h 2} & =0.0456 \mathrm{in}^{2}
\end{aligned}
$$

So, $A_{s h}=0.0855 \mathrm{in}^{2}$

Use N0.2 wire hoops

$$
A_{s w}=0.098 \mathrm{in}^{2}>0.0855 \mathrm{in}^{2} \quad O K
$$

\section{Summary:}

* Longitudinal reinforcement: 4 No. 3 rebar

* Transverse reinforcement: No.9 steel wire hoops @ 0.9 in 